
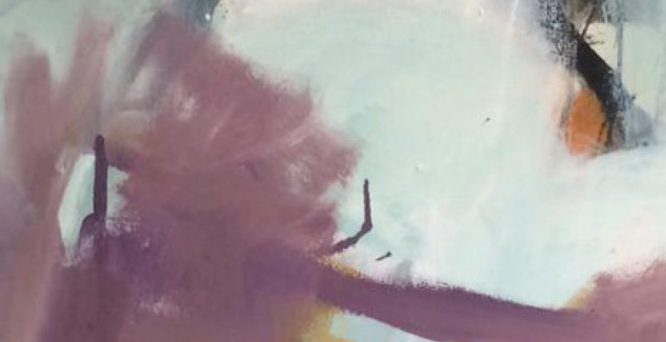

Marta Kowalczuk-Walędziak Alicja Korzeniecka-Bondar Wioleta Danilewicz Gracienne Lauwers (eds.)

\title{
Rethinking \\ Teacher Education for \\ the 21st Century
}

Trends, Challenges

and New Directions

Verlag Barbara Budrich 

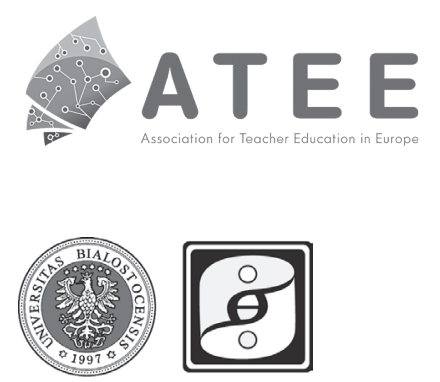

The publication has received financial support from the Polish Ministry of Science and Higher Education under subsidy for maintaining the research potential of the Faculty of Pedagogy and Psychology, University of Bialystok.

The organization of the ATEE 2018 Spring Conference "Designing Teacher Education and Professional Development for the $21^{\text {st }}$ Century: Current Trends, Challenges and Directions for the Future" was financed under agreement 550/P-DUN/2018 with the funds from the Polish Minister of Science and Higher Education for the dissemination of science.

\section{El-EduLAw}

The conference and conference proceedings were made possible by the additional EduLAw project co-funded by the Erasmus+ Programme of the the European Union. The European Commission support does not constitute endorsement of the contents which reflects the views only of the authors, and the Commission cannot be held responsible for any use which may be made of the information contained therein. 


\title{
Rethinking \\ Teacher Education \\ for the $21^{\text {st }}$ Century \\ Trends, Challenges \\ and New Directions
}

\author{
Edited by \\ Marta Kowalczuk-Walędziak \\ Alicja Korzeniecka-Bondar \\ Wioleta Danilewicz \\ Gracienne Lauwers
}

Verlag Barbara Budrich

Opladen, Berlin \& Toronto 2019 
(C) 2019 This work is licensed under the Creative Commons Attribution-ShareAlike 4.0. (CC-BY-SA 4.0)

It permits use, duplication, adaptation, distribution and reproduction in any medium or format, as long as you share under the same license, give appropriate credit to the original author(s) and the source, provide a link to the Creative Commons license and indicate if changes were made. To view a copy of this license, visit https://creativecommons.org/licenses/by-sa/4.0/

(C) 2019 Dieses Werk ist beim Verlag Barbara Budrich GmbH erschienen und steht unter der Creative Commons Lizenz Attribution-ShareAlike 4.0 International (CC BY-SA 4.0): https://creativecommons.org/licenses/by-sa/4.0/

Diese Lizenz erlaubt die Verbreitung, Speicherung, Vervielfältigung und Bearbeitung bei Verwendung der gleichen CC-BY-SA 4.0-Lizenz und unter Angabe der UrheberInnen, Rechte, Änderungen und verwendeten Lizenz.

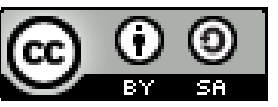

This book is available as a free download from

www.barbara-budrich.net (https://doi.org/10.3224/86649453).

A paperback version is available at a charge.

The page numbers of the open access edition correspond with the paperback edition.

$\begin{array}{ll}\text { ISBN } & 978-3-8474-2241-9 \text { (paperback) } \\ \text { eISBN } & 978-3-8474-1257-1 \text { (ebook) } \\ \text { DOI } & 10.3224 / 84742241\end{array}$

Verlag Barbara Budrich GmbH

Stauffenbergstr. 7. D-51379 Leverkusen Opladen, Germany

86 Delma Drive. Toronto, ON M8W 4P6 Canada

www.barbara-budrich.net

A CIP catalogue record for this book is available from

Die Deutsche Bibliothek (The German Library) (http://dnb.d-nb.de)

Jacket illustration by Bettina Lehfeldt, Kleinmachnow - www.lehfeldtgraphic.de

Language revision by Alison Romer, Lancaster, UK

Typesetting by Mieczysław Rabiczko, Bialystok, Poland

Printed in Europe on acid-free paper by paper\&tinta, Warsaw 


\section{Contents}

Acknowledgements $\quad 9$

The Editors $\quad 11$

\section{Introduction}

Chapter 1

A Time for Reflection and Dialogue:

How Do We Educate Teachers to Meet the Challenges of the $21^{\text {st }}$ Century?

Marta Kowalczuk-Walędziak, Alicja Korzeniecka-Bondar, Wioleta Danilewicz, and Gracienne Lauwers

\section{PART I \\ Issues, Trends and Policies}

Chapter 2

Still Building a Better World? Research Reflections on Teacher Education and Identity

Amélia Lopes

Chapter 3

Reshaping Teacher Training to Get the Right Education System for a Knowledge Society

Gracienne Lauwers

Chapter 4

Let It Begin with Me: The Forging of a Professional Teacher Educator Self

Jennifer Yamin-Ali 
Chapter 5

The Albanian Student-Teacher Perspective on Reasons for

Choosing Teaching as a Career

Livia Nano, Nada Kallçiu, and Nikoleta Mita

Chapter 6

Educational Agility

98

Neus Lorenzo Galés and Ray Gallon

Chapter 7

No Teacher without a Student... A Theoretical Analysis and

Practical Implications of Educational Changes in the Era

of Digital Natives

111

Katarzyna Skok

Chapter 8

Initial Teacher Education Policies: A Comparison between Italy and the UK. Recent Trends and Future Prospects

Francesco Magni

Chapter 9

Initial Teacher Training Challenges in a Context of Educational Reform in Lithuania

Aušra Rutkiené and Tetiana Ponomarenko

Chapter 10

The Teaching Profession in Albania and the Continuous Need

for Improvement through Teacher Training Reforms

Heliona Miço

Chapter 11

Teaching Practice in the Albanian Context: Student-Teachers'

Perceptions regarding their Experience in Teaching

168

Manjola Zaçellari (Lumani)

Chapter 12

Teachers' Workplace and Personal Wellness: Perspectives from South African Legislation and Policies

Erika Kruger and Lynette Jacobs 


\section{PART II \\ Challenges and Tensions}

Chapter 13

An Exploration into the Value of Formative Assessment and the Barriers Associated with the Implementation of Formative Strategies 203

Frances Green

\section{Chapter 14}

The Importance of Physical Activity in the Normative

Development of Mental Body Representations during

Adolescence. Implications for Teacher Education

Beata Mirucka and Monika Kisielewska

\section{Chapter 15}

Children's Rights and Human Rights as a Key Condition for the Education of Transformative Teachers

Anna Babicka-Wirkus

\section{Chapter 16}

Are Innovations a Contribution to the Professional Development of Teachers?

Elżbieta Jaszczyszyn and Iwona Lewkowicz

\section{Chapter 17}

Teachers' Team Learning in the Context of Creating Learning Schools: Implications for Teacher Education

Bożena Tołwińska

\section{Chapter 18}

Components, Models and Operational Mechanisms of Teacher Collaboration

Katalin Tóth-Pjeczka, Nóra Rapos, and Judit Szivák

\section{Chapter 19}

Didactic Cooperation between Teachers and Students in Higher Education: Utopia or Real Opportunity? 


\section{PART III \\ Practices and Strategies}

Chapter 20

A COOL Lab for Teacher Education

Barbara Sabitzer, Heike Demarle-Meusel, and Christoph Painer

Chapter 21

Intercultural Learning for Pupils and Teachers: A Good Practice

Case Study from an Erasmus+ Project

Elisa Briga

Chapter 22

A Restorative Approach to Address Cyber Bullying

Roelof Petrus Reyneke

Chapter 23

Motivational Strategies of Local and Foreign Students:

Socio-Cultural Commonalities and Differences

Julia Kazakova

Chapter 24

The Importance of Emotional Intelligence in the Creative Activity of Students

Katarzyna Szorc and Beata Kunat

Chapter 25

Exploring Learning and Teaching Needs of Elderly People:

A Comparative Study

Emilia Kramkowska, Wioleta Danilewicz,

Tomasz Prymak, and Joăo Pedro Constâncio

Index

398 


\section{Acknowledgements}

This book has its origins in the intellectually enriching experience of the ATEE Spring Conference which took place on June 7-9, 2018 at the University of Bialystok, Poland. I am grateful to the Association for Teacher Education in Europe (ATEE) for their support, and particularly to Åsa Morberg (President of the ATEE), Ronny Smet (RDCs coordinator), and Mariagrazia Tagliabue (Head of the Office) who have contributed greatly to the improved quality of the conference programme.

I would like to extend my gratitude to the Dean's Board and my colleagues from the Faculty of Pedagogy and Psychology of the University of Bialystok for their great support and friendly working atmosphere before, during and after the conference.

I also express my special thanks to the reviewers for their helpful and constructive comments that have helped to improve the quality and readability of the chapters:

Linda Daniela, University of Latvia, Latvia

Gracienne Lauwers, Free University of Brussels, Belgium

Roza Valeeva, Kazan Federal University, Russia

Otilia Clipa, Stefan cel Mare University of Suceava, Romania

Wioleta Danilewicz, University of Bialystok, Poland

James Underwood, University of Northampton, UK

Zanda Rubene, University of Latvia, Latvia

Alicja Korzeniecka-Bondar, University of Bialystok, Poland

Marta Kowalczuk-Walędziak, University of Bialystok, Poland

Special thanks go to Professor Gracienne Lauwers - the coordinator of the EduLAw Erasmus+ programme 'Introducing modules on law and rights in programmes of teacher training and educational sciences: A contribution to 
building rights-based education systems in countries in transition' - for her contribution to the organization of the conference and her support throughout the process of completing this book.

Finally, I would like to thank all of the chapter contributors for giving their time and sharing great expertise on teacher education for the $21^{\text {st }}$ century.

Marta Kowalczuk-Walędziak Chair of the Organising Committee 


\section{The Editors}

Marta Kowalczuk-Walędziak (Ph.D.) is an assistant professor at the Faculty of Pedagogy and Psychology, University of Bialystok, Poland. Her main research interests focus on the impact of research higher degrees on teachers' professional development, linking educational theory and practice (practitioner research), and the sense of social agency of educational professionals. She is a member of the Administrative Council of the Association for Teacher Education in Europe (ATEE). She serves on the editorial board of the Eastern European Journal of Transnational Relations, and is an associate editor of the Polish Journal of Educational Studies. In 2016, she was awarded a Scholarship for Outstanding Young Scientists from the Ministry of Science and Higher Education in Poland (2016-2019). Currently, she is a short-term visiting professor at the Department of Human and Social Sciences at the University of Bergamo, Italy.

Alicja Korzeniecka-Bondar (Ph.D.) is an associate professor at the Faculty of Pedagogy and Psychology, University of Bialystok, Poland. Her research interests deal with teachers' lives, balance between work and life, temporal dimension of teachers' work, building communities of learners in higher education, and developing academic writing skills. She is an Editorin-Chief of the journal "Parezja. Czasopismo Forum Młodych Pedagogów przy Komitecie Nauk Pedagogicznych PAN" ["Parrhesia. Journal of the Forum of Young Scholars at the Committee of Education Sciences of the Polish Academy of Sciences"]. She is the author and co-author of 70 scientific articles concerning various aspects of teacher's work and education. Her most recent book is: Daily Time at School. Phenomenographic Study of Teachers' Experiences (2018). 
Wioleta Danilewicz (Ph.D.) is an associate professor at the Faculty of Pedagogy and Psychology, University of Bialystok, Poland. She is an Associate Dean for Scientific Affairs of the Faculty of Psychology and Pedagogy of the University of Bialystok. She serves as an Editor-in-Chief of the Polish Journal of Educational Studies. Her main research interests focus on the modern family, and social consequences of migration and multicultural education. She is an Author and Editor of numerous publications in the field of education (social pedagogy).

Gracienne Lauwers, Lic. Iur., Lic. Arts. (Belgium), Ph.D. Law (Netherlands) is professor of Law at the Vrije Universiteit Brussel (Belgium) and visiting professor at Trento University (Italy), Vytautas Magnus and Vilnius University (Lithuania), and the University of the Free State (South Africa). She serves as the executive director of the European Association for Education Law and Policy and is currently grantholder of the Erasmus+ EduLAw project on the introduction of Law and Rights Modules in Teacher Training Programmes. She has published widely on issues of education law and policy. 


\section{Introduction}




\title{
Chapter 1
}

\section{A Time for Reflection and Dialogue: How Do We Educate Teachers to Meet the Challenges of the $21^{\text {st }}$ Century?}

\section{Marta Kowalczuk-Walędziak*, Alicja Korzeniecka-Bondar*, Wioleta Danilewicz, and Gracienne Lauwers**}

${ }^{*}$ Faculty of Pedagogy and Psychology, University of Bialystok, Bialystok, Poland

${ }^{* *}$ Vrije Universiteit Brussel, Brussel, Belgium

\begin{abstract}
The reality of teachers' work in the $21^{\text {st }}$ century is changing rapidly. Bringing technology into schools, the increasing complexity of learning and teaching in diverse classrooms, the growing societal expectations of raising students' achievements and the need for tailoring and implementing innovative teaching practices are just some of the factors driving this change. In this situation, teacher education and professional development arise as a substantial means to prepare teachers to confront these and other challenges to the teaching profession. This introductory chapter sets the stage for this book by exploring different issues of (re)designing teacher education and professional development in accordance with current as well as future circumstances. It aims to address the main question on how we educate (future) teachers to meet the challenges of the $21^{\text {st }}$ century. In particular, it focuses on main actors, contextual factors and reflective strategies of improving the quality of teacher education and professional development. KEYWORDS: teacher education, teacher professional development, $21^{\text {st }}$ century, (re)designing teacher education and professional development
\end{abstract}

\section{Introduction}

Anyone who thinks that this book will be a series of highly normative guidelines about what $21^{\text {st }}$ century teacher education should, or should not be like - or what makes or does not make effective teacher education

CONTACT Marta Kowalczuk-Walędziak, EMAIL: m.kowalczuk@uwb.edu.pl 
programmes - may be disappointed. Instead, the main aim of this book is to invite a readership to continue a reflective conversation on how we educate (future) teachers to meet the challenges of the $21^{\text {st }}$ century. This, immediately, raises important questions about this invitation: who is 'we', why now, and why the reflective conversation? Before we start to answer these questions, it is noteworthy that in this book the term 'teacher education' is used in its broadest sense and refers both to initial teacher preparation and continuing professional development.

\section{Who is 'we'?}

Answers to the first question include all those who recognize that the preparation for and launch of new strategies for preparing (future) teachers to meet the challenges of our fast-changing global world requires the attention of various actors involved in the teacher education process. These include governments; local, regional and national authorities; policymakers; teacher educators; researchers; lawyers; the private sector; the non-profit sector and finally, what is very important, student teachers and teachers themselves. It is noteworthy that all of these groups assign different priorities to the most important issues to be solved, improved or examined in order to make true progress. Therefore, it is vital to analyse and coordinate these multiple voices, perspectives, principals and proposals in order to develop a more comprehensive picture of the current systems of teacher education and its further developments. Therefore, the authors of the chapters included in this book represent a wide range of expertise and experiences, e.g. teacher educators, researchers, lawyers, practitioners, and heads of non-profit organizations.

\section{Why now?}

Over the last two decades of the $21^{\text {st }}$ century schools and teachers across the globe have been faced with many challenges, tensions and paradoxes (Ben-Peretz and Flores, 2018). According to Flores (2016, p. 190), these include:

the multicultural settings in which teachers have to work and a broadening of their role, which goes beyond the traditional boundaries of subject matter; changes occurring in social agencies; greater influence of the mass media in the education of children and young people; the co-existence of different educational models in a multicultural society the fragmentation 
of teachers' work; growing opportunities for learning outside school owing to the development of information and communication technologies; and, the increasing accountability, bureaucracy and public scrutiny.

In this context, teacher education arises as a substantial means to prepare teachers to confront these and other new challenges to the teaching profession. This assumption is supported by some studies indicating that teachers' effectiveness depends on the quality of their pre-service or in-service training (Darling-Hammond, 2017; OECD, 2011; Zuzovsky, 2009). However, it needs to be indicated that the quality of teacher education and professional development has a positive impact not only on teachers themselves (especially in terms of knowledge and skills), as well as their students' learning outcomes and school development, but also on the economic growth and intellectual property of (future) societies. Indeed, as Linda Darling-Hammond (cited in Martin and Mulvihill, 2017, p. 81) emphasized, "[t]he work of teaching is the work on which this profession and all others depend”. This seems to be particularly important in societies which have experienced "political, socio-economic and spiritual transformations in recent decades" (Valeeva and Gafurov, 2017, p. 343), and as consequence, the models of teacher preparation need to be redefined. This issue will be broadly discussed in this book in reference to the Albanian (Chapter 10, Miço; Chapter 11, Zaçellari (Lumani)), and to some extent the Russian contexts (Chapter 23, Kazakova).

There is a growing body of research indicating that different countries across the globe have been making a considerable effort of reforming their teacher education systems (e.g., Livingston and Shiach, 2009; Mayer, Pecheone, and Merino, 2012; McIntyre, 2005; Munthe, Malmo, and Rogne, 2011; Valeeva and Gafurov, 2017), and creating new strategies and approaches amidst the above-mentioned challenges. Although these efforts demonstrate in many cases a powerful potential to build new ways of educating teachers, they should be systematically evaluated by the extent to which they address fast-changing classroom realities (Borawska--Kalbarczyk, Tołwińska, and Korzeniecka-Bondar, 2019). Furthermore, as Darling-Hammond argues (cited in Martin and Mulvihill, 2017), there is still "a lot of work to do in the profession to take the best models of teacher education and make those the routine and the norm, rather than the exception” (p. 78).

Against this background, it is highly relevant to rethink the objectives, content and methodologies of teacher education for the $21^{\text {st }}$ century. Therefore, this book is intended to provide valuable and fresh insights from research studies and examples of best practices from Europe and all over 
the world on the strengths and limitations of different models, strategies, approaches and policies related to teacher education and training in and for the changing times. These efforts may inspire existing or possible national and local activities to better match the changes that have taken place.

\section{Why the reflective conversation?}

This is mainly because the intention of this book is not only to familiarize readers with new models, strategies, and approaches to teacher education, and how they have been implemented in different contexts, but also to promote critical reflection and stimulate a discussion on teachers' preparation, and to some extent within the preparation of teachers. According to Dewey (1933, p. 11) 'reflection' is “an active, persistent and careful consideration of any belief or supposed form of knowledge in the light of the grounds that support it, and further conclusions to which it leads”. By emphasizing the need to rethink teacher education for the $21^{\text {st }}$ century in this way, we would like to stress the necessity of giving attention to alternative views, solutions and approaches to different issues in teacher education, to listen to more than one side of the issue, and to understand and respect reasons and expectations of different actors in the teacher education process. Bearing in mind the first question who is 'we'? such dialogical and reflective approaches may also be useful in creating partnerships between different groups responsible for the quality of teacher education as well as in closing or reducing still-existing gaps or those back-and-forths between theory and practice, research and practice, policy and practice (Darling-Hammond, 2017).

\section{ATEE 2018 Spring Conference}

This book not only invites readers for reflective conversation on the body of its content, but it presents a culmination of the reflective and intellectually enriching conversations that took place during the ATEE 2018 Spring Conference on 'Designing Teacher Education and Professional Development for the $21^{\text {st }}$ century: Current Trends, Challenges and Directions for the Future’ (Bialystok, 7-9 June 2018).

The Association for Teacher Education in Europe (ATEE) ${ }^{1}$ is a nonprofit European organisation aimed at enhancing the quality of teacher

1 See https://atee.education. 
education in Europe and supporting the professional development of teachers and teacher educators at all levels. The ATEE involves members from more than forty countries and offers them a wide range of experiences concerning research projects, seminars, discussions, publications, etc. The Research and Development Communities (RDCs) are the core of this organisation, creating a backbone for social coherence within the Association. They provide the first platform for dialogue, exchange and joint international activities between individuals and institutions. In addition, the exchange of research and practice is facilitated by the publication of the European Journal of Teacher Education.

A large proportion of the Association's activities relate to the organisation of winter, spring and annual conferences that provide a unique international forum for critical reflection, active dialogue and exchange of research and practice in the field. The Annual Conference is held each year in a different country and covers a wide range of issues related to teacher education. Two smaller conferences, the Spring Conference and the Winter Conference, are also organised each year. During these meetings specific themes in the field are discussed.

The main aims of the ATEE 2018 Spring Conference were to (1) address the major trends, challenges and strategies for $21^{\text {st }}$ century-oriented teacher education and professional development; (2) provide valuable and fresh insights from research studies and examples of best practices from Europe and all over the world on the strengths and limitations of different models, strategies, approaches and policies related to teacher education and professional development in and for the changing times. The conference was hosted by the Faculty of Pedagogy and Psychology of the University of Bialystok (Poland), which is the largest higher education institution for teachers and other educational professionals in north-eastern Poland, with a long-standing tradition of teacher education. The University of Bialystok has been developing scientific cooperation with the largest institutions in the world and has conducted international research projects. Because of its cross-border location, it also provides a good base from which to strengthen relationships between researchers and educators from Eastern Europe and the Baltic Countries (Lithuania, Belarus, Ukraine and Russia)². Therefore it served as a perfect place for international discussion on teacher education 
and professional development for the $21^{\text {st }}$ century. ${ }^{3}$ The conference received significant interest from researchers from all over the world. Over 150 delegates, in particular from Poland, the United Kingdom, Lithuania, Latvia, Russia, Belarus, Serbia, Italy, Belgium, Sweden, Finland, Portugal, Croatia, Hungary, Australia and Japan attended the event.

The conference theme was developed by discussing the following issues:

- $\quad$ Teacher Education for Diversity

- Teachers' Digital Competences

- $\quad$ Reforming Teacher Education: Standards and Qualifications

- Teacher Education: Policy and Law

- $\quad$ Teacher Educators

- $\quad$ New Strategies for Improving the Quality of Teachers and Teacher Education

- Becoming a Teacher

- $\quad$ Towards the Development of Teacher Identity

- $\quad$ ICT and Digital Resources in Teacher Education

- $\quad$ Dialogue, Collaboration and Teacher Learning Communities

- $\quad$ Teacher Education Policies

- Teachers' Professional Development Needs

- $\quad$ Models and Strategies of In-service Teacher Education

- Teachers' Everyday Work

- Dealing with Challenging Students - Cyberbullying in Education

One of the important parts of the conference was a presentation of the Erasmus+ project results: 'Introducing Modules on Law and Rights in Programmes of Teacher Training and Educational Sciences: a Contribution to Building Rights-Based Education Systems in Countries in Transition'. ${ }^{4}$ The main aims of this project are to support eligible partner countries (Belarus, Russia, Albania) in updating their curricula and to better prepare their staff and students for a rights-based school governance and teaching process, and to

3 The conference was supported with funds from the Polish Minister of Science and Higher Education for the dissemination of science (No. 550/P-DUN/2018).

4 The ERASMUS+ Application 573540-EPP-1-2016-1-BE-EPPKA2-CBHE-JP 'Introducing Modules on Law and Rights in Programmes of Teacher Training and Educational Sciences' was submitted with the consortium including Vrije Universiteit Brussel, Vytautas Magnus University, University of Bialystok, European Association for Education Law and Policy, University of Tirana, Aleksander Moisiu University of Dürres, Francisk Skorina Gomel State University, Belarusian State Pedagogical University, Moscow City University, Kutafin Moscow State Law University, Mari State University, Northern (Arctic) Federal University named after M.V. Lomonosov, National Research University Higher School of Economics. See http://edulaweu. eu and https://www.youtube.com/channel/UCZXUc4iZZ63S1ityarIm_Tg. 
respond to pro-active rights demands in societies in transition. ${ }^{5}$ The project's indirect aim was to increase good lawyer-educator collaboration to improve decision making in education (Lauwers, 2017). The conference speakers from all countries involved in a project strongly emphasized - by providing some examples from their countries - that collaboration between educators and lawyers is needed to promote effective teaching, learning, school leadership, and educational innovation. This is also reflected in some book chapters written by project coordinator and participants (see e.g. Chapter 3, Lauwers; Chapter 6, Nano, Kallçiu, and Mita; Chapter 9, Rutkienė and Ponomarenko; Chapter 10, Miço; Chapter 11, Zaçellari (Lumani)).

\section{Overview of the book}

This book presents written and improved versions of selected papers and keynotes presented during the conference. They are divided into three sections: 'Issues, Trends and Policies', 'Challenges and Tensions' and 'Practices and Strategies'.

The papers arranged in the first and largest section of this book discuss some broader issues, trends, reforms and policies related to teacher education at both national and institutional levels. These include: the concept of identity in teaching and teacher education (Chapter 2, Lopes); the quality, identity and status of teacher educators (Chapter 3, Yamin-Ali); reforms of teacher education (Chapter 4, Lauwers; Chapter 10, Miço; Chapter 11, Zaçellari (Lumani)); motivations for becoming a teacher (Chapter 5, Nano, Kallçiu, and Mita); the need for student-oriented and technology-rich teaching (Chapter 6, Galés and Gallon; Chapter 7, Skok); and teacher education policies in different countries (Chapter 8, Magni; Chapter 9, Rutkienė and Ponomarenko; Chapter 12, Kruger and Jacobs).

The second section of the book is about challenges and tensions in the implementation of new models and strategies to improve teacher education, and the challenges forced into everyday teaching practice with implications for teacher education. These include: the importance of physical activity in the normative development of mental body representations during adolescence (Chapter 14, Mirucka and Kisielewska); children's rights and human rights (Chapter 15, Babicka-Wirkus); the value of formative assessment strategies (Chapter 13, Green); education innovations (Chapter 16, 
Jaszczyszyn and Lewkowicz); and collaboration in teacher work and teacher education (Chapter 17, Tołwińska; Chapter 18, Tóth-Pjeczka, Rapos, and Szivák; Chapter 19, Krajewska).

In the third section of the book, the papers describe practices and strategies aiming at improving teacher education that have already been implemented at both national and institutional levels. These are specific examples of projects and actions which may develop specific competencies of teachers, e.g. digital literacy and computational thinking (Chapter 20, Sabitzer, Demarle-Meusel, and Painer), and intercultural competences (Chapter 21, Briga). This section also includes theoretical and research insights on restorative approaches to address cyber bullying (Chapter 22, Reyneke); motivational strategies of local and foreign students (Chapter 23, Kazakova); the importance of emotional intelligence in developing students' creative activity (Chapter 24, Szorc and Kunat); and learning and teaching needs of elderly people (Chapter 25, Kramkowska et al.).

Collectively, these papers contribute to the current debate on the strengths and limitations of different models, strategies, approaches and policies related to teacher education and training in and for the changing times. The authors provide a number of suggestions, inspirations and recommendations for theory, research and practice in teacher education that may be considered for use in different contexts. However, they also pose a lot of new questions and concerns about the future of teacher education that may be discussed in future conferences or addressed in future research.

Finally, this book would be of interest to a wide audience of scholars, teachers, headteachers, student teachers, education authorities, policymakers and representatives of professional teaching associations or government bodies searching for effective ways of teacher education for the $21^{\text {st }}$ century.

\section{References}

Ben-Peretz, M., and Flores, M.A. (2018). Tensions and Paradoxes in Teaching: Implications for Teacher Education. European Journal of Teacher Education, 41 (2), 202-213.

Borawska-Kalbarczyk, K., Tołwińska, B., and Korzeniecka-Bondar, A. (2019). From Smart Teaching to Smart Learning in the Fast-changing Digital World. In: L. Daniela (Ed.), Didactics of Smart Pedagogy. Smart Pedagogy for Technology Enhanced Learning (pp. 23-390). New York: Springer.

Darling-Hammond, L. (2017). Teacher Education around the World: What Can We Learn from International Practice? European Journal of Teacher Education, 40 (3), 291-309. 
Dewey, J. (1933). How We Think: A Restatement of the Relations of Reflective Thinking to the Educative Process (2nd revised edition). Boston: D.C. Heath.

Flores, M.A. (2016). Teacher Education Curriculum. In: J. Loughran and M.L. Hamilton (Eds.), International Handbook of Teacher Education (pp. 187-230). Dordrecht: Springer.

Valeeva, R.A., and Gafurov, I.R. (2017). Initial Teacher Education in Russia: Connecting Theory, Practice and Research. European Journal of Teacher Education, 40 (3), 342-357.

Lauwers, G. (2017). The Erasmus+ EduLAw Project for Strengthening Rights-based Education. Eastern European Journal of Transnational Relations, 1 (1), 19-29.

Livingston, K., and Shiach, L. (2009). Con-constructing a New Model of Teacher Education. In: A. Campbell and S. Groundwater-Smith (Eds.), Connecting Inquiry and Professional Learning in Education: International Perspectives and Practical Solutions (pp. 83-96). Abingdon: Routledge.

Martin, L.M., and Mulvihill, T.M. (2017). Current Issues in Teacher Education. An interview with Dr. Linda Darling-Hammond. Teacher Educator, 52 (2), 75-83.

Mayer, D.R., Pecheone, R., and Merino, M. (2012). Rethinking Teacher Education in Australia: The Quality Reforms. In: L. Darling-Hammond and A. Lieberman (Eds.), Teacher Education around the World. Changing Policies and Practices (pp. 110-129). London: Routledge.

McIntyre, D. (2005). Opportunities for a More Balanced Approach to ITE: Can We Learn Again from Research and Other Experience? Scottish Educational Review, 37, Special Edition, 5-19.

Munthe, E., Malmo, K.A., and Rogne, M. (2011). Teacher Education Reform and Challenges in Norway. Journal of Education for Teaching, 37 (4), 441-450.

OECD. (2011). Building a High-Quality Teaching Profession: Lessons from around the World. Retrieved January 5, 2019 from http://www.oecd.org/education/ school/programmeforinternationalstudentassessmentpisa/buildingahigh-qualityteachingprofessionlessonsfromaroundtheworld.htm.

Zuzovsky, R. (2009). Teachers’ Qualifications and Their Impact on Student Achievement Findings from TIMSS-2003 Data in Israel. Retrieved January 11, 2019 from https://www.iea.nl/sites/default/files/irc//IRC2008_Zuzovsky2.pdf. 
PART I

Issues, Trends and Policies 


\title{
Chapter 2
}

\section{Still Building a Better World? Research Reflections on Teacher Education and Identity}

\author{
Amélia Lopes \\ Faculty of Psychology and Education Sciences, University of Porto, Portugal; \\ Centre of Research and Intervention in Education (CIIE)
}

\begin{abstract}
This paper aims to present the crucial contemporary challenges of teacher education, which are seen as tightly related with those of both the teaching profession and society. After a brief overview on some of the main successes in teacher education in the last decades, teachers' professional identity is identified as a concept that carries hope for the future. For the future I will then argue about this critical usage of the concept and the importance of an ecological version of it in teaching and teacher education, allowing us to go deeper into the individual and collective conditions of 'real change'. Afterwards, research findings and reflections demonstrating the role of identities and the ecological system in educational change will be emphasized, focusing on three key issues: teacher education environments and the main challenges of teaching profession; collective identity in the teaching profession and CPD; research in the teaching profession and the identity of teacher educators.
\end{abstract}

KEYWORDs: identity; identity of teacher educators; teaching profession

\section{Introduction}

It is my intention in this paper to stress the importance of relationships - individual, interindividual, organizational and interinstitutional - in the education of teachers and on how the use of the concept of identity has contributed to affirm such importance. I will begin by recalling how the professional model has inspired strong progress in teacher education,

CONTACT Amélia Lopes, EMAIL: amelia@fpce.up.pt 
accounting for a number of successful achievements in teacher education in the last decades, but also bringing light on some important dilemmas. In a second step, identity is identified as a concept that carries hope for the future. I will argue about the importance of an ecological version of it in teaching and teacher education, allowing us to go deeper into the individual and collective conditions of 'real change'. It includes the subjective dimension (relational and communicational) of teachers' professionalization processes. Afterwards, research findings and reflections demonstrating the role of relationships in teacher education processes will be emphasized, focusing on three key issues: teacher education environments and teachers' identities; research, teaching and teacher educators' identities; and the teaching profession and collective identity of teachers.

\section{The professional model and successes in teacher education in the last decades}

Education has always had a regulatory dimension and an emancipatory one (Santos, 1995). The two dimensions need each other, but it is the emancipatory dimension that moves education forward - through what it creates, invents, and proposes.

The model of a professional teacher (Bucherberger, Campos, Kallos, and Stephenson, 2000) has been one of the inspirational sources, working against the bureaucratic/conformist and/or technical vision of the teaching profession. A professional has the political and scientific autonomy to make decisions in the field of professional knowledge and about the profession in general. A professional is, with his/her peers, the author of his/ her profession with respect for those he/she serves. Specifically, professional teachers, especially knowledgeable of the ethical and epistemological challenges of their profession, make decisions about it (in relation to other decision-makers) for the benefit of children, young people, families, regions and society.

Due to this relationship established with society as a whole (its past, present and future), the power of teachers is massive, which is why the teaching profession has been the subject of various forms of control throughout its history. Still, nowadays, after decades of deepening the professional model of a teacher, these attempts at control are felt and take on new and dangerous qualities. It is these dangers - of deprofessionalization and privatization - and how to deal with them that have concerned many authors (Ben-Peretz and 
Flores, 2018). António Nóvoa, in a 2017 article entitled 'To firm the position as a teacher, to affirm the teaching profession', states that "[We are] facing a crucial moment in the history of teachers and the public school" [...] "We need to rethink our institutions and our practices with boldness and daring” (p. 1114).

In order to address this request, a sustained knowledge base already exists that allows us to affirm the professional model by demonstrating its efficiency/effectiveness. Linda Darling-Hammond, in an article entitled 'Teacher Education Around the World: what we learn from international practice', published in 2017 in The European Journal of Teacher Education (Darling-Hammond, 2017a) describes successful teacher education policies and practices in Australia (focusing on Victoria and New South Wales), Canada (focusing on Alberta and Ontario), Finland and Singapore. As the author herself (Darling-Hammond, 2017) proposes, identifying which characteristics teachers' education and professional development systems judged as quality (regarding its results concerning students) is important because it broadens the perspective of the possible and because, in a comparative perspective, it shows how ideas work in practice.

In the comparison of the above-mentioned countries, two general characteristics were identified:

- $\quad$ on the one hand, in these countries or states, the professional ideal has a lot of strength, teachers have great value and teaching is an important profession - it has a knowledge base that must be acquired so that all students can learn;

- $\quad$ on the other hand, school education and training in these situations are effectively organized as systems, that is to say, they include various harmonizing components relating to: recruitment; initial education; induction, continuous education; and collective improvement of practice; its systemic quality implies balancing these components - one cannot be too demanding in recruitment or avoid investing in the symbolic value of the profession.

Specifically, in relation to initial education, the following characteristics were identified:

- $\quad$ the management and development of the curriculum is more important than its organization; in this, the importance of the relationship between theory and practice and the development of teachers' capacity to teach diverse students is emphasized; 
- $\quad$ special attention is given to the construction of pedagogical thinking capacities so that the teacher can manage the teaching process in a diagnostic way, using research as a basis and conducting action research;

- $\quad$ thorough knowledge is developed in the fields of child development, learning and pedagogy; the final assessment involves researching a problem of practice in a rigorous way;

- $\quad$ great emphasis is placed on the teaching of students who show difficulties, and once this has been considered it becomes an excellent way to learn how to teach all students;

- $\quad$ internship takes place in special teacher training schools run by universities with curricula and practices similar to those of public schools; these schools are run by teachers specially selected for their skills and it is part of their responsibility to train new teachers;

- $\quad$ the teacher (educators) are specially trained in supervision, teacher professional development and assessment strategies;

- $\quad$ schools develop research in liaison with the university's teacher training department.

From these topics it can be concluded that how to improve educational systems and students learning is already known; however, what to do to make it real in different contexts and cultures needs the consideration of the specificities of those contexts and cultures.

\section{The relational and subjective dimension of teachers' professionalization: an ecological version of the construction of teachers' professional identities}

In an article entitled 'Comparative Global Perspectives on European Teacher Education', also published in The European Journal of Teacher Education, in 2014, Francesca Caena analyses practices concerning the reform of teachers' education and Higher Education in Europe, more specifically in England, France, Spain and Italy. Regarding initial teacher education in the countries involved in her study, Francesca Caena (2014) refers to the following common tensions:

- $\quad$ between the academic and the professional requirements of the courses;

- among several axes of the professional profile of teachers - content knowledge, pedagogical knowledge, management of interactions in the classroom; 
- $\quad$ among emphasis on knowledge, values or skills;

- $\quad$ among modes of articulation between higher education institutions and schools;

- between cultures of collaboration or isolation;

- $\quad$ between formative or summative evaluation of students' learning;

- $\quad$ and between the functional and social roles of the teacher educator, that is, between developing and evaluating skills or building professional identities.

All of these tensions refer to current central challenges of teacher education, but the latter, to some extent, encompasses all the others in distinguishing between the acquisition of functional or social roles through initial teacher education.

This is also a good summary of the place of identity in teacher education. In fact, the use of the concept of identity is part of a critical approach to the teaching profession and to the teacher as a professional. Identity emerges as an antidote (or an alternative) confronting the technical and entrepreneurial vision of teachers and their education.

Several hopes of improving the teaching profession and teacher education are built around identity studies. In the article 'Trends in Teacher Education: a review of papers published in The European Journal of Teacher Education over 40 years', Livingston and Flores (2017, p. 560) state that "further research is needed in regard to preservice teachers' identity development during initial teacher education and career-long professional learning”. And Kay Livingston (2016), in a way, explains why this is important: "Discussions inevitably led to further questions about the role of teacher education in the development of teachers' professional identity. In particular, how to support the development of professional identities that enable teachers to take an inquiring, reflective and collaborative approach to learning and teaching in school” (Livingston, 2016, p. 401).

Why is identity invoked when we wish teacher education to be more consistent and purposeful? Why is identity the answer? Identity is meaning and the meanings of being a teacher are changing because the meanings of being, themselves, are changing. And it is a big change. It is how we understand the world, the way we behave, individually and collectively, that are changing. The search for identity is the search of new subjectivities in new practices and it convenes all the levels of the ecological and social system. 
The teaching profession was crucial in the construction of modern society and its subjectivities and, therefore, its change also impacts the whole of society today. Speaking about the crisis of modernity and the insistent appeal to the concept of identity, Kenneth Gergen (1987) affirms that this is a sign that the modern conceptions of knowledge and the individual are in transformation. Using several approaches, he says that the Cartesian maxim "I think, therefore I am" is replaced by the motto "I communicate, therefore I am”. This point of view synthesizes the depth of the (educational) change that the concept of identity construction intends to account for.

And as schooling has had a systemic structure and dynamic, the construction of new meanings of the teaching profession will have as well. The construction of professional teaching identities is necessarily an ecological construct.

In the conception of the construction of professional identity as an “ecological construct” (Lopes, 2007, 2009) three perspectives converge: that of the construction of professional identity as a double transaction "for real social change” (Dubar, 1995), the ecology of human development (Bronfenbrenner, 1979) and the social-psychology approach (Doise, 2002).

The double transaction includes the relational transaction - of the individual with others and their contexts - and the biographical transaction that takes place in the individual, between what he/she was, is and wants to be. The two transactions can match or not, giving place to processes of negotiation, adaptation or submission.

The ecological perspective emphasizes the historical, situated and systemic nature of the relational transaction. Along with Bronfenbrenner (1979), it is considered that the individual is active in the construction of her/ his development scenarios, which are constituted by different subsystems in interaction - the micro, the meso, the exo and the macro. Social-psychology adds psychosocial content to these interactions, distinguishing between individual, interpersonal, institutional and societal levels. According to Blin (1997, p. 58), this approach of professional identity considers the professional to be "a socially inserted being [allowing] the construction of systems of explanation articulating the individual and the social [...] and opening room to propose answers to the recurrent question of the passage between the micro and the macro social levels".

This approach is important to research and apply to teacher education - its main idea reports to the fact that whatever level of analysis or action is in focus, the other levels are present or should be analytically present, 
since solutions at one level interfere at different levels. Also, in this sense, teachers, but also diverse stakeholders, policy makers, and the whole of society, are protagonists of the construction of a valued teaching identity.

Building professional identities and not just competencies through education implies this ecological vision, and, to be effective, it implies an ethics of communication as well. Dubar (1995; 2000) refers to the negotiation process which the double transaction calls for as the construction of identity 'for real social change'. The systemic change that the concept of teacher identity intends to give account of has all its foundation in communicational processes. These processes of recognition and inclusion emerge as alternatives to the modern processes of hierarchization and exclusion that still characterize schools. As in the past, teachers have been craftspeople of modern society, which is now in crisis; they will be important to the renewal of society and school in the present.

To this end, the principles behind the modern school - social reproduction, conformity and exclusion - give way to those of social creativity, agency and solidarity. At a time of great attack on the professionalism of teachers, democratic professionalism (Sachs, 2001), as Ben Peretz and Flores (2018, p. 203) suggest, calls for the deepening of inclusive education, specifically through culturally responsive pedagogies and more demanding processes of academic inclusion. Darling-Hammond (2017b), in an article entitled 'Teaching for Social Justice: Resources, Relationships, and Anti-Racist Practice', published in Multicultural Perspectives, identifies four guiding principles for an inclusive education: equal resources leading to equitable opportunities; equal opportunity for a kind of deeper learning (calling for a curriculum that "supports critical thinking, problem solving, communication, collaboration, and applications of knowledge to real-world problems” p. 136); emphasis on social/emotional, as well as on academic skills; and personalization and relationships. Regarding the first, Linda Darling-Hammond says that "a common curriculum focused on $21^{\text {st }}$ century skills [needs to be offered] to all of [the] students through ninth or tenth grade" (ibid, p. 136). The author goes on to say that "intensive teacher training is needed to offer a more challenging curriculum to heterogeneous groups of students, because this teaching demands sophisticated skills to scaffold and differentiate instruction (ibid, p. 137).

Promotion of diversity and inclusion are guiding principles that challenge the whole ecological system by calling for changes in the relationship of teachers with students in class, but also in the schools, communities, 
educational policies and models of society. To educate supportive, creative and active identities, supportive, creative and active identities are needed. Identity compels the rethinking of the ends and processes of teacher education by calling for a profound change/renewal in the training environments.

\section{Research findings and reflections demonstrating the role of relationships in teacher education processes}

Regarding current educational discourses, Biesta (2012, p. 8) asserts that talking about learning is not enough, because "education always needs to engage with questions of purpose, content and relationships". Of these three questions, which education (and identity) is always engaged with, relationships have been less considered and reflected on. However, as stated before in this chapter, the claims for identity in (teacher) education come from a main change in relationships now seen as a way of producing society a communicational society.

The following research findings on teacher education and identities showing the importance of relationships and environments and with an ecological inspiration will be presented. These findings must be seen as ideal types (in a Weberian sense), and therefore independent of geographical or historical contexts in which the studies were conducted.

Three key issues will be focused upon: teacher education environments and teachers' identities; research, teaching and teacher educators' identities, and the teaching profession and collective identity of teachers.

\section{Teacher education environments and teachers' identities}

In this first section of the research the relationship between preservice teacher education curricula and the professional identities formed in them was analysed. Four curricula corresponding to different historical periods in the same geographic context were studied. The research was supported by an ecological conception of curriculum integrating cultural, political, institutional and classroom contexts; also, the formal dimension of the curriculum and the informal (referring, in Pacheco's terms, 1994, to aspects intentionally used, but not formalized) and the non-formal dimensions (coinciding with the hidden curriculum, which is unconscious and not formalized) were appreciated. The curricula were characterized mainly through document analysis and the respective identities (which were called first professional identities) were researched using interviews producing 
biographical narratives, which covered the period of initial training and the periods before and after training. In the interviews, teachers' perspectives on the curriculum were also collected.

In this research study two conclusions must be highlighted. The first is a condition for proceeding to the second and concerns the fact that different curricula effectively correspond to different identities. The second conclusion involves the relation between certain dimensions of the curricula and certain dimensions of the professional identity formed in them.

The interactionist theories of professions and professionalism demonstrate that training climates are crucial in the first professional socialization; specifically, in the case of teachers, because we all have an experience with the profession from a very young age and for many years, and therefore initial training needs not only to help shape a possible model of a teacher but also to deconstruct the implicit model constructed over time. Hence, students should be offered opportunities and conditions of identity conversion, to which Berger and Luckman (1986) call "moving to a new house," and which translates into the expression "I used to think that ... and now I think ...”. In teacher education, changes in the conceptions of authority and knowledge, and their respective practices, are the main concerns.

Of the four curricula studied, two of them as ideal types are especially useful to develop the argument about the importance of relationships and communication in building active, supportive and creative professional identities: the professional learning climate and the academic learning climate. From the contrasted analysis of the two curricula/climates, several important conclusions are drawn. One is general and concerns how the formal curriculum makes a difference. The existence of an explicit education project that includes the professional model to be formed, as well as objectives, contents and methodologies to be prioritized seems to be crucial for the collective mobilization (collective action) of educators and students around this project.

In the 'professional learning climate', the teacher is seen as a critical professional, a pedagogue and a transformative agent: to dignify the teacher status and role was the central aim. The formal curriculum includes interdisciplinary areas, optional seminars, specific times for curricular activities outside the classroom and the development of projects with the families and communities to which pupils belong. The curriculum development is based on professional tasks, team work and research topics, and on modalities of formative assessment. 
In the 'professional learning climate', the informal curriculum is very important as well. The educators' use of innovative methods and out-ofclass activities are valued by student teachers, who, as young adults (Ribeiro, 2007), especially stress the importance of learning activities involving interpersonal relationships, participation and personal commitment.

In the 'academic learning curriculum' the formal curriculum is a set of programs of the different disciplines that make up the study plan. These programs mostly include the scientific content to be addressed and the bibliography - with no reference to the pedagogical methods to be adopted. The assessment is mostly summative, involving examinations. Apparently, this curriculum is concerned with deepening the scientific nature of teacher education but adopting, in that which concerns formative relationships and communication, the worst of the traditional higher education institutions.

The learning relationship with peers is an important means of analysis of these curricula. In the professional learning curriculum learning is connected with friendship and "took place both in peer group and collective activities" through which students negotiated their own curriculum development (Lopes and Pereira, 2012, p. 33).

In the 'academic learning curriculum', learning is separated from friendship. To live with colleagues and to learn with them are separated issues. The peer group is still a convivial place but students must also cope with the stress coming from the intensification of their academic work.

In abstracting and interpreting these results, it is worth saying that the disconnection between learning and participation, and between learning and user-friendliness reflects the academic nature of the curriculum. The life-world of teacher training seems to be an important part of its quality; in fact, the active involvement of students in the curriculum is of central importance to the formation of lifelong learning and a transformative professional identity.

\section{Research, teaching and teacher educators' identities}

In the last decade the relationship between research and teacher educators' identities has become a more and more recurrent issue. The possible academization of teacher education taking place in higher education institutions is not the unique reason for this. In fact, sometimes teacher education identities are under study for the opposite reason, as they tend to be excessively centered on practice and pedagogy only (see Ellis and McNicholl, 2015 regarding the UK situation). As stressed by Swennen, Jones and 
Volman (2010) and by Zgaga (2015), the education systems and the systems of teacher education are very different between certain countries. The 'pure academic' and the 'pure practitioner' teacher educators' identities could be two opposite poles between which a lot of other possibilities exist across countries and within them - notably according to the kind of teachers being trained and training institutions.

In the second section of the analysis, educators' identities and education environments in teacher and nurse education were compared. A nurse educator and anthropologist, talking about his own experience of being a nurse educator and teacher educator, says:

[Ever, since I arrived] at nursing school, I always [felt] like a guest. Let's say, like a guest. [...] it may be that we are very welcoming to a guest in our home, but a guest in our home is not a part of our household. Therefore, that person is a guest. [...] [At the teacher education school] I didn't feel like a guest, I felt more like a teacher. There you go. Among many others who were there, I was just another teacher [...] I always felt like just another teacher who was part of an institution. [In this nursing school] there is an identity there and that predates, perhaps, the school itself, which characterizes nursing as a profession, and the nurses who are then at a nursing school [...]. As such, school has an identity that doesn't overlap the profession, but it is an identity that bears very strong, very strong similarities [to the profession]. [...] teaching schools, [...] don't have a very strong identity, or not as strong [...]. Because even the teachers themselves have a very dispersed identity (in Lopes, Pereira, and Mouraz, 2013).

This statement in a way sums up the main findings of the research under consideration in this analysis, in which differences between the case of teacher education and the case of nursing education are not important as such, but as two kinds of professional higher education.

One of the differences between these two kinds of professional higher education concerns whether the educator's identity is of a dual nature (mediating or hybrid) or not (Pereira, Lopes and Marta, 2015); the other one concerns the links among professionalism, research and the professional field.

A dual identity (Boyd, 2010) consists of the way professional educators' (precedent) identities as practitioners are present in their identities as higher professional educators. We call 'pure academic' those higher professional educators who only have an academic career and are not concerned with their professional relevance when educating professionals.

Dual identities appear then as something good in professional higher education. The findings show that they can emerge in three different ways. 
They may emerge because of the educator's biography (if the educators have also been school teachers, a situation, for example, very common in England but rare in Portugal), or by function or position - even if they have not been school teachers, educators still perform the functions of supervision of the practical aspects of training. The third way is through institutional commitment (Lopes, 2014) - when the training climate is so strong that all educators feel obliged to be professionally relevant (as in the case of the professor of anthropology in the nursing course).

Concerning connections between research, teaching and their respective occupational fields, two different kinds of connection were found: one that is strong (in the case of nursing) and one that is weak (in the case of teaching): in the strong one, research is a means to empower the profession and, in the weak, research is a means to empower individual educators' academic identities (Lopes et al., 2014). Moreover, while teacher educators feel responsible for the professionalism of each individual future teacher, nurse educators feel responsible for the collective professionalism of nurses.

It is clear that teacher training will be all the more relevant for the teaching profession the more there are conditions for the emergence of dual identities and for the emergence of strong relationships between the profession, the educators' research and the training.

This emergence implies specific training relationships translated into training cultures strongly associated with the profession, integrating the pedagogical and scientific components into the same professional training framework, and with sustained, enlightened and potentially symmetrical communication among educators at the universities and educators at the schools.

\section{The teaching profession and the collective identity of teachers}

The teaching profession is weakly present in teacher education: teachers of different sectors do not see each other as belonging to the same profession; there is a strong division in teacher education between those who teach in university and those who teach in schools, those who are expert in History or Mathematics and those who are expert in Psychology or Sociology, as well as between those who teach theoretical issues and those who supervise practice, and so on. The result is that teacher educators are concerned with teachers' professionalism but they seem not to have a collective professional foundation to invoke.

These issues are also identified by Grossman and McDonald (2008), who boldly assert that "teacher education is somewhat of an orphan, connected to 
neither of its natural parents [teaching and higher education] (Grossman and McDonald, 2008, p. 185) and by António Nóvoa (2007, p. 24), who claims that there is a need to foster the permeability and overlap between "the community of teacher educators" and the "community of school teachers".

Although the teaching profession is a collective profession in its exercise mode, in its organization and in its purpose an approach to the collective identity of teachers is very rare. And yet the importance of this debate is high, especially when the collective nature of teaching can no longer be ensured by regulations only and actually needs a common vision and commitment.

In fact, continuous professional development includes the feeling of belonging to a collective network with a participatory nature in a joint process, and the investment in its corresponding communicative and relational processes.

Through running an action research study (Lopes, 2002) aimed at promoting creative processes in school education in two communities, each of them comprising a primary school and a kindergarten, it was quickly verified that in requiring creativity the research project was really dealing with deep individual and collective changes in teachers' identities.

As a means to follow teachers and start a joint process of change together with them, small groups of teachers with an advisor/researcher were created. At the beginning they meet weekly, and then fortnightly, to reflect on practices narrated by them in writing; the writings were about practices that teachers considered important to be shared and discussed, although teachers were free to write about them or not. At the beginning and at the end of the intervention, two questionnaires were carried out, one concerning the psychosocial identity of each teacher and another one related to the relational climate of the school. The group meetings were recorded.

The study concluded that all teachers want to participate in innovative dynamics (provided they are given adequate individual and organizational conditions), but change is blocked by recognition problems that are felt in communication.

Change implies the creation of a new culture in which everyone feels recognized. In this creation, the individual, the group and the organizational work combine. The group was the starting point of the work, welcoming and stimulating individuals from the first moment, so that later this could be projected to the school. At school level, change is reflected in the existence of 
a convincing and relevant project of school functioning. To get there, communication cannot be taken for granted; it is rather a fundamental element of real change and focuses on decentralized innovation - the one that promotes openness to others and includes them (as opposed to the centralized one that closes itself to some and excludes others). It carries (communicational) individual changes (conversions) and must have material translation in the schools' organization: spaces, times, work groups, etc.

Therefore, the reconstruction of a collective identity for teachers addresses the construction of new interpretive communities and practices in schools, which continuous professional development must invest in.

\section{Final reflections and purposes}

As we have seen, in countries with good systems of teacher education, the image of the profession is strong and valued. These same countries have systems of continuous professional development that assure the collective improvement of teaching practices. Thinking about the impact of both initial education and continuous professional development on the improvement of teaching in action, and also on the strengthening of the teaching profession and teacher professionalism, António Nóvoa defends the creation of "a new place for the education of teachers" guided by the "imperative of professionalization” (Andrews, Bartell and Richmond, 2016 cited in Nóvoa, 2017, p. 1116). In this place, the profession of 'teacher' is produced, "not only in terms of education, but also in terms of its affirmation and public recognition, people committed to both university work and the future of the teaching profession” (ibid.) and it becomes united.

This is a crucial proposal. The intention is not to equalize all entities - theory and practice, university teachers and school teachers, etc.; the goal is to pursue another relationship, another dialogue, among the differences or the different instances. This is also the conclusion of research studies on the role of advanced education (PhD studies) into the professional activity of teachers (Kowalczuk-Walędziak et al., 2017; Lopes and Menezes, 2018): it is from the dialogue between universities and schools, a dialogue that the teachers in advanced education themselves represent, that the development of teachers and the improvement of schools emerge. 


\section{References}

Berger, P., and Luckman, T. (1964). The Social Construction of Reality: A Treatise in the Sociology of Knowledge. London: Penguin Books.

Ben-Peretz, M., and Flores, M.A. (2018). Tensions and Paradoxes in Teaching: Implications for Teacher Education. European Journal of Teacher Education, 41 (2), 202-213.

Biesta, G. (2012). Giving Teaching Back to Education: Responding to the Disappearance of the Teacher. Phenomenology and Practice, 6 (2), 35-49.

Blin, J.F. (1997). Représentations, Pratiques et Identités Professionnelles. Paris: L'Harmathan.

Boyd, P. (2010). Academic Induction for Professional Educators: Supporting the Workplace Learning of Newly Appointed Lecturers in Teacher and Nurse Education. International Journal for Academic Development, 15 (2), 155-165.

Bronfenbrenner, U. (1979). The Ecology of Human Development: Experiments by Nature and Design. Cambridge, MA: Harvard University Press.

Bucherberger, F., Campos, B. Paiva, Kallos, D., and Stephenson, J. (2000). Green Paper on Teacher Education in Europe: High Quality Teacher Education for High Quality Education and Training. Umea: TNTEE Publications.

Caena, F. (2014). Comparative Global Perspectives on European Teacher Education. European Journal of Teacher Education, 17 (1), 106-122.

Darling-Hammond, L. (2017a). Teacher Education around the World: What Can we Learn from International Practice? European Journal of Teacher Education, 40 (3), 291-309.

Darling-Hammond, L. (2017b). Teaching for Social Justice: Resources, Relationships, and Anti-racist Practice. Multicultural Perspectives, 19 (3), 133-138.

Doise, W. (2002). Da Psicologia Social ŕ Psicologia Societal. Psicologia: Teoria e Pesquisa, 18 (1), 27-35.

Dubar, C. (1995). La Socialisation - Construction des Identités Sociales et Professionnelles. Paris: Armand Colin.

Grossman, P., and McDonald, M. (2008). Back to the Future: Directions for Research in Teaching and Teacher Education. American Educational Research Journal, 45 (1), 184-205.

Kowalczuk-Walędziak, M., Lopes, A., Menezes, I., and Tormenta, N. (2017). Teachers Pursuing a Doctoral Degree: Motivations and Perceived Impact. Educational Research, 59 (3), 335-352.

Lopes, A., and Menezes, I. (2018). A Construçăo de si Como Investigador: Reflexőes Sobre os Processos Deformaçăo Pós-graduada. Educar em Revista, 34 (71), 103-124.

Lopes, A., and Pereira, F. (2012). Everyday Life and Everyday Learning: The Ways in which Ore-service Teacher Education Curriculum Can Encourage Personal Dimensions of Teacher Identity. European Journal of Teacher Education, 35 (1), 17-38.

Lopes, A. (2002). Constructing Professional Identities in Portuguese Primary School Teachers. Identity: an international journal of theory and research, 2 (3), 241-254. 
Lopes, A. (2007). La Construcción de Identidades Docentes Como Constructo de Estructura y Dinámica Distémicas: Argumentación y Wirtualidades Teóricas y Prácticas. Profesorado: revista de curriculum y formación del profesorado, 11 (3), 1-25.

Lopes, A. (2009). Teachers as Professionals and Teachers” Identity Construction as an Ecological Construct: An Agenda for Research and Training Drawing upon a Biographical Research Process. European Educational Research Journal, 8 (3), 461-475.

Lopes, A. (2014). A Docęncia Como Prática: Questőes de Identidade e Formaçăo. In: A. Graça, P. Queirós, and P. Batista (Eds.), O Estágio Professional na (Re)construçăo da Identidad e Professional Emeducaçăo Física (pp. 270-287). Porto: Universidade do Porto, Faculdade de Desporto.

Lopes, A., Boyd, P., Andrew, N., and Pereira, F. (2014). The Research-Teaching Nexus in Nurse and Teacher Education: Contributions of an Ecological Approach to Academic Identities in Professional Fields. Higher Education, 68 (2), 167-183.

Lopes, A., Pereira, F., and Mouraz, A. (2013). The Initial Education of Helping Professionals: Unity and Diversity. In: A. Lopes (Ed.), Formaçăo Inicial de Professores e de Enfermeiros: Identidades e Ambientes (Initial Education of Teachers and Nurses: Identities and Environments (pp. 181-191). Lisboa: Mais Leituras.

Nóvoa, A. (2007). O Regresso dos Professores. In: Ministério da Educaçăo Desenvolvimento Profissional de Professores Para a Qualidade e Para a Equidade da Aprendizagem ao Longo da Vida (pp. 21-28). Lisboa: Ministério da Educaçăo (Direcçăo-Geral dos Recursos Humanos da Educaçăo) Comissăo Europeia (Direcçăo-Geral de Educaçăo e Cultura).

Nóvoa, A. (2017). Firmar a Posiçăocomo Professor, Afirmar a Profissăo. Cadernos de Pesquisa, 47 (166), 1106-1113.

Pacheco, J.A. (1996). Currículo: Teoria e Praxis. Porto: Porto Editora.

Pereira, F., Lopes, A., and Marta, M. (2015). Being a Teacher Educator: Professional: Identities and Conceptions of Professional Education. Educational Research, 57 (4), 451-469.

Ribeiro, A. (2007). Jovem Adulto em Desenvolvimento e Formaçăo. In: A. Lopes (Ed.), De uma Escola a Outra (pp. 63-71). Porto: Afrontamento.

Sachs, J. (2001). The Activist Teaching Profession. Buckingham: Open University Press.

Santos, B.S. (1995). Toward a New Common Sense: Law, Science and Politics in the Paradigmatic Transition. London: Routledge.

Swennen, A., Jones, K., and Volman, M. (2010). Teacher Educators: Their Identities, Sub-identities and Implications for Professional Development. Professional Development in Education, 36 (1-2), 131-148.

Zgaga, P. (2015) Rethinking Teacher Education in Europe and Beyond, editorial introduction. Education Inquiry, 6 (3), 231-239. 


\title{
Chapter 3
}

\section{Reshaping Teacher Training to Get the Right Education System for a Knowledge Society}

\author{
Gracienne Lauwers
}

Vrije Universiteit Brussel, Brussel, Belgium

\begin{abstract}
Societies move from a labour-intensive economy into more of a knowledge-based economy. In terms of training teachers to prepare their students with the right skill set for the $21^{\text {st }}$ century labor market, the Flemish Community of Belgium has reshaped its teacher training system and starts in 2019-2020 with the so-called educative master's. This paper analyses the underlying logic of the reforms for teacher recruitment, development and support for teacher education, and the remaining challenges. Finally, it makes critical comments with regard to the proposed reforms. KEYWORDs: teacher education reform, Flemish Community of Belgium, challenges to teacher education, $21^{\text {st }}$ century labor market
\end{abstract}

\section{Introduction}

The trend towards a knowledge-based innovation-led economy for a rapidly changing world increases pressure on policy makers to educate and train the talents and skills of their citizens to allow them to achieve their full potential, and contribute to the global competitiveness of the national economy. What is the respective role of teacher training in a post-industrial knowledge economy? How can teacher training do justice to the students in the $21^{\text {st }}$ century? Should future teacher training substantially differ from the training undergone by the teachers in the last century? 
This article seeks answers to the challenges of teacher training. It is divided into three parts. First, it outlines the strategic priorities at community level. It then analyses the recent reforms of teacher education in the Flemish Community of Belgium. Finally, it makes critical comments with regard to the proposed reforms.

\section{The basic principles of European education policy}

The supply of skilled labour as a result of qualitatively better education has increased worldwide. Competition occurs no longer just as a result of a cheap low skilled labour force. By 2020, 20\% more jobs in the EU will require high level qualifications (CEDEFOP, 2018):

The EU labour market has long been transforming, moving from heavy industry to digital technology and services, and from a broad base of often low-skilled jobs to a knowledge economy requiring different and higher-level skills.

Europe seeks to implement certain indicators and benchmarks for training and education systems by $2020^{1}$, as follows:

- $\quad$ at least $95 \%$ of children between the age of four and the starting age of compulsory primary education are participating in early childhood education;

- $\quad$ no more than $15 \%$ of all 15 -year-olds are underachievers in reading, maths or science;

- $\quad$ no more than $10 \%$ of all 18 to 24 year olds are early leavers from education and training;

- $\quad$ at least $40 \%$ of 30 to 34 year olds have tertiary educational attainment;

- $\quad$ at least $15 \%$ of adults participate in lifelong learning;

- $\quad$ at least $20 \%$ of all higher education graduates and $6 \%$ of all 18-34 year-olds spend part of their studies or training outside their home country;

- $\quad$ at least $82 \%$ of all graduates (20 to 34 -year-olds with at least a secondary school diploma) have entered employment within three years of graduating.

1 Indicators, quantitative targets and benchmarking: https://ec.europa.eu/eurostat/statistics-explained/index.php/Europe_2020_indicators_-_education\#General_overview

Strategic framework for European cooperation in education and training (ET 2020): http:// ec.europa.eu/education/policy/strategic-framework_nl; and https:/ec.europa.eu/eurostat/statistics-explained/index.php/Europe_2020_indicators_-_education\#General_overview. 
However, European competitiveness is undermined by skills mismatches, in part because education is still too distant from the business world. ${ }^{2}$ To create a better interaction between higher education and the wider economy, the flow of knowledge and the required skills are crucial and a primary responsibility of policymakers. This also includes educational reforms.

Teachers will be indispensable to achieving the transition towards a knowledge economy and teaching the skills that economies need. Policies should revise the professional profile of teachers at all levels, as well as those of school leaders and of teacher training, and prepare them to strengthen the provision of transversal skills such as entrepreneurial initiative, digital skills and foreign languages that increase employability for the students. They should improve the performance of student groups with high risk of early school leaving and low basic skills, to develop world-class vocational education and training to raise the quality of vocational skills and increase the efficiency of funding in education. ${ }^{3}$

It will be, above all, the work in classrooms that will be crucial to the future of Europe. It is in the classrooms and schools that this future is being built (European Commission, 2018). The chief architects of a prosperous Europe are the teachers and school principals. But Europe must address its challenges in order to compete in the global knowledge-based economy. ${ }^{4}$

Societal realities create challenges for education and training provision. These include:

- $\quad$ The massive retirement of baby-boom generation teachers ${ }^{5}$ and severe teacher shortages in some subject areas, resulting in an increased demand for qualified teachers at all levels. Comprehensive policy actions should boost the attractiveness of the teaching profession and include well-resourced strategies to recruit, retain and develop high-quality teachers. One of the underlying reasons for the teacher

2 Eurostat, Labour Force Survey, Figures on employed tertiary education graduates overqualified for their jobs. See also: http://ec.europa.eu/eurostat/statistics-explained/index.php/Europe_2020_indicators_-_employment\#Skills_mismatches_in_the_labour_market.

3 Communication from the Commission to the European Parliament, the Council, the European Economic and Social Committee and the Committee of the Regions, Rethinking Education: Investing in skills for better socio-economic outcomes/* COM/2012/0669 final */.

4 Joint Report of the Council and the Commission on the implementation of the strategic framework for European cooperation in education and training (ET 2020), New priorities for European cooperation in education and training (2015/C 417/04). https://eur-lex.europa.eu/legal-content/EN/TXT/HTML/?uri=CELEX:52015XG1215(0 2) \&from=NL

5 Eurostat, UOE/Eurydice Key data on education, Table on Age Distribution of Teachers in Lower and Upper Secondary Education. 
training reforms in Flanders is the need to attract students with a strong commitment to a teaching career.

- $\quad$ Teachers need to scale-up the use of ICT in learning and teaching. It is essential that initial teacher training and professional in-service training for teachers equip teachers with knowledge and skills to use the potential of the new technologies, in order to meet the expectations of and stimulate digital-born learners. Teachers should master ICT well in order to stimulate the use of open, flexible and individualised learning environments. This requires good computer skills, but some Member States are still lagging behind, with nine Member States having over $50 \%$ of $16-74$ year olds with no or low computer skills. ${ }^{6}$

- Attention in teacher training should be focused on the development of transversal skills. ${ }^{7}$ Knowing how to teach entrepreneurial skills ${ }^{8}$ should contribute to new business creation and to the employability of students. At the national level only six Member States have a specific strategy for entrepreneurship education ${ }^{9}$ and a focus from secondary to higher education on the opportunity of business creation as a career destination. ${ }^{10}$ To address this, the Commission has already published (in 2013) policy guidance to support improvements in the quality and prevalence of entrepreneurship education across the EU. To support Member States the Commission identified tools to assess progress and demonstrate the acquisition of entrepreneurial skills. ${ }^{11}$

- $\quad$ Education systems should guarantee that basic skills are achieved by all. Literacy, numeracy and basic mathematics and science are key foundations for lifelong learning and are a gateway to employment and inclusion. Nevertheless, underperformance remains with the share of 15-year olds in Europe who have not acquired basic skills at around $20 \%$, and five countries having over $25 \%$ low achievers in reading. ${ }^{12}$

Eurostat, Information Society Statistics. http://ec.europa.eu/eurostat/web/microdata/community-statistics-on-information-society.

7 Transversal skills such as the ability to think critically, take initiative, problem solve and work collaboratively will prepare individuals for today's varied and unpredictable career paths.

8 For an overview of entrepreneurial skills, cf Staff Working Document on the Assessment of KeyCompetences

9 Entrepreneurship Education at School in Europe - National Strategies, Curricula and Learning Outcomes (Eurydice, 2012).

10 To address this, in 2013 the Commission will publish policy guidance to support improvements in the quality and prevalence of entrepreneurship education across the EU.

11 Global Entrepreneurship Monitor 2018, https://www.gemconsortium.org

12 OECD, table on Percentage of Low Achievers in Reading, in Mathematics, in Sciences 
- $\quad$ Qualitative vocational education and training should be further developed through targeted investment with demand-driven training. Combined work- and school-based VET (Vocational Education and Training) should be further developed with built-in mechanisms to adapt to demand for skilled labour. A legal framework should be elaborated with the participation of social partners. ${ }^{13}$

- $\quad$ Language learning needs particular attention. In a world of international commerce, foreign languages are a factor for competitiveness on the labour market and thus increase the employability and mobility of young people, whereas poor language skills are a major obstacle to the free movement of a worker. The target defined by the European Heads of State is 'mother tongue plus two'. ${ }^{14}$

Both policy makers and citizens are responsible for participation in lifelong learning. Currently, the participation levels in adult learning in most Member States is alarmingly low. Europe will only resume growth through higher productivity and the supply of highly skilled workers. Legal reforms on the recognition of nanodegrees, obtained through an online private education provider, ${ }^{15}$ could encourage citizens to participate in training and lifelong learning. This would also slowly end the quasi-monopoly of traditional educational institutions to issue recognised qualifications.

\section{Reforms put in place by the Flemish Community of Belgium}

In May 2018 the Flemish Parliament adopted a decree for strengthening teacher training. This decree ${ }^{16}$ paved the way for 'new' educative programs.

From the 2019-2020 academic year onwards, the reformed teacher training programs in Flanders consist of the educative bachelor's program in nursery, primary education or secondary education, the educative master's program in secondary education or art, and the educative graduate training for secondary education.

13 CEDEFOP European Centre for the Development of Vocational Training, based on data from Eurostat, UOE, Table on Proportion of VET students enrolled in combined work- and schoolbased VET, as a \% of all students in upper secondary VET. two or more foreign languages.

15 E.G. open online leerplatform Udacity.

16 Decreet betreffende de uitbouw van de graduaatsopleidingen binnen de hogescholen en de versterking van de lerarenopleidingen binnen de hogescholen en universiteiten, 4 mei 2018, B. St. 16 juli 2018. 
Teacher training at level 6 EQF (European Qualifications Framework) is initial teacher training and consists of a professional bachelor's degree. The educative bachelor's programs in nursery, primary education or secondary education are organised by university colleges as 180 ECTS (European Credit Transfer System) study programs with a practical component of 45 ECTS.

Level 7 EQF trains secondary education university-trained teachers. The educative master's program in secondary education or arts is organised by universities ${ }^{17}$ and consist of master's programmes of 90 or 120 ECTS, including 60 ECTS in teaching as a profession. The 15 ECTS practical component of the 60 ECTS in teaching can begin during the academic bachelor's. The diploma awarded equals an educative master's, whereas before, specialist subject teachers needed to complete their university degree with a postgraduate diploma in education, including a traineeship in a school. The courses include thorough pedagogical training, thorough didactic training, and a large amount of practical training. It is left to the universities to decide whether courses in the teacher training programs include the teaching of a philosophical or ideological vision on education, education law, or other additional subjects.

Teacher training at level 5 EQF (higher professional education) is the educative graduate training for secondary education organised by university colleges for candidate teachers with sufficient technical or practical experience in a particular field. This study programme consists of 90 ECTS with a practical component of 30 ECTS. The inflow of students for this study program consists of future teachers with professional expertise in a particular technical subject. Level 5 focuses solely on the basic competences of a teacher and does not have any subject content in its training program.

The overall goal of the reforms is to insist that the teachers, no matter how difficult their circumstances, can offer world-class education in level 5, level 6 and level 7 of the EQF. The reforms also aim to improve the quality of students registering in teacher education. ${ }^{18}$ This is realized through a compulsory non-binding entrance exam for secondary school students for pre-school, primary school and secondary education. The compulsory

17 Organised in the Schools of Arts.

18 Memorie van toelichting bij het ontwerp van decreet betreffende de uitbouw van de graduaatsopleidingen binnen de hogescholen en de overdrachtsmaatregelen voor de lerarenopleidingen [Explanatory memorandum to the draft decree concerning the development of graduate programs within the university colleges and transfer measures for the teacher training courses] https://www.vlaanderen.be/nl/nbwa-news-message-document/document/09013557801ea13e. 
non-binding entrance exam aims to "strengthen the study choice not to limit the inflow". ${ }^{19}$ Students are encouraged to reflect on their numeracy, literacy and other subject skills.

It is expected that teacher training institutions will use less effort and time teaching youngsters who start off with sufficient abilities. Of course, fewer students will start teacher training but a larger percentage of them will earn a diploma. If the best students are studying teacher education, it is hoped that it results in more recognition for the teaching profession as well. Quality teacher training must be guaranteed through the provision of quality education, qualitative research, qualitative staff and quality infrastructure. However, critics of the entrance exam say that it will lead to students being excluded. They also fear for a shortage of teachers, especially in urban areas.

From 2019 on, Flanders will have teacher training at level 5, 6 and 7 of the European (and Flemish) qualifications framework. The current initial teacher training level will become level 6 of the qualifications framework with the bachelor's degree being taught at the university colleges.

Teacher training students at level 7 of the qualification framework for secondary education will be university-trained teachers. The centres for teacher training will be integrated into universities and will no longer exist as autonomous post-graduate non-university institutions. Thorough pedagogical training, thorough didactical training, and a large practical training (internship) is included.

The teacher training at level 5 of the qualifications framework (higher professional education) concerns students with professional expertise in a particular technical subject. Level 5 is exclusively aimed at the transfer of basic competences of the teacher and has not any subject content in its training program.

\section{Critical considerations about the on-going teacher training reforms in the Flemish Community of Belgium}

The estimated impact of the reform is to provide training for teachers who can in their turn provide a world-class education at level 5, level 6 and level 7 of the qualifications framework, no matter how difficult their working conditions. 
A number of remarks can be made on these reforms. First, the existing teacher training courses are sometimes characterised as 'sclerotic'. Most university college and university teacher training programmes never had to prove their impact, nor has any ever had its accreditation removed. A substantial number of students in teacher training programmes leave the teaching profession within a period of five years in the classroom. After finishing their teacher training, students do not feel they are anywhere near ready for the reality of the classroom and are ill-prepared for the management of complex classrooms. Unlike in Asia, teaching in Western Europe remains very much 'a closed-door profession' with little feedback. Today $40 \%$ of teachers in the OECD have never taught alongside another teacher or given feedback to another teacher. Rather than spending their time on theoretical courses, teachers should learn techniques that cover everything from discipline to critical thinking. Theoretical courses on how to teach are insufficient. Teaching technique should be practised and assessed and improved continually to satisfy the needs of classrooms and schools.

Second, teachers must be trained in instilling and practicing common values in students, a persistent element in European declarations. ${ }^{20}$ Teaching common values includes debating real-world scenarios that students may one day face, making students see beyond the short-term. Students should learn how common values like equality and respect for others, that they may find in their own religious and philosophical convictions, serve as external reference points for their decision making. These common values are more important than what may pass for the groupthink, which is often an underlying factor of bullying in schools. Teachers who manage their classrooms on these common values can mold a culture which is the very foundation of rights-based school management.

Third, mentorship in teacher training by outsiders is an underlying focal point for the EU in the development of a system of continued professional development of teaching staff, and in its discussions on how to "introduce systematic approaches to continuous professional development of [...] teachers, trainers and mentors in both school and work-based settings”. ${ }^{21}$ Furthermore,

20 Cfr. European Commission follow up of the Gothenburg Summit 'New measures to boost key competences and digital skills of European citizens, to promote common values and awareness of the functioning of the European Union'.

21 Communication from the Commission to the European Parliament, the Council, the European Economic and Social Committee and the Committee of the Regions, Draft 2015 Joint Report of the Council and the Commission on the implementation of the Strategic framework for European cooperation in education and training (ET2020) New priorities for European cooperation in education and training $\{$ SWD(2015) 161 final $\}$. 
"stronger links between education, business and research, and involvement of social partners and civil society will strengthen the impact of ET 2020 and the relevance of learning systems to increase Europe's innovation capacity." 22 Students in teacher training are already mentored by tenured teachers and trainers, and teacher training institutions have been doing a lot of work to broaden the network of support that their students get. However, while teacher trainers and teachers can be mentors, they should also be mentored at the same time in order to align their teacher training programmes with the realities of the labour market and the accelerating pace of societal changes. For the teacher training to be successful, it is required that the staff in teacher training programmes have a good understanding of the implications of current changes. Mentoring by an outsider is a good way of helping staff in teacher training to view the wider context of change in which their teaching is operating (Johnson and Ridley, 2004). Teacher training programmes need more cooperation with organizations and corporations, providing opportunities not only for student teachers, but also for teacher trainers to see what both the economy and society needs and expects from future teachers. Teacher trainers need others to develop their programmes. Attending conferences and seminars is not enough.

Fourth, project-based learning could to a large extent support and supplement theoretical training. The challenges in the future will be drastically different from the challenges of the past. Creativity, experience, and effective collaboration will be important determiners of success. Project based learning promotes skills such as curiosity, creativity, effective collaboration, non-cognitive skills, and continuous reflection on and improvement of the learning process. All these skills are very important for facing the challenges that the knowledge economy presents.

Fifth, students have to learn to think globally and to understand different cultures. Students will be not only citizens of their country but citizens of Europe and of the world. Schools in the Flemish Community of Belgium have the most culturally, ethnically and religiously diverse group in history. Students are also living in an interconnected global world. Staff in teacher training programmes have to think globally and train their students to teach students in diverse classes to understand different cultures, how to deal with classes of diverse student groups and to teach these students to be 
proud of what is different about them, but also to be proud of what they have in common. ${ }^{23}$

Next, new ways of providing teaching and providing education for adaptive-learning techniques should be included in teacher training programmes. The traditional way of providing education consists of grouping the students on the grounds of age, and in secondary education on the grounds of age and ability, and then teaching particular subjects to the whole group.

Finally, technological progress could be an answer to the challenges that the knowledge economy poses from the lifelong learning point of view. This requires changes in the way education is delivered. Artificial intelligence, in particular, is one step closer and creates the possibility for adaptive-learning techniques. ${ }^{24}$ Teacher training should instruct teachers how to use techniques for virtual classrooms and adaptive-learning techniques.

\section{To conclude}

Since 1945, the training of teachers was aligned with an educational system for the industrialization of the economy and has encouraged specialization so that students learn more and more about less and less.

In a knowledge economy, knowledge becomes obsolete more quickly, thereby obliging employees to (re)learn new skills and competences. Lifelong learning becomes interwoven with full-time work. With the automatisation of professions, the tasks where human skills are most valuable will constantly change. What a student learned at school is not enough for lifelong employment in a knowledge economy.

Improving individuals' soft skills, such as communication skills, self-confidence, self-awareness and the ability to work with others, as well as language skills and cultural competences, is also becoming increasingly

23 November 2004 Council of the EU, Common Basic Principles for Immigrant Integration Policy in the EU: "integration is a dynamic, long-term and continuous two-way process of mutual accommodation, not a static outcome. [...] The integration process involves adaptation by immigrants, both men and women, who all have rights and responsibilities in relation to their new country of residence", and "'everybody resident in the EU must adopt and adhere to the basic values of the EU as well as to Member States laws. [...] Views and opinions that are not compatible with such basic values might hinder the successful integration of immigrants into their new host society and might adversely influence the society as a whole".

Cfr. 2006 Nederlandse Onderwijsraad, 'Een meer evidence based onderwijs'

https://www.onderwijsraad.nl/upload/documents/publicaties/volledig/naar_meer_evidence_ based_onderwijs.pdf. 
important. More emphasis is placed on 'character skills' such as perseverance and curiosity, which are highly valued by employers and closely match the ability of employees to adapt to new situations and acquire new skills.

These economic and societal challenges require 'other' teachers. And to get 'other' teachers at school, teacher training must be reformed. Teacher training reforms should train teachers for the world we live in and not for the world in which the teacher educators themselves have grown up.

With well-trained teachers, reforms can be successfully implemented in schools. Internal resistance to do what reformers try to achieve must be overcome. With world-class teacher training, there is hope that the students undergoing teacher training will in their turn provide quality education to all their students.

It follows from these critical remarks that such teacher training must comprise a multidisciplinary team in order to develop an education system that meets the needs of a knowledge-based economy and complex (urbanized) society. A teacher training that is only anchored around pedagogues and subject-related didactics is outdated and starts from the needs of the past, not the needs for the future.

\section{References}

CEDEFOP. (2018). European Centre for the Development of Vocational Training, Briefing note June 2018. Retrieved December 15, 2018 from http://www.cedefop. europa.eu.

European Commission/EACEA/Eurydice. (2018). Teaching Careers in Europe: Access, Progression and Support. Eurydice Report. Luxembourg: Publications Office of the European Union.

Johnson, W.B., and Ridley, C.P. (2004). The Elements of Mentoring. Basingstoke: Palgrave Macmillan. 


\title{
Chapter 4
}

\section{Let It Begin with Me: \\ The Forging of a Professional Teacher Educator Self}

\author{
Jennifer Yamin-Ali \\ School of Education, The University of the West Indies, St. Augustine, Trinidad and Tobago
}

\begin{abstract}
This study focuses on the professional identity of teacher educators in a university-based teacher education institution. Its purpose is to identify ways in which teacher educators in a university setting could improve their professional practice and better cope with the demands and expectations of their position. Purposive sampling was used and the instrument for data collection was a semi-structured interview. The study presents findings on how those twenty-one teacher educators have coped in their teacher educator role, how they have been improving their practice, how they felt they have been growing professionally during their tenure as teacher educators, and how their institution has contributed positively to their growth. Discussion and conclusions consider implications for the development of teacher educators within their professional roles and responsibilities in light of literature in the field and written statements made in the international fora including the Caribbean in which this study is located.
\end{abstract}

KEYWORDs: teacher educators, professionalisation, professional identity, professional growth

\section{Introduction and background}

The forging of a professional self is inextricably tied to the forging of a personal self. It is likely that all professions have explored and even struggled with the complex concept of professional identity.

The concept of 'professional identity' has been described by Stalburg (2015) as a complex state which involves beliefs about knowledge, its justifications and applications. Stalburg, like others, proposes that such an

CONTACT Jennifer Yamin-Ali, EMAIL: jyaminali@gmail.com 
identity is shaped by (among other influences), role-modeling and others' expectations, and does evolve over time. Along the journey of a professional, its inherent experiences are the instruments that carve the nature of the particular individual. The novice, in this case, the novice teacher educator, due to the peculiar positioning of teacher education historically, is impelled to strategically and of necessity, forge a professional identity for him or herself.

Teacher educators, in terms of their professionalism, are a body of practitioners with disparate developmental features along that journey or continuum of growth. Observations by researchers in the field of teacher education help us to understand the complexity of the professional dilemma that a novice teacher educator may face. Some of the features identified by van Velzen et al. (2010) as essential to the transition from teacher to teacher educator, are, for example, the courage to learn by trial and error, the ability to be pro-active in engaging with colleagues and other relevant groups, and reliving one's own experiences as a teacher in order to understand the experiences and concerns of one's student-teachers. These features are different from, but in addition to, the other new professional skills novice teacher educators would have to battle with. As they are catapulted into the world of academia including conducting research and the intricacies of organisational and bureaucratic systems, they face the additional challenge of feeling de-skilled, isolated and insecure about expectations of their performance (Murray and Male, 2005).

The following quotes give an indication of the kinds of feelings and views that formed part of the identity of the teacher educator participants in this research and either propelled or stifled their growth. Whether the participant was junior or senior is indicated in brackets.

I just went to a meeting with lots of egos ... the kind of respect we have for each other as educators and researchers is not where it should be. (Junior)

You have to be multidimensional ... expectations and reality clashed ... I had to readjust ... to really be part of the institution. (Junior)

It's like you're thrown in ... and ... sink or swim ... (Junior)

You have to get over the need not to appear needy, stupid ... (Junior) 
People's work ethic is very high and the level of professionalism and the attention to getting things right has influenced the way I operate. (Junior)

The best years of my life I've spent at SOE. (Senior)

I see myself as larger than the Dip.Ed ... part of a larger picture of research and teacher development. (Junior)

What we do is consume research by others ... we're not a department that is deeply involved in producing indigenous knowledge. (Senior)

This research proposes that the quality of teacher education rests on the quality of teacher educators' work and practice. Consequently, that quality is determined by the ways in which teacher educators are prepared professionally and personally, whether it be formally or informally. While this conclusion is not novel, the context of this particular study strengthens the international literature base. This is a qualitative case study of 21 teacher educators in a teacher education institution in a developing country. Each was interviewed and the transcripts were analysed through hand-coding and categorisation of codes into themes. Findings revealed that both novice and experienced practitioners attempted to master their craft through critical reflection on their practice, purposeful learning experiences, and learning-by-doing. Personal growth also strengthened their practice which, to some extent, was also enhanced by their own research. Institutional factors that have impacted their work positively were identified. The chapter presents recommendations for focusing on the preparation of teacher educators in light of the varied roles they must fulfil in the broad context of teacher education. Fundamentally, this research sheds light on how both novice and experienced teacher educators forged their professional identity and professional practice, with each impacting the other.

\section{Literature review}

While in the field of education, much attention has focussed on teacher education as whole, no such parallel is evident with regard to a focus on teacher educators except perhaps in recent years. Although standards and 
requirements for the teaching profession have been explored, dictated by policy and implemented in many settings in several countries, the concept of teacher educator as 'professional', while discussed and explored by many (Cochran-Smith, 2005; Davey, 2013; Dinkelman, Margolis, and Sikkenga, 2006; Murray and Male, 2005; Williams, Ritter, and Bullock, 2012; Reichenberg, Kleeman, and Sagee, 2013; Reynolds, Ferguson-Patrick, and McCormack, 2013), has not necessarily found a firm footing in the variegated context of teacher education. Beyond the experience of teacher educators in a university setting, it has been found by Holland (2014) that new university lecturers "mostly find their initial time in the role to be stressful and poorly managed". Further to this, she shares that they described their lives using "the language of war, battle and struggle" and that "the levels of university bureaucracy impeded their teaching effectiveness; they battled with time management and felt tension between the levels of control, audit and freedom within their roles” (p. 3). Swennen and van de Klink (2009) assert that "beginning teacher educators experience high levels of stress and insecurity during the first years in their new profession” (p. 1).

It is to be noted that in a general sense, university teacher educators are simultaneously university lecturers. This review will examine some of the realities of the teacher educator's professional reality including challenges and suggestions from researchers in the field, and will provide a justification for the research presented in this paper.

\section{Challenges}

(a) Identity and self-efficacy

Research has shown that teacher educators who have transitioned from 'teacher' to 'teacher educator' find themselves in a bind as they struggle with "negotiating the terrain” (Mac Donald Cruickshank, McCarthy and Reilly, 2014, p. 2) of expectations of expertise and performance. Combined with this is the complexity of identity construction which is characterised by fragmentation, fluidity and the transitory (Henkel, 2005; Hickman, 2010). Thus, while the teacher educator is attempting to be grounded in a specific professional identity, the reality of adapting to change and context exacerbates the struggle. The notion of such struggle is supported by McAnulty and Cuenca (2014, pp. 49-50) who conclude:

The experience of being a first-time teacher educator is complex and nuanced, driven by the need to shape a new professional identity, balance 
the difficulties of academic pressures, and navigate the transition through learning by doing ... the first-time teacher educator must prioritize and become intentional about exploring his or her identity development. This involves challenging conceptualizations of what it means to be a teacher educator and the insecurities associated with this new identity...

Creating learning paths and "tailored pathways" (Lunenberg et al., 2016, p. 4) in an effort to establish one's professional identity adds to the 'schizophrenic' situation (Ducharme, 1993, p. 4) and the multifaceted nature (Smith, 2011) of the ever-emerging teacher educator. However, developing the confidence of the teacher educator, referred to by Bandura (1997) as self-efficacy, while seeming to be a positive goal, did not necessarily indicate a direct relationship with the development of teacher educator competence, according to Borg, Clifford, and Htut (2018). This perhaps points to the need for enhanced measurement procedures for project monitoring and evaluation as suggested by Borg, Clifford, and Htut (2018).

The impact of challenges to identity formation is not to be underestimated. MacDonald et al. (2014) contend that their "experiences of negotiating expectations to develop teacher educator and researcher identity and scholarship indicates a very fine line where challenge can work to extend or constrict professional development and identity formation” (pp. 12-13).

\section{(b) Transitioning}

In much of the literature on teacher educator identity and the carving of an identity, there is present the notion of teacher educator as researcher and the associated anxieties. MacDonald et al. (2014) describe how as neophytes, they defined themselves as a "distinct 'tribe' of 'pre- ECRs” (early career researchers) who had to negotiate their transition from the classroom to a teacher education context. They report having a lack of access to information and resources to guide them in engaging in research and no explicit targets for how much or what kind of research they were expected to produce. They point to the paradox of pre-service teachers being viewed as undergoing a process of learning and developing their values and beliefs, while novice teacher educators are not given the opportunity to learn how to become researchers. They suggest, based on Murray's (2008) comments on induction for teacher educators and their own experiences, that "further research that details how teacher educators might conduct themselves to meet the expectations of contributing to their respective fields by carrying out and publishing is ... essential (Mac Donald et al., 2014, p. 2). 
Induction for teacher educators seems to be an obvious need and its benefits have long been noted (Hodkinson and Taylor, 2002; Smith and Ingersoll, 2004). It is further supported by van Velzen et al. (2010) who cite Billett (2004), Glazer and Hannafin (2006) and Boyd et al. (2007) to emphasise induction as a contemporary phenomenon with regard to professional learning in the workplace. They also highlight the point that both formal and informal learning opportunities are certainly appropriate for induction purposes. Collaborative training activities were considered important for newcomers, in addition to mentoring and supervision, team teaching, co-teaching and maximum communication with colleagues (Velzen et al., 2010 citing Hodkinson and Taylor, 2002). While factors external to the self are helpful to one's practice, one's own research into one's practice, students' learning and responses can be instrumental in one's development (Zeichner, 2005). He proposed that teacher educators "think consciously about their role as teacher educators and engage in ... self-study and critique of their practice” (p. 123).

Research conducted by van Velzen et al. (2010) concluded that novice teacher educators were challenged by a lack of knowledge about procedures and routines and access to such information, as well as by a lack of skills for preparing and delivering courses, working with large groups and motivating students in the new context. The value of courses and workshops was inconclusive and it was reported that the mentoring experience is dependent on the relationship with the mentor and the frequency and quality of conversations.

What we can note is that teacher educators' concerns morph as they journey along their career paths. According to van der Klink et al. (2017), their research showed that neophytes' concerns were characteristic of the "induction phase" and described these concerns as "surviving in a new and complex context", citing the origin of the phrase "induction phase" as van Velzen et al. (2010). Van der Klink et al. (2017) found in their research that as their experience grew, teacher educators' identities tended to shift toward better serving the needs of their student-teachers and found this observation to be consistent with that of Conway and Clark (2003) and Dengerink, Lunenberg, and Kools (2015).

\section{(c) Researcher identity}

One of the areas of greatest stress for novice teacher educators in the university context is the need to engage in conducting research. This expectation is noted by Celik (2011) while MacDonald et al. (2014) point out that "for those teachers transitioning into teacher education contexts, there is often 
limited opportunity for learning how to conduct research beyond what is essentially learnt 'on the job' through trial and error”' (p. 2). As early career researchers (ECRs) in Scotland, they said: "uncertainty around where we 'fit' in beginning the ECR journey within our professional academic landscape was the cause of angst and had implications for both our professional and personal self-efficacy" (p. 8). They concluded that "through the examination of events critical to our becoming researchers in a teacher education context, the implications of not being able to locate ourselves within a distinctive and appropriate professional identity emerge as significant” (p. 12). Similarly, in the South Korean context, most of the concerns surveyed teacher educators had regarding professional development had to do with conducting research (Hwang, 2014).

Despite the angst and uncertainty mentioned above, the real need for teacher educators to be active researchers cannot be disputed. In discussing the professional development of teacher educators, van der Klink et al. (2017) introduce the justification for this need for teacher educators to earn respect in academia by building their research capacity in their own field. They link this notion to Ball's (1998) idea of the role of research in the process of universification. Additionally, teacher educators should be using the findings of their own research, perhaps practice-based research, to broaden and deepen the understandings and practice of their own students. This is supported by Ellis, McNicholl, and Pendry (2012, p. 692) who state that "the hybrid vigour of the teacher educator therefore arises from their capacity to develop new knowledge across multiple social settings and at different levels of specialisation and abstraction". The teacher educator's requirement to conduct research is amply presented by Tack and Vanderlinde (2014) in their study which concludes that in order to develop the teacher educator's 'researcherly disposition', a deep engagement is needed on a cognitive, affective and behavioural level. In this vein, it is expected that they study their practice purposefully and disseminate their new knowledge. Tack and Vanderlinde (2014) assert that this approach requires "methodological expertise, theoretical knowledge about teacher education and a deep commitment towards one's role as a teacher educator-researcher" (p. 314).

The establishment of a teacher-research identity takes about three years according to Ramirez and Allison-Roan (2014) who cite Bullock and Ritter (2011) and Murray and Male (2005) to support this position. Ramirez and Allison-Roan suggest that teacher educators merge their teaching and 
research as well as their values and practices through the use of self-study, narrative inquiry and living educational theory. These approaches afford value to collaboration, self-knowledge and development, examination of our stories from transformed perspectives, and the interplay between our personal theories and how they impact our practice (Childs, 2005; Whitehead and McNiff, 2006).

\section{Justification for this research}

Despite research published by some prominent researchers in the field (Bates, Swennen, and Jones, 2011; Ben-Peretz, 2013; Davey, 2013; Dinkelman, Margolis and Sikkenga, 2006; Ducharme, 1993; Korthagen, 2000; Loughran et al., 2004; McAnulty and Cuenca, 2014; Murray and Male, 2005; Shagrir, 2011) there is a paucity of research that focuses on the novice teacher educator and induction into the role, though in recent times, the focus has been increasing (Swennen and van der Klink, 2009). Those that do have that focus draw attention to the challenges of becoming a teacher educator.

It has been suggested by MacDonald et al. (2014) that "further research that details how teacher educators might conduct themselves to meet the expectations of contributing to their respective fields by carrying out and publishing research is ... essential” (p. 2). Despite significant and seminal work that has been published since 2014 when this comment was made, for example by Murray (2008), Swennen and van de Klink (2009), and Boyd et al. (2011), among others, no research focusing on the Caribbean context has been published except for Yamin-Ali (2017), which highlighted tensions in the work of teacher educators through a case study approach.

CARICOM stands for Caribbean Community and Common Market and is defined as an organization made up of fifteen Caribbean nations to promote economic integration among members. In its Human Resource Development (HRD) 2030 strategy, five main elements are seen to be germane to the success of the strategy: efficiency, support, mobilization, seamlessness, and harmonization. A key element that has not been identified is that of training for teacher educators. Furthermore, Trinidad and Tobago, the context of this research, has not adopted the regional standards for teaching. Linked to this, the professionalization of teachers has not moved beyond the stage of criteria for employment and (for secondary schools) promotion. Licensure for teachers is not yet part of this professionalization 
process. This gap in professionalization from teachers to teacher educators stymies the HRD 2030 Strategy. Clearly, the struggle to professionalise teacher educators is essential.

The perspectives and emphases presented in the review of literature provide somewhat of a picture of the general experience of the novice teacher educator in a tertiary education setting, in what ways they might be challenged, and some ways in which they might cope with those challenges. The research presented in this paper zooms in on a particular context where we are able to read about the actual experiences of teacher educators' coping strategies and growth processes as described by them. Such findings will continue to carve a path for policy-makers and practitioners in the field to begin to fill the gap that is evident in the preparation of teacher educators for their role.

To support the need for this research, it must be pointed out that van Velzen et al. (2010) were of the view that "comparing the good and bad of the arrangements in different countries can help us further in developing a powerful induction programme” (p. 72). Further to this, van der Klink et al. (2017) advocated platforms for teacher educators to share and compare "practices, experiences and country-specific interpretations of concepts” (p. 176). They also suggested the need to establish the relative impact of institutional conditions on induction experiences. This research provides some such findings which have significance for their call for further in-depth research into the international comparison of the professional development of teacher educators.

\section{Methodology}

\section{Research questions}

The research questions guiding this study were:

1. What was the context of the teacher educators at a School of Education in Trinidad prior to coming there to work?

2. How have they coped in their teacher educator role?

3. In what ways have they grown personally at the School of Education?

4. How has the institution (SOE) impacted their work and growth in a positive way? 


\section{Methodological Approach}

The study is guided by the qualitative case study approach which facilitates deep understanding of real life phenomena including contextual conditions (Yin, 2009). Qualitative research inquiry through the use of case study is advocated by Stake (2005).

The strength of the case study approach is that participant's voices are given weight and allow for deep and rich data. However, the limitation is that the findings are not generalizable in that they do not represent the whole sample or the whole population.

This study could be seen to be insider research since the researcher is a member of the population. Thus, even the questions posed to the participants could be deemed to have an inherent bias. However, the insider position of the researcher facilitated a deep understanding of the context and enabled relevant probing to capture as much pertinent detail as possible in the participants' responses.

\section{Participants}

Twenty-one teacher educators from one institution who all taught on one specific programme participated in the research. Purposive sampling was used to ensure that data collected would be rich (Patton, 1990) and that "a great deal about issues of central importance to the purpose of the research” were captured (Merriam, 2002, p. 12).

Their experience as teacher educators ranges from one to twenty years. Eight of the twenty-one participants had worked as secondary school teachers for between nine and fifteen years and nine had taught at that level for over fifteen years. Eight hold a Master's degree and six of them are currently pursuing a PhD. Three of those with a $\mathrm{PhD}$ have a Masters with specialisation in Teacher Education. Some who hold the PhD pursued it while they were working as teacher educators at the institution. All have professional teacher qualifications except one. While thirteen of the twenty-one possess a $\mathrm{PhD}$ in education, their qualifications do not include teacher education specifically.

\section{Data collection}

Interviews that used a semi-structured protocol guided the collection of data. The core questions posed to the participants were:

1. What are your tertiary level qualifications? 
2. How many years have you worked at the various levels of the education system?

3. Why did you leave your immediate past position to come to the SOE?

4. Why did you come to the SOE specifically?

5. How did this move come about? (Did you apply for a position?)

6. Where you ready for your role as a teacher educator?

7. How did you cope when you first came?

8. How have you been improving your practice?

9. In what ways have you grown personally?

10. What institutional factors have impacted your work or practice positively?

Each participant was interviewed for approximately one hour, before which the purpose of the research was explained. The interviews spanned a period of approximately three months. They were audio-recorded with the permission of the interviewees. They were assured of confidentiality and that their names would not be used at any time in connection with the research or the interviews. In the presentation of findings pseudonyms are used. All interviews were transcribed by hand, and stored electronically. Each participant received a copy of his or her transcript for member-checking.

\section{Data analysis}

Each interview was hand-coded and categorised. Constant comparative analysis was employed to ensure full capture of details and connections. At the first stage, all individual concepts were coded numerically for ease of use (Ryan and Bernard, 2003; Strauss and Corbin, 1990). Those concepts, represented in chunks of data, were handled in a new document. Concepts identified in the transcripts were re-examined using constant comparative analysis to ensure thoroughness and rigour of analysis (Leech and Onwuegbuzie, 2007). Connections among concepts were identified to add to the original list. This enabled the initial formation of categories. Each concept within the newly formed categories were examined for relatedness to each other. Interpretation of data played a key role in this phase. Codes within categories were examined again to ensure or establish consistency of codes (Miles and Huberman, 1994). Relevant themes emerged from exploring the categorised data which needed to be adjusted at times for accuracy of categories. For example, data had to be analysed across the questions since responses from some questions were applicable to others. For example, 
"Why did they come to the SOE?" was directly applicable to "Why did they leave their last job"? For efficiency of presentation and to make sure that all data pertinent to themes were included, codes from separate question responses which were supportive of each other were clustered under related categories.

Several themes emerged from the analysis. Under Research Question 1, three themes emerged: Reasons for leaving their past positions to come to the SOE; Reasons for coming to the SOE; Level of readiness and ability to cope. Under Research Question 2, one theme emerged: Strategies for coping. Under Research Question 3, six themes emerged: Overall growth; Broad Understandings; Personal characteristics; Tools to deal with job demands; Appreciation of others; Communication. Under Research Question 4, four themes emerged: Guidance; Team Spirit; Administrative features; Facilities/Institutional Support.

\section{Findings}

\section{Research Question \#1: What was the context of the teacher educators at a School of Education in Trinidad prior to coming there to work?}

Reasons for leaving their past positions to come to the SOE Having been teachers at the secondary level, twelve indicated that they left those positions for personal benefits/reasons. Among those reasons were that being at the tertiary level would better enable further studies; he/she: felt ready for something different; wanted to come back home (from abroad); wanted a Caribbean experience; saw it as an escape from the teaching position at secondary level; felt the remuneration would be better; felt there was no possibility of promotion in the last teaching position; found the former position frustrating; had a contract that had ended.

Eleven of them left for reasons which could be described as professional or intellectual. One or more wanted to move to a different level having completed a $\mathrm{PhD}$; thought exposure to teaching at the tertiary level would have been "good"; always had the intention of moving to this level at some point; felt the need to "do more" after the Masters; found the tertiary level "appealing"; saw the move as a natural progression due to tertiary experience and interest; became interested in the broader field of education; had a remote dream to teach at this level. 
Reasons for coming to the SOE

Among the reasons cited for coming to work at the SOE, there were seventeen professional ones and seven personal ones. The professional reason indicated by seven of them was that they like working with teachers or had former tertiary experience. Four felt they had a contribution to make. Three saw their own experience of the Dip. Ed. to be useful since it was the programme which they would be teaching on. Two of them wanted the exposure to the tertiary level and one saw it to be an opportunity for intellectual stimulation.

Seven personal reasons were proffered for the desire to work at the SOE. Three saw it as an opportunity for a better standard of living. Two saw it as an escape from their secondary school teaching, one saw it as "convenient”, and for another it was a second choice after not getting a desired post.

\section{Level of readiness and ability to cope}

The twenty-one educators who were employed at the School of Education (SOE) and were participants in this research began their teacher educator career with varying degrees of experience as teachers. Nine had over fifteen years' experience as a secondary school teacher, eight had between nine and fifteen years, three had between four to eight years and one had between one to three years' experience. Six of them had between one to three years' experience as a primary school teacher. Their experience at the tertiary level ranged from two to seven years, with that experience being largely part-time.

According to their own statements, seven of the twenty-one educators felt ready for the position of teacher educator, while another seven were ambivalent about their state of readiness and seven others indicated that they did not feel ready when they first came to the position. In terms of their state of readiness, they described how they coped in their position as teacher educator having transitioned from school teacher.

\section{Research Question \#2: How have they coped in their teacher educator role?}

Strategies for coping

(Ellipses indicate words removed for clarity)

Several coping strategies were employed by these novice teacher educators. On an individual and personal level, some engaged in reflection as 
they struggled with the new experience. A strategy used by Gary was to pay attention to the "cross disciplinary" aspect of teaching and learning. Working on weak points was also seen to be instructive by Larry, while Patricia "learned from my students on Field Days ... look at individual TPs [Teaching Practice] ... from students' research ... and strategies that I have not tried [before]".

Another strategy used by many included purposeful learning, where some chose to learn from others:

Joshua: I learn from others in areas that I'm not so familiar with.

Barbara: I discuss with colleagues.

Gary: Group membership in Curriculum (a course) [helped]. Jasmine: talking to other people ... asking for advice (I'm not afraid to say I don't know and ask for help.

Ann: being able to talk to people ... interacting not in a formal way ... there's a level of sympathy ... because somebody recognises that ... you might be going through a hard time.

June: continue to seek assistance ... there was always an open door with certain people who asked about my coping and gave tips.

Candice: try to do things a little differently each year getting new ideas from ... colleagues too.

Some made use of University provided training (workshops). Conference attendance and presentations with feedback were also experiences that some benefitted from. Reading research publications was seen to be helpful in the learning process. Supervising research projects was also seen to be a useful learning experience by Jasmine. In the early phase of Larry's teaching at the SOE, attending all non-specialisation plenary sessions on the main programme he taught on helped him to be comfortable with the required content. Brian used “action research to build [his] practice”. This practice continues for many.

Unofficial mentors provided support for Gary and June. The institution was fortunate to have a few senior members who were natural mentors. Janice became a member of professional organisations which provided the stimulation and confidence she needed to move forward. The discipline and experience of planning his work also strengthened Gary's ability to cope. For most, if not all, 'learning-on-the-job' was the overarching experience. 


\section{Research Question \#3: In what ways have they grown personally at the School of Education?}

Personal growth formed the mainstay of all of the practitioners in a variety of ways, and to a large extent, contributed to the experience of 'learning-on-the-go'.

\section{Overall growth}

As in other fields and as is to be expected, becoming "more mature" was recognised by Joshua, a senior faculty member, as evident in his journey. He said "I think I've matured as an intellectual, as an academic, and as a teacher, teacher educator ... and I treasure that. I have grown to be more broad-minded in my understanding of what education is". He further explains that he grew to understand that "there are a multiplicity of perspectives ... and ... each has a value". He gained a "variability of understanding, flexibility of interpretation ... but I don't know that I would have been as enriched ... if I had stayed at the secondary school level”. However, he credits this growth to not only his teacher educator career but to "being in other places" where he gained from "a wider experience in the society" and recommended that "young and upcoming" professionals "need to be more involved".

\section{Broad understandings}

There were three indications of the development of broad understanding since joining the staff of the SOE. Joshua said that he had become "more broad-minded in [his] understanding of education" while Gary felt that he had developed "a social competency" and for him there was "growth in clarity [of educational matters]”.

\section{Personal characteristics}

Some faculty shared that they had grown in terms of their personal characteristics. A relatively new member of staff, Tennille, felt that she had become "more patient ... and open to new ideas", and was able "to critique in a more positive and sensitive way". This referred to her feedback to students. Ann learned to control her temper and tried to "treat them [students] like people first". Jasmine, relatively junior, indicated that she was more "willing to learn from others and to listen". She had also become a "lot more assertive ... calmly assertive" and "more confident". Confidence was an area of growth mentioned by another junior faculty member, June: 
"constantly reflecting ... building on my own experiences to be able to deal with situations ... less anxious ... more confident based on experience". Kay said she had "grown increasingly self-reliant yet while trying to work and collaborate with others ... more independent, flexible... and [has developed] more initiative". Growth in perseverance in terms of her research agenda was cited by Andrea as a major way in which she had grown. "Not letting anything stump me" was how Kay described the perseverance she had developed. Through the Dip. Ed. experience Janice said that "her values re integrity strengthened”. She was able to strengthen her philosophy that "every single person is important" and transfer it to dealing with her students".

\section{Tools to deal with job demands}

In terms of demands of the job, some persons developed specific tools to cope. "Personal organisation" was one such tool for Patricia. "Learning not to let things get you flustered" and "observing how other lecturers handle situations" helped Brian to cope, while Candice recognised that "if you're not willing to take some blows from some others and feedback, you will never grow and ... it hurts at times”. Resilience, therefore, was seen to be not just a crucial characteristic to enable functioning in this environment, but also a necessary tool.

\section{Appreciation of others}

There was evidence of a growth of appreciation of others as seen in the comments made. Joshua had "learned to be more accommodating of colleagues ... to be more supportive ... judgementality had gone ... [I am] more tolerant”. Bernard, felt he had learned "how to be a little more tolerant ... accept diversity in a broad sense". He felt he had grown in "wanting to be a better human being". A junior colleague, Brian, indicated that "in dealing with adults he had to change to accommodate personalities, their ways of doing thing ... to arrange a common ground for sanity purposes”. Similarly, Dana tried "to understand students' personal needs/situations" while Hannah traced her growth in her efforts to be more "empathetic" and "patient", trying "to listen to the other person's views", and Bernard had grown in the "professional caring" he had for colleagues and students. Jeremy, a stalwart of the institution, shared that he had "learnt to accept people for who they are ... to respect their beliefs, understandings and perspectives ... to accommodate a lot more than before, to be very flexible when I'm in 
a meeting". Larry, another senior member, said that he now "understands students' situations more". He now has more patience with teachers through "being able to analyse where they are". He also indicated that in terms of dealing with his colleagues, he was now "compromising and letting things go ... letting them [colleagues] learn their own lessons”.

Further to this, Mary said that she had grown "in the way she interacts with teachers in the system" with more regard for their own expertise. Related to this point, another senior faculty member, Sandra, pointed out that through applying what she knew from other contexts, she "learnt to let people be". Hannah, a senior member, felt she had grown as she developed the philosophy that "there is always something positive about a person". In addition, she had consciously tried to develop her interpersonal skills in the teaching context. There was further evidence of growth in terms of collegiality. For many this seemed to be a major hurdle. Patricia, a junior member, explained that she "had to grow into seeing herself as an equal with her former teachers". Another junior member said that along the way she had "sprung into relationships with colleagues" because she "started to see people differently ... actually having normal conversations with people”.

\section{Communication}

An interesting phenomenon that arose within the discussion on personal growth among the faculty was the issue of communication. For example, Barbara said that initially she "had to read things fifteen times before sending emails ... took more care with communications being sent out”. Patricia indicated that for her too, communication was a factor in her growth, seeing that there were "so many different personalities to interact with", referring to student-teachers. "How to communicate with people" was an area of growth for Bernard. Hannah, who was quite experienced, was more specific by saying that she tried to "use language that is politically correct, diplomatic". With even more experience, Jeremy said "I think all the time about what people are saying and when I shape the response ... I hear what they are saying and try to make sense of it and coordinate what they're saying."

\section{Research Question \# 4: How has the institution (SOE) impacted their work and growth in a positive way?}

In any discussion of professionalism and performance, one has to consider that it is not only the individual's efforts and personality on which their 
work is hinged, but also the nature of the organisation to which they belong. In light of this, we examine here the institutional factors which these teacher educators saw as having a positive impact on their professionalism.

\section{Guidance}

According to Tennille, a novice, having a good mentor proved to be helpful to her. Closely aligned to this, a more experienced lecturer, Janice, benefited in that, as she shares, "there are people in the institution I can speak to and look to as examples”.

\section{Team Spirit}

Team spirit was another contributor to their ability to advance on their professional trajectory. Jasmine, for example, felt that "people are willing to step up and at least take responsibility, ownership to some extent”. Sandra, a relatively junior member, specifically cited "teamwork" as a factor that has impacted her work positively and Larry, a very senior staff member, cited "collegiality" as a factor, elaborating that "we don't have animosities ... I think we could talk when we have discussions. I don’t think people are afraid to say what they want and have people come down on them". Sean endorses this point by sharing his view that the atmosphere at the SOE was “really collegial”. It was “a comfortable workplace ... people tend to collaborate, the atmosphere is warm and hospitable, individuals are welcoming and willing." Kay’s experience was similar. She "likes the lecturers" and "has good relationships" with them and says "I see people having domains of knowledge and experience that I don't have and can benefit from”. Jeremy, who had spent many years at the SOE, shared his positive experience of "being able to discuss with colleagues without the fear of being victimised". As a matter of fact, he indicated that the best years of his life were spent at the SOE. Hannah supported this general concept of team spirit by adding that she saw "collaboration to do research" as a feature that was alive at the institution. Janice felt that there was a common team vision where the "staff want to see improvement”.

\section{Administrative Features}

Some administrative features of the institution were seen to be positive factors in the realisation of the professional growth and stance of some of the participants of this research. Being people-oriented was one such feature, as Jasmine pointed out: “[Recent Heads of Departments], I really 
find were really people-oriented and have put the needs of the staff and the department ahead of budget and whatever else". Mary felt that "the HOD's unspoken appreciation ... has made [her] want to give back so much", and Kay saw the HOD as "fair, forward-thinking, human and accessible ... enables things". Such enabling was highlighted by Candice who indicated that she had been given "a lighter workload to help her complete her PhD”. She did not see the wider university system as being sufficiently supportive in that context. Janice saw "the history of the institution as a positive thing" in that it had built a positive reputation for itself within the society and wider.

"The use of committees as an organizing structure" was seen by Mary to be a positive administrative factor and Candice saw committees to be a "positive experience", just as she saw the "research cluster drive ... learning from others" made her feel that doing research "was not as difficult as you're making it out to be".

Interestingly, Brian's comment about the SOE was: “people's work ethic is very high and the level of professionalism and the attention to getting things right ... influenced the way I operate”.

\section{Facilities/Institutional support}

What one is provided with in the workplace can make a difference to how one works, while how one works depends on individual preferences. Sandra expressed her appreciation for "the private space of offices". "I like alone time" she said. On the other hand, Janice felt that "the secretarial support system works well" for her, and Barbara commended the "good tech support".

Additionally, the value of professional development opportunities offered by the University as well as the opportunity to participate in conferences was highlighted by some.

\section{Discussion and conclusion}

While the teacher educators in this research possessed at least a Master's in Education, and, with the exception of one, had had the student experience of the Dip. Ed. programme which they were employed to teach on, none were formally prepared to function as a teacher educator. That twelve of the twenty-one left their prior positions for personal reasons to come to the teacher education institution is significant. Their motivation to effectively build an identity as a teacher educator at that point could be said to be low. Even the eleven who left their prior positions for professional or intellectual 
reasons seemed vague about the reason for their desire to leave those positions - in most cases, teaching at the secondary level. While some had experience at the tertiary level in teacher education as part-time lecturers, that experience would have been purely in the teaching role, and based on their own experiences as both a secondary school teacher and a tertiary student. Thus, when faced with the multifaceted nature of their role as teacher educator, they would have experienced the struggle and tension of many in higher education contexts (MacDonald et al., 2014; McAnulty and Cuenca, 2014; Holland, 2014). The initial struggle as they transitioned might have been frantic in nature, thus making it almost impossible to prioritize and become intentional about exploring their identity development as McAnulty and Cuenca advise (2014).

However, when we consider that among the reasons cited for coming to work at the SOE, there were seventeen professional ones (they liked working with teachers or had former tertiary experience; they had a contribution to make; they saw their own experience of the Dip. Ed. to be useful since it was the programme they which they would be teaching on; they wanted the exposure to the tertiary level and one saw it to be an opportunity for intellectual stimulation), the motivation appears to be stronger with the potential for development of a teacher educator identity including serving the needs of their student-teachers (Conway and Clark, 2003; Dengerink, Lunenberg, and Kools, 2015, van de Klink et al., 2010). The strategies for professional learning utilised by these teacher educators are perhaps universal to the profession. Many of them are certainly informal bearing in mind that there was no formal induction (Billett, 2004; Boyd et al., 2007; Glazer and Hannafin, 2006). Mentoring and communication with colleagues (Hodkinson and Taylor, 2002) must not be overlooked as essential induction tools. Consequent to the unfolding of this research, a formal mentoring system has been put in place at this university for all departments. It is yet to be fine-tuned.

It is noteworthy that for some participants, learning from their students was instrumental in their own learning. Based on the notion that neophyte teacher educators are challenged by the need to conduct research as part of their natural role, they should be encouraged to describe this concept and experience of 'learning from students' in self-study, narrative inquiry and living educational theory. In this way, they would be able to merge their teaching and research in a less painful way (Ramirez and Allison-Roan, 2014). Furthermore, judging from the myriad of strategies these practitioners 
used to 'cope' in their role, they could ignite their research agendas by developing their research into their own practice, including feeding their research findings into their students' learning thereby enriching their own capacity and that of their students (Zeichner, 2005). Additionally, just as they shared their views and experience for this research, so too could they begin to engage in self-study and critique of their practice (Zeichner, 2005).

A prime example of data that could be used for their self-studies is the collection of ways in which they have grown personally: Overall growth; Broad understandings; Personal characteristics; Tools to deal with job demands; Appreciation of others; Communication. Exploration and examination of these elements of their stories from transformed perspectives can provide the interplay between their personal theories and how they impact their practice as advocated by Childs (2005), and Whitehead and McNiff (2006). These unplanned outcomes also have implications for the design of a formal induction programme for teacher educators. The positive relationship between the personal and the professional self must be reiterated here in order to emphasize that planning for professional development must encompass both elements.

While there would have been contextual challenges for these teacher educators (Yamin-Ali, 2017), they did indicate some institutional enablers to their practice. The guidance, team spirit, administrative features and institutional support and facilities which they identified perhaps need to be augmented and sustained. If a balance could be forged between these positives and the stress resulting from levels of university bureaucracy, time management and control (Holland, 2014), then the growth challenge would be a healthy one as opposed to a debilitating one. In other words, there is also much room for institutional growth that feeds lecturers' growth.

While on an international level, this research has a place in supporting the call for formal induction and continuous professional development for teacher educators, it is also a call for attention to such development regionally and nationally. This research focuses on the university-based teacher educator. The findings from this research would be useful for planning the content and design of a teacher educator induction programme in addition to a teacher educator qualifying programme.

These would not only enhance the efficacy of practising teacher educators, but would ultimately improve the quality of teaching at the various levels of the education system. Concurrently, decision-making at all levels would be strengthened through the knowledge, skills and dispositions 
developed by adequate professional development, thereby forging a suitable path for the emerging professional teacher educator.

\section{References}

Ball, S. (1998). Big Policies/Small World: An introduction to International Perspectives in Education Policy. Comparative Education, 34 (2), 119-130.

Bandura, A. (1997). Self-Efficacy: The Exercise of Control. New York, NY: W.H. Freeman.

Bates, T., Swennen, A., and Jones, K. (2011). Teacher Educators: A Professional Development Perspective. In: T. Bates, A. Swennen, and K. Jones (Eds.), The Professional Development of Teacher Educators (pp. 7-19). London: Routledge.

Ben-Peretz, M. (Ed.). (2013). Teacher Educators as Members of an Evolving Profession. Lanham, Maryland: Rowman \& Littlefield.

Billett, S. (2004). Workplace Participatory Practices: Conceptualising Workplaces as Learning Environments. Journal of Workplace Learning, 16, 312-324.

Borg, S., Clifford, I., and Htut, K.P. (2018). Having an EfECT: Professional Development for Teacher Educators in Myanmar. Teaching and Teacher Education, 72, 75-86.

Boyd, P., Harris, K., and Murray, J. (2007). Becoming a Teacher Educator: Guidelines for the Induction of Newly Appointed Lectures in Initial Teacher Education. Bristol: Higher Education Academy.

Boyd, P., Harris, K., and Murray, J. (2011). Becoming a Teacher Educator: Guidelines for induction ( $2^{\text {nd }}$ ed.). Bristol: Higher Education Academy.

Bullock, S.M., and Ritter, J.K. (2011). Exploring the Transition into Academia through Collaborative Self-study. Studying Teacher Education, 7 (2), 171-181.

Celik, S. (2011). Characteristics and Competencies for Teacher Educators: Addressing the need for Improved Professional Standards in Turkey. Australian Journal of Teacher Education, 36 (4), 73-87.

Childs, K. (2005). Just Where Do I Think I'm Going? Working with Marginalized and Disaffected Youths and their Self-study. In: C. Mitchell, S. Weber, and K. O'Reilly-Scanlon (Eds.), Just Who Do We Think We Are? Methodologies for Autobiography and Self-study in Teaching (pp. 142-153). Abingdon: Routledge Falmer.

Cochran-Smith, M. (2005). Teacher Educators as Researchers: Multiple Perspectives. Teaching and Teacher Education, 21, 219-225.

Conway, P., and Clark, F. (2003). The Journey Inward and Outward: A Re-examination of Fuller's Concerns-based Model of Teacher Development. Teaching and Teacher Education, 19, 465-482.

Davey, R. (2013). The Professional Identity of Teacher Educators: Career on the Cusp? Abingdon: Routledge.

Dengerink, J., Lunenberg, M., and Kools, Q. (2015). What and How Teacher Educators Prefer to Learn. Journal of Education for Teaching, 41 (1), 78-96.

Dinkelman, T., Margolis, J., and Sikkenga, K. (2006). From Teacher to Teacher Educator: Experiences, Expectations, and Expatriation. Studying Teacher Education, 2 (1), 5-23. 
Ducharme. E.R. (1993). The Lives of Teacher Educators. New York: Teachers College Press.

Ellis, V., McNicholl, J., and Pendry, A. (2012). Institutional Conceptualisations of Teacher Education as Academic Work in England. Teaching and Teacher Education, 28 (5), 685-693.

Glazer, E., and Hannafin, M. (2006). The Cooperative Apprenticeship Model: Situated Professional Development within School Settings. Teaching and Teacher Education, 22, 179-193.

Henkel, M. (2005). Academic Identity and Autonomy in a Changing Policy Environment. Higher Education, 49, 155-176.

Hickman, R. (2010). Self-portrait: An Account of the Artist as Educator. International Journal of Education and the Arts, 11 (2), 1-15.

Hodkinson, S., and Taylor, A. (2002). Initiation Rites: The Case of New University Lecturers. Innovations in Education and Teaching International, 39 (4), 256-264.

Holland, F. (2014). Teaching in Higher Education: An Interpretive Phenomenological Analysis. In: SAGE Research Methods Cases. Thousand Oaks: SAGE Publications.

Hwang, H. (2014). The Influence of the Ecological Contexts of Teacher Education in South Korean Teacher Educators Professional Development. Teaching and Teacher Education, 43, 1-14.

Leech, N.L., and Onwuegbuzie, A.J. (2007). An Array of Qualitative Data Analysis Tools: A Call for Data Analysis Triangulation. School Psychology Quarterly, 22 (4), 555-584.

Loughran, J.J., Hamilton, M.L., LaBoskey, V.K., and Russell, T. (Eds.). (2004). International Handbook on Self-Study of Teaching and Teacher Education Practices. Dordrecht: Kluwer Academic Publishers.

Lunenberg, M., Murray, J., Smith, K., and Vanderlinde, R. (2016). Collaborative Teacher Educator Professional Development in Europe: Different Voices, One Goal. Professional Development in Education, 43, 556-572.

MacDonald, A., Cruickshank, V., McCarthy, R., and Reilly, F. (2014). Defining Professional Self: Teacher Educator Perspectives of the Pre-ECR Journey. Australian Journal of Teacher Education, 39 (3).

McAnulty, J., and Cuenca, A. (2014). Embracing Institutional Authority: The Emerging Identity of a Novice Teacher Educator. Studying Teacher Education, 10 (1), 36-52.

Merriam, S.B. (2002). Qualitative Research in Practice: Examples for Discussion and Analysis. San Francisco: Jossey and Bass.

Miles, M.B., and Huberman, A.M. (1994). An Expanded Sourcebook: Qualitative Data Analysis (2nd ed.). Thousand Oaks: SAGE Publications.

Murray, J. (2008). Teacher Educators' Induction into Higher Education: Work-based Learning in the Micro Communities of Teacher Education. European Journal of Teacher Education, 31 (2), 117-113.

Murray, J., and Male, T. (2005). Becoming a Teacher Educator: Evidence from the Field. Teaching and Teacher Education, 21 (2), 125-142.

Patton, M.Q. (1990). Qualitative Evaluation and Research Methods (2nd ed.). Thousand Oaks: SAGE Publications. 
Ramirez, L.A., and Allison-Roan, V.A. (2014). A Collaborative Retrospective Analysis of Becoming Teacher Educators. Educational Journal of Living Theories, 7 (1), 39-52.

Reichenberg, R., Kleeman, S., and Sagee, R. (2013). The Professional Development of Teacher Educators in the Context of the School of Professional Development at the MOFET Institute. In: M. Ben-Peretz (Ed.), Teacher Educators as Members of an Evolving Profession (pp. 105-133). Lanham, Maryland: Rowman \& Littlefield.

Reynolds, R., Ferguson-Patrick, K., and McMormack, A. (2013). Dancing in the Ditches: Reflecting on the Capacity of a University/School Partnership to Clarify the Role of a Teacher Educator. European Journal of Teacher Education, 36 (3), 307-319.

Ryan, G.W., and Bernard, H.R. (2003). Techniques to Identify Themes. Field Methods, 15 (1), 85-109.

Shagrir, L. (2011). Professional Development of Novice Teacher Educators: Professional Self, Interpersonal Relations and Teaching Skills. In: T. Bates, A. Swennen, and K. Jones (Eds.), The Professional Development of Teacher Educators (pp. 55-70). London: Routledge.

Smith, K. (2011). The Multi-faceted Teacher Educator: A Norwegian Perspective. Journal of Education for Teaching: International research and pedagogy, 37 (3), 337-349.

Smith, T.M., and Ingersoll, R. (2004). What Are the Effects of Induction and Mentoring on Beginning Teacher Turnover? American Educational Research Journal, 41 (3), 681-714.

Stake, R.E. (2005). Qualitative Case Studies. Retrieved December 11, 2018 from http://www.besafe-project.net/files/.../Stake_2005_qualitative\%20case\%20 studies.pdf.

Stalburg, C.M. (2015). Instructional Methods in Health Professions Education Course. University of Michigan. Creative Commons Attribution Share Alike-3.0 License: http://creativecommons.org/licenses/by-sa/3.0/ https:/open.umich.edu/.../0104f13-ms-coursera-imhpe-cstalburg professional_identitY_formation.pdf.

Strauss, A., and Corbin, J.M. (1990). Basics of Qualitative Research: Grounded Theory Procedures and Techniques. Thousand Oaks: SAGE Publications.

Swennen, A., and van der Klink, M. (2009). 'Epilogue'. In: A. Swennen and M. van der Klink (Eds.), Becoming a Teacher Educator: Theory and Practice for Teacher Educators (pp. 219-225). Dordrecht: Springer.

Tack, H., and Vanderlinde, R. (2014). Teacher Educators’ Professional Development: Towards a Typology of Teacher Educators' Researcherly Disposition. British Journal of Educational Studies, 62 (3), 297-315.

van der Klink, M., Kools, Q., Avissar, G., White, S., and Sakata, T. (2017). Professional Development of Teacher Educators: What Do They Do? Findings from an Explorative International Study. Professional Development in Education, 43 (2), 163-178.

van Velzen, C., van der Klink, M., Swennen, A., and Yaffe, E. (2010). The Induction and Needs of Beginning Teacher Educators. Professional Development in Education, 36 (1-2), 61-75. 
Whitehead, J., and McNiff, J. (2006). All You Need to Know About Action Research. Thousand Oaks: SAGE Publications.

Williams, J., Ritters, J., and Bullock, S.M. (2012). Understanding the Complexity of Becoming a Teacher Educator: Experience, Belonging, and Practice within a Professional Learning Community. Studying Teacher Education, 8 (3), 245260.

Yamin-Ali, J. (2017). Tensions in the Work Context of Teacher Educators in a School of Education in Trinidad and Tobago: A Case Study. European Journal of Teacher Education, 41 (1), 66-85.

Yin, R.K. (2009). Case Study Research Design and Methods. Thousand Oaks: SAGE Publications.

Zeichner, K.M. (2005). Becoming a Teacher Educator: A Personal Perspective. Teaching and Teacher Education, 21, 117-124. 


\title{
Chapter 5
}

\section{The Albanian Student-Teacher Perspective on Reasons for Choosing Teaching as a Career}

\author{
Livia Nano, Nada Kallçiu, and Nikoleta Mita \\ Faculty of Social Sciences, University of Tirana, Tirana, Albania
}

\begin{abstract}
The way the teaching profession in Albania has been perceived by pre-service teachers, by in-service teachers and by the general public as well has changed over the years. The teaching profession used to have a high status and regard before the 1990s, but it has dropped significantly since then. During the two last decades the government has shown concern about improving the status of the teaching profession, but it still remains low. The aim of this study is to investigate student-teachers' reasons for becoming a teacher. This research has applied a mixed methodology, combining survey methods and focus groups. A survey that explores choosing the teaching profession as a career was adapted and contextualized for the Albanian context. A sample of 449 student-teachers from eight public universities was selected using a stratified random sampling technique. Data from the survey questionnaire were analyzed via descriptive statistics. The analysis revealed that the highest rated reason for choosing the teaching career was intrinsic motivation, followed by favorable working hours/holidays and the third reason was job security. It is believed that the findings and recommendations of this research may provide useful insight into the future of teacher education programs and the teaching profession. KEYWORDs: teaching profession, becoming a teacher, reasons for teaching profession, student-teacher, intrinsic motivation, extrinsic motivation.
\end{abstract}

\section{Introduction and background}

During the last two decades the Parliament and Government of Albania have approved a number of laws and regulations that have impacted the 
development of education in general and the teaching profession in particular, by supporting changes in the Albanian education system, improving the educational opportunities of students and raising the status of teachers. In 2010, the Albanian government included the teaching profession in the list of regulated professions (Law no. 10375, date 16.12.2010). Given the importance of credentials to the professions, requirements for new teachers have been an important issue in school reform.

To become a teacher in Albania includes three steps: a) Initial teacher education (pre-service teacher education) in the universities; b) Induction that is intended for those who have already completed basic pre-employment education and preparation. During the induction, teacher candidates must complete one school year teaching practice, pass the state exam and receive their teaching license; c) In-service training and continued professional development.

Despite the reform, the status of teachers still remains low. A significant indicator of the low status of the teaching profession in Albania is the low average grade of students who choose the teacher education programs at universities in Albania. In 2018, in order to improve the quality of teachers, the Government of Albania took the decision that the admission criteria for the teacher education programs should be the grade point average 7 (Council of Ministers, 2018, decision 216). Choosing the best students for teaching careers remains a priority strategic objective for the country. Related to this, if the government wants to encourage the best students and the most committed ones, it is also important to understand the reasons behind the choice of a teaching career, in addition to the steps already undertaken. There is a lack of research in the country in this regard, and thus this study is aimed at investigating what motivates students in Albania to become teachers, and could represent an effort to add a stone to this process.

\section{Literature review}

The reasons for choosing teaching as a career have been a research topic for more than the last three decades.

In teacher education literature, three types of motives for selecting teaching as a career are highlighted: intrinsic motives (e.g. pay and benefits, holidays, job security); extrinsic motives (e.g. personal satisfaction, love for the profession); altruistic motives (e.g. being in service for others) (Brookhart and Freeman, 1992; Moran et al., 2001). This is considered to 
be a traditional perspective. Beside this, other perspectives are developed, such as Super's development of self-concept theory (1953). This theory emphasises that the self-perception of the person plays an important role in career choice. In other words, people choose those occupations that permit them to express their self-concepts. Holland's theory of vocational types (1959) emphases personality types as the major influence in career choice (Nauta, 2010). Gottfredson's theory (1981) determines sex-type rating and prestige level as two variables for choosing a profession, while Bandura's Social Cognition theory (1986) is another perspective that has been applied in vocational psychology to help explain how individuals make career choices. According to this theory, self-perceptions about abilities to reach the goal (self-efficacy) play a central role in the career decision-making process. People move towards those career choices that require capabilities they think they either have or can develop. Self-efficacy beliefs and outcome expectations (expectations one has of the result of the behaviour) in turn shape people's interests, goals and actions. However, these are also influenced by contextual factors (e.g. job/training opportunities etc.) (Fouad, 2014).

Expectancy-value theory is an elaborated theory for academic and career choices (Eggen and Kauchak, 2007; Richardson and Watt, 2005; Wigfield and Eccles, 2000). According to Eccles-Parsons et al. (1983) expectancy-value theories depend on two key factors: the first one is the individual's expectancy of success, in other words, individuals' beliefs about how well they will do on upcoming tasks, and ability beliefs about how good they are; and the second one is the value the individual gives to that task or activity - in other words how important, interesting, or useful a given task or activity is to the individual (Ozurk, 2012). According to this theory, what career choice is taken depends on the perceived likelihood that the behaviour will lead to the goal and the subjective value of that goal.

The majority of research studies base their interpretations on the traditional perspectives. Hayes (1990 cited in Moran et al., 2001) found that American student-teachers entering teaching rated altruistic reasons as more significant. According to a study by Stiegelbauer (1992 cited in Fullan, 1993) Canadian prospective teachers expressed the desire to be role models for students. Hammond (2002) found that trainees frequently drew upon their own past experience of teaching as well as their own interest to explain their career choice. Norwegian and British pre-service teachers rated "enjoying teaching" and "enjoying working with children" higher 
than the other factors, emphasizing intrinsic reasons (Kyriacou et al., 1999). Sinclair (2008) concluded that prospective teachers are multi-motivated.

Watt and Richardson (2007) conducted a study with pre-service teachers enrolled in three Australian universities using a comprehensive scale named Factors Influencing Teaching Choice (FIT-Choice), which they developed in 2006, relying on the expectancy-value theory. They found that the intrinsic value of teaching and the desire to make a social contribution were the highest rated motivations.

In summary, the international literature indicates that reasons for becoming a teacher are different and multi-faced with the intrinsic motivations as the highest rated motivations. However, there is no research on this aspect in the Albanian context. Therefore we carried out a study that explores the reasons for becoming a teacher in Albania, the methodology of which is presented below.

\section{Methodology}

The aim of this research was to investigate student-teachers' reasons for becoming a teacher. The following research questions were addressed:

1) For what reasons do student teachers in Albania choose teaching as a career?

2) Do the reasons given by student-teachers differ according to gender, type of program of study and university entrance preference list?

This research applied a mixed methodology, combining survey methods and focus groups. Two focus groups were conducted to explore the cultural relevance of the questionnaire and two other focus group discussions were conducted after collecting quantitative data, in order to explore reasons for choosing teaching from a qualitative perspective and illustrate quantitative findings.

\section{Participants}

A random sampling was used to select student teachers from seven public universities that provide teaching education programmes. The study followed 449 student teachers from the University of Tirana (30\%), from the University of Durres (11\%), the University of Elbasan (11\%), the University of Gjirokastra (11\%), the University of Korça (11\%), the University of Sports (4\%), the University of Shkoder (11\%), and the University of Vlora 
(11\%). Student teachers were attending the following programmes: ${ }^{1}$ Teaching of elementary education (20\%); Teaching of preschool education (13\%); Teaching of physical education (7\%); Teaching of math and natural sciences (19\%) and Teaching of Humanities and Social Sciences (41\%). Among the student-teachers, $79 \%$ were female and $21 \%$ were male. Most of them (92\%) have achieved a general gymnasium education and the rest of the sample (8\%) have achieved a professional gymnasium level. $60 \%$ of the sample had chosen a teaching study program as their $1^{\text {st }}$ or $2^{\text {nd }}$ preference in the application form for university admission into a Bachelor/Master program; $21 \%$ had chosen a teaching study program as their $3^{\text {rd }}$ to $5^{\text {th }}$ preferences; and $20 \%$ of the sample had chosen a teaching study program between their $6^{\text {th }}$ to $10^{\text {th }}$ preferences, from among other study programs that they had applied to before entering the Bachelor/Master program. Finally, 28\% of the sample was attending a Bachelor program in teaching and the rest (72\%) were attending a Master program in teaching.

\section{Instrument, data analysis and procedure}

The questionnaire used in this study was developed through the following steps: a) A literature review in the field and a search for instruments used for this purpose was conducted. This step resulted in selecting and adapting the Choosing the teaching profession as a career scale (5-point Liker scale) developed by Lai, Chan, and Ko (2005), and the scale used by Kane and Mallon (2006), as most appropriate in covering the main reasons for choosing a teaching career in the Albanian context; b) Two focus group discussions with student-teachers were conducted to check the cultural relevance of the chosen instrument as well as to include/remove items if necessary, in order to better understand how student-teachers in an Albanian context think about the issue. Focus group analysis resulted in adding five new items to the questionnaire; c) The forward-translation and back-translation of the scale was used to make sure that the meaning of the adopted items was the same as the original scale items; d) The scale was pretested with student-teachers in order to evaluate how they understood

1 This variable has been re-coded by grouping the program of studies according UNESCO-UIS ISCED Fields of Education and Training 2013. 1) Teaching in Elementary Education (includes: Bachelor in Teaching in elementary education and Master in Teaching in elementary education); 2) Teaching in preschool education (bachelor program only); 3) Teaching of physical education; 4) Teaching Math and Natural Sciences (includes Master Programs - Teaching informatics; Teaching mathematics; Teaching natural sciences); 4) Teaching of humanistic and social sciences (includes: Master programs - Teaching foreign languages; Teaching Albanian language and literature; Teaching history-geography; Teaching social sciences). 
the language of the adapted items, as well as how they responded to the overall questionnaire.

The final version of the questionnaire was subject to factor analysis in order to identify and regroup variables into the scales. Exploratory factor analysis with principal component extraction was performed, after which the number of factors was determined by both Eigen values $(>1)$ and the screen plot. These criteria suggested a three-factor solution, accounting for $54.3 \%$ of the variance. KMO $>0.05$ and Bartlett's test of sphericity $<0.000$ suggest the appropriateness of factor analysis for the variables. The rotation method was Varimax with Kaiser Normalization. Items were eliminated from the factor pattern matrix when the factor loading was $< \pm 0.300$. This process resulted in the development of five subscales: Intrinsic motivation (10 items); Pay and other benefits (3 items); Job access/security and status (5 items); Influence of others (4 items) and Program admission criteria (2 items). Only one item, Teaching simply as a choice just to pursue higher education, did not fit in one of the five factors produced.

The reliability coefficients for two scales respectively: Intrinsic motivation (.877) and Program admission criteria (.866) was good; two other scales have acceptable alpha reliabilities: Job access/security and status and Influence of others; only the factor/scale Pay and other benefits (.634) has a questionable alpha coefficient. The reliability coefficient for the entire questionnaire was an acceptable one (.729).

Data from the survey questionnaire was analyzed via descriptive and inferential statistics using SPSS 20. More specifically, three levels of analysis were conducted: 1) frequency analysis of student teachers responses per each questionnaire item, also identifying items with the highest and lowest scoring; 2) crosstabs analysis according to gender, study program and preference rank; 3) factor analysis for five factors with associated statistical analysis of significant differences both across and within groups. The Kolmogorov-Smirnov test was used to test the normality of distribution of the score. The distribution was not normal. Homogeneity of variance was tested using the Levene test. The Mann-Whitney and Kruskal-Wallis The non-parametric tests were used to compare the means for five factors according to gender, program of study, preference rank of teaching and attending a Bachelor/Master teaching program.

Qualitative data analysis of the transcripts of the focus groups was content-based, focusing on identification and coding of categories and used to illustrate quantitative findings. 


\section{Findings}

The results obtained in this study are presented in this section as follows: first, the frequency distribution of student-teachers' reasons for choosing a teaching career, illustrated with findings obtained from focus group discussions; and second, the factor analysis of five factors are identified.

\section{(1) Frequency analysis and qualitative analysis}

This section discussess the frequency distribution of student-teachers' reasons for choosing a teaching career, illustrated with findings from focus group discussions.

The highest scored item was Wanted to do a job in which I can feel proud of myself, of which $60 \%$ of student-teachers strongly agreed on as a reason for choosing a teaching career. This was followed by Enjoy working with children/teenagers (56\% strongly agree); Wish to teach the subject I like (55\% strongly agree); Wanted to do something meaningful with my life (54\% strongly agree). Almost all of the high scoring items (reported as strongly agree and agree by more than $70 \%$ of student-teachers) are linked with behaviors that are personally and internally rewarding, such as the desire to help children/contribute to society, as well as motives related to personal or professional development (see Table 1.). This can also be illustrated by qualitative data analysis:

I have always preferred to become a teacher, even though family members have encouraged me to become a doctor or something else. If I were back in time and had to decide about my career, I would make the same career choice (female student teacher).

I remember that when I was in high school, it was so evident how much influence a teacher could have on his students, so one of the reasons I have chosen this profession is to contribute to the young generation (male student teacher).

Another reason may be 'fame' because being a teacher means more opportunity to get to know many people and build a career (male student teacher)

Teaching literature is my passion; however, salary is another good reason (female student teacher)

I have a passion for teaching, that's why I have chosen it, I had an average grade of 8.5 (considered good) and chose it by the desire to continue a teaching career (male student teacher) 
The item with the highest percentage score in terms of choosing a teaching career driven by extrinsic motivation is Good working hours (38\% of respondents reported strongly agree).

Suitable working hours are a good reason for choosing a teaching career. Weekends are off and you have lots of holidays. This working schedule can provide teachers with an opportunity to do a second job (female student teacher).

The existing mentality is that teaching is a great profession for females; you have more time to bring up your own kids and be more present at home (female student teacher).

Great working hours. You get home at $2.00 \mathrm{pm}$ (female student teacher).

This is followed by Better job security (24\% of respondents indicated strongly agree) and More holidays (24\% of respondents indicated strongly agree).

Teaching is thought to be a stable profession; it provides you with a secure job and there is no risk of being fired/transferred due to political affiliations (female student teacher).

High social status (19\% of student-teachers strongly agreed).

Becoming a teacher is equal to having a high status for a female. I tend not to strongly agree with this; however, my grandparents who live in rural areas consider my teaching career as a great achievement (female student teacher).

A similar pattern can also be observed if strongly agree and agree are analyzed together (see the Table 1 for more details). It is interesting to notice that $44 \%$ of student-teachers strongly agreed and agreed with teacher's good salary as a reason for choosing a teaching career. $46 \%$ of student-teachers agreed and strongly agreed that they have also chosen this career, among other reasons, for the fact of the government's attention and high regard for the profession.

A teacher's salary is acceptable. It is not very good. However, it is quite OK (female student teacher).

With regards to finding a job as a teacher, quantitative data analysis revealed that about $27 \%$ (strongly agree and agree) of student-teachers have declared this as a reason for their career choice.

The majority of females consider attending a teaching study program as the only opportunity to find a job in the future (female student teacher). 
It is easy to find a job as teacher especially in the north of the country or in rural areas; you can even get a job without a Master degree in teaching. It is more difficult to find a job in Tirana and Durres (two main cities of the country) (female student teacher).

Reasons related to the influence of others, such as family, peers, mass media, and teachers, were reported as strongly agree and agree by fewer student-teachers. Among these items influence of family members (36\%) was the highest scored item, followed by influence of teachers (29\%) and influence of peers (14\%). Very few respondents reported to have chosen a teaching career due to mass media influence (9.8\%) and low university admission/entrance competition (12\%).

I know peers who have chosen this career because their family members have guided them to do so (female student teacher).

My teachers, when I have told them that I have chosen a teaching career, haven't approved my choice because they consider it an exhausting profession. They (teachers) think differently from others, who don't work as teachers and consider teaching as an easy profession (female student teacher).

I have won the right to study in three different Master programs, but I have chosen teaching in Social Sciences among those [entrance criteria wasn't an issue for her] (female student teacher).

As for the item of the questionnaire Choosing a teaching career simply as a choice to pursue higher education, it does not relate to any of the five-factor intrinsic/extrinsic reasons: $28 \%$ of the respondents were declared strongly agree (11\%) and agree (17\%). Among this group 25\% were female student-teachers vs. 38\% male student teachers. 51\% of student-teachers of Natural Sciences agreed and strongly agreed with this fact as opposed to half of this percentage for student-teachers attending other study programs, and $42 \%$ of student-teachers ranked teaching as their $6^{\text {th }}$ to $10^{\text {th }}$ preference option of study vs. only $20 \%$ of those who had ranked a teaching program as their $1^{\text {st }}$ or $2^{\text {nd }}$ preference.

Some students find themselves in a teaching program just to have a university diploma, as to have a university diploma is trendy and a necessity at the same time. This is more relevant for males than for females (male student teacher).

My first preference has been to become an economist, teaching literature was my second choice (female student teacher). 
The frequency table below shows reasons for choosing a teaching career for all items of the questionnaire used.

Table 1. Reasons for choosing a teaching career for all items of the questionnaire used (items with * indicates items with highest percentages)

\begin{tabular}{|c|c|c|c|c|c|c|}
\hline & \multicolumn{2}{|c|}{$\begin{array}{l}\text { Strongly disagree } \\
\text { and disagree }\end{array}$} & \multicolumn{2}{|c|}{$\begin{array}{l}\text { Strongly agree } \\
\text { and agree }\end{array}$} & \multirow[b]{2}{*}{ Mean } & \multirow[b]{2}{*}{ SD } \\
\hline & Frequency & Percentage & Frequency & Percentage & & \\
\hline \multicolumn{7}{|c|}{ Factor one - Intrinsic motivation } \\
\hline \multicolumn{7}{|c|}{ Helping children/society } \\
\hline Wish to help others & 10 & 2.2 & 403 & $89.8^{*}$ & 4.40 & 0.768 \\
\hline $\begin{array}{l}\text { Enjoy working with children/ } \\
\text { teenagers }\end{array}$ & 13 & 2.9 & 388 & $86.4^{*}$ & 4.38 & 0.839 \\
\hline $\begin{array}{l}\text { Wanted to make a contribution } \\
\text { to society }\end{array}$ & 9 & 2 & 386 & $86^{*}$ & 4.31 & 0.802 \\
\hline \multicolumn{7}{|c|}{ Personal and professional development } \\
\hline $\begin{array}{l}\text { Like working in the school } \\
\text { environment }\end{array}$ & 12 & 2.7 & 393 & $87.5^{*}$ & 4.36 & 0.825 \\
\hline $\begin{array}{l}\text { Like challenging nature of the } \\
\text { job }\end{array}$ & 27 & 6 & 316 & $70.4^{*}$ & 3.9 & 0.894 \\
\hline Wish to teach the subject I like & 13 & 2.9 & 381 & $84.9^{*}$ & 4.36 & 0.847 \\
\hline $\begin{array}{l}\text { Gives opportunities for } \\
\text { continuing education }\end{array}$ & 12 & 2.7 & 381 & $84.9^{*}$ & 4.27 & 0.813 \\
\hline Teaching fits to my personality & 19 & 4.2 & 350 & $78^{*}$ & 4.14 & 0.907 \\
\hline $\begin{array}{l}\text { Wanted to do a job in which } \\
\text { I can feel proud of myself }\end{array}$ & 10 & 2.2 & 396 & $88.2^{*}$ & 4.45 & 0.801 \\
\hline $\begin{array}{l}\text { Wanted to do something } \\
\text { meaningful with my life }\end{array}$ & 25 & 5.6 & 324 & $87.1^{*}$ & 2.85 & 0.409 \\
\hline \multicolumn{7}{|l|}{ Extrinsic motivation } \\
\hline \multicolumn{7}{|l|}{ Factor two - Pay and other benefits } \\
\hline Higher salary & 74 & 16.5 & 199 & 44.3 & 3.35 & 0.961 \\
\hline Good working hours & 16 & 3.6 & 371 & $82.8^{*}$ & 4.16 & 0.855 \\
\hline More holidays & 46 & 10.3 & 280 & 62.5 & 3.74 & 0.999 \\
\hline \multicolumn{7}{|c|}{ Factor three - Job security and status } \\
\hline Better job security & 35 & 7.8 & 284 & 63.4 & 3.78 & 0.953 \\
\hline High social status & 38 & 8.5 & 270 & 60.3 & 3.70 & 0.918 \\
\hline Good career prospect & 25 & 5.6 & 320 & $71.4^{*}$ & 3.88 & 0.856 \\
\hline $\begin{array}{l}\text { Government's high regard for } \\
\text { this profession }\end{array}$ & 87 & 19.4 & 206 & 46 & 3.34 & 1.113 \\
\hline
\end{tabular}




\begin{tabular}{lcccccc}
\hline & \multicolumn{2}{c}{$\begin{array}{c}\text { Strongly disagree } \\
\text { and disagree }\end{array}$} & \multicolumn{2}{c}{$\begin{array}{c}\text { Strongly agree } \\
\text { and agree }\end{array}$} & & \\
\cline { 2 - 8 } & Frequency & Percentage & Frequency & Percentage & Mean & SD \\
\hline Easier to find teaching vacancies & 164 & 36.6 & 119 & 26.6 & 2.84 & 1.113 \\
\hline Factor four - Influence of others & & & & & & \\
\hline Influenced by peers & 331 & 73.7 & 62 & 13.8 & 2.02 & 1.226 \\
\hline Influenced by family members & 204 & 45.4 & 162 & 36.1 & 2.80 & 1.384 \\
\hline Influenced by teachers & 240 & 53.5 & 125 & 27.8 & 2.54 & 1.321 \\
\hline Influenced by mass media & 311 & 69.3 & 44 & 9.8 & 2.06 & 1.076 \\
\hline $\begin{array}{l}\text { Factor five - program admission criteria } \\
\text { Influenced by low university }\end{array}$ & 342 & 76.2 & 53 & 11.8 & 1.96 & 1.117 \\
\hline $\begin{array}{l}\text { admission criteria } \\
\text { Influenced by low entrance } \\
\text { competition }\end{array}$ & 336 & 74.8 & 54 & 12 & 1.96 & 1.121 \\
\hline $\begin{array}{l}\text { Teaching simply as a choice to } \\
\text { pursue higher education }\end{array}$ & 245 & 54.6 & 128 & 28.5 & 2.56 & 1.365 \\
\hline
\end{tabular}

\section{(2) Factor analysis}

The questionnaire for exploring reasons for becoming a teacher was subject to factor analysis to identify key constructs. Factor analysis produced five factors as explained below:

Table 2. Reasons for becoming a teacher - factor analysis

\begin{tabular}{lc}
\hline Factor one: Intrinsic motivation (helping others/personal development) & Loading factor \\
\hline Wish to help others & .727 \\
\hline Enjoy working with children/teenagers & .691 \\
\hline Wanted to make a contribution to society & .771 \\
\hline Like working in the school environment & .728 \\
\hline Like challenging nature of the job & .504 \\
\hline Wish to teach the subject I like & .657 \\
\hline Gives opportunities for continuing education & .633 \\
\hline Teaching fits to my personality & .675 \\
\hline Wanted to do a job in which I can feel proud of myself & .715 \\
\hline Wanted to do something meaningful with my life & .703 \\
\hline Reliability of the scale: .877 & \\
\hline Factor two - Pay and other benefits (extrinsic motivation) & .319 \\
\hline Higher salary & .758 \\
\hline Good working hours & Loading factor \\
\hline
\end{tabular}




\begin{tabular}{lc}
\hline More holidays & .818 \\
\hline Reliability of the scale: 634 & Loading factor \\
\hline Factor three - Job access/security and status & .560 \\
\hline Easier to find job vacancies & .601 \\
\hline Better job security & .714 \\
\hline High social status & .711 \\
\hline Good career prospect & .774 \\
\hline Government's high regard for this profession & Loading factor \\
\hline Reliability of the scale: .757 & .644 \\
\hline Factor four - Influenced by others & .821 \\
\hline Influenced by peers & .793 \\
\hline Influenced by family members & .591 \\
\hline Influenced by teachers & \\
\hline Influenced by mass media & Loading factor \\
\hline Reliability of the scale: .755 & .802 \\
\hline Factor five - program admission criteria & .869 \\
\hline Influenced by low university admission criteria & \\
\hline Influenced by low entrance competition &
\end{tabular}

Factor One: intrinsic motivation

The analysis revealed that on average the respondents choose their teaching career for extrinsic reasons $(M=4.3)$. This was the highest rated factor/reason for choosing the teaching profession. The frequency distribution of this factor shows that the majority of participants (49.5\%) strongly agree, with a significant difference to other categories $(p<0.0001)$

According to gender, the responses from student-teachers reflected significant difference in Factor One. The result of the t-test showed that females have a higher mean score $(M=4.4)$ as compared to males $(M=4.1)$ with a significant difference $(p<0.001)$. Females tend to strongly agree with this factor more than males do on all items. The most significant difference according to gender can be noticed in the following items: Teaching fits my personality, of which $82.5 \%$ of women strongly agreed or agreed as opposed to men, of whom only 60\% strongly agreed and agreed; Enjoy working with children/teenagers (strongly agreed or agreed by $90 \%$ women vs. $72 \%$ men); Wanted to do a job in which I can feel proud (91\% women as opposed to $76 \%$ men); Wanted to do something meaningful with my life ( $90 \%$ women vs. $75 \%$ men). 
There were also significant differences in Factor One according to study preference for teaching in the application form for university admission. Respondents who had teaching as their $1^{\text {st }}$ or $2^{\text {nd }}$ option in the preference list have a higher mean score in Factor One $(M=4.40)(p<0.001)$ as compared to those who had ranked teaching as their $3^{\text {rd }}$ to $5^{\text {th }}$ preference $(M=4.20)$ and $6^{\text {th }}$ to $10^{\text {th }}$ preference $(M=4)$. This was more evident if comparing the reasons for a teaching career among those who had ranked teaching as their $1^{\text {st }}$ or $2^{\text {nd }}$ preference and those who had ranked teaching as $6^{\text {th }}$ to $10^{\text {th }}$ preference in the following items: Teaching fits to my personality $\left(1^{\text {st }}\right.$ and $2^{\text {nd }}$ preference $M=4.23$ vs. $6^{\text {th }}$ to $10^{\text {th }}$ preference $M=3.8$ ); Wanted to do a job in which I can be proud ( $1^{\text {st }}$ and $2^{\text {nd }}$ preference $M=4.53$ vs. $6^{\text {th }}$ to $10^{\text {th }}$ preference $M=4.2$ ); Wanted to make a contribution to society ( $1^{\text {st }}$ and $2^{\text {nd }}$ preference $M=4.4$, which is $90 \%$ of respondents vs. only $70 \%$ of respondents who had teaching as their $6^{\text {th }}$ to $10^{\text {th }}$ preference $M=4$ ).

The analysis of variance showed significant difference (sig.=.000) in choosing a teaching career based on intrinsic motivators according to the program of study student-teachers are attending. While there were no meaningful differences between student teachers attending Teaching in Elementary Education $(M=4.40)$ and Teaching Physical Education $(M=4.40)$, this factor is significantly stronger if compared with student-teachers attending Teaching Math and Natural Science programs $(M=4.00)$, and slightly different with student-teachers attending Teaching in Preschool Education $(M=4.20)$ and Teaching in Humanities and Social Sciences programs $(M=4.30)$. This is more evident when analyzing individual items within the factor. For example, 93\% of student-teachers of Elementary Education have chosen a teaching career because, among other reasons, they wish to help others, as opposed to only 75\% of students in Teaching Math and Natural Sciences programs. 94\% of students of Teaching Elementary Education enjoy working with children/ teenagers, vs. only 69\% of students in Teaching Math and Natural Sciences programs of study. 87\% of student-teachers of Elementary Education and 83\% of student-teachers of Physical Education reported that teaching fit their personality, vs. $75 \%$ of student-teachers of Preschool Education, and finally $79 \%$ of student-teachers of Humanities and Social Studies, vs. only 64\% of student-teachers of Math and Natural Sciences.

There were no significant differences in Factor One according to attending a bachelor program vs. a master program in teaching. 
Factor Two: Pay and other benefits

The analysis revealed that choosing a teaching career due to good salary, good working hours and possibilities for more holidays was the second most rated reason from student-teachers with a mean score of 3.80. The frequency distribution of this factor shows that the majority of participants (38.9\%) 'Agree', with a significant difference to other categories $(p<0.0001)$. The analysis of variance revealed that there is a significant difference in reasons for choosing a teaching career for pay and other benefits (i.e. working hours and holidays) according to gender. Females have slightly higher mean score $(M=3.80)$ as compared to males $(M=3.60)$ with a significant difference $(p=0.02)$. This is also more evident when analyzing individual items within the factor. This difference is more evident in terms of the favorable working hours the teaching profession offers, as $86 \%$ of female respondents consider this as a strong reason as opposed to $72 \%$ of men; and the possibility for more holidays, of which $65 \%$ of females strongly agree and agree vs. 54\% of male respondents. As for the reason for choosing teaching as a career being due to the good salary one can get, quite similar percentages of male (43\%) and female (45\%) respondents agreed on this.

No significant difference was found in this factor with regards to program of study ( $p=0.1$ ), preference rank for teaching in the application form $(p=0.7)$, or attending a bachelor or master program in teaching $(p=0.8)$.

Factor Three: Job access/security and status

The analysis revealed that on average the respondents are somewhat neutral about choosing their teaching career for status and job security reasons $(M=3.30)$. This was the third-rated factor/reason that influenced choosing a teaching career. The frequency distribution of this factor shows that the majority of participants (32.2\%) 'Agree', with a significant difference to other categories $(p<0.0001)$.

Analysis of variance also showed that there were no significant differences in the mean score between females and males $(p=0.2)$ between attending a bachelor program or a master program in teaching $(p=0.4)$, among categories of preference rank of teaching $(p=0.1)$ or among different programs of study $(p=0.09)$.

\section{Factor Four: influence of others}

The analysis revealed that on average the respondents tend to be somewhere in between disagreeing and being neutral about the influence of others in 
choosing the teaching profession $(M=2.40)$. This was the forth-rated factor/ reason for choosing a teaching career. The frequency distribution of this factor shows the majority of participants (34.2\%) indicated 'Strongly disagree' with a significant difference to other categories $(p<0.0001)$.

Analysis of variance found a significant difference in the mean score of females and males $(p<0.001)$ with regards to choosing a teaching career due to the influence of others. Males have a higher mean score $(M=2.70)$ than females $(M=2.20)$. For example $20 \%$ of male respondents reported to have chosen a teaching career influenced by peers as opposed to only $12 \%$ of female respondents; influence of teachers was also reported by $39 \%$ of male student-teachers vs. only $24 \%$ of females.

There is also a significant difference in the mean score between those who attend a bachelor program in teaching and those who attend a master program in teaching $(p<0.001)$. master's student-teachers have a higher mean score $(M=2.50)$ vs. bachelor's student-teachers $(M=2.02)$, indicating that the influence of others is more evident in choosing the master program in teaching than when choosing a bachelor program. When analyzing the individual items $16 \%$ of master student-teachers reported peer influence in choosing a teaching career vs. only $7 \%$ of bachelor student-teachers; $41 \%$ of master's student-teachers reported family influence vs. only $23 \%$ of bachelor student-teachers; 34\% of master's student-teachers reported teachers influence vs. only $11 \%$ of bachelor's; and $13 \%$ of master's student-teachers reported being influenced by mass media for choosing their teaching career vs. only $2 \%$ of bachelor student-teachers.

A significant difference (sig.=.000) was also found in choosing a teaching career based on the influence of others according to program of study. While there were no meaningful differences between student-teachers attending Teaching in Elementary Education $(M=2.00)$ and Teaching Preschool Education $(M=1.90)$, this factor is significantly stronger if compared with student teachers attending Teaching of Natural Science programs $(M=2.70)$ and Teaching Physical Education $(M=2.50)$, and slightly different if compared with students attending Teaching in Humanities and Social Sciences $(M=2.30)$. This is more evident when analyzing individual items within the factor. For example $46 \%$ of students in Teaching Math and Natural Sciences and $57 \%$ of students in Teaching Physical Education reported to have been influenced by family members for choosing a teaching career, vs. only 30\% of students of Elementary Education, 19\% of students in Teaching in Preschool Education and 35\% of students in Teaching Humanities and Social Sciences. 
Analysis of variance found no significant difference in the mean score among student-teachers according to their preference rank of teaching $(p=0.3)$.

\section{Factor Five: program admission criteria}

On average, respondents reported that low admission criteria in the teaching program is not a reason to choose a teaching career $(M=2.00)$. The frequency distribution of this factor shows the majority of participants (44.9\%) 'Strongly disagree', with a significant difference to other categories $(p<0.0001)$.

Analysis of variance found a significant difference according to gender in the reasons for career choice and teaching program admission criteria. Males have a higher mean score $(M=2.20)$ as compared to females $(M=1.90)$ with a significant difference $(p<0.001)$. While $15 \%$ of male respondents admit that low university admission criteria and low competition is one of the reasons for choosing a teaching career, less than $11 \%$ of female respondents hold this attitude.

There is also a significant difference among three groups according to how they have ranked teaching as their career preference. The third group, those who ranked teaching as their $6^{\text {th }}$ to $10^{\text {th }}$ option in the study program preference list has a higher mean score $(M=2.60)(p<0.001)$, as compared to the group who has ranked teaching as their $1^{\text {st }}$ or $2^{\text {nd }}$ option in the preference list $(M=1.70)$ and $3^{\text {rd }}$ to $5^{\text {th }}$ option in the preference list $(M=2.10)$, indicating that $25 \%$ of those who have selected teaching as their $6^{\text {th }}$ to $10^{\text {th }}$ preference for their future career were influenced by low university admission criteria, $v s$. only $6 \%$ of those who had teaching as their $1^{\text {st }}$ or $2^{\text {nd }}$ option in the preference list.

No significant difference was found for this factor in terms of attending a bachelor or master program in teaching $(p=0.3)$, as well as among different programs of study $(p=0.1)$.

\section{Conclusions}

The analysis revealed that the highest rated reason for choosing the teaching profession was intrinsic motivation. This was closely followed by the good salary/favorable working hours/holidays a teaching career can offer. The third reason for choosing this career was job security and the status the teaching profession can provide. Some future teachers chose this career 
influenced by others; however this reason was the fourth reason in line. Low program admission criteria seemed not to have any influence in choosing a teaching career.

Females who had ranked teaching as their $1^{\text {st }}$ or $2^{\text {nd }}$ option in the study program admission application form, as well as students attending Elementary Education programs and Physical Education programs, are more driven than others to have chosen this career based on intrinsic motivation. Students attending Teaching Math and Natural Sciences programs tend to be less driven than others in terms of choosing this career based on intrinsic motivation. Females tend to be driven more from favorable working hours and holidays that a teaching career can offer than male respondents do when choosing the career.

Male students tend to be more influenced by others in choosing their teaching career than do female students. Furthermore, the influence of others is more evident in choosing a master program in teaching than when choosing a bachelor program, as well as among students of Teaching Math and Natural Sciences and Teaching Physical Education as opposed to other groups.

Both males and females disagree that low admission criteria have influenced their career choice; however, female students tend to be more against this fact. Furthermore, student-teachers who had ranked teaching as their $1^{\text {st }}$ or $2^{\text {nd }}$ option in the preference list tend to disagree more with the fact that low admission criteria have influenced their career choice.

\section{Recommendations and further research}

As research on teacher education in Albania is very limited and tends to be relatively small-scale, fragmented and non-cumulative, which is less valuable in support of systemic change, it is recommended that longitudinal, large-scale studies take place.

An in-depth qualitative study to explore the motives for choosing the teaching profession, and the reasons behind those motives would be helpful for both universities and policymakers.

New admission policies for teacher education, the impact of initial motivations in teacher recruitment, retention and effectiveness, and the quality of candidates for initial teacher education need to be the focus of discussion and national research. 


\section{References}

Brookhart, S.M., and Freeman, D.J. (1992). Characteristics of Entering Teacher Candidates. Review of Educational Research, 62 (1), 37-60.

Brown, M.M. (1992). Caribbean First-year Teachers’ Reasons for Choosing Teaching as a Career. Journal of Education for Teaching, 18 (2), 185-195.

Council of Ministers. (2018). Decision no. 216 Criteria for establishing the average grade for accepting applicants for teaching programs. Albania.

Eggen, P., and Kauchak, D. (2007). Educational Psychology (7 th $^{\text {Edition}) . ~ N e w ~ J e r s e y: ~}$ Pearson Education International

European Commission. (2010). Developing Coherent and System-wide Induction Programmes for Beginning Teachers: A Handbook for Policymakers. European Commission Staff Working Document SEC (2010) 538 final.

Fouad, N.A. (2014). Social Cognitive Career Theory: Introductory Review. In: J.L. Swanson and N.A. Fouad. Career Theory and Practice: Learning through Case Studies ( $3^{\text {rd }}$ Edition). Los Angeles: Sage Publications.

Fullan, M.G. (1993). Why Teachers Must Become Change Agents. Educational Leadership, 50 (6), 12-17.

Gottfredson, L.S. (1981). Circumscription and compromise: A Developmental Theory of Occupational Aspirations. Journal of Counseling Psychology (Monograph), 28 (6), 545-579.

Hammond, M. (2002). Why Teach? A Case Study Investigating the Decision to Train to Teach. ICT, Journal of Education for Teaching, 28 (2), 135-148.

Kane, G.R., and Mallon, M. (2006). Perceptions of Teachers and Teaching. New Zealand: Ministry of Education.

Kyriacou, C., Hultren, A., and Stephens, P. (1999). Student Teachers’ Motivation to Become a Secondary School Teacher in England and Norway. Teacher Development, 3, 373-381.

Lai, K., Chan, K., Ko, K., and So, K. (2005). Teaching as a Career: A Perspective from Hong Kong Senior Secondary Students. Journal of Education for Teaching, 31 (3), 153-168.

Law no.10357, date 16.12.2010 - an addition to the Law no.10 171 date 22.10.2009 for regulated professions in the Republic of Albania.

Moran, A., Kilpatrick, R., Abbott, L., Dallatt, J., and McClune, B. (2001). Training to Teach: Motivating Factors and Implications for Recruitment. Evaluation and Research in Education, 15 (1), 17-32.

Nauta, M.M. (2010). The Development, Evolution, and Status of Holland's Theory of Vocational Personalities: Reflections and Future Directions for Counselling. Journal of Counselling Psychology, 57 (1), 11-22.

Ozurk, E.O. (2012). Contemporary Motivation Theories in Educational Psychology and Language Learning: An Overview. The International Journal of Social Sciences, 3 (1), TIJOSS and ARF.

Richardson, P.W., and Watt, H.M.G. (2005). I've Decided to Become a Teacher: Influences on Career Change. Teaching and Teacher Education, 21 (5), 475-489.

Sinclair, C. (2008). Initial and Changing student Teacher Motivation and Commitment to Teaching. Asia-Pacific Journal of Teacher Education, 36 (2), 79-104. 
Skilbeck, M., and Connell, H. (2003). Attracting, Developing and Retaining Effective Teachers: Australian country Background Report for OECD. Canberra, ACT: Department of Education, Science and Training.

Super, D.E. (1953). A Theory of Vocational Development. American Psychologist, 8, 185-190.

Watt, H.M.G., and Richardson, P.W. (2007). Motivational Factors Influencing Teaching as a Career Choice: Development and Validation of the FIT-choice Scale. The Journal of Experimental Education, 75 (3), 167-202.

Wigfield, A., and Eccles, J.S. (2000). Expectancy-Value Theory of Achievement Motivation. Contemporary Educational Psychology, 25, 68-81. 


\title{
Chapter 6
}

\section{Educational Agility}

\author{
Neus Lorenzo Galés* and Ray Gallon** \\ * The Transformation Society; Universitat Autonoma de Barcelona, Barcelona, Spain \\ ** The Transformation Society; Universitat de Barcelona, Barcelona, Spain
}

\begin{abstract}
Educational systems are facing a transformation process that includes not only changes in their methodologies and techniques, but deep evolution of teachers' mindsets and social perceptions. The need for a dynamic, flexible, and open learning environment for every child is creating the necessity of more complex but enriched principles for teaching and learning. The Agile Manifesto describes a mindset to be applied to the creative development of software. Educational agility can be seen as the application in the school context of the strategies, principles, and values that agile thinking has brought to software development. In this paper, the authors provide an initial reflection on what agile schools, agile teachers, and agile students bring to the scene for improving quality in education. They also suggest the elements for creating a community of practice to debate, apply, execute, and evaluate educational agility in the real world. Future case studies will provide evidence of how agile mindsets can change learning theory, communication theory, teachers' and students' roles, methodologies, strategies, resources, and assessment processes.

KEYWORDs: Agile learning, common good, education, emerging technologies, Industry 4.0, student-centred approach
\end{abstract}

\section{Context}

We are building a world where we face the evolution of information and communications technologies into 'smart', hyper-connected autonomous systems driven by artificial intelligence (Josefowicz, Gallon, and Lorenzo, 2017). In this world of Industry 4.0 we are asked to develop an economy of

CONTACT Neus Lorenzo Galés, EMAIL: neus@transformationsociety.net 
flexibility and dynamic change (Bouzol-Boitman et al., 2016). At the same time, intergovernmental instances are demanding sustainability, concern for the environment, and orientation to the common good (United Nations, 2015). Many indicators show that the traditional sequences used in education are no longer adapted to respond to these challenges, and more global skills are needed to combine both technology and humanism (Marope, Griffin, and Gallagher, 2018). More and more experts assert that education needs to develop new approaches towards what is called the 'age of agility' (Gaulden and Gottlieb, 2017).

Human cultures have evolved by converging technology (tools and procedures) and communication (language and its symbolic representation of the world, argumentation), articulated collectively in a way that facilitates interacting with the environment, both to adapt to it and to change it. This is a continuum that we have segmented into phases in order to study it more easily. From the point of view of modern economic production, we can speak of four major industrial revolutions (Lorenzo and Gallon, 2018):

- $\quad$ In the $18^{\text {th }}$ century, the advent of steam power permits the first mechanical automation. Humans begin building powered, automatic machines.

- $\quad$ In the early $20^{\text {th }}$ century, mass production techniques create the notion of industrialisation. Machines build machines.

- $\quad$ In the mid $20^{\text {th }}$ century, the cybernetic revolution gives machines a role in performing massive calculations. Machines take on a role of helping humans to make decisions.

- In the $21^{\text {st }}$ century, interconnected cyber-physical systems function independently, driven by artificial intelligence and powered by big data. Machines are now making decisions in the place of humans.

Communications technology, and the capacity for knowledge transfer, has always been a part of these types of advances. Printing helped humans pass from oral to written knowledge transmission. Electronic communication has enabled evolution from individual to collective, transmedia transmission. Today, we are developing a complex, highly automated, integrated global mass communications system. The education process should be able to help students operate in this extremely diverse environment, at personal or collective level, to manage content, learning processes, and a diversity of mindsets.

An agile approach to teaching and learning in modern environments should be able to offer a flexible, structured situation that is adaptable enough to offer multiple paths to meet growing demands for personalised learning. 
In this paper, the authors provide an initial reflection on what agile schools, agile teachers, and agile students bring to the scene for improving quality in education. They also suggest the elements for creating a community of practice to debate, apply, execute, and evaluate educational agility in the real world.

\section{What is agile?}

Agility, as it is used in this paper, is based on a manifesto that was originally written for software developers. It represents a mindset, rather than a methodology, in which software is developed over multiple iterations, and each iteration represents a fully functioning part of the final product (Agile Alliance, 2001).

If we adjust the Agile Manifesto to the world of education, it reads:

We value:

Individuals and interactions over processes and tools

Meaningful learning over the measurement of learning

Stakeholder collaboration over complex negotiation

Responding to change over following a plan

That is, while there is value in the items on the right, proponents of the

Agile Movement value the items on the left more (Briggs, 2014).

Figure 1 shows different iterations of learning processes where motivation drives and stimulates planning, analysis, design, building, testing, deployment, and review: the traditional elements of an agile cycle.

Many methodologies have been developed to implement agile, but anyone who follows one rigidly will miss the point. Adopting an agile mindset means changing the internal culture of learning institutions. One of the most challenging factors is the need to remain nimble in the face of change. Today's society is evolving so rapidly that information can become obsolete in the time needed to validate it, and that means we need to rethink our notions of success and failure. Indeed, failure is a great teacher when we validate the effort made and study what we can do the next time to make things better. "The faster we fail, the more solutions we try, and the smarter we fail, the more knowledge we bring to the next iteration. Instead of looking back at problems, Agile schools look forward to solving them” (Briggs, 2014). 


\section{Agile Iterations}

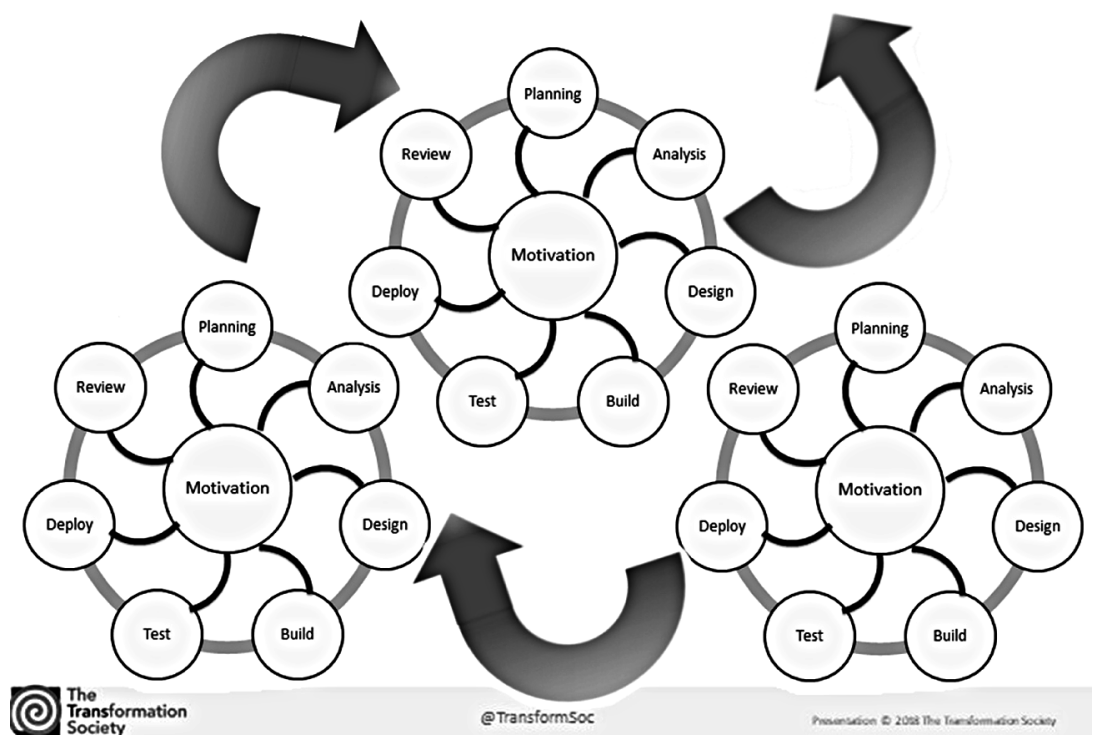

Figure 1. Iterations in agile learning

Source: The authors/Transformation Society

Agile development has twelve principles, and instructional coach Steve Peha, while working on a Gates Foundation project, elaborated a version of the twelve principles as characteristics of agile schools (ibid.):

1. Their highest priority is to satisfy the needs of students and their families through early and continuous delivery of meaningful learning.

2. They welcome changing requirements, even late in a learning cycle, and harness change for the benefit of students and their families.

3. They deliver meaningful learning frequently, from a couple of days to a couple of weeks, with a preference to the shorter timescale.

4. School and family team members work together daily to create learning opportunities for all participants.

5. They build projects around motivated individuals, give them the environment and support they need, and trust them to get the job done.

6. They recognize that the most efficient and effective method of conveying information to and within a team is face-to-face conversation.

7. Meaningful learning is their primary measure of progress. 
8. Their processes promote sustainability. Educators, students, and families should be able to maintain a constant pace indefinitely.

9. They believe that continuous attention to technical excellence and good design enhances adaptability.

10. Simplicity - the art of maximizing the amount of work done - is essential.

11. The best ideas and initiatives emerge from self-organizing teams.

12. At regular intervals, teams reflect on how to become more effective, then tune and adjust their behaviour accordingly.

According to Steve Newhall, of Korn Ferry Consultants, the objective should be to achieve these five characteristics of agile learning (IEDP Developing Leaders, 2014):

Mental Agility - how comfortable are they [learners] in dealing with complexity?

People Agility - are they skilled communicators who can work with diverse people?

Change Agility - do they like to experiment? Are they not afraid to be at the forefront of change?

Results Agility - can they deliver results in first-time situations?

Self-Awareness - do they recognise their own strengths and weaknesses?

Agile education is still in early stages of development. In part, it is a response to problems that all modern societies are having as their schools evolve and change, pushed by emerging technologies (Lorenzo and Gallon, 2018b). The initial conceptual framework for such change was built on the idea that changing the tool would change education. Very quickly, however, it became obvious that having the most advanced computers in the classroom will not change how teachers relate to students if there is not, at the same time, training to help teachers change their approach to knowledge, power, and assessment.

To pass from a traditional teaching approach, usually based on linear sequences and evolutionary methodologies, to an agile mindset defined by holistic and systemic approaches where simultaneous, iterative tasks are necessary to develop a project, is a huge challenge for schools and educational systems. 


\section{A new pedagogy with an agile mindset}

For centuries, the instructional sequence at school has been presentation-practice-production. The teacher did the presentation, the students practiced and produced evaluable results. After this sequence, the teacher could assess the results and reorient the students' learning processes through repetition and drill. More elaborated versions of this also took into account the progressive development of students' capabilities, and proposed inverting the order of the sequence, giving the student a more active role. The new sequence became practice-presentation-product. In this case, presentation is not done by the teacher, but through common sharing and consolidating what the students have been practicing. This is more motivating and responds to a more natural learning process. Today, where the process and product are both considered results in education, with equal importance, a more holistic mindset requires sequences to be more diverse, flexible, and creative. We can start with a rule or a question, with debate, with a challenge or problem, or just with an intuition or a wish. A natural follow-on to this is that linear processes are reaching the limits of their effectiveness, and that classroom learning needs to adapt to the multi-focus, networked world that has developed around us. Neuroscience is now providing the scientific basis for these holistic approaches rooted in social constructionism (Lorenzo and Gallon, 2018a), connectivism (Siemens, 2004), and collaborative knowledge building (Scardamalia and Bereiter, 2003). All of these are well adapted to the agile mindset in hyper-connected environments.

As early as 1945, Dr. Vannevar Bush, director of the U.S. Office of Scientific Research and Development, wrote:

When data of any sort are placed in storage, they are filed alphabetically or numerically, and information is found (when it is) by tracing it down from subclass to subclass. It can be in only one place, unless duplicates are used; one has to have rules as to which path will locate it, and the rules are cumbersome. Having found one item, moreover, one has to emerge from the system and re-enter on a new path.

The human mind does not work that way. It operates by association. With one item in its grasp, it snaps instantly to the next that is suggested by the association of thoughts, in accordance with some intricate web of trails carried by the cells of the brain. It has other characteristics, of course; trails that are not frequently followed are prone to fade, items are not fully permanent, memory is transitory. Yet the speed of action, the intricacy of trails, the detail of mental pictures, is awe-inspiring beyond all else in nature (Bush, 1945). 
Dr. Bush's article is widely credited with being the first representation of what we now call hypertext, the ability to link directly from one source to another, inside a single computer or across the world via the Internet. This notion of associative thinking correlates research done by Roger C. Schank (1995) on learning by doing. According to Schank (1995), we integrate "scenes" - small activities we learn as we execute them - into the situation where we learned it, and can then generalize it to other situations. For example, we learn how to use the index of a textbook while in class at school, and we integrate it into a situation or, as Schank calls it, a "Memory Oganisation Packet (MOP)" that we identify as "school-task." We can then generalize that learning into a different MOP, for instance exploring a list of links online, that forms a MOP we identify as "online research.” This generalization process is associative in the sense that Vannevar Bush meant in his article, and it creates learning development in what Vigotsky called the Zone of Proximal Development (Vigotsky, 1934, p. 208).

Vigotsky and Schank provide the learning theories that underpin a new agile educational mindset. To apply these theories practically in an agile classroom, some additional important pedagogical issues need to be considered:

- Educational and social aim: inclusion, consciousness raising

- Communicative concept: holistic interaction in the digital age

- Psycho-educational theory: connectivism, social constructionism

- Teachers' roles: facilitator, creator of opportunities

- Students' roles: protagonist of autonomous growth experiences

- Skills and competences: International frameworks for micro/macro skills for intrapersonal, interpersonal, and proactive development

- Methodologies: contextualised personalisation in hybrid environments (human-machine interaction)

- Space, time, and additional resources: meaningful tools, material resources, and organisational strategies, needed to apply a specific methodology

- Assessment criteria: principles for establishing multi-level indicators of success

- Dynamics of change: expectations for cognitive, social, and cultural transformation 


\section{Student-centred aims}

The progression from tool-centred strategies towards a more interactive approach where teacher implication and student agency are seen as elements of a modernizing process, has brought a lot of techniques and strategies to the table during recent years. WebQuests (Dodge, 2001), flipped classrooms (Bennett et al., 2013), or design thinking (Buchanan, 1992) were seen as recipes for forcing the teacher to change roles, and for the student to become an active learner and protagonist in the process. We are starting to see now, that although necessary, strategies and techniques are not enough if they are not sustained and driven by a clear set of principles and values that respect students' needs, individually and as a group, as well as families' demands and concerns, social requirements, and participatory ethics. It is with this frame of mind that agile can become a highly advanced vehicle for introducing the idea that curriculum is not just a list of contents, or a collection of procedures, but a whole paradigm of proposals for applying healthy techniques, sustainable methodologies, and ethical values in assessment. Collaborative participation in networks that autonomously organise iterations of exploration and self-evaluation provide a collective platform for modelling, experiencing, and validating teaching and learning processes. In this type of agile network, we can reframe Peha's (2011) twelve characteristics of agile schools as twelve student-centred agile principles:

1. Students can receive attention according to their personal learning rhythms, their learning styles, and their families' requirements, with respect for the diversity of cultures around them.

2. Students benefit from flexible itineraries and fluid curricula so they are able to respond confidently to change and unexpected situations in the future.

3. Students will perform activities, tasks, and projects of different durations in different time scales, to achieve a globally continuous learning process.

4. Students will participate in decision-making processes together with families, teachers, and educators, to develop self-agency.

5. Students will participate autonomously in exploring different educational situations inside and outside school in order to develop awareness and respond to the trust and resources they are given. 
6. Students will develop communication skills for interacting with others - both classmates and digital collaborators, with an emphasis on faceto-face interaction.

7. Students will use meaningful learning as the measure of their own process, through techniques such as project-based learning, problem solving, etc.

8. Students will practice self-engagement and continuously develop sustainable lifelong learning processes.

9. Students will emphasize self-imposed high standards and critical thinking and will creatively analyse continuous possibilities for rigorous improvement of technical quality.

10. Students understand the importance of efficiency through personal and collective engagement to find simple, sustainable solutions.

11. Students will participate in teams and groups that self-organise to implement creative responses and innovative solutions.

12. Students will develop inquiring minds by participating in regular collaborative self-evaluation sessions in order to propose improvement.

These agile principles are intended to contribute to an educational system where the student is at the centre and is the main protagonist of the entire learning process. Applying them can open new ways of understanding the teaching process itself.

Teachers need to abandon the traditional self-centred protagonist role in the classroom and start taking up the facilitating and guiding personas that give them authority through knowledge, planning, management, and evaluation of the whole process. The traditional instructional sequence can be replaced with any approach that affects the four main stages of children's learning processes:

Emotion - cognitive science has shown that the detonator of mental reaction is a biochemical process that occurs when a somatic stimulus alters brain chemistry to create an alert to interact - internally or externally - with the unknown (Arnone, Small and McKenna, 2011). The emotional response helps fix learning in memory.

Curiosity - natural curiosity can be quite disorganised or it can be rigorous and meticulous. Teachers can guide students through the first understanding of hypothesis and methodology, to help students see all the variables and acquire strategies for different disciplines. 
Research - a planned process that creates the complete arc from problem to solution. It implies planning, provision for individual and collective action, production, and assessment of the results. It requires communication of the process, embedded in formal learning and applicable to nearly every discipline. The great danger is to get trapped in silos. This can be avoided by facilitating iterative collaboration among students. Proactive innovation - this is the rising above stage. It is marked by a transcendent understanding, and must include all the previous stages. This is where the student integrates knowledge and experience, and consolidates competencies that allow her or him to generate innovation.

\section{Why is agility important?}

Our globalised society is constantly pushing out goals that can often be confusing and contradictory. We speak of growth and sustainability together, ask our technologists to make our machines autonomous and independent, but fear how they might affect our privacy, or even our safety. As educators, we are charged with preparing children to live in a world populated by these pressures and technologies, and with helping people of all ages to integrate and adjust to exponential change. An agile mind that has values oriented towards the common good is an essential part of that preparation.

Figure 2 shows an agile relationship between goals and strengths, with recursive iterations that build learning processes through emotion, curiosity, research and proactive innovation. Each iteration of an agile learning process advances students closer to their goals, and builds their strengths, helping them to understand the common good by enlarging their initial vision into real action, and from there to deep transformation. The idea of considering learning as a personal transformative process is an inclusive conceptualization that recognizes individual achievements and collective evolution. International institutions such as the OECD, the European Union or the United Nations have all produced educational frameworks based on different stages of skills development and knowledge acquisition.

Dr. Mmantsetsa Marope and her group at the UNESCO Global Curriculum Network have provided a framework for curricula transformation in technological environments, that can also be useful for developing agile strategies in school and in lifelong learning. Her report stresses that individual performance cannot be fully mature unless it is also integrated into social development and oriented towards the common good. Agile schools 


\section{Recursive Helicoid for Agile Learning}

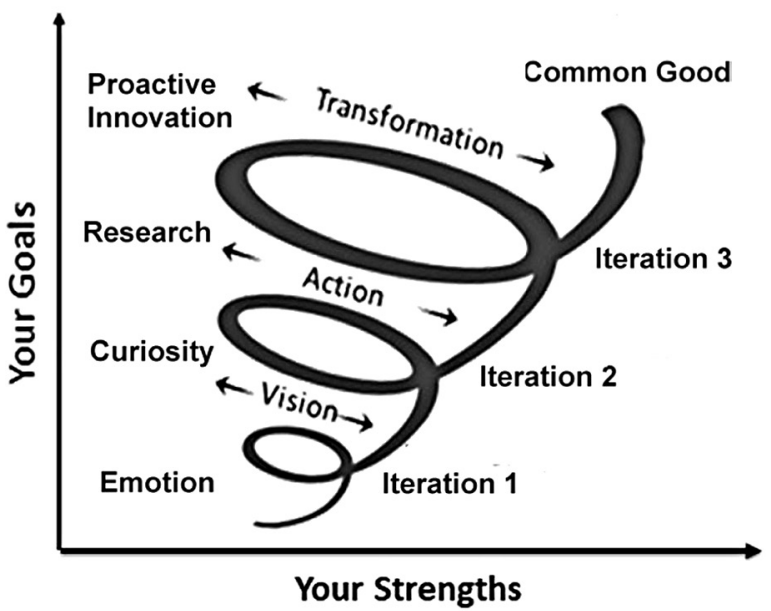

Figure 2. With each iteration in the agile process students advance in goals and strengths

Source: The authors/Transformation Society

can provide opportunities for students to explore how accelerating change affects the lives of individuals and communities at different levels. The UNESCO report (Marope et al., 2018) proposes that to engage and promote well-being, students need a minimum of:

- $\quad$ Awareness, Adaptability, Agility to Adapt

- Innovation Empowerment, Social Justice

- Productivity Sustainability, Efficiency

- Justice, Democracy, Good Governance

- $\quad$ Social Cohesion, Equity and Inclusion, Citizenship

- $\quad$ Domain Specialisation, Human Resources, Human Capital

- $\quad$ Functional Literacy, Digital Society, Health and Well-Being

Principles and values are essential to build knowledge and develop ethical and sustainable practices. 


\section{Conclusion}

Agile in education is an opportunity to escape from rigid procedures and content silos, and to enter a dynamic mindset where transformation and improvement are the goals. Agile cannot be another fashionable recipe. It is a bridge between technique, strategy, and values, and it must be seen as an opening for teachers to reflect, debate, and rethink not only procedures, but the purpose of education. Only with debate and reflection can we find opportunities to put it into practice, do case studies, and discover evidence for agile possibilities in education. Open-minded research will provide a space for experimentation and learning, leading to an agile expert community of practice.

\section{References}

Agile Alliance (2001). The Agile Manifesto. Retrieved August 28, 2018 from https:// www.agilealliance.org/agile101/the-agile-manifesto/.

Arnone, M., Small, R.V. and McKenna, P. (2011). Curiosity, Interest and Engagement in Technology-Pervasive Learning Environments: A New Research Agenda. Retrieved August 28, 2018 from https://www.semanticscholar.org/paper/Curiosity-\%2C-interest-and-engagement-in-learning-\%3A-a-Arnone-Small/dbde9556743dee5f50f3e7e42fb4cf3dee7d0559.

Bennett, B.E., Spencer, D., Bergman, J., Cockrum, T., Musallam, R., Sams, A., Fisch, K., and Overmeyer, J. (2013). The Flipped Class Manifest. Retrieved August 28, 2018 from http://www.thedailyriff.com/articles/the-flipped-classmanifest-823.php.

Bouzol-Boitman, B., Thévenon, O., Adema, W., and Clarke, C. (2016). Be Flexible! Background Brief on How Workplace Flexibility Can Help European Employees to Balance Work and Family, OECD Directorate for Labour, Employment, and Social Affairs, Social Policy Division. Retrieved August 28, 2018 from https:// www.oecd.org/els/family/Be-Flexible-Backgrounder-Workplace-Flexibility. pdf.

Briggs, S. (2014). Agile Based Learning: What Is It and How Can It Change Education? Sydney: informED. Retrieved August 28, 2018 from https://www.opencolleges.edu.au/informed/features/agile-based-learning-what-is-it-and-how-canit-change-education/.

Buchanan, R. (1992). Wicked Problems in Design Thinking. Design Issues, 8 (2), $5-21$.

Bush, V. (1945). As We May Think. The Atlantic Monthly, Boston, USA, July, 1945 pp. 101-108. Retrieved August 28, 2018 from https://www.theatlantic.com/magazine/archive/1945/07/as-we-may-think/303881/.

Dodge, B. (2001). FOCUS: Five rules for writing a great WebQuest. Learning and Leading with Technology, 28 (8), 6-9, 58. Retrieved April 6, 2018 from http:// webquest.org/sdsu/focus/focus.pdf. 
Gaulden, J., and Gottlieb, A. (2017). The Age of Agility, Education Pathways for the Future of Work. Denver: America Succeeds. Retrieved August 28, 2018 from http://ageofagility.org/wp-content/uploads/2018/05/Age-of-Agility-Report.pdf.

IEDP Developing Leaders. (2014). Why 'Learning Agility' Is Key to Leadership Success. Online editorial, 20 August 2014. Retrieved August 28, 2018 from https:// www.iedp.com/articles/why-learning-agility-is-key-to-leadership-success/.

Josefowicz, M., Gallon, R., and Lorenzo, N. (2017). Transmedia and Transliteracy in Nemetical Analysis. In: M. Khosrow-Pour (Ed.), Encyclopaedia of Information Science and Technology, Fourth Edition. Hershey, PA: IGI Global.

Lorenzo, L., and Gallon, R. (2018). Inclusive Policies for Humanist Digital Transformation. Presentation slides, WFATE Biennial Conference, Melbourne, Australia. Retrieved August 28, 2018 from https://www.slideshare.net/TransformationSociety/inclusive-policies-for-humanist-digital-transformation.

Lorenzo, L., and Gallon, R. (2018a). A Social Constructionist Model for Human-Machine Ecosystems. In: L. Daniela and M. Lytras (Ed.), Learning Strategies and Constructionism in Modern Education Settings (pp. 25-49). Hershey, PA: IGI Global.

Lorenzo, L. and Gallon, R. (2018b). Smart Pedagogy for Smart Learning. In: L. Daniela (Ed.), Didactics of Smart Pedagogy-Smart Pedagogy for Technology Enhanced Learning. Berlin: Springer.

Marope, M., Griffin, P., and Gallagher, C. (2018). Future Competences and the Future of Curriculum - A Global Reference for Curricula Transformation. International Bureau of Education - UNESCO. Retrieved March 17, 2018 from https://www. google.com/search?client=safari\&rls=en\&q=international+bureau+of+education\&ie=UTF-8\&oe=UTF-8.

Peha, S. (2011). Agile Schools: How Technology Saves Education (Just Not the Way We Thought it Would). InfoQ. Web magazine. Retrieved August 28, 2018 from https://www.infoq.com/articles/agile-schools-education.

Scardamalia, M., and Bereiter, C. (2003). Knowledge Building. In: J.W. Guthrie (Ed.), Encyclopedia of Education (2 ${ }^{\text {nd }}$ ed.). New York: Macmillan Reference. Retrieved February 15, 2014 from http://ikit. org/fulltext/2006_KBTheory.pdf.

Schank, R.C. (1995). What We Learn When We Learn by Doing. Research Paper. Institute for the Learning Sciences, Northwestern University, Technical Report No. 60. Retrieved June 26, 2017 from http://cogprints.org/637/1/LearnbyDoing_Schank.html.

Siemens, G. (2004). Connectivism: A Learning Theory for the Digital Age. Elearnspace: everything elearning. Retrieved August 28, 2018 from http://www.elearnspace. org/Articles/connectivism.htm.

United Nations. (2015). Transforming Our World: The 2030 Agenda for Sustainable Development. Resolution of the United Nations, A/Res/70/1. Retrieved April 11, 2018 from https://sustainabledevelopment.un.org/content/documents/21252030\%20Agenda\%20for\%20Sustainable\%20Development\%20web. pdf.

Vigotsky, L.S. (1934). Thinking and Speech. In: Blunden, A. (curator), Lev Vigotsky Archive. Retrieved August 28, 2018 from https://www.marxists.org/archive/ vygotsky/works/words/Thinking-and-Speech.pdf. 


\title{
Chapter 7
}

\section{No Teacher without a Student... A Theoretical Analysis and Practical Implications of Educational Changes in the Era of Digital Natives}

\begin{abstract}
Katarzyna Skok
University of Bialystok, Faculty of Pedagogy and Psychology, Bialystok, Poland

ABSTRACT: The aim of this paper is a theoretical analysis of the shift from the traditional classroom experience to student-oriented, technology-rich and novelty-driven teaching. The paper discusses digital natives' learning process in the light of Kahneman's two styles of thinking: the fast, intuitive, automatic System 1 and the slower, analytic System 2. In addition, an analogy between institutional education and games is introduced. In both cases, applications of novel approaches and method-forced engagement may lead to externally motivated pursuit of obligatory, yet irrelevant goals. This thesis is supported by theories and examples coming from the subject literature. The paper ends with some conclusions for students' learning. First, it is important to support students' intrinsic motivation by promoting autonomy, competence and relatedness (self-determination theory) as early as possible (and then throughout the whole educational process). Second, learning may be unpleasant, but should be effective.

KEYWORDS: innovative education, digital natives, System 1, gamification, self-determination theory
\end{abstract}

\section{Introduction}

The shift from traditional classroom experience to innovative technology and novelty-based teaching is a fact. In many cases it relates to already existing changes, which can indicate an ideal model which many teachers aspire to reach. It is argued that since the new generation of students

CONTACT Katarzyna Skok, EMAIL: kskok488@gmail.com 
differs from the earlier ones, the previously offered methods are no longer appropriate (Prensky, 2016, pp. 1-2). Technically savvy adolescents not only are now more competent in new media environment, but they also possess unique needs and traits (Prensky, 2001b; Tapscott, 1999). Prensky (2016) proposes much more than a mere paradigm shift in instruction, he advocates a profound change in curriculum. The focus switches from 'how to teach and learn' to 'what to teach and learn'.

This paper brings together the theoretical background of cognitive and behavioural science related to thinking and decision making, sociological and psychological observations on digital natives, and conclusions stemming from empirical studies. The aim of the chapter is a critical approach to a broadly understood innovative education and an answer to Prensky's (2001a) question 'Should the digital native students learn the old ways, or should their digital immigrant educators learn the new?'

\section{System 1 and System 2}

Kahneman (2011, p. 20-21) described the dichotomy between two systems of thinking :

System 1 operates automatically and quickly, with little or no effort and no sense of voluntary control. System 2 allocates attention to the effortful mental activities that demand it, including complex computations. The operations of System 2 are often associated with the subjective experience of agency, choice, and concentration.

System 1 includes such activities as detecting hostility in the voice, completing the phrase 'bread and ...' or driving a car on an empty road. System 2, on the other hand, relates to more complex thinking: searching memory to identify a surprising sound, comparing two washing machines for overall value or checking the validity of a complex logical argument.

The above systems are complementary. When System 1 has a problem, System 2 uses deeper analysis to solve it. Emotional and superficial System 1 generates impressions and intuitions, and deliberate System 2 turns them into beliefs and voluntary actions usually with no or little modification. Kahneman shows that humans are not purely rational

1 The dichotomy dates back to works of William James and underlies different concepts within social, personality and cognitive psychology; in psychology of memory depicted as a difference between implicit and explicit memory. 
'Econs', ${ }^{2}$ and their decisions are often based on heuristics and biases (e.g. anchoring or loss aversion).

The above dichotomy also contributed to research on personality and individual differences. While System 2 performs better than System 1 in abstract thinking, comprehending cause-and-effect relations, delaying gratification, and planning for the future, the opposite is valid for the effortless direction of everyday behaviour. It was found that an experiential learning system (System 1), but not a rational learning system (System 2) was associated with some desirable attributes, such as creativity, sense of humour, aesthetic judgement, intuition, as well as self-reported measures of empathy and social popularity (Norris and Epstein, 2011). There is evidence that intuitive, unconscious thinking may underlie some aspects of intelligence (Kaufman, 2011). Also, engaging in simple external tasks that allow the mind to wander (which diminishes System 2 attention resources) may facilitate creative problem solving (Baird et. al, 2012).

\section{Digital natives}

The term digital natives (along with the term digital immigrants) was popularised by Prensky (2001a, 2001b). It denotes individuals born during the digital era (after 1980) who have grown up immersed in digital technologies. This generation is regarded as unique since these people do not know a world without computers, Internet and mobile phones. Digital immigrants, on the other hand, had to acquire new era skills and style of perceiving things, which has always been natural for digital natives. According to Prensky's view, the change between generations is deeper than the one directly related to media use. Digital natives have 'hypertext minds', they do not think sequentially but parallelly. They are attached to cell phones or other devices, simultaneously download music, play video games and use social media (Prensky, 2001a, 2001b). They are proficient in multitasking and multiprocessing, depend on communications technologies for connecting with others and accessing information (Bennett, Maton, and Kervin, 2008), expect immediate gratification, and are interactive (Oblinger and Oblinger, 2005).

Because the Internet has changed since Prensky popularised his dichotomy, new terms for depicting these changes have emerged, such as

2 The distinction between Humans and Econs was introduced by Richard Thaler (Kahneman, 2011, p. 273). The term Econ describes fully rational, consistent and logical aspect of human decision making. 
the Google Generation or i-Generation, both also called second generation digital natives - people born after 1993 (Joiner et al., 2013). Unlike the first generation, they have grown up with Web 2.0 technology, where content is generated by users (YouTube, social networking sites, blogs). The shift includes preference for audiovisual processing over the traditional textual one and higher interactivity (Grigoryan, 2018).

It is necessary to add that the above observations have met substantial criticism, mostly due to the lack of sufficient empirical evidence on the proposed distinctiveness of the categories of people and their skills or abilities (Bayne and Ross, 2007; Bennett, Maton, and Kervin, 2008). It was noted that the suggested implications for education bear the hallmarks of 'moral panic'. Nonetheless, since the concept of between-generation changes has been generally accepted in the academic discussion, the further part of this paper assumes it as a framework.

\section{Digital natives and education}

Digital natives' unique educational skills, abilities and preferences stem directly from their generational traits. These are the following (Bennett, Maton, and Kervin, 2008; Oblinger and Oblinger, 2005; Prensky, 2001b; Smith, 2012; Tapscott, 1999):

- $\quad$ need for individual-based learning: customization of learning process; learning at one's own pace; enabling different ways of acquiring knowledge

- $\quad$ multiprocessing and multitasking: desire to be busy, ability to focus attention on different activities (e.g. playing an online game and doing homework together with schoolmates via social network)

- $\quad$ high-speed learning: preference for short portions of learning material; difficulty with focusing attention on longer and more effortful tasks

- $\quad$ multimedia orientation: preference for graphics over text

- device orientation: preference for using electronic devices (cell phones, tablets) over books; preference for electronic communication

- collaboration and peer learning: in class and at home via social network

- $\quad$ need for instant gratification and immediate feedback: desire to feel one is making progress; need for fast, safe correction; anxiety upon reflection one might have gone the wrong way 
- $\quad$ interactivity (see: need for instant gratification and immediate feedback above): interest in virtual, multi-linear, audiovisual environments, such as interactive games, serious games, simulators, gamification

- $\quad$ learning via action rather than passively; preference for experiential or discovery-based learning over traditional acquiring knowledge

- playfulness: need for entertainment and emotional engagement.

As mentioned in the previous section, the uniqueness of the digital natives' abilities and skills has been questioned in academic discourse (Bayne and Ross, 2007; Bennett, Maton, and Kervin, 2008). The proposed educational shift is based on the new generation's expectations and demands rather than the necessity of adapting to the new changing world. In fact, revolution in education might bring more harm than profit. This thesis is supported by the observations below.

\section{Multiprocessing and multitasking}

While a genuine ability to multitask can undoubtedly be an advantage, it is necessary to ask whether it is always beneficial and worth reinforcing. In more complex circumstances, multitasking can result in cognitive overload. For example, in a situation of a distracting memory task (increased attention load), a reasoning was correct when it did not conflict with the believability of a conclusion. However, in case of the conflict, individuals made mistakes (De Neys, 2006). Loss of concentration and errors may happen because the brain shifts between competing stimuli (Rubinstein, Meyer, and Evans, 2001). This supports the thesis that depleted attention resources may undermine deeper cognitive processing. Multitasking may be good for low-focus tasks or ones strictly related to common knowledge and stereotypes (Kahneman's System 1). As Kahneman states (2011, p. 23): “The often-used phrase 'pay attention' is apt: you dispose of a limited budget of attention that you can allocate to activities, and if you try to go beyond your budget, you will fail.” There is no empirical evidence that digital natives have better attention and working memory than the previous generations. Reinforcing multiprocessing and multitasking in education may lead to shallowness of knowledge.

\section{Interactivity, learning via action, playfulness, multimedia and device orientation}

Humans are interactive and relational by nature. They prefer interaction because it is more engaging and enjoyable than solitary action, which is 
devoid of feedback when dealing with life's events and circumstances. So stating that digital natives are more interactive than past generations is an exaggeration. Contemporary adolescents just live in a more interactive environment and have more interactive tools at their disposal. The question remains, whether current education technology can find correct solutions to suit the current needs. Empirical studies on the use of gamification in education concentrate mostly on students' engagement and increased motivation, finding learning outcomes mostly positive (Hamari, Koivisto, and Sarsa, 2014; Ortiz, Chiluiza, and Valcke, 2016). Academic performance is measured rarely, yet is giving positive results (Ortiz, Chiluiza, and Valcke, 2016; Sousa-Vieira et al., 2015). It is worth noting that the positive results relate mostly to the science, technology, engineering and mathematics fields. Non-gamification studies include positive findings of the use of simple, gambling-based games in teaching mathematics (Howard-Jones and Demetriou, 2008) or iPad implementation as a language learning tool (Grigoryan, 2018). On the other hand, it was noticed that attention must be paid to possible negative outcomes, e.g. increased competition (Hakulinen, Auvinen, and Korhonen, 2013). Another problem is a risk of distraction by external rewards and the 'overjustification' effect (Lepper et al., 1973), more widely discussed in the next sections. Similarly, using electronic devices for educational use may be less enjoyable than at home. For example, according to Downes' study (2002), primary school children felt that they had less sense of control over their computing activity at school than at home. One could also ask a more general question: do we need just skills or is knowledge an essential part of education? Performing routine tasks may require only mastered skills and some intuition, but what about a situation when something unusual happens or a successful performance depends on deeper understanding of the problem?

\section{Need for instant gratification}

The need for instant gratification seems rather disadvantageous than beneficial. Some research showed that students were frustrated when not instantly gratified in their search for immediate answers (Bennett, Maton, and Kervin, 2008). The easiness of using search engines and finding 'cutand-paste' answers (Vie, 2008) makes more effortful work discouraging and unreflexive copying of materials available online (often without even reading it) becomes a standard (Skok and Laszewicz, 2014). This paints the picture of digital natives' interactions with text as shallow, random and 
often passive (Bennett, Maton, and Kervin, 2008). Students are not critical and have no analytical skills to assess the information that they find on the web (Rowlands et al., 2008).

It was noticed that an innovative approach does not necessarily support performance. Students - given high autonomy of expression - lacked basic academic skills. Three Facebook-mediated studies in the area of humanities showed a low level of study skills. Students had problems with synthesising and managing information, poor management of time and their learning was superficial (Ramble, 2012). Communication within Facebook preferred empty, phatic connection over high-content, meaningful communication (Boon and Sinclair, 2009). Also, low engagement, superficiality of postings and a 'cut-and-paste' attitude were observed (Skok and Laszewicz, 2014).

Innovative education as proposed by Prensky (2001a, 2001b) and Tapscott (1999) may result in some future problems. The proposition itself seems appealing as it aims at producing skilled workers for job markets, conscious residents of the new socio-digital world. Yet it brings concerns about shallowness and the lack of deeper reflection. The new conformist citizen might base his/her opinions on what he/she reads and sees on YouTube or Facebook (and the information would come mostly from a narrow segment of followed users). Still there is no clear evidence on how digital natives' tailored programmes impact two different areas of education: sciences and humanities. Skills required in the field of science and humanities are substantially different.

Some important questions remain: what do students need? Do they just need enjoyment? Is effortful dull work acceptable for them? Partial answers to these questions were given by Skok and Harasimczuk (2018). According to this gamification study, students' attitudes were pragmatic and inclined towards elements leading to receiving better grades (extra points and tasks) and improving learning organization (fast feedback, cooperation). On the other hand, features potentially threatening the self-esteem (competition, communicators ${ }^{3}$ ) were ranked low. So the above questions can be summed up in one: what is more important, fun or achievement? In other words: should the learning process be pleasant and painless or rather effective? To answer this question a game analogy is introduced.

Potential risk of surveillance by a teacher. 


\section{Game analogy}

Playing games should be fun. Players engage in a game to feel excitement and immersion. Yet fun is not always their most important motivator. Skok's (2013) study shows that in MMORPGs (massive multiplayer online role playing games) pragmatic goals can take away all the initial enthusiasm. Players' attitudes evolve from conscious fun to the 'production' of game achievements, which is automated, dominated by a goal and lacks player's involvement. They can agree to events and actions unacceptable in other situations. They can perform boring repeatable tasks day by day or hour by hour to receive a desired gratification. 'Grind' is a common description of such activities. They voluntarily assume dull daily duties which they are happy to finish to relax after the game. It is not rare to spot game 'job appointments' with fixed working hours, requirements and benefits. Paradoxical behaviours also include resignation from winning (extremely passive and humiliating activity leading to consolation rewards), in-game suicide (killing oneself over and over again) and absence from the game (using 'bots'). In such cases playing is not considered fun but rather a means to fun. One has to overcome difficulties to gain gratification. This can be explained by motivational shift: from intrinsic motivation (joy, excitement) to extrinsic ('grind'). Player's paradox can also describe what may happen with a student's motivation when he/she is situated in an innovative (game) learning environment. A student may either strive for the programme's extrinsic rewards (badges, points, ranks) to 'do well', or to treat them instrumentally (e.g. linking YouTube videos and pasting googled phrases without prior watching or understanding them - just to get better marks). In both cases it would bring the risk of possible exploit and neglecting the real purpose of an activity. Another problem is enforced mandatory fun (Mollick and Rothbard, 2014) when a learner genuinely interested in knowledge is confronted with some off-topic duties.

The above objections may not apply to discovery-based or experiential learning.

\section{Intrinsic and extrinsic motivation}

According to Deci and Ryan (1982, p. 1) "For young children, self-directed learning is a fact of life. They are curious, they go to things that interest them, they marvel at each new discovery, and they drive their parents crazy 
with questions." Older children, however, have considerable resistance to learning. They depend on directives from teachers or parents, on grades and gold stars, on various forms of external recognition (Deci and Ryan, 1982). Deci and Ryan (1985) proposed self-determination theory to address this problem. According to it, people (students) can have three motivational states: they can be intrinsically motivated, extrinsically motivated or amotivated. In the first case individuals are driven by curiosity, exploration and play; in the second one they strive for external goals, feel more pressure and their attention is partially focused on the desired outcome rather than on the activity itself. In the third case, people are helpless, passive and non-responsive (Deci and Ryan, 1982).

Self-determination theory proposes three factors determining motivational outcome. The first is competence that is associated with consistency. One's own behaviour can lead to predictable results or not. A competent student knows he/she can handle the work properly and understands that final success is a matter of effort. An incompetent student, on the other hand, develops a sense of failure and expects continued initiations and efforts to be fruitless. This, in turn, often leads to low self-esteem and learned helplessness (Seligman, 1972). Competence can be enhanced by fast positive feedback and a possibility to safely explore and test different solutions. The latter was called the art of failure by Juul (2013) and related directly to games. Players often fail in games, yet it does not discourage them. On the contrary, they are motivated to play more in order to escape their own inadequacy. Similarly, students who could safely fail and then restart, would not lose their competence. This observation is supported by the flow theory. An optimal experience (flow) is experienced when a person with a high skill level is confronted with a high challenge level (Csikszentmihalyi, 1997, p. 30). In a learning process it might mean feeling safe dealing with challenges. Purely negative feedback should be avoided (Deci, Cascio, and Krusell, 1973) and if necessary for correction, it should be delivered in a positive manner ('this could be improved' instead of 'you are wrong').

The second factor determining motivational outcome is autonomy. Autonomous students feel that they have choice. They self-organize experience and behaviour and their activity is concordant with their integrated sense of self (Deci and Ryan, 2000). Autonomy is undermined when individuals receive external gratifications (money, tangible rewards, badges, marks) because they experience their actions to be regulated by external 
control. Of high importance is the way the feedback is communicated. It can have a controlling or an informational aspect. The function of the controlling aspect is to generate a particular behavioural outcome that is desired by the communicator. On the other hand, the informational aspect is to provide the person with adequate information about his or her performance (Deci and Ryan, 1982). If good marks are perceived as a final goal of learning, a learner loses intrinsic motivation. The above-mentioned overjustification effect (Lepper et al., 1973) explains how intrinsically driven behaviour can develop into extrinsically motivated after being gratified externally. For example, children reading books for fun may lose the fun, if their reading becomes controlled by marks. Similarly, students interested in particular fields of study and forced to take part in some innovative learning programme, may give up their private activity and concentrate on external gratifications.

The third factor contributing to self-determination is relatedness: the need to interact with, be connected to, and experience caring for other people (Baumeister and Leary, 1995). It was observed that when children were performing an interesting activity in the presence of an adult stranger who ignored them, their intrinsic motivation decreased. The same shift can be observed when students are taught by a cold and uncaring teacher (Ryan and Deci, 2000). ${ }^{4}$

Although self-determination theory had been constructed long before digital natives discourse emerged, its suggestions are crucial for today's education and strikingly similar to some propositions made by advocates of the new teaching and learning paradigm. These fundamental rules are the following (Deci and Ryan, 1982):

- $\quad$ freedom within limits and possibility of choice: children should be allowed to solve their own problems, learning structures should provide guidance and allow children to assess their own competence;

- $\quad$ teachers as facilitators of learning (as early as possible);

- $\quad$ as little standardization as possible (including teaching and learning methods);

- $\quad$ less emphasis on teachers' evaluation; too many requirements might deplete their energy and intrinsic motivation;

- $\quad$ active learning (e.g. learning some material in order to teach it to others);

4 Self-determination theory evolved into organismic integration theory (Deci and Gagné, 2000) where decisive factors became the sense of control and autonomy (Ryan and Connell, 1989). 
- $\quad$ team work: opportunity to work together in a supportive environment;

- $\quad$ avoiding direct negative feedback that would harm self-esteem; learning structures should facilitate the possibility of success (avoiding learned helplessness training); negative feedback as an information about a challenge;

- $\quad$ informational feedback instead of controlling feedback; students who received the feedback 'you did really well' were more task engaged afterwards than students who heard 'you did really well, I'll be able to use your data' (Pittman at al., 1980, p. 230).

It should be noted that negative feedback is sometimes necessary. This paradox stems from the nature of self-determined behaviour. Controlling students to let them reach for success may bring detrimental results. Children allowed to fail are more likely to succeed. On the other hand, when 'forced' to succeed, they will either be compliant and not able to take responsibility for their success, or they may reactively fail in order to retain their freedom (Deci and Ryan, 1982).

\section{Conclusions}

The new abilities and skills of digital natives seem a little exaggerated. They do possess higher fluency with new technology devices and they are not only consumers of web resources but they also create them. Never before have so many people of different walks of life had the possibility to find information on practically any subject. Nonetheless, finding a correct path in this jungle might be a real test for their information literacy. When a library is put aside, the Google Generation may seek fast answers on Wikipedia or anywhere the search engine directs them, ask others on Facebook or in a chat room. Digital natives seem to despise effort because it often proves to be less effective. And despite all the generational advantages, employers report that their employees' basic skill levels, critical thinking ability, and initiative are developmentally lacking (Dziuban, Moskal, and Hartman, 2005). A conclusion that comes to mind is that digital natives overuse System 1 and neglect System's 2 critical power. As Prensky (2001b, pp. 3-5) puts it:

it's as though their cognitive structures were parallel, not sequential [...], their brains are almost certainly physiologically different [...], their attention spans are not short for games, for example, or for anything else that 
actually interests them [...]. Further, 'digital natives' accustomed to the twitch-speed, multitasking, random-access, graphics-first, active, connected, fun, fantasy, quick-payoff world of their video games, MTV, and Internet are bored by most of today's education.

One can ask what the perspectives of the current education system are. To rephrase Prensky's (2001a) question: Should education preserve the oldschool values, or should the new era teachers adapt to the new students?

If the above-mentioned assumption is correct, the modern school has to oppose novelty and reinforce the standard old-school requirements, yet using some technological adjustments. The new technology enables teamwork, interactivity and safe feedback to a degree that has not been known before. The game analogy above shows that people are able to put much effort into their actions as long as they see it is meaningful. And pleasure and easiness are not necessarily top motivators.

Current students may come with two learning attitudes. They can be intrinsically or extrinsically motivated - inclined toward knowledge and motivated by curiosity, or external goal oriented - desiring acclaim, better performance and better marks. These two attitudes should be approached in two ways.

When the motivation is intrinsic:

- $\quad$ teaching and reinforcing autonomy (different ways of finding solutions, different ways of reaching a goal)

- method-forced engagement and enjoyment may lead to externally motivated pursuit of obligatory, yet irrelevant goals

- $\quad$ safe learning environment (the art of failure)

- $\quad$ main rule: facilitate and do not hinder.

When the motivation is not intrinsic:

- $\quad$ emphasis on the use of effortful analytic System 2

- $\quad$ fast feedback and the art of failure; enabling challenges

- $\quad$ no pain, no gain; pain rewarded even if not leading to gain

- $\quad$ reinforcing multitask, fast-paced, technology-rich learning may lead to superficiality of learning results

- $\quad$ demonstrating responsibility for one’s life (increasing autonomy)

- $\quad$ as much choice as possible (while goals are fixed)

- $\quad$ main rule: show that effort may be worthwhile. 
Basically, it is about the preservation or restoration of primal childlike curiosity. This can be accomplished when one's purpose of learning is not the pursuit of external gratifications. Cognitive dissonance theory supports this assumption: in case of dull, boring tasks (such as - for many digital natives - System's 2 effortful analyses), low reward and insufficient justification will help develop intrinsic interest (Festinger and Carlsmith, 1959).

\section{Final remarks}

It should be noted that the majority of studies on digital natives' educational innovations is made in the field of science. More research in the area of humanities might shed some light on the real distinctiveness of the present and past generations. Perhaps the different skills required to achieve success entail different kinds of facilitation. Also, Kahneman (2011) applies his System 1/System 2 dichotomy mainly to economics and in general to decision-making, and digital natives raise the discourse predominantly in the education field. It is worth empirical assessment, if the generational shift has its cognitive consequences. Finally, the philosophical question of the nature of education remains. Is knowledge a value per se or maybe it is just an instrument that we have at our disposal?

\section{References}

Baird, B., Smallwood, J., Mrazek, M., Kam, J., Franklin, M., and Schooler, J. (2012). Inspired by Distraction: Mind Wandering Facilitates Creative Incubation. Psychological Science, 23 (10), 1117-1122.

Baumeister, R.F., and Leary, M.R. (1995). The Need to Belong: Desire for Interpersonal Attachments as a Fundamental Human Motivation. Psychological Bulletin, 117 (3), 497-529.

Bayne, S., and Ross, J. (2007). The 'Digital Native' and 'Digital Immigrant': A Dangerous Opposition. Proceedings of the Annual Conference of the Society for Research into Higher Education (SRHE). Retrieved July 25, 2018 from http:// api.ning.com/files/lJKwMzj6sgFtDU0QqLLrpwu*Inq0*AKnRvABUa2YFPOa-vT552n0h9bYoaVStqfQX8*5D978F1M*DM*xuEznG0rxTGJO0BUL/ Wk1BayneandRossArticleDigitalNativesandDigitalImmigrants.pdf.

Bennett, S., Maton, K., and Kervin, L. (2008). The ‘Digital Natives’ Debate: A Critical Review of the Evidence. British Journal of Educational Technology, 39 (5), 775-786.

Boon, S. and Sinclair, Ch. (2009). A World I Don't Inhabit: Disquiet and Identity in Second Life and Facebook. Educational Media International, 46 (20), 99-110.

Csikszentmihalyi, M. (1997). Finding Flow: The Psychology of Engagement with Everyday Life. New York: Basic Books. 
Deci, E.L., Cascio, W.F., and Krusell, J. (1973). Sex Differences, Positive Feedback and Intrinsic Motivation. Paper presented at the Eastern Psychological Association Convention, Washington, D.C., May 1973. Retrieved July 25, 2018 from https://files.eric.ed.gov/fulltext/ED076904.pdf.

Deci, E.L., and Ryan, R.M. (1982). Curiosity and Self-Directed Learning: The Role of Motivation in Education. Retrieved January 9, 2019 from https://files.eric. ed.gov/fulltext/ED206377.pdf.

Deci, E.L., and Ryan, R.M. (1985). Intrinsic Motivation and Self-determination in Human Behavior. New York: Plenum Press.

Deci, E.L., and Ryan, R.M. (2000). The 'What' and 'Why' of Goal Pursuits: Human Needs and the Self-Determination of Behavior. Psychological Inquiry, 11 (4), 227-268.

De Neys, W. (2006). Dual Processing in Reasoning: Two Systems but One Reasoner. Psychological Science, 17 (5), 428-433.

Downes, T. (2002). Blending Play, Practice and Performance: Children's Use of Computers at Home. Journal of Educational Enquiry, 3 (2), 21-34.

Dziuban, C., Moskal, P., and Hartman, J. (2005). Higher Education, Blended Learning and the Generations: Knowledge is Power -No More. In: J. Bourne and J.C. Moore (Eds.), Elements of Quality Online Education: Engaging Communities (pp. 85-102). Needham, MA: Sloan Center for Online Education.

Festinger, L., and Carlsmith, J. (1959). Cognitive Consequences of Forced Compliance. Journal of Abnormal and Social Psychology, 58 (2), 203-210.

Grigoryan, T. (2018). Investigating digital native female learners' attitudes towards paperless language learning. Learning Technology, 26. Retrieved July 25, 2018 from https://journal.alt.ac.uk/index.php/rlt/article/view/1937/pdf.

Hakulinen, L., Auvinen, T., and Korhonen, A. (2013). Empirical Study on the Effect of Achievement Badges in TRAKLA2 Online Learning Environment. In: Proceedings of Learning and Teaching in Computing and Engineering (pp. 47-54).

Hamari, J., Koivisto, J., and Sarsa, H. (2014). Does Gamification Work? A Literature Review of Empirical Studies on Gamification. $47^{\text {th }}$ Hawaii International Conference on System Science. Retrieved July 25, 2018 from http://ieeexplore.ieee.org/ stamp/stamp.jsp?tp=andarnumber $=6758978$.

Howard-Jones, P.A., and Demetriou S. (2008). Uncertainty and Engagement with Learning Games. Instructional Science, 37 (6), 519-536.

Joiner, R., Gavin, J., Brosnan, M., Cromby, J., Gregory, H., Guiller, J., Maras, P., and Moon, A. (2013). Comparing First and Second-Generation Digital Natives' Internet Use, Internet Anxiety, and Internet Identification. Cyberpsychology, Behavior, and Social Networking, 16 (7), 549-552.

Juul, J. (2013). The Art of Failure: An Essay on the Pain of Playing Video Games. Cambridge: MIT Press.

Kahneman, D. (2011). Thinking Fast and Slow. New York: Farrar, Straus and Giroux.

Kaufman, S.B. (2011). Intelligence and the Cognitive Unconscious. In: R.J. Sternberg and S.B. Kaufman (Eds.), The Cambridge Handbook of Creativity (pp. 442-467). New York: Cambridge University Press. 
Lepper, M.R., Greene, D., and Nisbett, R.E. (1973). Undermining Children’s Intrinsic Interest with Extrinsic Rewards: A Test of the 'Overjustification’ Hypothesis. Journal of Personality and Social Psychology, 28 (1), 129-137.

Mollick, E.R., and Rothbard, N. (2014). Mandatory Fun: Consent, Gamification and the Impact of Games at Work. Retrieved July 25, 2018 from http://papers.ssrn. com/sol3/papers.cfm?abstract_id=2277103.

Norris, P., and Epstein, S. (2011). An Experiential Thinking Style: Its Facets and Relations with Objective and Subjective Criterion Measures. Journal of Personality, 79 (5), 1043-1079.

Oblinger, D., and Oblinger, J. (2005). Educating the Net Generation. Retrieved July 25, 2018 from https://www.educause.edu/ir/library/pdf/pub7101.pdf.

Ortiz, M., Chiluiza, K., and Valcke, M. (2016). Gamification in Higher Education and STEM: A Systematic Review of Literature. $8^{\text {th }}$ Annual International Conference on Education and New Learning Technologies - Edulearn16, Barcelona, Spain. Retrieved July 25, 2018 from https://www.researchgate. net/publication/305708437_GAMIFICATION_IN_HIGHER_EDUCATION_ AND_STEM_A_SYSTEMATIC_REVIEW_OF_LITERATURE

Pittman, T.S., Davey, M.E., Alafat, K.A., Wetherill, K.V., and Kramer, N.A. (1980). Informational versus Controlling Verbal Rewards. Personality and Social Psychology Bulletin, 6 (2), 228-233.

Prensky, M. (2001a). Digital Natives, Digital Immigrants. On the Horizon, 9 (5), 1-6.

Prensky, M. (2001b). Digital Natives, Digital Immigrants, Part II: Do They Really Think Differently? On the Horizon, 9 (6), 1-6.

Prensky, M. (2016). Education to Better Their World: Unleashing the Power of $21^{\text {st }}$-Century Kids. New York: Teacher College Press.

Ramble, P. (2012). Critical Discourse Analysis of Collaborative Engagement in Facebook Postings. Australasian Journal of Educational Technology, 28 (2), 295-314.

Rowlands, I., Nicholas, D., Williams, P., Huntington, P., Fieldhouse, M., Gunter, B., Withey, R., Jamali, H.R., Dobrowolski, T., and Tenopir, C. (2008). The Google Generation: The Information Behaviour of the Researcher of the Future. Aslib Proceedings, 60 (4), 290-310.

Rubinstein, J.S., Meyer, D.E., and Evans, J.E. (2001). Executive Control of Cognitive Processes in Task Switching. Journal of Experimental Psychology. Human Perception and Performance, 27 (4), 763-797.

Ryan, R.M., and Connell, J.P. (1989). Perceived Locus of Causality and Internalization: Examining Reasons for Acting in Two Domains. Journal of Personality and Social Psychology, 57 (5), 749-761.

Ryan, R.M., and Deci, E.L. (2000). Self-Determination Theory and the Facilitation of Intrinsic Motivation, Social Development, and Well-Being. American Psychologist, 55 (1), 68-78.

Seligman, M.E.P. (1972). Learned Helplessness. Annual Review of Medicine, 23 (1), 407-412.

Skok, K. (2013). Paradoks Gracza, Czyli co Motywuje Graczy do Korzystania z Gier Online. Homo Ludens, 5 (1), 233-252.

Skok, K., Harasimczuk, W. (2018). Gamifikacja Edukacji - Badanie Motywacji Studentów. Homo Ludens, 11 (1), 189-208. 
Skok, K., and Laszewicz, M. (2014). Problemy Związane z Wykorzystaniem Innowacyjnych Form Nauczania - Analiza Jakościowa Zajęć Przeprowadzonych za Pośrednictwem Facebooka. In: M. Suświłło and N.A. Fechner (Eds.), Edukacja XXI wieku. Podmioty, środowiska i obszary edukacyjne. Wyzwania i zagrożenia połowy XXI wieku (pp. 79-90). Poznań: Wydawnictwo Wyższej Szkoły Bezpieczeństwa.

Smith, E.E. (2012). The Digital Native Debate in Higher Education: A Comparative Analysis of Recent Literature. Canadian Journal of Learning and Technology, 38 (3), 1-18.

Sousa-Vieira, M.E., López-Ardao, J.C., Fernández-Veiga, M., Rodríguez-Pérez, M., and López-García, C. (2015). Using Social Learning Methodologies in Higher Education. International Journal of Engineering Pedagogy, 5 (2), 64-72.

Tapscott, D. (1999). Educating the Net generation. Educational Leadership, 56 (5), $6-11$.

Vie, S. (2008). Digital Divide 2.0: 'Generation M' and Online Social Networking Sites in the Composition Classroom. Computers and Composition, 25 (1), 9-23. 


\title{
Chapter 8
}

\section{Initial Teacher Education Policies: A Comparison between Italy and the UK. Recent Trends and Future Prospects}

\author{
Francesco Magni \\ University of Bergamo, Bergamo, Italy
}

\begin{abstract}
European education systems are facing tricky challenges; both the aims and the structures of them must be rethought from the roots. The European education systems (and, above all, the Italian one) leave many students behind intellectually, civically and morally. Educational leaders disagree about why this is so. Teacher education policies could have a great impact in facing these educational challenges. The topic is debated in many EU countries where education policy makers are wondering even more frequently about the best ways to attract young, prepared, and motivated graduates to the teaching profession. Through an analysis of the Italian and English legislation and policy documents, this paper will draw a comparison between the two countries, highlighting some of the main recent reforms and future prospects concerning teacher education policies, in order to think out of the box and learn from each other about what matters and what works in different contexts, and imagine new paths and future prospects for a better initial teacher education system.

KEYWORDS: initial teacher education, education policies, comparative education, work-related learning, Law no. 107/2015
\end{abstract}

\section{Introduction}

In our complex and global societies, European education systems are facing tricky challenges. In the face of profound and epochal changes, both the aims and the structures of European education systems must be rethought from the roots. European education systems (and, above all, the Italian

CONTACT Francesco Magni, EMAIL: francesco.magni@unibg.it 
one) leave many students behind intellectually, civically and morally. Educational leaders disagree about why this is so. Concerning this key issue, teacher education policies could have a great impact in facing these educational challenges (Ellis and Orchard, 2014; Evans, 2013; Furlong, CochranSmith, and Brennan, 2009). Over the last years, attention to the teaching profession, teachers and teacher education has increased, also becoming an important matter debated at European level (European Commission, 2013). With the teaching profession currently evolving and facing "a number of challenges, including an ageing population, variable working conditions and negative views of the profession” (OECD, 2015b, p. 88), in many European Countries policy makers are wondering about the best ways to attract young, prepared and motivated graduate students to the teaching profession. But this is the broad European context. Within this general framework, there are profound differences among the initial teacher education systems of the individual States, from the historical, pedagogical, institutional and political point of view. This is the case in Italy and England, and this paper will focus on a comparison between these two countries which have a very different initial teacher education system, and are both currently involved in some recent attempts at reform.

In England, for example, in the next few years there will be a real shortage of teachers in some geographical areas and disciplinary sectors (House of Commons, 2017) and the current challenge is how to attract a greater number of motivated and talented young people to the teaching profession (European Commission, 2014).

On the contrary, in Italy, the situation appears instead diametrically opposite. Due to teacher education and recruitment policies occurring over a period of time, "in a chaotic way often under the pressure of needs and demands unrelated to the enhancement and improvement of the quality of the school system" (Saltari, 2014), Italy has to deal with the legacy of the past decades - a legacy that today means a long waiting list of temporary teachers waiting for permanent employment. In the last few years, a massive operation has been launched for the recruitment of teachers in Italy. Thanks to the extraordinary occupational plan required by Law no. 107/2015, almost 100,000 temporary teachers were hired during the autumn of 2015, over 63,000 in 2016, and over 51,000 in 2017. The overcoming of some heavy legacies of the past (Bertagna, 2017), combined with the fall of decades of "ideological barriers" (Bertagna, 2015), seemed, until a few years ago, to suggest the unfolding of a favourable space for the discussion 
of genuinely reforming perspectives of the Italian system of initial teacher education. Instead, despite a huge effort of economic resources, what has been defined as an “institutionalized precariousness” (Gremigni, 2013) remains prevailing.

Someone might wonder, why make a comparison between two such different systems? Why not compare two more similar systems (such as, for example, the French and the Italian ones)? The answer is simple: because, in order to think about other paradigms and experiences it is useful, from a comparative education perspective (Argentin and Giancola, 2013; Cowen-Kazamias, 2009; Darling-Hammond, 2017; Larsen, 2010; Manzon, 2011, 2018; Nóvoa and Yariv-Mashal, 2003; Sayer, 2006), to look at the English case, which is very different from the Italian one and for this reason particularly interesting for an Italian observer (Magni, 2018). In this way, it will be possible overcome some historical paradigms that seem indisputable and unreformable, to think out of the box and imagine new paths and future prospects for a better initial teacher education system in Italy. In fact, as has been emphasized at the international level, "the teaching challenges posed by higher expectations for learning and greater diversity of learners around the globe will likely be better met if nations can learn from each other about what matters and what works in different contexts" (Darling-Hammond, 2017, p. 307).

The way in which teacher training is structured in England, its historical evolution and the pedagogical paradigms attached to its different training paths, and the role that, in this context, it plays in the constant relationship between theory and practice or between schools and universities has much to teach the Italian case and the regulations resulting from Law no. 107/2015.

\section{The recent reforms in Italy}

In the last few years the Italian government - through Law No. 107/2015 and Legislative Decree No. 59/2017 - tried to change the system of initial teacher education for secondary teachers (Magni, 2017). There have been no changes for the initial teacher education for primary school teachers; the current model requires that after the five-year Master's degree in primary education, during which there are also periods of traineeship, and the achievement of qualified teacher status, it is possible to take part in national competitions, in order to obtain a public employment in a school as a teacher. 
Otherwise, for the initial teacher education of secondary school teachers, the new (consecutive) scheme provides that, after a Master's degree $(3+2$ years) and the overcoming of additional university exams (for a total of 24 credits in disciplinary fields such as pedagogy, anthropology, psychology, didactics, or special education), candidates sit a national examination. After that, if the examination has been passed, the aspiring teacher is hired with a three-year fixed-term contract at a school and, at the same time, enrolled in a three-year teacher education course which is university-based. During these three years, the teacher-trainee has to attend university courses (60 CFU, university credits), carry out an internship (10 CFU) and gain the teacher qualification (1 year). Then, during the second and third years, the student/trainee has to carry out a research project (Action Research), attend university lessons in innovation and educational experimentation (15 CFU) and some workshops (9 CFU). During the second year the student/trainee can teach as a substitute for a maximum of fifteen days. During the third year he/she can teach in school as a substitute teacher. Finally, at the end of the third year, the student/trainee is employed as a full-time permanent teacher.

The Italian way to become a secondary teacher is very long (thirteen years of primary and secondary education + five years of university courses for a master's degree + 24 CFU university exams + the national examination + three years of initial teacher training). For young Italians it is impossible to begin to teach before the age of 28. Furthermore, there is only one way to become a teacher and it is very uncertain because candidates have to wait for the results of the national public examination. Moreover, Italian teachers are the oldest in the European Union: in 2015, more than 57\% of teachers in Italy were aged over 50 (UE 36\%) and more than 18\% were aged 50-60 (UE 9\%) (Eurostat, 2017).

All of this is not only about the teacher education system, but reveals the underlying values and priorities of a given socio-political context. In fact,

an analysis of the teacher education policy in any state system is deeply revealing of the currently dominant values within that society. Through defining how and where teachers should be prepared for their work and sometimes through prescribing exactly what they should know and be able to do, we see how those in power in society are seeking to shape the world for future citizens (Menter, 2016, p. 3). 


\section{Recent trends in teacher education in England: theory vs. practice?}

The English case is very interesting from an Italian perspective. First of all because there are multiple and diversified roads into teaching. Secondly, there is a constant relationship between theory and practice. Then, there are the partnerships existing between schools and universities. Moreover, compared to the Italian case, it is a shorter, less uncertain path into teaching, with a greater choice of different options.

Starting from the relationship between theory and practice, in her foreword to a recent book about teacher education, Cochran-Smith (2016) identifies in "the practice turn", one of the five trends in current educational policies for teacher training in England. She writes:

the practice turn has emerged internationally in the face of mounting claims that college and university preparation programmes have failed to produce effective teachers in part because of the long-perceived 'gap' between theory and practice. The notion of a 'theory-practice gap' is based on the perceived failure of the university model of teacher education, which presumably emphasizes theory, values and belief at the expense of actual teaching practice, thus leaving new teachers on their own to implement or translate theory into practice (Cochran-Smith, 2016, p. xiii).

Similarly, other authors (Mattsson, Eilertsen, and Rorrison, 2011; Reid, 2011) recognize that teacher education reforms are internationally placing much greater emphasis on learning to teach in extended practice periods in schools.

Firstly, we must remember that in England, as early as the $19^{\text {th }}$ Century,

a classroom-based apprenticeship model of teacher preparation was favoured. [...] Recent governments of all political persuasions have [...] once again pursued a more extensively work-place model of teacher pre-service and continuing professional learning (McNamara, Murray, and Jones, 2014, p. 1).

Although the English teacher education system has a long-standing model based on pupil-teacher apprenticeship, between the 1970s and 1990s, "teacher education became increasingly academic and its relationship with practical teaching skills became extremely tenuous” (ibid., p. 185).

The last thirty years have been a period of unremitting change for pre-service teacher education in England. This period has been seen as a "pendulum swing" (Murray et al., 2016), "away from the dominance 
of higher education institutions (HEIs) towards a greater role for schools and teachers in the formation of beginning teachers" (Mutton, Burn, and Menter, 2017, p. 14). And the path chosen by recent English governments, of all political persuasions, has increasingly moved up towards a workplace model of initial teacher education.

Until the mid-eighties,

initial teacher education in England was the exclusive province of higher education; government automatically recognized university-validated qualifications for the formal award of 'Qualified Teacher Status'. [...] The following ten years were a period of intense struggle and confrontation between government and higher education, a struggle which higher education eventually lost (Furlong et al., 2009, p. 46).

Firstly, in 1984, the establishment of the Council for the Accreditation of Teacher Education, the prescription of minimum periods of school-based training (DES, 1984; DES, 1989) to widen "practical preparation of teachers, involving more classroom experience" (Craft, 1984, p. 338), and the introduction of the notion of 'accreditation' was the first major state intervention into pre-service teacher training. Particularly, the latter has been used to diversify training provision in order to include school-based routes and later for the introduction of School-Centred Initial Teacher Training (SCITT) in 1993. The new routes were also intended to widen and diversify the pool of applicants to teaching.

But for a first period that lasted several years, these new routes into teaching had very limited impact and traditional routes offered through universities and colleges of education were the vast majority. Furthermore, after a long history of attempts (DES, 1983; McNair, 1944), partnerships between schools and universities in teacher education began to develop as voluntary relationships with formal agreements (for example in 1987 the Oxford Internship Scheme was launched (Benton, 1990)). Then, the circulars 9/1992 (DfE, 1992) and 14/1993 (DfE, 1993) mandated a statutory requirement for higher education institutions to build up partnerships with schools, with the expectation that they would "exercise a joint responsibility for the planning and management of courses and the selection, training and assessment of students” (DfE, 1992, paragraph 14, see also Mutton et al., 2008). Nonetheless, as claimed by some authors, the model has probably shifted from entirely university-led to entirely school-led (Furlong et. al., 2000).

Meanwhile, in 1994 the Council for the Accreditation of Teacher Education was replaced with the Teacher Training Agency (it is to be noted 
the shift from the term 'education' to 'training'). The Agency re-launched work-based routes (called 'Employment Based Initial Teacher Training'), which reached around $20 \%$ in the late 2000s.

During the following years, there was a general deregulation of the English education system and "a shift in location of initial and continuing professional learning from university to school, with increasing interest in learning that occurs outside structured, pre-determined curricula and [teachers undertaking] ever more varied roles” (McNamara, Murray, and Jones, 2014, p. 193).

In June 2010, the Secretary of State for Education in England, Michael Gove, announced his intention to "reform teacher training to shift trainee teachers out of college and into the classroom" (DfE, 2010), because of his belief that "teaching is a craft and it is best learnt as an apprentice, observing a master craftsman or woman" (Gove, 2010). Just two weeks earlier, Gove had announced the abolition of the General Teaching Council of England, a little over ten years after it had been created.

Despite other documents (DfE, 2011a; DfE, 2011b; DfE, 2012; House of Commons, 2012) and reassuring noises about the continuing role of universities in the teacher education process from the document The Importance of Teaching (DfE, 2010), the English government promoted more school-based initial teacher training pathways.

This happened despite the fact that not only were there criticisms and misgivings by some commentators who noted that "postgraduate pre-service teachers already spend two-thirds of their training in the workplace on professional placement” (McNamara, Murray, and Jones, 2014, p. 183), but also Ofsted itself, the government's own inspectorate of pre-service teacher education, in its 2010 annual report had estimated that "there was more outstanding initial teacher education delivered by higher education-led partnerships than by school-centred initial teacher training partnerships and employment-based routes" (Ofsted, 2010, p. 59). These inspections found that $46.8 \%$ of the 64 higher education institutions inspected were deemed outstanding, compared to $39.0 \%$ of employment-based routes and $22.7 \%$ of school-centred routes. Even if it is true that there was "any evidence that a further increase in the proportion of practice-based training (over and above the two-thirds currently mandated) will automatically and inevitably lead to better quality learning for pre-service teachers” (McNamara, Murray, and Jones, 2014, p. 184), this was the path undertaken by the recent English governments. Questions such as: ‘What do teachers learn on-the-job?’ and 
'How, if at all, do they learn from experience?' are still “the central problem in policy-making and professional practice” (Ellis and Orchard, 2014, p. 1).

Training teachers who are able to think then act, and vice versa, and are able to judge and redesign their own acts, is increasingly crucial in face of the new challenges in the global context (Bertagna, 2016; Magni, 2016). But if there is, on the one hand, a wide agreement internationally about the importance of a good and effective initial teacher education, there is, on the other, "a wide range of views about how to develop it" (Darling-Hammond et al., 2012, p. 151), even if it is possible to recognize the most recent trends of evolution in initial teacher education around the world. And this may explain the great variety of different attempts at teacher training in the English system.

\section{Multiple roads into teaching}

To understand the great success that work-based learning has in England and the preference for a differentiated system, it is perhaps useful to refer to the figure of Ellen Wilkinson, Minister of Education from 1945 to 1947. One of her last acts before her death in 1947 was to compose a foreword to a Ministry pamphlet entitled The New Secondary Education, in which she defended "the uniqueness of the individual child, and the necessity of developing forms of education that could relate to individual needs and interests” (Jones, 2016, p. 22). Commenting on her proposals for reform, she wrote: "these plans put the child first. [...] Their variety is designed to suit different children, not different income groups [...] No child must be forced into an academic education which bores it to rebellion, merely because that type of grammar school education is considered more socially desirable by parents" (Wilkinson, 1947, pp. 3-4); “some are attracted by the abstract approach to learning", while others, the majority, "learn most easily by dealing with concrete things" (ibid., p. 23). This is reflected in the second characteristic of the English system, very different from the Italian one: the multiple, differentiated roads into teaching.

In England, the percentage of teachers trained through 'alternative routes' compared to the academic one has increased from about 2\% in 1997 to $20 \%$ in 2009 and continues to grow to over $50 \%$ in recent years (Whitty, 2014). This is a diversification, however, which not only concerns the initial phase but which continues during the professional development of the teacher: "we see an increasingly differentiated teaching workforce both 
by route of entry and by nature of the responsibility" (Childs and Mender, 2013, p. 102).

To name a few routes to teaching, in addition to the undergraduate route (provided by Higher Education institutions), England has School-centred Initial Teacher Training (SCITT), School Direct, Teach First, Troops to Teachers, Researchers in Schools (RiS), Future Teaching Scholars, Now Teach, Premier Pathways and the new Postgraduate teaching apprenticeship, starting from September 2018 (Magni, 2018).

Among the new different routes to become teachers recently introduced in the English education system, one of them is called School Direct. What is new about this teacher education programme is the fact that it gives to individual schools, rather than universities, the possibility to choose with a broad discretion - their candidates for certification, and then the possibility to train their teachers directly in the schools.

School Direct is an innovative route into teaching, introduced in 2012/2013 and designed to enable schools to take a leading role in Initial Teacher Education (ITE), whilst still working in close partnership with an accredited ITE provider, like universities. After one-year of full-time training, the 'apprentice-teacher' gains Qualified Teacher Status (QTS). On successful completion of the School Direct program there is an expectation that trainees will be offered employment, either by the school in which they trained or elsewhere within the group of schools involved in the School Direct provision. However, this employment is not guaranteed. School Direct provides a real period of practical training to be carried out directly in schools after graduation, starting with what has been called a 'deep dive approach' to school life. In this way it would be possible to pursue two main goals: on the one hand to carry out a model of dual education in teacher education, which links simultaneously theory and practice; on the other, to promote and support the greater autonomy of schools. Despite some concerns (Wilson, 2013), School Direct has been a great success, growing from 722 apprentices-teachers in 2012/2013 up to 17,609 in 2015/2016.

\section{Future prospects}

The English case can be a touchstone for those educational systems - like the Italian one - still too uniform, rigid and centralized. In fact, in the face of a global perspective and current 'liquid' and complex societies (Bauman, 2001), in order to sustain wide improvement in education systems "societies 
are increasingly demanding strategies characterized by diversity, flexibility and choice" (Hopkins, 2013, p. 64). As it has been noted,

future-oriented pedagogies involve large measures of collaborative and creative problem-focused learning to release wide-ranging talents for innovation and to liberate teachers and learners from bureaucratic constraints. [...] Indeed, a broader and less constricted curriculum and system of assessment are needed to facilitate reformed methods of teaching. [...] Smarter pedagogies and a more adequate organization of schools and teaching will bring significant improvements to knowledge, skills and competences that are needed for raising national economic competitiveness and increasing ecological sustainability. Specifically, well-developed teaching methods include cooperative learning, problem-based learning and creative problem-solving (Sahlberg and Oldroyd, 2010, p. 296).

Therefore, the English teacher education system appears profoundly distant to, and full of suggestions and ideas from, the system currently in force in Italy (as well as from the one being implemented after the recent legislation). It is still too centralized, uniform; initial training paths for secondary teachers are too long, expensive and uncertain, not only in their final outcome, but also in the timing of their beginnings. Moreover, a system such as the Italian one, where theory and practice remain separated, where school and university are distant and mutually suspicious, where the prospect of workbased learning is still a mirage, generates an absurd fragmentation (Hudson, 2017), worthy only of nineteenth or twentieth century logic.

\section{References}

Argentin, G. and Giancola, O. (2013). Diventare Insegnanti in Europa. Una Comparazione tra Quattro Paesi. Scuola Democratica, 3, 863-877.

Bauman, Z. (2001). The Individualized Society. Cambridge: Polity Press.

Benton, P. (Ed.). (1990). The Oxford Internship Scheme: Integration and Partnership in Initial Teacher Education. London: Calouste Gulbenkian Foundation.

Berner, A.R. (2017). Pluralism and American Public Education: No One Way to School. New York: Palgrave Macmillan.

Bertagna, G. (2015). La Buona Caduta Degli Steccati. Nuova Secondaria, 9, 3-4.

Bertagna, G. (2016). Dall'esperienza alla Ragione, e Viceversa. L’alternanza Formativa come Metodologia Dell'insegnamento. Ricerche di Psicologia, 3, 319-360.

Bertagna, G. (2017). La Pedagogia della Scuola. Dimensioni Storiche, Epistemologiche ed Ordinamentali. In: G. Bertagna and S. Ulivieri (Eds.), La Ricerca Pedagogica nell'Italia Contemporanea. Problemi e Prospettive (pp. 34-111). Roma: Edizioni Studium.

Cowen, R., and Kazamias, A.M. (2009). International Handbook of Comparative Education. Netherlands: Springer. 
Casaschi, C., and Magni, F. (2018). Work-Related Learning as a Didactic Methodology for Teacher Education. Revista Internacional de Formaçăo de Professores, 3 (1), 205-226.

Childs, A., and Mender, I. (2013). Teacher Education in 21 ${ }^{\text {st }}$ Century in England. A Case Study in Neoliberal Public Policy. Revista Espańola de Educación Comparada, 22, 93-116.

Cochran-Smith, M. (2016). Foreword. In: Teacher Education in Times of Change (pp. $\mathrm{x}-\mathrm{xv}$ ). Bristol, UK: Policy Press.

Darling-Hammond, L., and Lieberman, A. (Eds.). (2012) Teacher Education around the World: Changing Policies and Practices. New York: Routledge.

Darling-Hammond, L. (2017). Teacher Education around the World: What Can We Learn from International Practice? European Journal of Teacher Education, 40, 291-309.

Department for Education and Science (DES). (1983). White Paper - Teaching Quality. London: HMSO.

Department for Education (DfE). (1992). The New Requirements for Initial Teacher Training (Circular 9/1992), London.

Department for Education (DfE). (1993). The Initial Training of Primary School Teachers: New Criteria for Courses (Circular 14/93), London.

Department for Education (DfE). (2010). The Importance of Teaching. The schools White Paper 2010. London (www.education.gov.uk).

Department for Education (DfE). (2011a). Training our Next Generation of Outstanding Teachers. An Improvement Strategy for Discussion, London.

Department for Education (DfE). (2011b). Training our Next Generation of Outstanding Teachers. An Implementation Strategy, London.

Department for Education (DfE). (2012). Education Committee. First Special Report. Great Teachers: Attracting, Training and Retaining the Best Teachers. Government response to the Committee's ninth Report of session 2010-2012 Education Committee, London.

Ellis, V., and Orchard, J. (Eds.). (2014). Learning Teaching for Experience. New York: Bloomsbury.

European Commission (2014). Study on Policy Measures to Improve the Attractiveness of the Teaching Profession in Europe, 1-2. Luxembourg: Publications Office of the European Union.

Eurostat. (2017). Teachers in the EU, 4/10/2017.

Evans, M. (Ed.) (2013). Teacher Education and Pedagogy: Theory, Policy and Practice. Cambridge: Cambridge University Press.

Furlong, J., Barton, L., Miles, S., Whiting, C., and Whitty, G. (2000). Teacher Education in Transition: Re-forming Professionalism? Buckingham: Open University Press.

Furlong, J., Cochran-Smith, M., and Brennan, M. (Eds.) (2009). Policy and Politics in Teacher Education. New York: Routledge.

Gove, M. (2010). Address to the National College's Annual Conference in Birmingham, 16 June 2010. 
Gremigni, E. (2013). Una Precarietŕ Istituzionalizzata. Diventare Insegnanti Nella Scuola Pubblica Italiana. Scuola Democratica, 1, 105-124.

Hopkins, D. (2013). Exploding the Myths of Schools Reform. Victoria: ACER Press. House of Commons. (2012). Great Teachers: Attracting, Training and Retaining the Best Teachers. London.

House of Commons. (2017). Supply of Teachers Report. London: Education Committee. https://publications.parliament.uk/pa/cm201617/cmselect/cmeduc/199/199. pdf.

Hudson, B. (Ed.). (2017). Overcoming Fragmentation in Teacher Education Policy and Practice. Cambridge: Cambridge University Press.

Larsen, M.A. (Ed.). (2010). New Thinking in Comparative Education. Rotterdam: Honouring Robert Cowen, Sense.

Jones, K. (2016). Education in Britain. 1944 to the Present. Cambridge: Polity Press, Second Edition.

Magni, F. (2016). L’alternanza Formativa e l'“agire in modo riflessivo” Nella Formazione Iniziale dei Docenti. Ricerche di Psicologia, 3, 361-369.

Magni, F. (2017). La Nuova (?) Formazione Iniziale dei Docenti in Italia. Uno Sguardo Comparato All'esperienza Inglese Dell'immediato Secondo Dopoguerra. Nuova Secondaria, 3, 19-22.

Magni, F. (2018). La sfida del “caso” Inghilterra. Formazione Iniziale e Reclutamento dei Docenti. Roma: Edizioni Studium.

Manzon, M. (2011). Comparative Education: The Construction of a Field. Hong Kong: CERC Springer.

Manzon, M. (2018). Origins and Traditions in Comparative Education: Challenging some Assumptions. Comparative Education, 54 (1), 1-9.

Mattsson, M., Eilertsen, T.V., and Rorrison, D. (Eds.) (2011). A Practicum Turn in Teacher Education. Rotterdam: Sense publishers.

McNair, A. (1944). Teachers and Youth Leaders (The McNair Report). London: HMSO.

McNamara, O., Murray, J., and Jones, M. (Eds.). (2014). Professional Learning and Development in Schools and Higher Education. Workplace Learning in Teacher Education. International Practice and Policy. Dordrecht: Springer.

Menter, I. (2016). Introduction. In: Teacher Education in Times of Change. Bristol: Policy Press.

Murray, J., and Mutton, T. (2016). Teacher Education in England; Change in Abundance, Continuities in Question. In: Teacher Education Group (Ed.), Teacher Education in Times of Change (pp. 57-74). Bristol: Policy Press.

Mutton, T., and Butcher, J. (2008). We Will Take Them from Anywhere: Schools Working within Multiple Initial Teacher Training Partnerships. Journal of Education for Teaching: International Research and Pedagogy, 34, (1), 45-62.

Mutton, T., Burn, K., and Menter, I. (2017). Deconstructing the Carter Review: Competing Conceptions of Quality in England's 'School-led' System of Initial Teacher Education. Journal of Education Policy, 32 (1), 14-33.

Nóvoa, A., and Yariv-Mashal, T. (2003). Comparative Research in Education: A Model of Governance or a Historical Journey. Comparative Education, 39 (4), 423-438. 
Ofsted (2010). The Annual Report of Her Majesty's Chief Inspector of Education, Children’s Services and Skills 2009/2010.

Reid, J. (2011). A Practice-turn for Teacher Education? South Pacific Journal of Teacher Education, 39 (4), 293-310.

Saltari, L. (2014). La Formazione e il Reclutamento degli Insegnanti in Italia. Rivista Trimestrale di Diritto Pubblico, 2, 445-475.

Sahlberg, P., and Oldroyd, D. (2010). Pedagogy for Economic Competitiveness and Sustainable Development. European Journal of Education, 45 (2), 280-299.

Sayer, J. (2006). European Perspectives of Teacher Education and Training. Comparative Education, 42, 63-75.

Wilkinson, E. (1947). Foreword. In: Ministry of Education, The New Secondary Education, London: HMSO.

Wilson, E. (2013). Building Social Capital in Teacher Education through University-School Partnerships. In: M. Evans (Ed.), Teacher Education and Pedagogy: Theory, Policy and Practice (pp. 41-59). Cambridge, UK: Cambridge University Press.

Whitty, G. (2014). Recent Developments in Teacher Training and their Consequences for the "University Project" in Education. Oxford Review of Education, 40 (4), $466-481$. 


\title{
Chapter 9
}

\section{Initial Teacher Training Challenges in a Context of Educational Reform in Lithuania}

\author{
Aušra Rutkienè and Tetiana Ponomarenko \\ Institute of Education, Vytautas Magnus University, Kaunas, Lithuania
}

\begin{abstract}
The current article comprises a review of the Lithuanian Teacher Training Concept, OECD reviews of school resources and teacher training governmental regulations, and discusses the strengths and challenges of initial teacher training in Lithuania in context of its reform. Specifically, the changes in the teaching competence framework and vision of initial teacher training, and the methods of initial teacher education acquisition and its structure are examined and discussed. Analysis of teaching competences has shown that the priority is given to general skills (reflective practice and research on-the-job) and didactic competences in order to focus prospective teachers on the actual teaching process. Initial teacher training is seen as a foundation for building a teaching career in lifelong learning terms. A mixed model of initial teacher training is expected to provide more opportunities to enter the teaching profession by alternative ways due to an expected lack of teachers. The internship practice in the structure of initial teacher training after graduation is viewed as a means to decreasing young teachers' dropping-out and ensuring a smooth transfer from university education to professional in-service activity.

KEYWORDs: initial teacher training, teaching competence framework, teacher training model, initial teacher training structure
\end{abstract}

\section{Introduction}

After the 1990s the Lithuanian educational system experienced crucial changes several times. One of the first documents was The General Concept of Lithuanian Education, presented to Parliament in 1992. The Concept was

CONTACT Aušra Rutkienė, EMAIL: ausra.rutkiene@vdu.lt 
based on goals, values and relationships germane to the building of a twenty-first century society, and posits four basic principles for Lithuanian education: humanism, democracy, commitment to Lithuanian culture and plurality, and renewal. These principles are still current. The structure of the educational system has also changed. The Law on Education was renewed in 2011.

The demographic situation in Lithuania changed after the 1990s: the number of inhabitants in Lithuania decreased. Changes in society, ICT development, and the establishment of the European Union also influenced changes in education and at the same time, teacher training. Students are changing and new competences are being required from teachers in schools. All the above-mentioned aspects have determined changes in the teacher training curriculum. The aim of this paper is to present the current initial teacher training situation in the context of reform based on documents and a literature review.

\section{Current socioeconomical and demographical situation}

An analysis of the socio-economic indicators demonstrates that the situation has improved during the last five years (source: Statistics Lithuania). The population in Lithuania decreased by 1,334, while the number of births was almost stable during the last five years (see Figure 1).

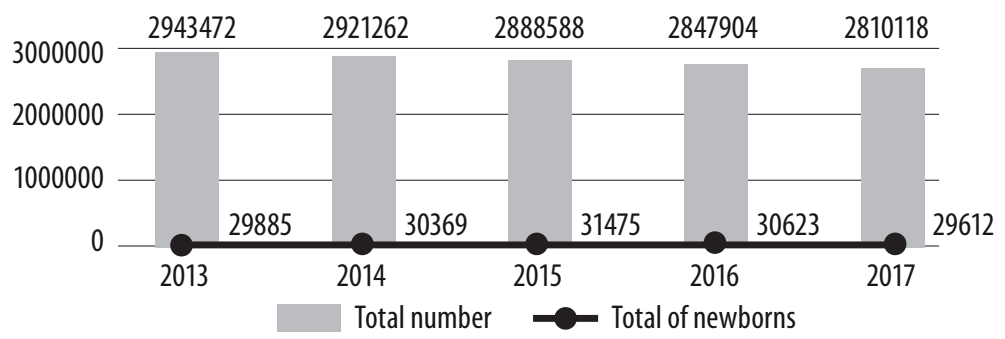

Figure 1. Total number of inhabitants and number of births Source: Statistics Lithuania

The number of students in pre-school and primary education is almost the same but the number of students in lower secondary and secondary education is decreasing. The total number of teachers also is decreasing (see Figure 2). 


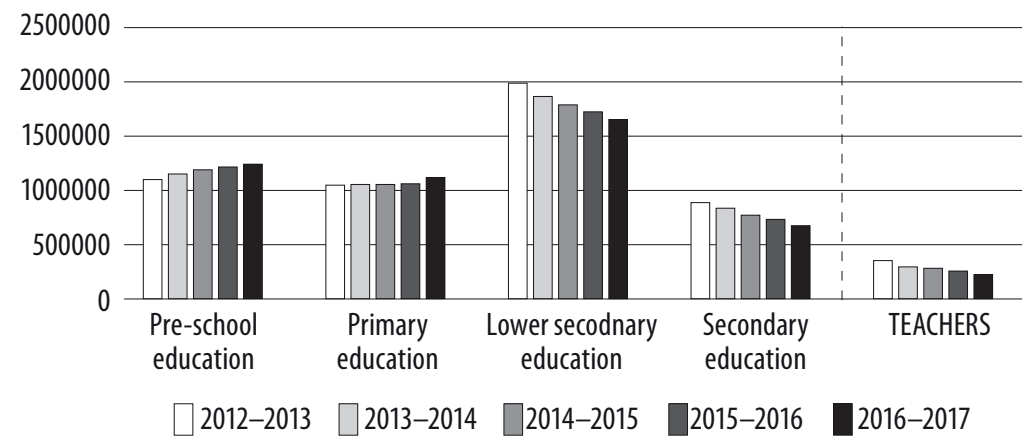

Figure 2. Number of students

Source: Statistics Lithuania

The number of students per teacher is one of the highest in Europe - 7-8 pupils per one teacher, although this ratio is less in rural areas and higher in big cities.

One of the biggest challenges in relation to the number of teachers is aging. The average age of teachers is almost 49 years (see Figure 3). The OECD report (Shewbridge et al., 2016) also pays attention to this serious problem in Lithuania.

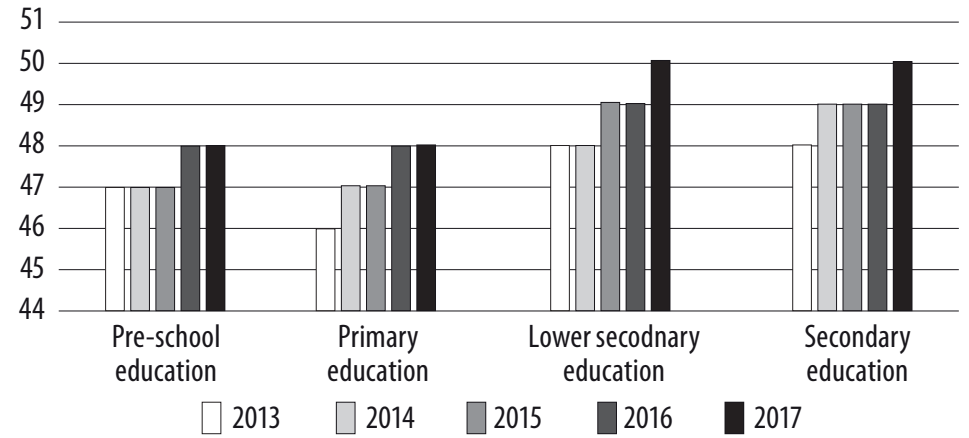

Figure 3. Teachers' average age

Source: EMIS

Most of the teaching staff in Lithuania is female. In low secondary and secondary levels only about $15 \%$ of teachers are males, and in pre-school or primary, males consist of less than $5 \%$ of the total number of teachers.

The Concept of a Good School was approved in December 2015. It serves as a guideline to schools in their development and improvement of 
education quality. The 'Description of Primary, Lower and Upper Secondary Education Programmes' document embodies the agreements on education objectives and learning outcomes of the national education community. The implementation of this document will facilitate the systematic development of teachers' qualifications and ensure the creation of a modern educational environment (Ministry of Education and Science, 2015).

\section{Teacher training system}

Institutions of higher education train teachers for early childhood education and care, primary teachers and subject teachers, social teachers, special education teachers, adult education and education management. Pre-school, primary school and subject teachers can work at schools if they have a teachers' qualification (according to Law, 2009). Teachers in Lithuania are trained by pedagogical-profile and some non-pedagogical-profile universities and colleges. Teachers are trained at colleges (providing non-university study programmes of higher education) and universities (providing basic professional study programmes, Bachelor's and Master's degrees and also specialized professional study programmes).

Teacher training in Lithuania follows two models: the concurrent model and the consecutive model. The concurrent model means that all components of the initial teacher training curriculum are combined from the outset, and the consecutive model is when studies in educational subjects, methods of teaching and pedagogical practice in schools enable students to qualify as teachers following their academic studies. Teachers for pre-school and primary education institutions and social pedagogues are trained only under the concurrent model. In Lithuania, the teacher training model has several common curriculum components: studies offering educational programmes, academic studies in subjects and certain disciplines related to school education programmes, subject or integrated study course methodology and pedagogical/school practice. For the last several years there have been one year non-degree pedagogical studies for persons who have a Bachelor in a particular subject. The studies include two blocks of equal value: academic studies and pedagogical practice.

The project of the new Teacher Training Regulation (2018) includes one more important aspect: after graduation teachers should spend one year at school as a pedagogical traineeship/final ‘on-the-job’ qualifying phase. 
The new Teacher Training Concept (renewed version adopted $29^{\text {th }}$ May 2018) includes some important aspects:

- $\quad$ Module of Pedagogical studies 60 ECTS

- $\quad$ In-service practice, at least 30 ECTS

- $\quad$ Recognition of competences (gained through practice and informally)

- 1 year of pedagogical traineeship (obligatory). After graduation teachers should spend one year at school as a pedagogical traineeship/final 'on-the-job' qualifying phase

- $\quad$ Teaching staff - at least 30\% must be practitioners with at least C1 level of English language proficiency.

\section{Teacher competence framework}

The recent research conducted by the Organization of Economic Cooperation and Development (OECD) on school resources in Lithuania has drawn a conclusion that initial teacher training in Lithuania is focused mostly on the acquirement of subject-related knowledge and studying the curriculum content, while less attention is given to the process of learning and subject didactics. Moreover, the studying of subjects must include the development of teacher's general competencies, as well as the ability to evaluate and reflect on his/her own teaching practice and to conduct research at school (Shewbridge et al., 2016).

The Teacher Training Concept specifies that teacher training must provide conditions for the would-be pedagogue to acquire competences that are necessary to fulfill his/her new role of an education organizer, creative educator, developer of opportunities, coach, adviser, partner and mediator between the pupil and various modern information sources. The basic components of the teacher's competence are general cultural competence, competence in the subject/subjects in which teachers are trained, and professional competence. Teacher training is oriented to the development of competences that the teacher will need in his/her practical work.

Requirements for teachers' competence are set out in the regulations on teacher training and those on discrete areas of studies and also in the Specifications of Teachers' Professional Competence.

In order to respond to the OECD advice and the needs of the contemporary Lithuanian school, the new requirements for initial teacher training were introduced by the Ministry of Education and Sciences of 
Lithuania. They are focused on enabling teachers to work in teams, involve students with special needs, foster interdisciplinary studies, use technologies, respond to students' individual needs, reflect on and improve personal professional practice and provide professional counselling for parents. Prospective teachers must achieve a C1 level of English language proficiency, due to the fact that $90 \%$ of modern scientific literature is being published in English. Prospective teachers must acquire a comprehensive general, cultural, social, political, economic and law education, communication and cooperation skills, lifelong learning provisions, and change and crisis management skills. Teacher must be able to plan, organize and carry out scientific research in order to identify learning disruptions, evaluate the learning process and plan further educational practice based on research data (Project of the Teacher Training Concept and its Basis, 2016).

The teacher competency framework is focused on the key competencies that teachers are expected to acquire and develop during initial teacher education and professional development. The framework was developed in order to organize initial teacher education, self-evaluation and appraisal of teacher's professional activities, planning teachers' professional development and career advancement in a way that could be matched with the Lithuanian qualification framework and provide sufficient guidance for teachers about what 'good teaching' means (Shewbridge et al., 2016). Teacher competencies are determined by political, economic, social and cultural development directions in Lithuania: an intelligent and integrated society, competitive economics, and striving for sustainable development. Qualified teachers are supposed to participate in the creation of a new vision of society and its educational system, creating the basis for the enhancement of the state's welfare, and to educate independent individuals, who will responsibly create their own future, as well as the future of Lithuania and the whole world (Project of the Teacher Training Concept and its Basis, 2016).

The teacher competencies are divided into three groups: 1) general competences; 2) didactical competencies and 3) subject-related competencies (see Table 1). It is noticeable that general and didactical competencies acquisition are prioritized over the subject-related competencies. General teacher competencies are focused on four main aspects: teachers' personal development and lifelong learning skills, professional communication skills, cultural competence, technologies and information management skills. Didactical competencies pay particular attention to learner's cognition skills, their individual learning needs, differentiation of teaching instruction, assessment of learners' 
progress, teacher's self-reflection and research-making skills. Subject-related competencies include knowledge and skills of curriculum delivery, self-evaluation of subject-specific knowledge and skills, and defining the areas which need to be trained or improved during professional development.

\section{Table 1. Description of teacher professional competencies}

\section{General competencies}

- Personal development and lifelong learning - knowledge and ability to manage one's own professional career and lifelong learning, based on self-reflection on professional activity, constant updating of knowledge and skills.

- Cultural competence - knowledge and skills to help to preserve the Lithuanian culture, to develop a sustainable and responsible society, to participate in the processes of transforming society and education by acting actively and openly.

- New technologies and information management skills - the ability to use modern digital technologies and equipment, information search, preparation of textual and visual information to develop students' information and visual communication culture, systematic development of their digital literacy.

- Professional communication - ability to establish and foster relationships with the school community, the public, relevant institutions and organizations, effectively communicating in national and foreign languages.

\section{Didactical competencies}

- Acknowledgement and understanding of learners' differences and aptitudes (identification of special needs and abilities) and assistance for learners.

- Preparation of educational environment, learning content and situations.

- Implementation and development of the educational curriculum.

- Assessment of learners' achievement and progress.

- Teacher's professional practice investigation - ability to evaluate and analyze the results of one's own professional activity, identify and solve problems and improve the quality of educational processes.

\section{Subject-related competencies}

- Knowledge and skills of delivering the curriculum, which corresponds to modern theories and knowledge in the related field as well as self-assessment, identification of further training in order to upgrade or acquire special skills.

Sources: OECD Reviews of School Resources, Lithuania, (2016); EVS (2016); Description of teachers' professional competences, Ministry of Education and Science of Lithuania.

Aiming to interconnect the stages of initial teacher training, the transition from initial training to actual workplace, teachers' professional development and a coherent system of lifelong learning and experience, the teacher competency framework was divided into four levels of mastership; thus, teachers' professional growth can be evaluated in accordance with the level of acquired competencies: knowledge, skills, values, views and other 
personal features which constitute a particular competence (see Table 2). The levels of professional competencies are interconnected and correspond to the levels of the Lithuanian Qualification Framework (2013).

Table 2. Levels of teacher professional competence

\section{Level of professional competency Brief description}

Corresponding level of Lithuanian Qualification Framework

\section{Beginning and strengthening}

Teacher's knowledge, skills and values meet the basic requirements of teacher formal qualification, acquired through formal or informal studies.

$6^{\text {th }}$ level

Bachelor's degree

\section{Professional growth}

Teacher applies constantly renewable knowledge and skills in personal professional practice.

$6^{\text {th }}$ level

Bachelor's degree

\section{Dissemination of experience}

Teacher applies complex and modern knowledge and skills and uses them to improve the results of personal and colleagues' practice.

\section{$7^{\text {th }}$ level \\ Master's degree}

\section{Evaluation and expertise}

Teacher's knowledge, skills and values provide the opportunity to perform research and analysis, and evaluate and improve personal practice as well as professional practice of colleagues and other educational institutions; to create and implement new methods and solutions to improve educational activity.

Sources: EVS (2015). Description of teachers' professional competences, Ministry of Education and Science of Lithuania; Ministryof Education and Science of Lithuania (2013). Qualification framework.

Teachers, regardless of the stage of their professional development, can use the current framework and evaluate the results of their own professional practice, reflect on their own professional achievement and/or plan further career possibilities. Moreover, teachers can assess the level of their professional competency and define the purposes of further qualification improvement and professional development.

The European Commission (2016) makes the following recommendations to the government for ensuring quality in teacher training:

- $\quad$ Additional funds for teachers.

- $\quad$ Support for talented student teachers. 
- $\quad$ Measures to improve the competencies and qualifications of teaching staff.

- $\quad$ Measures to attract graduates to the teaching profession.

- Initiatives to support young teachers.

\section{Conclusions}

The reform of initial teacher training and teaching qualification acquisition is aimed at accommodating the preparation of prospective teachers to the demographical challenges which Lithuania faces nowadays, and to make it more relevant to today's student needs by incorporating the results of recent research on the organization of teaching and learning processes. Initial teacher training in Lithuania is aimed at providing conditions for the prospective pedagogue to acquire the competences of a researcher, a creator of educational interactions and innovative curriculums in the context of global changes, and a student advisor, coach and partner.

\section{References}

European Comission. (2016). Education and Training Monitor. Luxembourg: Publications Office of the European Union. Retrieved December 5, 2018 from https:// ec.europa.eu/education/sites/education/files/monitor2016-lt_en.pdf.

European Comission. (2017). Education and Training Monitor. Luxembourg: Publications Office of the European Union. Retrieved December 5, 2018 from http:// www.ressources-de-la-formation.fr/doc_num.php?explnum_id=19761.

EVS Expert Group. (2015). Description of Teachers' Professional Competences (SFMIS Publication No. VP1-2.2.ŠMM-02-V-01-009). Retrieved December 5, 2018 from https://mtc.lt/attachments/article/434/Rekomendaciju_modelis_.pdf.

General Conceptof Lithuanian Education. (1992). Vilnius: Leidybos centras.

Lithuanian Law on Higher Education and Research. (2009). Retrieved December 5, 2018 from https://www.e-tar.lt/portal/lt/legalAct/TAR.C595FF45F869.

Lithuanian Ministry of Education and Science. (2015). The Concept of a Good School. Retrieved December 5, 2018 from https://www.e-tar.lt/portal/lt/legalAct/f2f65120 a7bb11e5be7fbe3f919a1ebe.

Lithuanian Ministry of Education and Science. (2013). Qualification Framework [PowerPiont slides]. Retrieved December 10, 2018 from https://www.smm.lt/ web/lt/smm-studijos/kvalifikaciju-sandara.

Lithuanian Ministry of Education and Science. (2018). Project on Teacher Training Regulations. Retrieved December 10, 2018 fromhttps://www.smm.lt/uploads/ documents/Pedagogams/03-07\%20PRReglamentas\%20(galutinisPI)1.pdf

Project of the Teacher Training Concept and its Basis (2016). Retrieved December 10, 2018 from https://www.smm.lt/uploads/documents/Pedagogams/Pedagog\%C5\%B3\%20rengimo\%20modelis_VU_MRU\%20ir\%20VK.pdf 
Shewbridge, C. et al. (2016). OECD Reviews of School Resources: Lithuania 2016. Paris: OECD Publishing. Retrieved December 5, 2018 from http://dx.doi. org/10.1787/9789264252547-en.

Statistics Lithuania. Retrieved December 5, 2018 from www.stat.gov.lt.

Teacher Training Concept. (2012). Retrieved December 5, 2018 from https://www. smm.lt/web/lt/pedagogams/mokytoju-rengimas.

The Description of Professional Competences of Teachers. (2007). Retrieved December 5, 2018 from https://e-seimas.lrs.lt/portal/legalAct/lt/TAD/TAIS.291726.

The Law on Education. (2011). Retrieved December 5, 2018 from https://e-seimas.Irs. lt/portal/legalAct/lt/TAD/TAIS.407836. 


\title{
Chapter 10
}

\section{The Teaching Profession in Albania and the Continuous Need for Improvement through Teacher Training Reforms}

\author{
Heliona Miço \\ Aleksander Moisiu University of Durres, Durres, Albania
}

\begin{abstract}
As a post-communist country, Albania is emerging from a closed planned social system and moving toward a trade market economy where society, technology and knowledge are always on the move. In order to face these challenges, people are needed whose skills and knowledge are in line with labour market requirements as well as with European standards. Therefore, teachers are the main tool to improve the quality of educational provision at all levels. Strengthening the capacity of teachers is a must in a country that is being transformed, as in Albania. The focus of the article is to present the teacher training reforms initiated by Albania and to analyse the professional profile of teachers, in order to highlight that teachers are lifelong learners. Through contemporary professional training and the development of teachers, the teaching profession will go hand in hand with European standards and it will better serve student learning. KEYWORDs: teacher, professional profile for teachers, mentoring, teacher education reform, teacher training.
\end{abstract}

\section{Introduction}

In post-communist Albania, the changing of education legislation towards an approximation of international instruments and European standards did not happen all at once. During twenty-eight years of transition, the adaptation of education legislation took time and is continuing to happen, above all, due to the desire of Albania to start membership negotiations

CONTACT Heliona Miço, EMAIL: heliona.bellani@gmail.com 
with the EU. In the decades of communist dictatorship, Albania was seen as a special case of extreme isolation (Zgaga, 2010, pp. 19-24). During the transition period the education system suffered huge damages (Héritier, 2005). The economic situation and under-managed transition processes in Albania had a strong impact on the education system, through the decline of participation in pre-university education, the low status of teachers, the poor teaching environment, poverty, and low private and social returns to education in the present labour market (OECD, 2002, p. 24). The essential difficulty in Albania is the mode of organizing and operating the educational system inherited from the communist regime (Sota, 2011, p. 32).

The first law regarding pre-university education was adopted in 1995, (On the pre-university education system Law of 1995) in a time when the Constitution of Albania had not yet been approved. ${ }^{1}$ The law underwent several changes, some of which were done to adapt the law not only to constitutional dispositions, but moreover to human rights and democratic principles. According to the law of 1995 on pre-university education, the basic requirements for the initial training and qualification of teachers are defined through and by the decisions of the Ministry of Education. Teachers and other teaching staff enjoy the right to receive post-university qualifications according to the requirements of the Ministry of Education.

Before the start of the Bologna process in higher education, pre-service training in education was divided between Tirana University, regional universities and some secondary pedagogical schools. The graduates of Tirana University were prepared to teach in high schools, while regional universities prepared their students to teach at basic elementary education level. Regarding the practice of the teaching profession, there was no arrangement between universities and local schools in order to let the students observe experienced teachers and practice teaching under their guidance (OECD, 2002, p. 29).

On the subject of in-service teacher training, it was the responsibility of Education Directorates to organize and conduct training and the qualification of school teaching staff by cooperating with specialized institutions (On the reorganization of educational directors in districts in the regional education directors and the education offices, Decision of the Council of Ministers, 2003). The programs for in-service training were developed by the Institute of Pedagogical Research and sent to the Educational Directorates at the beginning of the school year (Neuscu-Hendry et al., 1997,

1 The Constitution of Albania was approved on 21 October 1998 by Law no. 8417, dated 21.10.1998; http://www.qbz.gov.al/Kushtetuta\%20me\%20pjese/Kushtetuta\%201998,varianti\%201.pdf. 
p. 508). In general, university departments were not involved in in-service teacher training.

After the signing of the Bologna Declaration aiming for reform in Albanian higher education and creating the European Higher Education Area, ${ }^{2}$ new legislation in the higher education system in Albania was approved (On the Higher Education in the Republic of Albania Law of 2007), which aimed to modernize the system, as well as to organize study programs in cycles and evaluate them in credits, and thus transforming the whole higher education system (Papadhopulli and Miço, 2016, pp. 21-57). The study programs for preparing students for the teaching profession were reformed and organized into two cycles, bachelor and master.

At the same time, the Law On Regulated Professions in the Republic of Albania was approved and during 2011 the teaching profession was incorporated into the law as a regulated profession in Albania. These adjustments helped to give more impact to the status of the teaching profession.

The changes in pre-service training in education were accompanied by the approval of new legislation in the pre-university education system in Albania in 2012 (On the Pre-university Education System in the Republic of Albania Law of 2012) which for the first time determined the level of education needed for each category of teachers from pre-school to secondary education.

According to the law on pre-university education of 2012, pre-service training is provided for teachers corresponding to the level of education where they will practice the profession. For teachers of pre-school education only the diploma of the first cycle of university studies, the Bachelor, is required, while for teachers of primary education, low secondary education and the gymnasium, both bachelor and master degrees are required. The law was specific about the type of degree needed for future teachers, by stating that the diplomas should be in the field of education. A Master's degree in the field of education is required even for teachers of vocational education in professional subjects, such as those of oriented education ${ }^{3}$ and teachers working with disabled students. At the end of pre-service training, teachers of initial education and secondary education are entitled to practice the profession of teacher after successfully completing their professional internship and having successfully passed the state exams (On

$2 \quad$ Albania signed the Bologna Declaration in 2003 at the Berlin Ministers Conference.

3 Oriented secondary education in Albania includes choreographic schools, sports schools, foreign language schools and artistic schools. 
the Pre-university Education System in the Republic of Albania Law of 2012, Article 57).

The law regulates the continuous professional development of teachers as well. The real situation of a teacher's professional development and expectations is that teachers' training is centralized. Until 2010, the Albanian education system did not contain any element of decentralization, such as liberalization and the inclusion of more non-governmental institutions, which deal with long-life professional training (Lama et al., 2001, p. 49). For the first time, continuous professional development began to decentralize from the central government and to be offered by training agencies independent of the state. The new approach to training sessions for teachers is based on the demand-offer system, according to which the training sessions shall be held based on requests from the educational institutions and offers from public or private training agencies. The training programs shall be accredited by the Ministry of Education (On setting up the Accreditation Commission of Training Programs, Order of the Minister of Education and Science, 2011).

These measures taken towards the liberalization of the professional training of teachers and the accreditation of certified training agencies were evaluated as positive steps in the Progress Report of the European Commission of 2011 (EC 2011a, 60). However, attention is drawn towards building good governance capacities, in order to ensure efficient management of decentralised programs in the field of education and training.

Starting from the abovementioned analyses the main research question is: Are the Albanian reforms in the education sector associated with an improvement of teacher training and education? The answer to this question can be useful to better understand the development of the teaching profession through teacher training reforms, analysing all the steps needed to be passed for becoming a teacher, and the phases that follow during the exercise of the profession.

This chapter follows the methodology of key documents analyses (legislation, strategies, regulations, international treaties and conventions) which will cover an inclusive examination of the normative framework, the policies undertaken in the field and the obligations arising for Albania in the field of the teaching profession for evaluating the impact of the teacher training reforms on the quality of teachers.

The paper begins with a preview of the changes that occurred in the teaching profession during the years of transition throwing light on pre-service teacher training as well as on in-service training by presenting the progress 
in the teaching profession. To facilitate the understanding of the changes that have occurred in this profession, the paper continues with a detailed analysis of the reforms, emphasising their rationale and their impact on the teaching profession, highlighting the positive aspects but also the gaps in the legislation and policies regarding the approximation of the teaching profession to European standards. The teacher training reforms are discussed in the light of the accountability and quality of Albanian teachers.

The chapter closes with some findings and conclusions regarding the completion of the legislation and the effectiveness of the reforms in the teaching profession.

Referring to the sources used for the preparation of this paper, the study goes through an analysis of the national legislation affecting the teaching profession adopted by Albania throughout 1995-2018, the international obligations in this field, as well as several reports on the Albanian teaching profession by international organisations dealing with this field.

\section{The latest reforms in teacher training in Albania}

During 2014, a new curriculum package in pre-university education was conceived, according to a competence-based approach (On the adoption of the Strategy for the Development of Pre-University Education, for the period 2014-2020, Decision of the Council of Ministers, 2016). The main aim of the new curriculum reform is the shifting from a teacher-centred to a student-centred philosophy. In this context, a new teacher's role is one of the most important factors to be considered for the successful implementation of competence-based curriculum reform. However, the implementation, evaluation and further improvement of this approach are the real challenges that the pre-university education system is going to face in the future. Studies have shown that even as the Albanian education system is implementing many reforms, the professional development of teachers still remains a problem (Lama et al., 2001, p. 49).

According to the Communication of the European Commission (2012), "[...] new ways of learning, characterised by personalisation, engagement, use of digital media, collaboration, bottom-up practices and where the learner or teacher is a creator of learning content are emerging."

Based on the National Strategy of Pre-University Education 2014-2020, capacity development for teachers (in scientific and professional aspects) and principals (for leadership and management) is considered the greatest 
challenge for education in the years to come (On the adoption of the Strategy for the Development of Pre-University Education, for the period 20142020, Decision of the Council of Ministers, 2016). According to the Law on Pre-university Education, it is compulsory for every teacher to undertake three days of training per year. Based on these legal provisions, as a means for the professional development of teachers, it is required that each teacher specifically attends 18 hours of training per year (On the professional development of teaching personnel, Directive of the Ministry of Education and Sport, 2014).

According to the analyses of the Strategy on Pre-university Education 2014-2020, the new decentralized system which was applied for teacher training did not enable the development of training forms according to the needs of the schools, or online training; there resulted a variety of teachers not involved in training sessions, as well as the lack of a database for the organization and monitoring of teacher training. In the majority of European education systems, it is compulsory for schools to have a continuing professional development plan and to coordinate continuing professional development activities within the school (EC 2013 Key data on teachers and school leaders in Europe, p. 58).

Starting from these findings as well as from the new curricula approach, the Institute for Development of Education identified the needs for teacher training, the problematic fields and the issues which need to be focused on in the future professional development of teachers (On the establishment of the Institute for Development of Education, Decision of the Council of Ministers, 2010). Meanwhile the teacher training based on the decentralized system was suspended at the end of 2014 and the teachers did not receive any training for a period of three years.

During 2017-2018, the Ministry of Education and the Institute for Development of Education established priority areas where teacher training will be developed, as well as approved criteria and training programs for the continuing professional development of teachers. This is considered to be an on-going process because both institutions will periodically identify the needs for the continuing professional development of teachers and will accredit the teacher training programs. At the same time, in order to facilitate training information for every teacher, the training programs, sessions and the institutions/universities involved are published online, creating in this way a transparent method of following the training both on the part of the teachers and the monitoring institutions as well. 
Regardless of the progress made in the process of organizing teacher training and the tracking of teachers who follow the sessions, the content of the training programs and the measure of teachers' needs leave much to be desired.

There is a lack of interaction between top-level authorities, the institute that deals with the pre-university curricula and universities that offer pre-service teacher training. With this lack of harmony, the curricula in pre-university education in changed very rapidly in comparison with the changing of bachelor and master study programs in education. Consequently, the teachers are offered continuing professional development which is not synchronized with initial teacher education.

There is a lack of publication of data and information regarding every step followed in the teaching profession, starting from the quality of the students at the entry to higher education institutions, continuing with the analyses of the process of licensing of teachers and finishing with the analyses of the needs of teachers, regarding their professional field and according to their background education (Haxhiymeri and Mita, 2014, pp. 8-9).

Yet the implementation of the Bologna process in the area of initial teacher education faces some challenges. Universities reforming teacher education curricula do not have adequate knowledge of learning outcomes and competence-based curricula in school (primary and secondary education) and thus cannot adequately prepare teachers to implement them (EU, 2013, Teacher education and training in the Western Balkans, p. 19).

The teaching profession is organized into three categories in the Law on Higher education 2015, as pre-school teachers, primary education teachers, and lower and upper secondary education teachers. The initial training differs for the three categories of teachers:

a) The pre-school teachers are formed by the first cycle study program, the Bachelor, three academic years, 180 ECTS credits.

b) The primary education teachers are formed by the second cycle study program, the professional Master. The law does not clearly state the duration of the professional Master needed for primary education teachers, identifying no difference between one academic year at 60 credits and 2 academic years at 120 credits.

c) The lower and upper secondary education teachers are formed by a second cycle study program, the Master, 2 academic years, 120 credits. The law does not identify any difference between a professional Master and Master of Science, both organized into two academic years. 
In aiming to emphasize the need for educational study programs, the law has provided that the content of second cycle programs in the field of teaching should contain at least 25 percent of credits in the field of psycho-pedagogical training. The second cycle study programs that form teachers of the same field of study should have similar content in at least 80 percent of the curriculum.

Given that the universities in Albania which offer initial teacher education have a variety of study programs, some of which are very unique and inappropriate for the professional profile of future teachers, the standardization of initial teacher education will help students to acquire the same knowledge in a specific field of teaching. This core knowledge will be of specific importance when the pre-university education curricula, at least in public educational institutions, is the same throughout Albania.

Studies have shown that the quality of students at the start of initial teacher training during the last 20 years has been very low (Haxhiymeri and Mita, 2014, pp. 8-9). For this reason, in order to have better students in the teaching field, the admission of students into higher education institutions requires a higher average score in assessments taken during secondary education (Decision of the Council of Ministers, 2018). This requirement, coming from the top-level authorities, shows the acceptance of the fact that current teachers do not have the proper preparation for teaching, starting right from their university entrance level. However, well-resourced strategies are necessary to attract better students into education programs and to recruit, retain and develop high-quality teachers, spanning both initial teacher education and career-long professional development (EC 2013, Key data on teachers and school leaders in Europe, p. 58).

\section{Changes not only for the sake of reforms}

Albanian society is changing very rapidly. This is partly because of the desire for detaching itself from the past, and partly because of the will for adapting its society, economy, culture and ways of thinking to international and European standards. All these changes can become possible through education, therefore the teaching profession requires a continuous updating of knowledge and a holistic approach to make reforms valid. Pre-university stages of education should prepare pupils (On Pre-university Education System in the Republic of Albania Law of 2012): 
- $\quad$ To respect and protect national identity, and develop cultural heritage;

- $\quad$ To develop in the ethical, intellectual, physical, social and aesthetic aspects of life;

- $\quad$ To adjust to changes, have self-trust and a spirit of cooperation, be able to provide assistance for welfare, progress, freedom and democracy;

- $\quad$ To be deeply convinced that justice, peace, harmony, cooperation and respect for others are high human values;

- $\quad$ To respect the traditions of other peoples;

- $\quad$ To be aware of environmental protection.

These aims are incorporated into the teaching and learning process. Albania is in the middle of a curriculum reform for the pre-university education system. The curriculum reform is designed to make the curriculum for basic education more modular and comparable to competency-based curricula in EU Member States, as well as to introduce a modern ICT curriculum in basic and secondary schools (UNESCO's Report 2017, p. 15). The development of technology pushes education to include updated knowledge in the curricula and to make technology part of the education process.

These curricular changes are needed to be accompanied with updated knowledge about the teaching profession. The teachers of Albania presently vary in their qualifications and in their experience of more interactive, student-centred pedagogies. Studies have shown that about 70 percent of Albanian teachers have been educated during the communist regime (Lama et al., 2001, p. 48). There are teachers who were trained prior to Albania becoming democratic, and teachers trained more recently who may be quite comfortable with a constructivist approach, but who have been using the previous, more teacher-centred curriculum that preceded this reform (UNESCO's Report 2017, p. 16). It should be recognized that advance in education depends largely on the qualifications and ability of the teaching staff in general and on the human, pedagogical and technical qualities of the individual teachers (ILO/UNESCO Recommendations 1966 and 1997).

Consequently, teacher training reforms are very much needed in every country, particularly in countries which are under transformation such as Albania. Strengthening the capacity of teachers through contemporary professional training and development means children reach their potential in a knowledge-based society. 


\section{The 'professional profile for teachers' in Albania and the applicable legislation}

Teacher education may be organised in various ways, but usually includes a general and a professional component. The general component refers to general education courses and mastery of the subject(s) that candidates will teach when qualified. The professional part provides prospective teachers with both the theoretical and practical skills needed for teaching and includes in-class placements (European Commission/EACEA/Eurydice, 2013, p. 23).

In Albania, the Law of pre-university education has determined the level of education needed for each category of teachers, by organizing teachers in the following categories:

- $\quad$ Teachers of pre-school education;

- $\quad$ Teachers of primary education;

- $\quad$ Teachers of low-secondary education;

- $\quad$ Teachers of gymnasium;

- $\quad$ Teachers of vocational education.

Table 1. Organisation of the teaching profession in the Albanian legal framework

\begin{tabular}{cllll}
\hline No. $\begin{array}{l}\text { Category } \\
\text { of teachers }\end{array}$ & Level of education & \multicolumn{1}{c}{ Legal Reference } & \multicolumn{1}{c}{ Comments } \\
\hline $\begin{array}{l}\text { 1. } \\
\text { Teacher of } \\
\text { pre-school } \\
\text { education }\end{array}$ & Bachelor degree & $\begin{array}{l}\text { Article 57, Law of } \\
\text { pre-university educa- } \\
\text { tion; Article 83, Law of } \\
\text { higher education and } \\
\text { scientific research }\end{array}$ & \\
\hline 2 & $\begin{array}{l}\text { Teachers } \\
\text { of primary } \\
\text { education }\end{array}$ & $\begin{array}{l}\text { Bachelor degree and } \\
\text { Professional Master }\end{array}$ & $\begin{array}{l}\text { Article 57, Law of } \\
\text { pre-university educa- } \\
\text { tion; Article 83, Law of }\end{array}$ & $\begin{array}{l}\text { According to the law on higher } \\
\text { education, the second cycle of } \\
\text { studies should be 'Professional }\end{array}$ \\
& $\begin{array}{l}\text { higher education and } \\
\text { scientific research }\end{array}$ & $\begin{array}{l}\text { Master', which forms primary } \\
\text { school teachers }\end{array}$ \\
\hline $\begin{array}{l}\text { Teachers of } \\
\text { low-sec- } \\
\text { ondary } \\
\text { education }\end{array}$ & $\begin{array}{l}\text { Bachelor degree and } \\
\text { Master degree (120 } \\
\text { credits) according to } \\
\text { the relevant fields } \\
\text { where candidates will }\end{array}$ & $\begin{array}{l}\text { Article 57, Law of } \\
\text { pre-university educa- } \\
\text { tion; Article 83, Law of } \\
\text { higher education and } \\
\text { scientific research }\end{array}$ & $\begin{array}{l}\text { Second cycle programs in the } \\
\text { field of teaching should have at } \\
\text { least 25\% of credits in the field } \\
\text { be qualified }\end{array}$ & $\begin{array}{l}\text { of psycho-pedagogical training } \\
\end{array}$ \\
\hline
\end{tabular}




\begin{tabular}{ccccc}
\hline No. $\begin{array}{l}\text { Category } \\
\text { of teachers }\end{array}$ & Level of education & Legal Reference & \multicolumn{1}{c}{ Comments } \\
\hline 4 & $\begin{array}{l}\text { Teachers of } \\
\text { gymnasium }\end{array}$ & $\begin{array}{l}\text { Bachelor degree and } \\
\text { Master degree }(120 \\
\text { credits) according to } \\
\text { the relevant fields } \\
\text { where candidates will } \\
\text { be qualified }\end{array}$ & $\begin{array}{l}\text { Article 57, Law of } \\
\text { pre-university educa- } \\
\text { tion; Article 83, Law of } \\
\text { higher education and } \\
\text { scientific research }\end{array}$ & $\begin{array}{l}\text { Second cycle programs in the } \\
\text { field of teaching should have at } \\
\text { least 25\% of credits in the field } \\
\text { of psycho-pedagogical training }\end{array}$ \\
\hline 5 & $\begin{array}{llll}\text { Teachers of } \\
\text { vocational } \\
\text { education }\end{array}$ & $\begin{array}{l}\text { Bachelor degree and } \\
\text { Master degree in the } \\
\text { field of education }\end{array}$ & $\begin{array}{l}\text { Article 57, Law } \\
\text { of pre-university } \\
\text { education }\end{array}$ & $\begin{array}{l}\text { Teachers of vocational education, } \\
\text { holding professional specialisms, } \\
\text { such as oriented education and } \\
\text { working with disabled students, } \\
\text { shall have obtained the second } \\
\text { cycle diploma in the field of } \\
\text { education }\end{array}$ \\
\hline
\end{tabular}

The professional profile of teachers is not mentioned either in the Law of pre-university education or in the Law of higher education and research.

In 2011, the teaching profession was included in the Law of Regulated Professions, therefore earning the right to exercise a regulated profession if, after completing the appropriate initial training in the education field, candidates pursue professional practice, take the state exam, be registered in the respective Professional Order and obtain a license for practicing the profession. After the initial teacher education, the candidates perform professional practice and enter into the state exam of teachers, which is organized into twenty-three different profiles for the teacher profession. ${ }^{4}$

The professional profiles of teachers in the state exam are as following:

1. English language

2. Italian language

3. French language

4. German language

5. Greek language

6. Albanian language and literature

7. Social Science

8. History

9. Geography

$4 \quad$ The profiles are stipulated in Instruction No. 10, dated 3.4.2015 "On the content and form of the license of the successful candidate at the state exam for exercising of the regulated profession of teacher", and in the orders of the Ministry of Education and Science issued during 2012 on the establishment of state examination commissions. 
10. History and geography

11. History, geography and social education

12. Mathematics

13. Physics

14. Mathematics and physics

15. Informatics

16. Mathematics and Informatics

17. Chemistry

18. Biology

19. Biology and Chemistry

20. Physical Education

21. Figurative art

22. Music

23. Primary education

However, there are inconsistencies in the professional profiles of teachers between the initial training in the universities and the profiles of the Teachers for Albania competitive employment exam. According to the programmes offered by universities ${ }^{5}$ in the field of education, there are certain programmes such as Spanish language, Russian language, and Turkish language at the University of Tirana, for which the state exam in the teaching profession is not conducted.

On the other side, the organization of bachelor study programmes with two subjects such as History and German language, or Geography and Italian language at the University of Elbasan does not help to fulfil the profile of the future teacher, especially when the two branches of the bachelor study programmes have uneven credit weights.

Regardless of the fact that there are teaching profiles in the state exam with two or even three directions such as biology and chemistry, or history, geography and social education, and the teachers are provided with the respective licenses, the Teachers for Albania competitive employment exam does not cover profiles with double or triple directions (On the approval of orientation programs for the teaching portal for Albania 2017-2018, Order of the Minister of Education, Sports and Youth, 2018).

5 Decision of the Council of Ministers, No. 216, dated 20.04.2018, "On establishing of the average admission criteria of the candidates of the first cycle study programs and integrated study programs of the second cycle or transfer of studies in the intermediate years of these programs, in higher education institutions, for academic year 2018-2019”, appendix 1. This act has determined the universities which offer bachelor study programmes in the field of education and the average rating criterion for admission to these study programs. 


\section{The European qualification structure and national qualification framework regarding teacher education}

According to the National Qualification Framework, the category of teachers of pre-school education belongs to the $6^{\text {th }}$ level of the framework, while other teachers (primary education, low-secondary education and upper secondary education or gymnasium teachers) belong to the $7^{\text {th }}$ level of the framework (On Albanian qualification framework Law of 2010).There are similarities between the National Albanian Qualification and the European Qualification Structure, ${ }^{6}$ and therefore the categories of teachers belong to the same levels in both structures.

Regarding the description of the teaching profession in the national list of professions, all categories, including the academic staff, are known as "specialist of teaching" (On the approval of the national list of professions, Decision of the Council of Ministers, 2017). According to the prescription, teaching specialists teach the theory and practice of one or more disciplines at different educational levels, as well as conduct research, inspections, counselling for the improvement and development of specific concepts, theories and operational methods pertaining to their disciplines, and prepare various scientific documents and books in the field of teaching. They can be employed in various institutions that provide teaching services at different levels of education or undertake self-employment.

\section{Accountability of teachers in the course of teacher education reforms}

The reforms undertaken in the Albanian education sector aim to increase quality, particularly of the teachers. Including the teaching profession in the law of regulated professions in Albania was the first step towards the increase of accountability in this profession. In this way, there are some filters which help to clarify the teaching profession, starting from initial teacher education.

According to the Law on the regulated professions of 2009, the right to practice a teacher's profession can be earned, when the candidate passes three steps:

a) Perform professional practice;

b) Perform the state exam;

6 http://www.cedefop.europa.eu/en/events-and-projects/projects/european-qualificationsframework-eqf. 
c) Be registered in the respective Professional Order (national professional register).

There are certain regulations that must be followed for each respective step before exercising the profession. These legal provisions increase the accountability of individuals towards the teaching profession. They are associated with the approval of the general standards of teachers, the professional standards of general and scientific training of teachers as well as the ethical code of teachers. The standards describe what the teacher should know, what he or she should be able to do, and what ethical values should characterize the teacher's work. According to the standards, the evaluation of a teacher's work is organized through self-evaluation.

All the steps taken during the reforms in the education sector through the teaching license exams, the competitive employment exam and the use of standardized curricula, seek to hold teachers more accountable but increase the centralized control of schools as well (Ingersoll, 2011, p. 98). It is a fact that the quality of teachers and teaching is undoubtedly among the most important factors shaping the learning and the growth of students. On the other side, the proper policies to hold teachers accountable, reward high-performing teachers and remove those who do not meet the required standards are still missing.

\section{How does education reform include incentives for student-teachers actually teaching?}

Across the world, teachers' pay is overwhelmingly determined by their levels of education and years of experience (McEwan and Santibańez, 2005, p. 2). Even in Albania, the initial training and education, the continued professional development and the qualifications of teachers determine their pay. Every qualification category shall be accompanied with a supplemental amount to the salary, the extent of which shall be determined upon the decision of the Council of Ministers (On Pre-university Education System in the Republic of Albania Law of 2012).

Another incentive provided for in the Law of pre-university education for teachers is connected to the results of their work. Teachers are entitled to receive rewards for outstanding achievements from the local educational units. Even the director of the school has the ability to use a special annual fund for personal contributions to teachers during the year. According to the law, the criteria for using these funds shall be determined upon the 
decision of the Council of Ministers. Even though the Law in pre-university education entered into force in 2012, both decisions of the Council of Ministers have not been issued yet.

The lack of a legal basis, the unsustainable policies and the lack of comprehensive mechanisms for implementing reforms, make the incentives for teachers almost inexistent.

\section{Conclusions}

The teaching profession is always on the move. The adaptation of the study programs of the teaching profession to the standards of the Bologna Declaration has been a challenge for Albania, as before this period the organization of these programs has been very standardized.

Changes in those teaching programs associated with the relevant legislative and political changes after 2007 have initially led to the diversification of teacher education, which has evidenced the need for clearer rules regarding the teaching profession. The inclusion of this profession in the list of Albanian regulated professions has shown above all the need to approximate the teaching profession to the requirements and standards of the European Union.

The reforms implemented in Albania undoubtedly show the desire to improve the teaching profession, but they need to go in the heart of the content of this profession and not only its outer appearance. The reality shows that reforms are initiated without a continuous follow-up of all the stages of the teaching profession, making the changes look incomplete. In order for the reforms to be effective, a holistic long-term strategic policy with proper analyses and feedback for every stage of teaching profession is needed, including legislation, institutional changes, curricula, pre-service education, and teacher training.

\section{Acknowledgements}

The author would like to express her sincere gratitude to the Albanian colleagues who provided valuable comments and suggestions.

\section{References}

AMU \& AML Standard Profesionale Te Mesuesit (Professional Standards of Teachers). Retrieved May 20, 2018 from http://izha.edu.al/Biblioteka/Zhvillimi\%20 
Profesional\%20i\%20M\%C3\%ABsuesit/Standartet\%20Profesionale\%20te\%20 Mesuesit\%20AMU\&AML.pdf.

Communication from the Commission to the European Parliament, the Council, the European Economic and Social Committee and the Committee of the Regions (2012). Rethinking Education: Investing in skills for better socio-economic outcomes Strasbourg, 20.11.2012 COM (2012) 669 final.

Constitution of Albania (1998), approved on 21 October 1998 by Law no. 8417, dated 21.10.1998, Retrieved June 02, 2018 from http:/www.qbz.gov.al/Kushtetuta\%20 me\%20pjese/Kushtetuta\%201998,varianti\%201.pdf.

European Commission. (2011). Albania 2011, Progress Report, Brussels 12.10.2011, Sec (2011), 1205 Final.

European Commission. (2013). Key Data on Teachers and School Leaders in Europe. Eurydice Report, March 2013 Edition, Retrieved June 02, 2018 from https:// eacea.ec.europa.eu/national-policies/eurydice/content/key-data-teachers-andschool-leaders-europe-2013-edition_en.

European Commission. (2013). Teacher education and training in the Western Balkans: Report on Albania, October 2013, Publications Office of the European Union. Retrieved June 02, 2018 from https://publications.europa.eu/en/publication-detail/-/publication/7be56db6-2cfd-49f3-a567-b70784544b71/language-en.

Haxhiymeri E., and Mita N. (2014). Zhvillimi professional dhe vlerësimi I mësuesve në Shqipëri, Kualicionipër Arsimin e Fëmijëvenë Shqipëri, Tiranë 2014, Retrieved June 02, 2018 from https://www.crca.al/sites/default/files/publications/Raport\%20per\%20vleresimin\%20e\%20mesuesve.pdf.

Héritier, A. (2005). Europeanization Research East and West: a Comparative Assessment. In: F. Schimmelfennig and U. Sedelmeier (Eds.), The Europeanization of Central and Eastern Europe (pp. 199-209). Ithaca, NY: Cornell University Press.

ILO/UNESCO. (1996). Recommendation Concerning the Status of Teachers (1966) and UNESCO Recommendation concerning the Status of Higher-Education Teaching Personnel (1997). ED-2008/WS/24.

Ingersoll, R. (2011). Power, Accountability, and the Teacher Quality Problem. In: S. Kelly (Ed.), Assessing Teacher Quality: understanding teacher effects on instruction and achievement (pp. 97-109). New York: Teachers College Press. Retrieved May 22, 2018 from https://repository.upenn.edu/gse_pubs/236/.

Institute for Development of Education, Albania. (2016). The identification of the needs for training of the directors and teachers in pre-university education schools. National Report March 2016, Retrieved June 02, 2018 from: http://izha.edu.al/ new/2017/03/27/identifikimi-i-nevojave-per-trajnimin-e-drejtuesve-dhe-mesuesve-te-shkollave-ne-arsimin-parauniversitar/

Lama, I., Sula, A., and Gjokutaj, M. (2011). Current Issues of Teacher Training in Albania. Problems of Education in the 21 ${ }^{\text {st }}$ Century, 32, 47-57. Retrieved June 02, 2018 from http://www.scientiasocialis.lt/pec/node/572.

McEwan, P., and Santibańez, L. (2005). Teacher Incentives and Student Achievement: Evidence from a Mexican Reform, p. 2, Retrieved May 14, 2018 from http:// citeseerx.ist.psu.edu/viewdoc/download?doi=10.1.1.579.9811\&rep=rep1\&type $=$ pdf. 
Neascu-Hendry, L., Turek, I., Kviecinska, J., Kati, K., and S. Orlin, T. (1997). Implementing human rights education in three transitional democracies: Romania, Slovakia and Albania. In: G.J. Andropoulos and R.P. Claude (Eds.), Human Rights Education for the Twenty-first Century, Philadelphia: University of Pennsylvania Press.

OECD. (2002). Thematic review of national policies for education - Albania, Stability Pact for South Eastern Europe, CCNM/DEELSA/ED (2001)2, 15-Jul-2002, Retrieved June 02, 2018 from http://www.oecd.org/officialdocuments/publicdisplaydocumentpdf/?cote=CCNM/DEELSA/ED(2001)1/FINAL\&docLanguage=En.

On establishing of the average admission criteria of the candidates of the first cycle study programs and integrated study programs of the second cycle or transfer of studies in the intermediate years of these programs, in higher education institutions, for academic year 2018-2019, appendix 1, Decision of the Council of Ministers, 2018, No. 216, dated 20.04.2018.

On Higher Education in the Republic of Albania Law of 2007, No. 9741, dated 21.05.2007, (as amended), Retrieved June 02, 2018 from www.qpz.gov.al.

On Higher Education and Scientific Research in Institutions of Higher Education in Republic of Albania, Law of 2015, No. 80/2015.

On the Pre-university Education System Law of 1995, No. 7952, dated 21.06.1995, as amended, retrieved from www.qbz.gov.al.

On the Pre-university Education System in the Republic of Albania Law of 2012, No. 69 of 21.6.2012, Retrieved fromhttp://www.arsimi.gov.al/al/newsroom/ligje/ ligj-nr-69-2012-per-sistemin-arsimor-parauniversitar-ne-republiken-e-shqiperise \&page $=1$.

On Regulated Professions in the Republic of Albania Law of 2009, No.10171 dated 2.10.2009 as amended. Retrieved from www.qpz.gov.al.

On Setting up the Accreditation Commission of Training Programs, Order of the Minister of Education and Science, 2011, No. 110, dated 09.03.2011.

On the Adoption of the Strategy for the Development of Pre-University Education, for the Period 2014-2020, Decision of the Council of Ministers, 2016, No. 11, dated 11.01.2016, Retrieved from Official Bulletin No. 2, dated 19 January 2016.

On the Approval of Orientation Programs for Teaching Portal for Albania 2017-2018, Order of the Minister of Education, Sports and Youth, 2018, No. 4, dated 08.01.2018. Retrieved June 02, 2018 from http://www.arsimi.gov.al.

On the Content and Form of the License of the Successful Candidate at the State Exam for Exercising of the Regulated Profession of Teacher, Instruction of the Ministry of Education and Sport, 2015, No. 10, dated 3.4.2015.

On the Establishment of the Institute for Development of Education, Decision of the Council of Ministers, 2010, No. 67, dated 10.02.2010. Retrieved June 02, 2018 from http://www.qbz.gov.al.

On the General Standards of Teachers, Instruction of the Ministry of Education and Science, 2013, No. 5, dated 25.02.2013. Retrieved June 02, 2018 from www.qbz.gov.al.

On the Organization and Development of Professional Practices for the Regulated Profession of Teacher, Regulation of the Ministry of Education and Science, 2011, No. 336, dated 14.07.2011. 
On the Organization of the State Exams for Regulated Professions in the Republic of Albania, Regulation the Ministry of Education and Science, 2011, No. 82, dated 22.02.2011.

On the Organization of Computerized Testing of Candidates for Employment in Public Institutions of Pre-university Education, Instruction of the Ministry of Education, Sport and Youth, 2018, No. 12, dated 27.02.2018. Retrieved June 02, 2018 from http://www.arsimi.gov.al.

On the Professional Development of Teaching Personnel, Directive of the Ministry of Education and Sport, 2014, No. 26, dated 15.08.2014.

On the Reorganization of Educational Directors in Districts in the Regional Education Directors and the Education Offices, Decision of the Council of Ministers, 2003, No. 707, dated 16.10.2003.

Papadhopulli, S., and Mico, H. (2016). Higher Education and Research in Albania in the Way of Achieving the Objectives of Bologna Declaration. Working Papers in Higher Education, 2 (1), 21-57. Retrieved May 20, 2018 from http://www. wphes-journal.eu/

Sota, J. (2011). Educational Phenomena in Albania in the Years of Communist Dictatorship and the Reformation Efforts after Nineties. European Scientific Journal, 11 https://eujournal.org/index.php/esj/article/view/4721.

UNESCO (2017). Albania, Education Policy Review, Issues and Recommendations, Report, Paris, April 2017 ED-2017/WS/23. Retrieved June 02, 2018 from https:// ec.europa.eu/epale/sites/epale/files/albania_education_policy_review_issues_ and_recommandations_april_2017.pdf.

Zgaga, P. (2010). The Role of Higher Education in National Development. South-Eastern Europe and Reconstruction of the Western Balkans [online]. Retrieved May 20, 2018 from http://pefprints.pef.uni-lj.si/717/. 


\title{
Chapter 11
}

\section{Teaching Practice in the Albanian Context: Student-Teachers' Perceptions regarding their Experience in Teaching}

\author{
Manjola Zaçellari (Lumani) \\ Faculty of Education, Aleksander Moisiu University, Tirana, Albania
}

\begin{abstract}
The purpose of this study is to analyze the education reform in Albania, in order to observe the importance and the space that teaching practice (work placement) during their studies plays in the preparation of new teachers. In addition, the study aims to identify students' views of the problems encountered during their teaching practice. Qualitative methods were used for the aims of this study. The data was collected through document analysis (legislation, strategies, regulations) for analyzing how legislation regarding pre-university and higher education in Albania addresses teaching practice, and through semi-structured interviews and focus groups with student-teachers for identifying their perceptions of teaching practice. Students were posed 19 interview questions. During the administration of the interview process, data collectors explained its purpose, and answered questions from the interviewees to better clarify all questions. On the basis of the same principle, two focus groups were created with students of Bachelor and Master studies, who were later interviewed. After evaluating the responses, some important issues were identified, in particular regarding classroom management, coping with cases where there are children with special needs in class, the discrepancy between theory and practice, etc.
\end{abstract}

KEYWORDS: teaching practice, education reform, student-teachers, Albania

CONTACT Manjola Zaçellari (Lumani), EMAIL: manjola_zacellari@yahoo.com 


\section{Introduction}

The education system in Albania is undergoing constant changes, which are mainly related to the drafting of laws in line with international objectives, as well as to the successful implementation of the reforms undertaken so far. As a post-communist country, Albania is facing challenges which are not so simple and easy, specifically regarding the modernization of the education system, the approximation of the applied education legislation with the ones in those countries which have a high reputation and great achievements in the field of education, and the continuous training of teachers with the aim of adaptation to a new and multi-faceted reality. The most important issue of these changes lays in curricular reform, which aims to increase students' competence in the learning process and in life, to increase the inclusion of different students, and to engage and keep the students studying at least until the end of their basic education in order to enable Albanian children and young people to participate successfully in society (MoES, 2014, p. 7). Reforms success is closely connected to teacher training, especially in their initial training and formation. Various studies have shown that a teaching qualification is one of the most important factors in a school, one which has a direct impact and affects students' achievements (Rivkin et al., 2005, p. 415). Orientation towards pedagogical professionalism has replaced lesson-based teaching by giving more attention and shifting to the formation of teachers' ability so as to develop professional autonomy and to become active promoters of change. "A reality which is changing means expectations and tasks must be dealt with for teachers who are gaining new skills" (Abdurrahmani and Boce, 2011, p. 215).

In Albania, students often complain that during university studies they are not prepared and equipped adequately with practical knowledge, and that mostly the study programs that they follow only enable them theoretically, making it difficult to put into practice the theories learnt. This is noticeable especially in students of teaching programs. In the report of the European Commission, Teacher Education and Training in the Western Balkans (2013, p. 25), in the section on Albania, teaching practice is seen as "the least developed component in teacher training programs". Further in this report (pp. 11-26) it is stated that "in Western Balkan countries, teacher training programs tend to be theoretical, focusing more on subject knowledge than on practical training with teaching techniques that put the student at the center, or in inclusive education”. One of the main recommendations 
of this report relates specifically to the duration of teaching practice and the creation of unified programs for teacher education and training.

More widely, the issue of teaching practice is reflected in the assessment report which UNESCO compiled in 2015 on education policies in Albania, where it is stated that the process for the preparation of new teachers in Albania is not very developed. According to the research, there are a number of problems with the programs compiled for the initial training of student-teachers, even though the government is willing to tackle them through policy change. These challenges include the lack of sufficient and adequate preparation of the pre-university curriculum where the student is at the center, and the discrepancies between the initial teacher training programs and the opportunities for teaching practice (UNESCO, 2015, p. 137). While Abdurrahmani (2013, p. 55) notes that "not having the chance to attend lessons being held in a real classroom environment can be a reason why young teachers come up with lower scores on the qualification exam, especially in the practical section of the exam".

Various researchers find teaching practice as one of the most important elements of becoming a future teacher. According to Kasanda (1995, pp. 57-68), during teaching practice, "a student teacher is given the opportunity to try the art of teaching before actually getting into the real world of the teaching profession. Thus, teaching practice enables students with practical knowledge on using teaching methods, strategies, principles, techniques and practice or exercise different activities of daily school life". While Perry (2004, p. 2) notes that "teaching practice refers to the period of time in which a student teacher gains first experience in working with a particular group of children". Thus, teaching practice can be undertaken in a number of forms, such as a day per week over a semester, or in two- to six-week period. Kiggundu and Nayimuli (2009, p. 347) view teaching practice as "a form of work-integrated learning, a time when students are working in order to apply theory in practice". For Marais and Meier (2004, p. 221) "the term teaching practice represents the range of experiences to which student teachers are exposed when they work in classrooms and schools", while Stones and Morris (1972, p. 220) highlight three connotations of the term teacher practice: "the practicing of teaching skills and acquisition of the role of a teacher; the whole range of experiences that students go through in schools; and the practical aspects of the course as distinct from theoretical studies."

Undoubtedly, teaching practice is a very important process. During the period when it is conducted, students face the profession for the first time, 
being both students and teachers. Therefore, teaching practice turns into a very challenging process for them. Thus, students need to get acquainted with the main problems that accompany this process. We suggest that, if these challenges are not addressed properly, it may affect student-teachers' performance during their teaching practice, and that may affect their perceptions of the teaching profession.

The review of the literature indicates that in Albania there are no compiled studies analyzing how student-teachers perceive teaching practice and what their views are on the teaching profession (studies are mainly focused on reviews on teacher training reforms in Albania (Abdurrahmani and Boce, 2011; Lama et al., 2011), or in teachers' professional development (Gjedia et al., 2018), or in reports on mapping policies and practices for the preparation of teachers, etc. (Ikonomi et al., 2010). Thus, this study is an attempt to fill this gap, in order to observe the importance of student-teachers' perceptions of the process of teaching practice for evaluating the main problems they face and how to cope with them.

\section{Purpose of the study}

Given the above-mentioned issues, this study aims to analyze how different regulations or guidelines address the problem of teaching practice, aiming to provide a concrete picture of the achievements reached so far, and undertaken in compliance with the reforms in education, especially in teaching practice. Also, the study aims to explore students' views on certain problems they encounter during their teaching practice.

Research questions are formulated as follows:

1) How does education reform address the teaching practice of future teaching students?

2) How do students perceive the teaching practice and what are the difficulties they face?

3) How do student-teachers perceive their academic training in terms of their preparation with the adequate knowledge and practical skills?

\section{Research methods}

Qualitative methods were used for the aims of this study. The data was collected through documents analysis (legislation, strategies, regulations) 
for analyzing how legislation regarding pre-university and higher education in Albania addresses teaching practice, and through semi-structured interviews and focus groups with student-teachers for identifying their perceptions of teaching practice. The interviews were conducted in a warm and friendly atmosphere, allowing everyone to express their thoughts and views. Students were posed 19 interview questions. During the administration of the interview process, data collectors explained its purpose, and answered questions from the interviewees to better clarify all questions. On the basis of the same principle two focus groups were created with students of Bachelor and Master studies, who were later interviewed. Questions were related to problems student-teachers encounter during teaching practice, how they manage to solve them and the ways both the schools and universities help them to deal with these problems.

The sample includes 48 students from the Primary Teacher Education program who are at the end of the teaching practice. The students are at the end of the third year of their Bachelor studies and the second year of the Master studies in Elementary Education. All respondents are females, which is representative of this population ( $98 \%$ female gender). At all levels of education, especially at the primary level, there are more female teachers than male teachers. According to UNESCO Institute of Statistics in Albania since 2011, 100\% of primary education teachers are women (UNESCO, 2017, p. 137).

This study has limitations. These include using in-depth interviews with students from only one Albanian university, which hampers the ability to generalize the data.

\section{Results}

\section{Reform in the Albanian education system in light of the document analysis}

It was emphasized above that the Albanian education system has undergone a constant reformation during the recent years. Hence, in Albania there are several legal instruments that either directly or indirectly have affected the education sector. Some of them are related to initial teacher training. In addition, there are several regulations which regulate the functioning of the whole process. Part of this legislation adopted important amendments, particularly those related to the Law on Regulated Professions in the Republic of Albania (2009). It was implemented for the first time in 
2011 and included: regulations for the organization and conduct of professional practice for teaching, a regulated profession, which determined as necessary the certification of teachers who have completed one mandatory year of professional training (internship) and have passed the State Exam for Teachers.

However, the most comprehensive legal instrument among these laws is that of 2012, under which some of the most progressive principles in education were developed, including open and inclusive education of children with special needs, the greater role of parents in school governance, increased school independence, the emphasizing of the benefits of teaching practice, and the restructuring of basic education. This law improved the academic qualifications required for teachers' certification, asking teachers and directors to attend a compulsory three-day training on an annual basis, in order to achieve continuous professional development (MoES, 2012, p. 4420).

Even though for a long time teaching practice was not conducted as it should be, since Albania signed the Bologna Declaration in 2003, constant changes have been made in regard to study programs for teaching, and in particular to student-teacher preparation. Teaching practice is now seen as an integral part of initial teacher education in Albania. The practice is undertaken under the joint supervision of the university and the school. Before 2011 the process of preparation of new teachers, including teaching practice, was undertaken only under the supervision of higher institutions of education, after which teachers underwent a period of praxis for nine months (a school year) in selected schools before they sat for the State Exam, which allowed them to receive their license as teachers (MoES, 2011, p. 2). Now teaching practice is accomplished in two periods: firstly, during university studies (master studies) and then during one year of professional practice (internship) after university and before the teacher State Exam.

In 2015, the Ministry of Education and Sports drafted a new strategy called Pre-University Education Development Strategy 2014-2020, which was designed to take advantage of the pillars of the previous national plan and to further the reform in the education sector by closely linking it with strategies for the country's overall development and integration in the EU. This strategy outlined the strategic policy objectives that govern the pre-university education system related to: enhancing governance; leading and managing capacity and resources; qualitative and inclusive learning; ensuring the quality of achievement in compliance with the standards of 
EU countries; contemporary professional preparation and development of teachers and directors (MoES, 2014-2020, p. 27).

In addition to the adopted laws of pre-university education, in 2015 the Law on Higher Education and Scientific Research was drafted. Article 83 of this law states: "Study Programs of the second cycle study, which form teachers of the same field of study, should have at least 80 percent of the curriculum with similar content” (MoES, 2015, p. 29). But even though the reform has aimed at offering programs which prepare teachers in line with European standards, especially by adding a research thesis as a requirement for all programs, recent research has identified that initial teacher training programs do not have the same content. Even according to some reports made by the Ministry of Education and Sport "they differ from institution to institution and the curriculum is overloaded" (ibid.). Likewise, "in these programs, apart from being fragmented, they do not identify which ones are mostly considered necessary in order to have successful teachers” (ibid.).

Therefore, under these conditions, initial teacher training programs should be structured by collaborating with providers of these programs, i.e. with universities, but also with teachers and schools. All these institutions have to co-ordinate the work so that any student aspiring to become a teacher in the future understands the student-centered teaching philosophy and receives theoretical and practical knowledge in order to practice the profession in the future.

According to the report on the initial training of teachers in higher education institutions, drafted by the Institute of Educational Development (IED, 2016, pp. 23-29) "in order to improve the practice it is recommended that the key stakeholders provide useful data in line with the criteria of assessment for practitioners, mentors teachers or teachers”.

\section{How does the educational system in Albania work in terms of teachers' preparation?}

Undergraduate programs for teachers in Albania are designed for two cycle study programs, Bachelor studies (180 credits) lasting three years and Master studies (120 credits), undertaken consecutively. According to the law on pre-university education of 2012, the programs for elementary education teachers must be integrated, and all teachers should receive a Master's degree (MoES, 2012, p. 4419). The legislation regarding higher education clearly defines this requirement, and emphasizes the unification of the curriculum in up to $80 \%$ of the teaching programs, in order to standardize 
them and improve the quality of the programs. On the other hand, the law obliges teachers to take one year of internship and to take the license exam before being employed as a teacher in the education system.

What the law does not foresee is the place that professional practice in these programs should take, as well as the lack of a regulatory document regarding internship applications. According to IED (2016, p. 35) "the relationship between universities and schools during the period of professional practice is not regulated through any regulatory document and the supervision of the practice conduct and its assessment is accompanied by numerous problems. The mentoring system for the professional practice is vague and almost does not work".

As a result, this is a deficiency of the process of professional practice for the preparation of the new teachers, taking into account the main and important elements that the programs for initial teacher training should include. Thus, TALIS (Teaching and Learning International Survey) for teachers of the primary schools takes into account the integration of three main component elements related to the academic knowledge of the subjects to be acquired: "teaching theories, including teaching skills and student support and learning, as well as the classroom practice experience" (European Commission, 2013, p. 21).

It is noted that one of these elements is practical experience in a classroom environment where the student is a teacher. Since this process is occasionally accompanied by shortcomings, it would be advisable to schedule the practice earlier, and according to some guidelines it should even start from the first year of the study program. "The professional practice requires and must be given sufficient time and it must begin at the beginning of students' studies in order to give them the opportunity to practice and reflect upon the teaching strategies while learning and studying more for their course programs” (MoES, 2014, p. 29).

\section{Student views on teaching practice as part of their studies}

As outlined above, in order to explore Bachelor and Master's students' perceptions of their teaching practice, a series of interviews were conducted. The interview questions were focused on the following aspects: (a) Dealing with students with special needs, (b) Classroom management, (c) Practical-theoretical preparation, (d) Adoption of a new curriculum, (e) Methods of teaching, (f) Limited access to information technology. These aspects are described in detail below. 
(a) Dealing with students with special needs

When reviewing and analyzing the answers it turned out that a considerable part of the students who completed the internship after the completion of the first cycle of studies encountered difficulties in dealing with cases where pupils with special needs were part of the class. This was a very important problem for internship students of the Master study program, who claimed that in some cases the classrooms where they taught had two or three pupils with special needs. They reported they felt uncertain about how they should face such situations in the classroom, as in most cases the work is hampered by the lack of support teachers or specialists in the field. Student-teachers are in the first phase of practicing their profession and face, on the one hand, a new working environment, new colleagues, classroom leadership, teaching and other aspects related to life in school, and on the other hand, with various problems, such as those related to students with special needs who require maximum dedication, but also the qualified support of assistant teachers and complementary tools or aids. In addition, there is another problem related to the difficulties faced by interns, which is related to dealing with cases of students who prejudice other students (bullying). Furthermore, it can be stated that such cases are difficult not only for teachers who are young people, but also for experienced teachers, who are obviously familiar with work in all of its aspects.

\section{(b) Classroom management}

Classroom management is also a challenge. According to the interviewed students, this process becomes more difficult especially in cases where there is overcrowding in the number of students, and even when there is no prior planning (diary plan) of lessons. In some cases, when teaching topics are developed in the form of a conversation, it is difficult for practitioners to keep the students focused on topics that are not related to their main interest, or to prevent them from talking to each other or to concentrate and pay attention to what the other is saying. Some students say that this is one of the reasons why mentor teachers find it difficult to leave the practitioners to take over the class, because at the end of the internship, it takes time for the original teachers to manage the class as they used to before.

However, regarding classroom management and the progress of the teaching process, all practitioners stated that they kept a diary plan that guided them during the course. But despite their preparation, there are students who admit that "sometimes, nothing goes according to the predetermined daily 
plan. There are classroom situations that disrupt the planned program written in our diaries” (Student, D.M., female).

Such and other similar cases, according to students, endanger the progress of the entire teaching process. To successfully cope with these situations, they try to follow the models of their teachers or professors, and report that these are often their inspirational role-models. Asked if they feel professionally adept at this stage of professional practice, a student responded to this with: "I do not feel professionally much capable of teaching, as during university studies we learned mostly the theoretical aspect, which is what makes it difficult when the practice tasks are being undertaken during the professional practice. There are many more difficulties than I had thought.”

\section{(c) Practical-theoretical preparation}

This finding affirms a problem which almost all respondents reported in general terms. They thought that university studies prepare them theoretically, but then when it comes to practice and they become teachers themselves they are faced with a different reality to that they were taught and had been studying in textbooks. However, at this stage of their profession they admit unanimously that "there is still too much work to be done so that they can grow professionally”.

\section{(d) Adoption of a new curriculum}

It has been emphasized in this study that teaching in Albanian schools is being developed according to the new curriculum reform based on competencies and learning situations. Being a new approach, internship students find it difficult to adapt to this new reality and combine knowledge, skills and attitudes, and adapt to a familiar or new situation, or to link their own learning with different learning situations and not just the rigid transmission of knowledge. This kind of teaching is achieved mainly through interaction between the students and the learning environment, because only in this way can they develop their competences related to their personal development, social inclusion, etc. According to this view, a lesson implemented with this approach requires all teachers to take responsibilities, and especially new teachers who have not yet gained the right experience to link each new topic developed to a concrete situation that is both age-appropriate and is able to be understood by everyone. 
(e) Methods of teaching

In this context, it is necessary to use more effective methods of teaching. Respondents claim that one of these methods, which involves and engages all students, is learning through games. Although an effective method, some students say that sometimes pupils fail to understand where the game finishes and where the lesson begins. Other methods they use are discussions, conversations, group work, etc.

We point out here that when aiming for inclusion in both the teaching and the learning process, the practitioner-students claim that they often combine different methods, adapting to the needs of their students or their requirements. What they deem a deficiency in their work is the inability to use technological tools in teaching. In the schools where they teach, such services are not provided and information technology is hardly used to realize various lessons, while its multifaceted influence on teaching and learning is known widely. Researchers claim that "through technology the whole teaching process will change in the future" (Gleen and D'Agostino, 2008, pp. 6-14), changing the ratio of the factors that determine the process of education such as the student, the subject, the teaching methodology, the teacher and the parents.

\section{(f) Limited access to information technology}

In addition to these difficulties and sometimes the inadequacy of didactic means, or limited access to information technology, classroom management difficulties, lack of supportive/assistant teachers for children with special needs, etc. the future teachers claim that "they love the teaching profession"; some even say that "they would not change it with any other profession in the world”. (Student, K.D., female) hey admit that teaching practice is enabling them to face concrete situations, know their students and their characters, evidence what they know and what they need to improve.

\section{Discussion}

Teaching practice is a process that requires the good functioning of many elements so that it can be effectively implemented with a focus on the learner. The school and all responsible institutions should guide internship students towards effective theoretical and practical formation with different learning opportunities, as well as enable them to handle difficulties of various levels and be successful teachers. Although these are the basic goals 
of the reforms undertaken in Albania, from the analysis of the data compiled and mentioned above, there are still problems that need to be solved, when compared to the successful practices of countries with a developed educational system.

These problems vary from the difficulty that the internship students encounter when putting the knowledge they gained in theory into practice, as well as the difficulty they have when dealing with students with special needs due to the lack of assistant teachers or specialists in the field, problems with class management due to the large number of students and the overloaded classes, and lack of didactic tools, adaptation to the new curriculum, as well as the relationships with their mentor-teachers, institution leaders in general, and being called "inexperienced young people".

The results suggested are also supported by various studies and reports according to which initial teacher training programs in Albania do not sufficiently prepare students who will become teachers who assess pupils, prepare lessons, manage the class, and teach children with special needs who require special treatment in education as well pupils with different backgrounds (Vula et al., 2012, pp. 37-45).

The data observed through different methods of research convey that there are various factors which contribute to an effective initial teacher training. According to Hagger and McIntyre (2006, p. 33), "for the initial formation of teachers, there is a broad, structured teaching practice, as well as sustainable mentoring”. On the other hand, an individualized focus on teaching students is required. An integrated curriculum for initial teacher education is also required, which enhances their critical thinking, teaching and learning with relevant knowledge, understanding and research; effective partnerships between initial training providers (universities) and schools, and gives joint responsibilities and structured roles for planning, management, monitoring and evaluation.

The new curriculum based on competencies is another issue to be considered in our education system that presents challenges, not only for young teachers but also for experienced ones. Through this curriculum, teachers are required to move from a teacher-oriented one where the teachers themselves are the focus, to a student-oriented one where all learners can learn if they are engaged and supported properly. However, students undertaking professional practice sometimes find it difficult to develop the curriculum as it is required, and it is not entirely clear what it means, but also because in some schools where student-teachers are doing their internship learning 
is based on competences while others still make use of the old curriculum. Studies have shown that "in many low and middle income countries and post-communist countries, pedagogical practices continue to be dominated by the teachers, lecture-oriented and formal lectures, focusing on factual knowledge and procedural knowledge in order to prepare the students for the formal exams" (UNESCO, 2013/4, p. 7).

In circumstances where the changed curriculum requires a significant pedagogical shift, sustainable vocational learning seems to be a condition for success. But, considering the number of students per class, which is overloaded in Albania, it is difficult to develop pedagogical practices according to the demands of education researchers in the developed world. In such conditions, with overcrowded classes, which often exceed the normal number of students per class, it can be stated that "interns who have not gained the proper confidence, face great difficulties especially with classroom management” (Berk, 2005, p. 48).

The difficulty of classroom management is accompanied by another problem related to the theoretical and practical preparation of students during university attendance in Albania. In fact, "initial teacher training programs tend to be theoretical in all Western Balkan countries, focusing more on subject knowledge than on practical training and as well as in teaching techniques that put the student at the center and adopts an inclusive education” (European Commission, 2014, pp. 34-35). In these countries national frameworks, such as common professional teaching standards, are not used to guide the contents of the initial teacher training program; their use would bring significant changes to how providers offer teacher training.

By contrast, in OECD countries it is common for a government body or central authority to establish a framework regarding the content of the initial training programs for teachers. OECD research also recommends that such programs undergo and be subject to periodic accreditation and the ongoing evaluation of these frameworks in order to ensure quality, which is currently not the case in Albania.

The education system in Albania, through ongoing reforms, is trying to fix some of the shortcomings associated with the teaching practice, guided by the principle that it helps students to have higher performance in all aspects. According to a TALIS study conducted in 2013, "teachers from different countries who had completed initial training programs which dealt with the content, pedagogy and teaching practice for the subjects they were taught felt better prepared for their roles than teachers whose initial 
training programs did not cover those elements" (European Commission, TALIS, 2013, p. 13). This emphasizes once again the importance of continuous improvement of these programs, which aim at providing effective teaching, where the main beneficiary is not only the student, but also the entire education system of a country.

\section{Conclusions}

Albania is already facing a major challenge which is related to the modernization of the education system. All the reforms undertaken aim at adapting the applicable education legislation to that of those countries with great achievements in the field of education. For years, universities and training centers have aimed for the continuous training of teachers, in order to adapt them to a new and multi-faceted reality that responds to the ever-increasing need for quality in teaching and qualified teachers. Attention is also focused on initial teacher training. Teaching practice is a key element for initial teacher training in Albania, which is completed mainly in the last year of studies, and since the introduction of the Bologna system, it has been developed in the last semester of the Master study program and covers about $10 \%$ of the curriculum. It is undertaken in both primary and secondary schools. However, being in the reform stages, like the whole education system, teaching practice has its own problems, which require legal regulation and the engagement of all stakeholders involved in the process. Therefore, the issues highlighted in this study are mainly related to difficulties in dealing with students with special needs, classroom management, the new implemented curriculum, mentor-teachers, theoretical-practical approaches, and lack of technological didactic mean., The relationship with schools that allow these student-teachers to develop their professional practice should serve as indicator as to where this process can be improved, and make teacher training in Albania as effective as that in the developed EU countries, which we aspire to be part of.

\section{Acknowledgements}

The author would like to express her sincere gratitude to the Albanian colleagues who provided valuable comments and suggestions. 


\section{References}

Abdurrahmani, T. (2013). Extended Report. The Teacher Qualification Scheme: A Case of Albania. Problems of Education in the $21^{\text {st }}$ Century, 55, 11-27.

Abdurrahmani, T., and Boce, E. (2011). Pre-service, Teacher Training Reform in Albania: A Review. In: P. Picard and L. Ria (Eds.), Beginning teachers: a challenge for educational systems - CIDREE Yearbook 2011. Lyon. France: ENS de Lyon. Institut Français de l'Éducation.

Berk, R. (2005). Survey of 12 Strategies to Measure Teaching Effectiveness. International Journal of Teaching and Learning in Higher Education, 17 (1), 48-62.

European Commission. (2013). Teacher Education and Training in the Western Balkans. Report on Albania. Luxembourg: Publications Office of the European Union. Retrieved May 10, 2018 from http://ec.europa.eu/education/international-coorporation/documents/western-Balkans/teacher-training-report_en.pdf.

European Commission. (2013). The Teaching and Learning International Survey (TALIS). Retrieved April 22, 2018 from http://www.oecd.org/education/school/ EU-TALIS-2013_en.pdf.

European Commission. (2013). The Teaching and Learning International Survey (TALIS). p. 13. Retrieved April 15, 2018 from http:// ec. europa.eu/ assets/eac/ education/library/reports /2014/talis_en.pdf.

European Commission. (2014). Initial Teacher Education in Europe: An Overview of Policy Issues. Background note for the ET2020 Working Group on Schools Policy.

Gleen, M., and D’Agostino, D. (2008). The Future of Higher Education: How Technology Will Shape Learning. Retrieved December 22, 2018 from https://www.nmc. org/pdf/Future-of-Higher-Ed-(NMC).pdf.

Hagger, H., and McIntyre, D. (2006). Learning Teaching from Teachers: Realizing the Potential of School-based Teacher Education. Maidenhead: Open University Press.

Institute for Education Development. (2016). The Report of Initial Teacher Education in Albanian Higher Education Institutions. Retrieved May 4, 2018 from http:// izha.edu.al/new/wp content/uploads/2017/03/Raporti.pdf.

Kasanda, C. D. (1995). Teaching Practice at the University of Namibia: Views from Student Teachers. Zimbabwe Journal of Educational Research, 7 (1), 57-68.

Kiggundu, E., and Nayimuli, S. (2009). Teaching Practice: A Make or Break Phase for Student Teachers. South African Journal of Education, 29 (3), 345-358.

Marais, P., and Meier, C. (2004). Hear Our Voices: Student Teachers' Experiences during Practical Teaching. Africa Education Review, 1 (2), 220-233.

MoES. (2011). Regulation on the Organization and Development of Professional Practices for the Regulated Profession of Teachers. Retrieved June 10, 2018 from http:// www.arsimi.gov.al/wp-content/uploads/ 2018/02/dok-0004.pdf.

MoES. (2012). Law on the Pre-university Education System in the Republic of Albania (p. 4420). Retrieved June 10, 2018 from https:/arsimi.gov.al/files/userfiles/ parauniversitar/Ligj-nr-69-21-06-2012.pdf.

MoES. (2014). Core Curriculum for Lower Secondary Education. Retrieved April 7, 2018, from http://izha.edu.al/new/wp-content/uploads/2017/03/ Kurrikula-berthame-6-9.pdf. 
MoES. (2014). Strategy on Pre-University Education Development 2014-2020. Retrieved June 10, 2018 from https:/arsimi.gov.al/al/arsimi/shkolla/strategjia-e-zhvillimit-te-arsimit-parauniversitar-2014-2020.

MoES. (2015). Law on Higher Education and Scientific Research in Higher Education Institutions in the Republic of Albania. Retrieved June 11, 2018 from http://umt. edu.al/new/rregullore/Ligj 80-2015-22-07-2015.pdf.

Perry, R. (2004). Teaching Practice for Early Childhood: A Guide for Students. London: Routledge.

Rivkin, S., Hanushek, E., and Kain, J. (2005). Teachers, Schools, and Academic Achievement. Econometrica, 73 (2), 417-458.

Stones, E., and Morris, M. (1972). Teaching Practice: Problems and Perspectives: A Reappraisal of the Practical Professional Element in Teacher Preparation. London: Methuen.

UNESCO. EFA Global Monitoring Report. (2013/4). Teaching and Learning: Achieving Quality for All, Monitoring the Education for All Goals. Retrieved May 10, 2018 from https://en.unesco.org/gemreport/sites/gemreport/files/UNESCOLACFactsheet_EN_new.pdf.

UNESCO. (2017). Albania Education Policy Review: Issues and Recommendations. Retrieved May 10, 2018 from https://unesdoc.unesco.org/ark:/48223/ pf0000259245.

Vula, E., Saqipi, B., Karaj, T., and Mita, N. (2012). Moving towards Practice-Oriented and Research- Based Teacher Education: Challenges of Kosovo and Albania. Excellence in Higher Education, 3 (1), 37-45. Retrieved April 14, 2018 from http://ehe. pitt.edu/ojs/index.php/ehe/article/view/42/45. 


\title{
Chapter 12
}

\section{Teachers' Workplace and Personal Wellness: Perspectives from South African Legislation and Policies}

\author{
Erika Kruger and Lynette Jacobs \\ Open Distance Learning, University of the Free State, Bloemfontein, \\ Republic of South Africa
}

\begin{abstract}
Quality education is highlighted in global agendas such as Education for All, and numerous research reports, as a means to escape a life of destitution, particularly in developing countries. To a large extent, quality education depends on teachers' ability to create an enabling environment for learners to thrive. However, in South Africa, teachers have to pull this off in an environment that often does not support their own well-being due to lack of resources in school and community, heavy administrative loads, large numbers of learners in classes, negative learner behaviour and workplace bullying, and the subsequent below-par performance of learners in national examinations, as well as in international benchmark tests. We argue that teachers cannot provide quality education unless their wellness is taken care of. This paper offers an overview of the relevant South African legislation and policies related to the workplace and personal wellness of teachers. We make a number of observations, laying the ground work for a follow-up, more penetrating analysis and assessment of policy content and implementation.
\end{abstract}

KEYWORDS: human rights, education law, education policy, workplace wellness, personal wellness

\section{Introduction}

It is critical for a country's educational system to be responsive to local and global needs (Symaco cited in: Wolhuter, 2014, p. 1). In a country like

CONTACT Erika Kruger, EMAIL: iketlile@gmail.com 
South Africa, with its skewed income distribution, high levels of poverty and education inequality, an education system is required that can contribute to building "socially responsive economic and political systems" to support human development (Modisaotsile, 2012, p. 1). It is argued, not without criticism (Hanushek, 2013, p. 204; Hanushek and Woessmann, 2012, p. 268), that obtaining quality education supports the battle against poverty and underdevelopment (Harber and Mncube, 2011, p. 233) by creating opportunities for youth, improving earning capacity and providing opportunity to escape from a life of destitution (van den Berg, 2002, p. 1). The role of the teacher in terms of teaching quality, and in setting up an enabling environment, is fundamental to the learners' prospects of gaining from the education system, and also to inspire learners towards a "positive and rewarding life” (Hansen, Buitendach, and Kanengoni, 2015, pp. 1-2).

The South African education system, however, does not live up to these expectations. Indeed, Wolhuter (2014, p. 1) considers the education system "the weakest link in the chain tasked with uplifting society to its appropriate place in the world of the twenty-first century". Systemic factors that contribute to this situation include frequent curriculum changes; under-resourced schools; high workloads and administrative demands on staff members; staff shortages and large numbers of learners in a class. Many teachers lack content knowledge and pedagogical skills and learners generally perform poorly in international benchmark tests and in national examinations (van den Berg et al., 2011, p. 4; Zuma et al., 2016, p. 15). In addition, societal factors such as poor socio-economic circumstances of parents and the wider community, parents' lack of education and inability to support their children with school work, and violence at school and in the community negatively impacts on the education system (Hansen, Buitendach, and Kanengoni, 2015, p. 1; Jacobs, 2016, p. 16; Jacobs, 2013, p. 60).

It is inevitable that the factors discussed above would affect the quality of teaching as well as teachers' lived experience of their occupation and consequently their general well-being. In addition, on a personal level individual teachers may suffer health issues with high incidences of tuberculosis, HIV/Aids and lifestyle diseases like hypertension and diabetes (Hansen, Buitendach, and Kanengoni, 2015, p. 2; Laurence et al., 2016, p. 1000; Senekal et al., 2015, p. 2); high levels of physiological and psychological stress (Hansen, Buitendach, and Kanengoni, 2015, pp. 1-3; Vazi et al., 2013, p. 9) and in particular workplace stresses caused by physical, verbal and sexual abuse from colleagues, seniors, learners and even 
parents (De Wet and Jacobs, 2018, p. 20; Zuma et al., 2016, p. 104). All the above often result in low teacher effort (van den Berg et al., 2011, p. 4); low morale; burnout (van Tonder and Williams, 2009, p. 3); absenteeism; high levels of attrition (Fouche, Rothmann, and van der Vyver, 2017, p. 2) and reduced capacity to "transfer [a] positive outlook to students and cultivate a generation of positive, flourishing, committed and satisfied youth, who are able to excel in all spheres of life" (Hansen, Buitendach, and Kanengoni, 2015, p. 2). As the health and well-being of teachers are fundamental to the quality of teaching that they provide (Zuma et al., 2016, p. 1), we thus argue that unless authorities and individuals take care of the wellness of teachers, their functioning will be compromised and this will impact the quality of education that learners receive, which will affect society in general.

Internationally, employee wellness programmes have been around since the 1970s, and in South Africa since the 1980s, with The Chamber of Mines of South Africa taking the lead (Terblanche cited in Sieberhagen, Pienaar, and Els, 2011, p. 2). In recent years, paying attention to a population's levels of wellness and well-being have become entrenched in human resource (HR) management, but also in development studies. Sieberhagen, Pienaar and Els (2011, p. 2) point out that the introduction of employee wellness programmes has shown, with varying results, that both the organisation and employees benefit, and thus in the context of the challenges that teachers face, employee wellness programmes can benefit teachers and the education system. However none of the terms wellness, employee wellness, well-being and self-care are precisely defined in the literature and for the purpose of this article these must be conceptualised.

\section{Definition of wellness and workplace wellness}

Wellness is considered a subjective experience of life satisfaction and emotional reactions (Fischer and Boer, 2011, p. 164; Kruger, 2018, p. 112) and transcends the World Health Organization's (WHO) definition of health as "a state of complete physical, mental, and social well-being and not merely the absence of disease and infirmity" (World Health Organisation, 1946, par 1). Persons with high levels of wellness are able to fulfil their family and community roles, reach their maximum, but realistically feasible, potential through good relationships, self-development, personal improvement, and experiencing meaning in life (Kruger, 2018, p. 112; RSA DPSA, 2008, p. 31; Sieberhagen, Pienaar, and Els, 2011, p. 5). Well employees are, 
according to Rothmann and Rothmann (cited in Sieberhagen, Rothmann, and Pienaar, 2009, p. 2), "motivated, healthy, productive and committed to the organisation and its goals". This is consistent with positive psychology studies indicating that positive emotions can contribute to "optimal functioning” (Ryan and Deci, 2001, p. 14); job satisfaction, low levels of exhaustion, less burnout and increased job engagement (Hansen, Buitendach, and Kanengoni, 2015, p. 7).

Workplace or organisational wellness refers to institutionalised employee or workplace health promotion programmes (McGillivray, 2005, p. 126). These programmes have largely been set up according to the International Labour Organization (ILO) and the WHO definition of occupational health adopted in 1950, namely:

the promotion and maintenance of the highest degree of physical, mental and social well-being of workers in all occupations by preventing departures from health, controlling risks and the adaptation of work to people, and people to their jobs (WHO Regional Office for Europe, 2002, p. 2).

Increasingly, the concept has been expanded to also include the emotional, social, spiritual, financial and environmental requirements for employees' wellness, making the term well-being more appropriate (Kruger, 2018, p. 113). The ILO in addition refers to "all aspects of working life, from the quality and safety of the physical environment, to how workers feel about their work, their working environment, the climate at work and work organization” (International Labour Organization, 2018, p. 1).

Included in their definition of workplace well-being, Nielsen et al. include employees' job satisfaction; happiness both at work and outside of work, the pleasure or displeasure they derive from their job as well as from their interactions with colleagues, teammates, and supervisors as well as "organisational commitment, intention to remain with the organisation, work engagement, sense of purpose, and affective well-being” (Nielsen et al, 2017, p. 4). In this paper we have, however, adopted the term wellness instead of well-being to align with the more common usage of employee wellness and to prevent confusion when discussing EWPs.

\section{Employee Wellness Programmes}

Programmes introduced to improve employees' workplace wellness (EWPs) are intended to benefit individual workers as well as the organisation as a whole, and in the long run, create value for all stakeholders. Although 
EWPs initially emphasised the physical well-being of workers with mostly stand-alone programmes stressing behavioural change and medical-type interventions e.g. encouraging physical activity and weight loss and discouraging smoking and alcohol abuse (Otenyo and Smith, 2017, p. 15; Pillay, 2007, p. 40) EWPs have become a lot more sophisticated, offering diverse, wide ranging and often technologically-based services, particularly in the private sector (Otenyo and Smith, 2017, p. 4).

The aims and objectives of EWPs are to promote health and life skills, prevent illness and injuries and manage diseases (Kruger, 2018, p. 112). As Schneider (cited in Otenyo and Smith, 2017, p. 4) posits, its purpose is to ensure a productive workforce and to save money for the company or organisation and, in the case of public sector, the state and the taxpayer. Successful EWPs have been shown to be relatively successful in 1) reducing risks and injuries, employee turn-over, absenteeism, attrition, healthcare claims and 2) improving levels of employee commitment, efficacy, resilience, health, productivity, morale, work engagement, satisfaction and commitment (Otenyo and Smith, 2017, p. 4; Prochaska et al., 2011, p. 735).

As a result of the post-1994 political transformation in South Africa and its 'First World/Third World dichotomy', EWPs have developed very particular forms and complexities depending on the resources available (Govender and Terblanche, 2009, p. 394). Workplace wellness programmes are, however, not without its critics. Some denounce the neo-liberal and utilitarian premise of EWPs that improved health and wellness leads to decreasing costs for the company (McGillivray, 2005, p. 130) while others criticise the possibility of employees misusing and overusing services leading to increased rather decreased costs (Otenyo and Smith, 2017, p. 4).

\section{Public Service Employee Wellness}

Although EWPs were first introduced in the corporate world, it has also become a feature of HR management in the public sector, nationally and internationally. In South Africa the idea was mooted to the Public Service Commission in 1995 as a way of curbing worker turn over and to support people in dealing with the post-1994 political changes (Govender and Terblanche, 2009, p. 394). The South African Department of Public Service and Administration (DPSA) acknowledge that a large section of the population is employed as public service workers and that "the fate of society as a whole is closely intertwined with the health and well-being of public servants” and their dependents (Government of South Africa, 2018, 
par 3). Legislation and policy are therefore crucial to governing public service employees' (PSE) health and wellness, and four key role-players are involved in looking after the wellness of employees (Sieberhagen, Rothmann, and Pienaar, 2009, p. 3): 1) the employee e.g. through self-care and wellness practices; 2) professional organisations and trade unions "through negotiating health and wellness issues of their employees on their behalf with their employers”; 3) the management of organisations through implementation of relevant legislation and drafting policies; and 4) the national government, by means of the laws and national strategy it imposes and provision of the infrastructure to support the legislation.

In view of the importance of the role of teachers in education, the challenges that teachers in South Africa and beyond experience, and the effect that the challenges have on their personal and professional wellness, we argue that in the first place, the national government must enable the wellness of employees including teachers, and provide programmes to support this. This paper thus focuses on the national government's role in enabling and supporting teacher wellness by means of legislation and policies.

In this paper, we first explore general legislation and policies related to PSE wellness before giving a brief overview of the legislation and policies specifically relating to teachers.

\section{The South African legislative framework for teacher wellness}

The South African legislative framework for teacher wellness draws from general as well as education-specific laws, regulations and policies.

\section{South African Legislation Governing Employee Wellness}

A plethora of statutes, regulations and policies directly or indirectly pertaining to the well-being of employees have been adopted since 1994.

The Constitution of the Republic of South Africa (RSA, 1996a) is the foundation of democracy in South Africa and sets out the broadest outline for "human rights, employment, labour relations and good practice” (Rakepa, 2012, p. 36). It contains references related to wellness in terms of equity, absence of discrimination, and fair labour practices (RSA, 1996a, Section 23); everyone having the right to an environment that is not harmful to his/her health or well-being (RSA, 1996a, Section 24(a)); religious freedom (RSA, 1996a, Section 15) and health care services (RSA, 1996a, Section 27(1)(a)). 
The Occupation Health and Safety Act (RSA, 1993) regulates the health and safety of employees with reference to aspects such as work-related accidents, and expects the employer to provide and maintain a safe and risk-managed working environment. Employers must appoint health and safety representatives to identify potential hazards, report major incidents at the workplace and to make recommendations regarding health and safety issues to employers (Rakepa, 2012, p. 40; RSA, 1993, Preamble).

The Labour Relations Act (RSA, 1995) ensures that the fundamental rights and fair labour practices outlined in the Constitution are applied to all employees including teachers. It regulates relations between employers and workers e.g. limitations on the hours of work, and basic standards for employment including provisions for meal breaks and rest periods as well as different types of leave arrangements (ibid. Preamble). In addition, the Basic Conditions of Employment Act (RSA, 1997) and its amendments also deal with issues such as the number of hours that may be worked in a week, meal breaks, rest periods and leave arrangements. The overall aim of adhering to the conditions laid out in the Act according to Rakepa (2012, p. 37) is to allow PSEs to be productive and achieve their full potential.

The Employment Equity Act (RSA, 1998a) and its amendments regulate matters such as equal opportunity and unfair discrimination in the workplace on the grounds of race, gender, sex, pregnancy and marital status, and disabilities (RSA, 1998, Preamble). Directly related to health and wellness, the Act also regulates medical testing, HIV testing and psychological testing (RSA, 1998, Section 7).

The Skills Development Act (RSA, 1998b) and its amendments regard the workplace as an active learning environment where employees can learn new skills to improve productivity and employment growth (Rakepa, 2012, p. 39). The long-term objective is to enhance their quality of life and productivity whilst giving the employer the competitive edge. Sieberhagen et al. (2009, p. 6) states that this act influences wellness by increasing self-confidence and reducing stress.

While the above legislation applies to both the private and the public sector, there are specific laws and policies that govern public service employee wellness.

\section{Legislation and Policies Governing Public Service Employee Wellness}

The White Paper on Human Resource Management in the Public Service (RSA DPSA, 1997) was initiated to influence economic and social transformation 
by addressing personnel deployment and HR management, based on the premise that an effective and efficient public service depends on the commitment and proficiency of its employees - which in turn depends on how employees are managed (DPSA, 1997, Section 1.1). HR management in the public service is based on the values stated in the Constitution and shifts its focus from typical HR management functions to accommodate the needs of the organisation, but also the needs, values and culture of the employee. This implies that all matters affecting their careers and working environment, including health and wellness, become the responsibility of the each state department; from executive and senior management to the line managers, individual employees as well as organised labour (Western Cape Government, 1997, Introduction and Sections 3.2.5 -3.2.7).

In 2008 the Employee Health and Wellness Strategic Framework for the Public Service (EH and WSF) (RSA DPSA, 2008) was adopted by the DPSA to provide a comprehensive, holistic and responsive policy to maintain and improve the health and wellness of PSEs, their families and their dependents. It has its origins in the Employee Assistance Programme (EAP) model, confidential, short-term counselling services for individuals with personal problems affecting their work performance including wellness educational and promotion (Rakepa, 2012, p. 41). However, the EH and WSF takes an integrative approach to include the following four areas: firstly, the focus is on HIV, AIDS and TB to reduce the incidence and the impact on individuals, families, communities and society (DPSA, 2008, p. 23); secondly, to improve productivity and promote health by managing chronic and infectious diseases by implementing prevention programmes; risk assessment and support (DPSA, 2008, p. 29). In the third place, the focus is on safety, health, environment, risk and quality (SHERQ) (DPSA, 2008, p. 36). The fourth area is wellness management and proactive promotion of the physical, social, emotional, occupational and intellectual wellness of the individual, including supporting them in reaching their optimum levels of productivity and potential. Interventions include: creating a workplace culture and climate to support wellness; identifying psycho-social health risks; improving work-life balance; introducing workplace flexibility to accommodate work, personal and family needs; managing productivity and absenteeism, providing health education and skills development; managing retirement, elder care, childcare and family support; developing awareness and support programmes to deal with, among other things, lifestyle diseases, stress, discrimination, victimisation, harassment and workplace bullying (DPSA, 2008, p. 31). 
The Public Service Regulations (RSA DPSA, 2016) specifically refers to the responsibility of the heads of department to establish and maintain a safe and healthy work environment for employees, and allowing for their personal circumstances e.g. health conditions, disability and support (DPSA, 2016, Section 53). They are required to allocate adequate human and financial resources to appropriate health and well-being programmes for PSEs and their families which promote and increase awareness of inter alia HIV/AIDS and other sexually transmitted infections (DPSA, 2016, Sections 54 and 55). The impact of these programmes is also required to be monitored and evaluated.

While legislation regarding wellness of civil servants does not exclude teachers specifically, in South Africa there are specific legislation and policies that regulate education and the employment of teachers.

\section{Legislation and Policies Governing Teacher Wellness}

The terms and conditions of employment of educators are set out in the Personnel Administrative Measures (RSA DBE, 2016) and refers to a workload that should be "equitable" to ensure that teachers "on a particular level or an individual educator is not over-burdened” (DBE, 2016, Section A4.1.4). The expectation is that every educator must be able to account for 1800 actual working hours per annum (RSA DBE, 2016, Section A4.1.5).

The South African Council for Educators Act (RSA, 2000) organises the profession, and the related Code of Professional Ethics (as amended) (South African Council for Educators, 2018) regulates relationships between teachers and learners, parents, the community, colleagues, the DBE and SACE. Interpersonal relationships are furthermore informed by the South African Schools Act (RSA, 1996b) that stipulates that the School Governing Body (SGB) must consult with teachers, learners and parents about adopting a code of conduct for learners at the school (RSA, 1996b, Section 8). It requires the SGB to "promote the best interest of the school" and "support the principal, educators and other staff of the school in the performance of their professional functions" (RSA, 1996b, Section 20). The Regulations to Prohibit Initiation Practices in Schools (RSA DoE, 2002) makes it clear that "there should be a relationship of mutual trust and respect between learners, and between learners and educators” (Section 4.2).

Under the National Education Policy Act (RSA, 1996c), The National policy for an equitable provision of an enabling school physical teaching and learning environment (RSA DBE, 2010) defines what an enabling teaching 
environment is, and guides the provision of such an enviroment (RSA DBE, 2010, Executive summary). Also under this act, the health of teachers and learners is addressed in the Department of Basic Education National Policy on HIV, STIS and TB for Learners, Educators, School Support Staff and Officials in all Primary and Secondary Schools in the Basic Education Sector (RSA DBE, 2017). In the Foreword by the Minister, Ms Angie Motshekga, she prioritises the prevention of the spread of the diseases, while continuing "to provide access to treatment, care and support to those infected and/ or affected". She specifically emphasises that the DBE must "ensure that our valued teachers have the means to protect themselves from these diseases, and are supported to lead healthy lifestyles through improved Employee Health and Wellness Programmes." The policy stipulates that teachers should have access to employee health and safety programmes. These programmes, however mainly focus on "a safe and secure environment" and the prevention of HIV, STIS and TB and the care and support of teachers living with, or affected by, these diseases (RSA DBE, 2017, Sections 6.5.4 and 6.5.5).

The Action Plan to 2019 Towards the Realisation of Schooling 2030 (RSA DBE, 2015) plans to stimulate life-long learning for teachers in Goal 16, and in Goal 17 aims for a "teacher workforce that is healthy and enjoys a sense of job satisfaction". The emphasis is on problems in the community, substance abuse, HIV and TB, provision of laptops for teachers and teachers' remuneration. The indicator that they propose to measure job satisfaction with is non-absenteeism of teachers from work (RSA DBE, 2015, Section 6.4).

Several documents relate to school safety, including the Regulations: Safety measures at public schools (RSA DoE, 2001) that prohibits drugs and dangerous objects at schools, and the Education Laws Amendment Act (RSA, 2007) that allows for random search and seizure, as well as drug testing in schools. Clearly, the authorities have enabled safety and wellness through policies and regulations.

\section{Discussion}

In view of the importance of teachers to providing quality education, in this paper we examine the perspectives of two of the major stakeholders (the South African national government as law maker and the DBE as employer) in terms of monitoring and managing educators' levels of wellness. This is done by critically analysing the legislation governing employee wellness in general, and that of PWEs and teachers in particular. This study has 
launched us on the road to scrutinise policy content and the socio-economic and political context within which it has been written, before exploring its translation into practice, and we briefly list our observations.

Firstly, ubiquitous references to safety, health and wellness of workers in the legislation and policy documents indicate that the national government of South Africa, at least as far as policy intent, takes the matter seriously. Legislation on various levels governs the well-being of all workers in the country but also specific groups like PWEs and teachers. Legislators have gone to great lengths to develop frameworks to regulate employees' general health as well as HIV/Aids, TB and STDI in particular, and also addictions, safety, psychosocial problems and workplace conditions. The requirements in legislation guide employers away from the old-style EAPs and EWPs with its emphasis on clinical and lifestyle management programmes. Instead it engages in social responsibility programmes, emphasises the responsibility towards the families of workers and manages diversity, transformation and affirmative action (Govender and Terblanche, 2009, p. 934; Harper, 2000, p. 318).

Secondly, the State's approach to employee wellness is broad and comprehensive, encompassing the physical, psychological, social, and environmental aspects of health, wellness and safety of workers. At the same time policy documents, for instance the Employee Health and Wellness Strategic Framework for the Public Service (RSA DPSA, 2008) (EH and WSF), are very detailed e.g. referring to minutiae like training managers and supervisors in transformation leadership and engagement management (Zuma et al., 2016, p. 57); developing time management skills, helping employees to develop work-life balance; setting up communal lounges, canteens, gyms, and wellness centres as well as introducing aerobic classes and work-based sport and fitness activities (Zuma et al., 2016, p. 53).

Yet, while the policy documents cover a broad range of wellness concerns it is not unexpected that employee wellness is mostly viewed through the lens of curbing the HIV/Aids pandemic. An example is the Department of Basic Education's 2016 report on The Health of Educators in Public Schools in South Africa indicating that HIV prevalence had increased among educators since 2004 (Zuma et al., 2016, pp. 39 and 107) and as a result a large section of the report deals with HIV/Aids and related health problems like TB among educators. Although reference is made to STIs and non-communicable diseases as well as work-related stress, substance abuse, environmental concerns such as violence in schools and structural factors 
such as attrition, large class size and workload, these problems are mostly also linked to the HIV/Aids situation.

While there seems to be a comprehensive legislative framework towards workplace wellness and the study by Zuma et al. (2016, p. 102) points out that teachers consider their general health to be good, a constant stream of media reports and research studies convey the less-than-ideal state of South African teachers' health and wellness and the devastating consequences it has on their experience of work and on learners' experience of attending school (De Wet, 2010, p. 1458; Govender, 2016; Jacobs and De Wet, 2015, pp. 49-52; Vazi et al., 2013, p. 8). This dichotomy suggests a possible gap between policy-making and implementation. Indeed, Dreyer (2017, p. 1) points out that legislation alone is inadequate to ensure implementation of policies and that practice must "become contextually responsive" to deal with the challenging circumstances within which teachers work.

Based on this last point in particular, we propose that an analysis of the implementation of the legislative framework is required to consider the reality at grass roots level.

\section{Conclusion}

With this overview of the relevant legislation and policies in South Africa we introduced the question of whether teacher wellness or the seeming lack of it, is officially dealt with in the South African legislation. This has allowed us to make a number of observations, laying the ground work for a follow-up, more penetrating analysis and assessment of policy content and implementation, and then to gather empirical evidence from teachers (Taylor et al., 1997, p. 37).

While the focus of the paper is on the South African context, the challenges for teachers, and the need to take care of their wellness is imperative internationally in the context of the need for quality education for all, and we hope this paper will stimulate research in other parts of the world.

\section{References}

De Wet, C. (2010). The Reasons for and the Impact of Principal-on-Teacher Bullying on the Victims' Private and Professional Lives. Teaching and Teacher Education, 26, 1450-1459. 
De Wet, C., and Jacobs, L. (2018). Workplace Bullying, Emotional Abuse and Harassment in Schools. In: P.D’Cruz, E. Noronha, L. Keashly, and Tye-Will (Eds.), Special Topics and Particular Occupations, Professions and Sectors. Handbook of Workplace Bullying (Vol. 4). New York: Springer.

RSA DBE (Department of Basic Education). (2010). The National Policy for an Equitable Provision of an Enabling School Physical Teaching and Learning Environment; GN 515 of 2010. Pretoria: Government Printers.

RSA DBE (Department of Basic Education). (2015). Action Plan to 2019. Towards the Realisation of Schooling 2030. Taking forward South Africa's National Development Plan 2030. Pretoria: Government Printers.

RSA DBE (Department of Basic Education). (2016). Personnel Administrative Measures, GN 170 of 2016. Pretoria: Government Printers.

RSA DBE (Department of Basic Education). (2017). National Policy on HIV, STIS and TB for Learners, Educators, School Support Staff and Officials in all Primary and Secondary Schools in the Basic Education Sector. Pretoria: Government Printers.

RSA DoE (Department of Education). (2001). Regulations: Safety Measures at Public Schools. GN 1040 of 2010. Pretoria: Government Printers.

RSA DoE (Department of Education). (2002). Regulations to Prohibit Initiation Practices in Schools. GN 1589 of 2002. Pretoria: Van Schaik.

RSA DPSA (Department of Public Service and Administration). (1997). White Paper on Human Resource Management in the Public Service. Pretoria: Government Printers.

RSA DPSA (Department of Public Service and Administration). (2008). Employee Health and Wellness Strategic Framework for the Public Service. Pretoria: Government Printers.

RSA DPSA (Department of Public Service and Administration). (2016). Public Service Regulation, GN 878 of 2016. Pretoria: Government Printers.

Dreyer, L. (2017). Constraints to Quality Education and Support for All: A Western Cape Case. South African Journal of Education, 37 (1), 1-11.

Fischer, R., and Boer, D. (2011). What Is More Important to National Well-being: Money or Autonomy? Meta-analysis of Well-being, Burnout and Anxiety across 63 Societies. Journal of Personality and Social Psychology, 101 (1), 164-184.

Fouche, E., Rothmann, S., and van der Vyver, C. (2017). Antecedents and Outcomes of Meaningful Work among School Teachers. SA Journal of Industrial Psychology, 43, 1-10.

Govender, P. (2016, June 3). It’s Not Kids Bunking - It's Teachers. Retrieved August 28, 2018 from Mail and Guardian: https://mg.co.za/article/2016-06-02 -its-notkids-bunking-its-teachers.

Govender, T., and Terblanche, L. (2009). A Critical Analysis of the Prevalence and Nature of Employee Assistance Programmes in the Eastern Cape Buffalo City Municipal Area. Social Work, 45 (4), 394-413.

Government of South Africa. (2018). HIV Counselling and Testing (HCT) Campaign. Retrieved August 9, 2018 from https://www.gov.za/about-government/government-programmes/hiv-counseling-and-testing-hct-campaign. 
Hansen, A., Buitendach, J., and Kanengoni, H. (2015). Psychological Capital, Subjective Well-being, Burnout and Job Satisfaction amongst Educators in the Umlazi Region in South Africa. SA Journal of Human Resource Management, 13 (1).

Hanushek, E. (2013). Economic Growth in Developing Countries: The Role of Human capital. Economics of Education Review, 37, 204-212.

Hanushek, E., and Woessmann, L. (2012). Do Better Schools Lead to More Growth? Cognitive Skills, Economic Outcomes, and Causation. Journal of Economic Growth, 17 (4), 267-321.

Harber, C., and Mncube, V. (2011). Is Schooling Good for the Development of Dociety? The Case of South Africa. South African Journal of Education, 31, 233-245.

Harper, T. (2000). South Africa. In: D.A. Masi (Ed.), International Employee Assistance Anthology ( $2^{\text {nd }}$ edition, pp. 313-325). Washington: Dallen Inc.

International Labour Organization. (2018). Workplace Well-being. Retrieved July 20, 2018 from International Labour Organization: http://www.ilo.org/safework/ areasofwork/workplace-health-promotion-and-well-being/WCMS_118396/ lang--en/index.htm.

Jacobs, L. (2013). Towards Understanding Different Faces of School Violence in Different 'Worlds' in One Country. BCES Conference Book: Education in One World: Perspectives from Different Nations. 11, pp. 59-66. Sofia: BCES.

Jacobs, L. (2016). Education Provision to Everyone: Comparing Perspectives from Around the World. In: N. Popov, C. Wolhuter, J. Kalin, G. Hilton, J. Ogunleye, and E. Niemczyk (Ed.), BCES Conference Book: Education Provision to Every One: Comparing Perspectives from Around the World. 14, pp. 11-18. Sofia: BCES.

Jacobs, L., and De Wet, C. (2015). A Quantitative Exploration of the Effects of Workplace Bullying on South African Educators. African Safety Promotion Journal, 13 (2), 31-58.

Kruger, E. (2018). A Grounded Theory of ECD Principals' Self-care and Workplace Wellness-Promotion Practices. In: N. Popov, C.C. Wolhuter, J.S. Smith, G. Hilton, J. Ogunleye, E. Achinewhu-Nworgu, and E. Niemczyk (Eds.), BCES Conference Book: Education in Modern Society. 16, pp. 112-118. Sofia: BCES.

Laurence, E., Volmink, J., Esterhuizen, T., Dalal, S., and Holmes, M. (2016). Risk of Cardiovascular Disease among Teachers in Cape Town: Findings of the South African PaCT Pilot Study. South African Medical Journal, 106 (10), 996-1001.

McGillivray, D. (2005). Fitter, Happier, More Productive: Governing Working Bodies through Wellness. Culture and Organization, 11 (2), 125-138.

Modisaotsile, B. (2012, March). The Failing Standard of Basic Education in South Africa. Retrieved August 5, 2018 from Africa Institute of South Africa: http:// www.ai.org.za/wp-content/uploads/downloads/2012/03/No.-72.The-FailingStandard-of-Basic-Education-in-South-Africa1.pdf.

Nielsen, K., Nielsen, M., Ogbonnaya, C., Känsälä, M., Saari, E., and Isaksson, K. (2017). Workplace Resources to Improve both Employee Well-being and Performance: A Systematic Review and Meta-analysis. An International Journal of Work, Health and Organisations, 31 (2), 101-120. 
Otenyo, E., and Smith, E. (2017). An Overview of Employee Wellness Programs (EWPs) in Large U.S. Cities: Does Geography Matter? Public Personnel Management, 46 (1), 3-24.

Pillay, R. (2007). A Comparison of the Employee Assistance Programme (Eap) with HIV and Aids Workplace Programmes in the Gauteng Provincial Government. Unpublished MSD mini-dissertation, University of Pretoria.

Prochaska, J., Evers, K., Johnson, J., and Castle, P. (2011). The Well-being Assessment for Productivity: A Well-being Approach to Presenteeism. American College of Occupational and Environmental Medicine, 53 (7), 735-742.

Rakepa, T. (2012). The Implementation of Employee Assistance Programme of the Department of Education: A Case Study of Motheo District in the Free State Province. Unpublished Master of Public Administration dissertation, University of Stellenbosch.

RSA (Republic of South Africa). (1993). Occupational Health and Safety Act, 85 of 1993, as amended by Occupational Health and Safety Amendment Act, 181 of 1993. Pretoria: Government Printers.

RSA (Republic of South Africa). (1995). Labour Relations Act, 66 of 1995. Pretoria: Government Printers.

RSA (Republic of South Africa). (1996a). Constitution of the Republic of South Africa. Pretoria: Government Printers.

RSA (Republic of South Africa). (1996b). South African Schools Act, 84 of 1996. Pretoria: Government printers.

RSA (Republic of South Africa). (1996c). National Education Policy Act, 27 of 1996. Pretoria: Government Printers.

RSA (Republic of South Africa). (1997). Basic Conditions of Employment Act, 75 of 1997. Pretoria: Government Printers.

RSA (Republic of South Africa). (1998a). Employment Equity Act, 55 of 1998. Pretoria: Government Printers.

RSA (Republic of South Africa). (1998b). Skills Development Act, 97 of 1998. Government of South Africa.

RSA (Republic of South Africa). (2000). South African Council for Educators Act, 31 of 2000. Pretoria: Government Printers.

RSA (Republic of South Africa). (2007). Education Laws Amendment Act, 31 of 2007. Pretoria: Government Printer.

Ryan, R., and Deci, E. (2001). On Happiness and Human Potential: A Review of Research on Hedonic and Eudaimonic Well-being. Annual Review of Psychology, 52, 141-166.

Senekal, M., Seme, Z., De Villiers, A., and Steyn, N. (2015). Health Status of Primary School Educators in Low Socio-economic Areas in South Africa. BMC Public Health, 15 (186), 1-10.

Sieberhagen, C., Pienaar, J., and Els, C. (2011). Management of Employee Wellness in South Africa: Employer, Service Provider and Union Perspectives. Journal of Human Resource Management, 9 (1), 1-14. 
Sieberhagen, C., Rothmann, S., and Pienaar, J. (2009). Employee Health and Wellness in South Africa: The Role of Legislation and Management Standards. Journal of Human Resource Management, 7 (1), 1-9.

South African Council for Educators. (2018). The Code of Professional Ethics (as amended). Retrieved August 13, 2018 from SACE: https://www.sace.org.za/ pages/the-code-of-professional-ethics.

Taylor, S., Rizvi, F., Lingard, B., and Henry, M. (1997). Education Policy and the Politics of Change. London: Routledge.

van den Berg, S. (2002). Education, Poverty and Inequality in South Africa. Centre for the Study of African Economies Economic growth and poverty in Africa. Oxford. Retrieved June 1, 2018 from https://pdfs.semanticscholar.org/52ce/82c35e07bfd575c0cdd8d8c6b87f9be3d96c.pdf.

van den Berg, S., Taylor, S., Gustafsson, M., Spaull, N., and Armstrong, A. (2011). Improving Education Quality in South Africa. National Planning Commission.

van Tonder, C., and Williams, C. (2009). Exploring the Origins of Burnout among Secondary Educators. SA Journal of Industrial Psychology, 35 (1), 1-15.

Vazi, L., Ruiter, R., van den Borne, B., Martin, G., Dumont, K., and Reddy, P. (2013). The Relationship between Wellbeing Indicators and Teacher Psychological Stress in Eastern Cape Public Schools in South Africa. SA Journal of Industrial Psychology, 39 (1), 1-10.

Western Cape Government. (1997). White Paper on Human Resource Management in the Public Service. Retrieved June 20, 2018 from https://www.westerncape.gov. za/assets/departments/social-development/white_paper_on_human_resource_ management_in_the_public_service1.pdf.

WHO Regional Office for Europe. (2002). Good Practice in Occupational Health Services: A Contribution to Workplace Health. Copenhagen: World Health Organisation.

Wolhuter, C. (2014). Weaknesses of South African Education in the Mirror Image of International Educational Development. South African Journal of Education, 34 (2).

World Health Organisation. (1946). The Constitution of the World Health Organisation. New York: World Health Organisation.

Zuma, K., Simbayi, L., Rehle, T., Mbelle, N., Zungu, N., Mthembu, J. North, A., van Zyl, J., Jooste, S., Moyo, S., Wabiri, N., Maduna, V., Mabaso, M., Naidoo, I., Chasela, C. Chikovore, J., and the Educator Survey II Study Team. (2016). The Health of Educators in Public Schools in South Africa. Pretoria: Department of Basic Education and HSRC. 

PART II

\section{Challenges and Tensions}





\title{
Chapter 13
}

\section{An Exploration into the Value of Formative Assessment and the Barriers Associated with the Implementation of Formative Strategies}

\author{
Frances Green \\ University of Northampton, Northampton, UK
}

\begin{abstract}
This small case-study research is an exploration into the value of formative assessment and the barriers associated with the implementation of formative strategies. It begins with research into the current literature and then goes on to offer an innovative and original conceptual framework, built upon three key benefits of formative assessment and three barriers to the implementation of formative assessment. The case study had three stages. The initial stage was creating the conceptual framework. Secondly, the emerging stage of data collection was a questionnaire that was distributed to all the teaching staff within the school. The third stage was conducting two interviews, one individual and the other a focus group interview. The boundary of this study was that all the participants were from one school. However, many of the teachers involved in the study have a wide-ranging teaching career, prior to teaching within the current school. Some areas of the thesis are particularly interesting and have sparked the curiosity to explore and research further, such as the use of formative assessment to ensure that teachers act within the moment and modify their teaching based on the feedback from implemented strategies. Also, the barrier of self-efficacy, with all the dependencies that self-efficacy can be affected by has been a particularly interesting area to explore. Some areas for further research are suggested at the end.

KEYWORDs: formative assessment, facilitating learning, self-assessment, case study, qualitative, learner autonomy, pragmatic barriers, self-efficacy, ideological disposition, formative strategies, teaching, education, teacher training
\end{abstract}

CONTACT Frances Green, EMAIL: frances.green@live.co.uk 


\section{Introduction}

This paper looks at the implementation of formative assessment within a primary school. It determines the benefits associated with formative assessment and considers the barriers that are faced. Two research questions were chosen to frame this study and were used throughout the study as a constant frame of reference determining the direction of research. The research questions were as follows:

1) What do primary school teachers perceive as the value of formative assessment?

2) What are the barriers to formative assessment?

Assessment plays a fundamental part in understanding a child holistically. It is something that teachers use consistently and inherently throughout their daily practice, often without prompt or recognition, yet the word 'assessment' often causes additional burden and stress for teachers. The study looks at assessment within the school and determines the challenges that teachers are faced with. The research took place in a larger than average primary school in a relatively affluent area. The motivation for undertaking this study is that the school identified that formative assessment was an area that was inconsistent across the school and within classes. Formative assessment plays such a fundamental part of the entire 'assessment umbrella' and these are the strategies that are used so naturally within teaching. The demanding pace of the primary school curriculum creates the potential for difficulty to include everything required within each lesson. Therefore the study considers the challenges associated within formative assessment and looks to make suggestions for further research that could support teachers within the school.

\section{Literature review}

Although formative assessment is a well-studied area of research, it was difficult to find a readily prepared conceptual framework to structure the study. Therefore, aninnovative conceptual framework was designed that categorised the value of and barriers to formative assessment into sub-sections based on answering my research questions. The framework was based on the literature found and through the coding of the literature to spot recurrent, common themes. The framework was broken into two parts. 
Firstly, the common themes regarding the value of formative assessment are presented and secondly, the barriers associated with formative assessment are presented.

While researching the value of formative assessment, the following themes appeared predominantly:

- $\quad$ Firstly, formative assessment is beneficial for and contributes to facilitating children's learning (Black, 1998; Harrison, 2012).

- Secondly, formative assessment is a way of ensuring that teachers act 'in the moment'. This sub-section also refers to teachers modifying the lesson appropriately to meet the children's needs (Heritage, 2010; Clarke, 2014).

- $\quad$ Thirdly, a value within formative assessment is allowing and enabling children to be in control of their own learning (Black and Wiliam, 1998; Leahy et al., 2005).

While researching the barriers to implementing formative assessment, the following themes were found to be significant:

- $\quad$ Firstly, and most significantly, were the pragmatic barriers in implementing formative assessment. These include time restraints in all stages of the assessment process, the demanding pace of lessons and the arduous and content-heavy curriculum to be followed (Box, Skoog, and Dabbs, 2015).

- $\quad$ Secondly, the barriers that were closely related to self-belief, self-efficacy and personal identity that teachers have that may prevent them from successfully executing formative assessment or being unable to implement formative assessment to the highest quality (Pajares, 2009; Yan and Cheng, 2015).

- Thirdly, barriers relating to ideological disposition, such as not having been provided with high-quality or practical training to support assessment within teaching beyond the stage of in-service training (Vlachou, 2015).

\section{Formative assessment}

Learning is a continuum rather than a job to be completed (Clarke, 2014). Along this continuum, the 'thorny issue of assessment' (Harrison, 2012) plays a crucial part in supporting learning and adapting teaching to meet 
students' individual needs (Leahy et al., 2005). It is a well-received notion that school assessments serve two purposes: summative and formative (Yan and Cheng, 2015). However, through the eradication of levels, this view of teaching in the UK curriculum intended to change. By removing distracting, over-generalised levels and misleading signals, the government hoped to ensure deep, secure knowledge and understanding (GB: Department for Education, 2015). Standardised testing does play a big part in the holistic picture of a child; however, formative assessment began with a move away from summative assessment to help children to progress at being more in control of their learning (Clarke, 2014).

\section{Benefits of formative assessment}

The first benefit, regarding the importance of assessment in facilitating children's learning, has been well established (Antoniou and James, 2013). Effective formative assessment is known to increase self-esteem and raise the standards especially for children of lower ability (Black, 1998). The impact of formative assessment on children's learning is clear. Harrison (2012) advocates that formative assessment provides teachers and learners with data on their learning so that their future experiences can be matched to their needs, while Gardner (2012) explains that assessment in education should, first and foremost, serve the purpose of supporting learning.

The second benefit established is a common thread throughout all literature on formative assessment: it is the decisions and processes made in the moment and the opportunities created that move children's learning forward. Therefore, some authors see that all assessment is formative when the teachers use the information for formative purposes (Antoniou and James, 2013). Formative assessment encompasses all those activities undertaken by teachers that provide information within the lesson, which is then used as feedback to modify the teaching and learning activities in which they are engaged. It is when teachers make judgements and adjustments to teaching and learning in response to the assessment information. With guidance from Black and Wiliam, Heritage (2010) observes that formative assessment is not a thing that just tests children, but a process that occurs during teaching and learning involving both teachers and students. Clarke (2014) reciprocates this idea, explaining that mid-lesson 'learning stops' enable pupils to actively improve their work by seeing excellent examples and discussing possible improvements. Furthermore, Sornson (2012) refers 
to formative assessment as an ongoing, dynamic process because it delivers information during the instructional process. This part of the conceptual framework is significant because the pedagogy of formative assessment is designed upon making modifications to teaching to meet the needs of the children and as Leahy et al. (2005, p. 18) suggests, "In a classroom that uses assessment to support learning, the divide between instruction and assessment blurs.” Therefore, when assessment is implemented effectively, it is so embedded within the teaching at that moment, that the process of assessment is flawlessly integrated.

The third recurring theme observed within the literature was the significance of formative assessment in enabling children to take control over their learning. How children see themselves and their ability is central to the success of the learning environment (Clarke, 2003) and therefore, it is fundamental that children feel that they are in a secure environment that allows them to take risks and develop as autonomous learners. For feedback and assessment to be effective, it must cause thinking (Leahy et al., 2005). A key development made by Leahy et al. (2005) to Black and Wiliam's (1998) fundamental work on formative assessment identifies the importance of students becoming the owners of their own learning. Formative assessment is crucial in providing the opportunity and platform for children to succeed as autonomous learners.

\section{Barriers to formative assessment}

The pragmatic barriers associated with formative assessment refer to the challenges that are faced when dealing with formative assessment realistically and not theoretically. Box et al. (2015) worked with science teachers in secondary schools to identify the internally constructed and externally imposed contextual elements that constrained the use of formative assessment. Despite the fact that the study looked at secondary teachers, the views and observations extracted appear to be relevant in primary education too. A particularly interesting restraint or barrier identified in the study is that the teachers felt compelled to keep a demanding pace throughout their lessons that in turn kept them from reaching the full potential of formative assessment practices. Also, the pace needed to be retained in order to cover the required content of the curriculum that then caused the teachers to be reactive, rather than proactive. Likewise, in a study by Andrade and Cizek (2010), it was found that formative assessment strategies need to be maximally effective to 
make successful progress toward intended outcomes, which means keeping pace with increasing demands and expectations. When these expectations are unable to be upheld, students (and teachers) soon view their efforts as diminishing and most may eventually stop trying.

The second barrier presented is self-efficacy. Self-efficacy was well documented in the literature, as was formative assessment. However, there appeared to be no literature that analysed teacher self-efficacy within implementing formative assessment. Professional identity is multi-faceted and it is not a fixed attribute of a person but a relational phenomenon (Beijaard, Meijer, and Verloop, 2004). One of the major facets of professional identity is how good (or bad) you think you are at something and that is closely linked to self-efficacy beliefs. Self-efficacy beliefs are defined as the judgements that individuals hold about themselves and about their capabilities to perform courses of action at designated levels (Pajares, 2009). Self-efficacy is a widely used indicator of perceived difficulty (Yan and Cheng, 2015). More importantly, teachers' self-efficacy is a special type of self-efficacy that refers to one's beliefs in their capabilities to organise and execute the courses of action required to produce given attainments (Bandura, 1997). Pajares (2009) stresses that self-efficacy is not to be confused with outcome expectations. The teachers' workplace is a landscape that is very persuasive, demanding and restrictive (Reynolds, 1996). It is therefore important that teachers' self-efficacy is high because perceived self-efficacy is theorised to influence performance accomplishments both directly and indirectly on self-set goals (Zimmerman, Bandura, and Martinez-Ponz, 1992). These performance accomplishments are required in the fast-paced and demanding environment of a primary classroom.

The lack of appropriate teacher training and ideological disposition can also act as a barrier to implementing formative assessment. Poole (2016) mentions the lack of teacher training or professional development that acts as a barrier to implementing formative assessment in China. This is true too in England, whereby ineffective teacher professional development is an obstacle of effective formative assessment (Vlachou, 2015). This lack of training is closely related to the unequal distribution of resources (Zhang et al., in Poole, 2016). In England, one of the challenges of implementing formative assessment is the lack of understanding among teachers about the principles behind the procedures (Vlachou, 2015). Itappears to be a recurrent theme in the literature that there is an abundance of literature on effective theory, yet this does not closely align to the realistic paradigm within practice. 


\section{Methodology}

\section{Methodological approach}

This study intended to gain a deeper understanding of assessment through the eyes of others, to be able to see behind the complexities and challenges that are faced within this specific domain. The qualitative nature of this research will press for the understanding of complex interrelations (Stake, 1995) within formative assessment.

\section{Participants}

A key part of my research is the acknowledgment that the participants whowill be investigated have knowledge and feelings independent of the contribution given to this research (Hammersley, 2012).

\section{Data collection methods}

The influence on the choices of method and methodology was the decision for the study to be idiographic, built upon true description and narrative. The study followed Robson's suggestion to "listen more than you speak" (2011, p. 282). Qualitative small-scale research methods were considered the most appropriate and although the findingsmay not have been generalizable beyond the school, they were informative in nature. Integrated within the case-study research was the use of questionnaires and interviews.

\section{Ethical considerations}

Throughout each stage of the study, informed consent was obtained and each participant was assured thatconfidentiality and anonymity would adhere to British Educational Research Association's ethical guidelines (BERA, 2011).

\section{Case study}

Case-study research was chosen since it allows in-depth, multi-faceted explorations of complex issues in their real-life settings (Crowe et al., 2011). The study used a case-study approach through the investigation of contemporary phenomenon - the 'case' - in its real-world context (Yin, 2014, p. 2). It used a single-case design, referring to the school in which the teachers are employed, and was revelatory in nature by offering the opportunity to research a case that is heretofore 'unsearched' (Yin, 2009). While previous research suggests that case studies are a poor basis for generalisation 
(Stake, 1995), the intention was not to generalise beyond the school; rather it was to understand the current theoretical position of the school and to be able to make suggestions for further research to move forward in the implementation of formative assessment.

Some researchers question the value of case-study research because it is difficult to cross-check the information (Bell and Waters, 2014). However, triangulation was used to see the same thing from different perspectives (Laws, Harper, and Marcus, 2013). Triangulation of the research methods was therefore an effort to increase the internal validity of the study. Furthermore, an epistemological decision was made to validate the research with the participants, as suggested by Elliot (1978). This was completed at two stages: firstly after the interview stage, and then after the analysis of the data. This was to ensure that the participants had informed consent throughout the entire process of the research.

Twenty questionnaires were distributed to the teachers, the senior leadership team and the Special Educational Needs Co-ordinator (SENCo). A questionnaire was also given to a trainee teacher within the school. These questionnaires were used as the emerging stage of the data collection process in preparation for the interviews.

Theoretical sampling was undertaken for the interviews based on the responses given to the questionnaires. Interviews were used since they provide the opportunity tofollow up ideas, probe responses and investigate motives and feelings, which a questionnaire can never do (Bell and Waters, 2014). Two lengthy interviews were conducted. The first was a semi-structured interview with a teacher who had prior access to the suggested questions and talking points. The second was a focus-group interview. The three participants that made up the focus group were working within the same team at school and therefore had existing familiarity that facilitated discussion.

Since this was a small-scale study, it may be that if it were to be repeated, it would uncover significantly different results. However, the research instrument that I have created is neutral in effect and would be “consistent across multiple occasions of use” (Denscombe, 2014, p. 303). To ensure that the study is clear and repeatable, a condensed summary of my research collection process is situated below. 


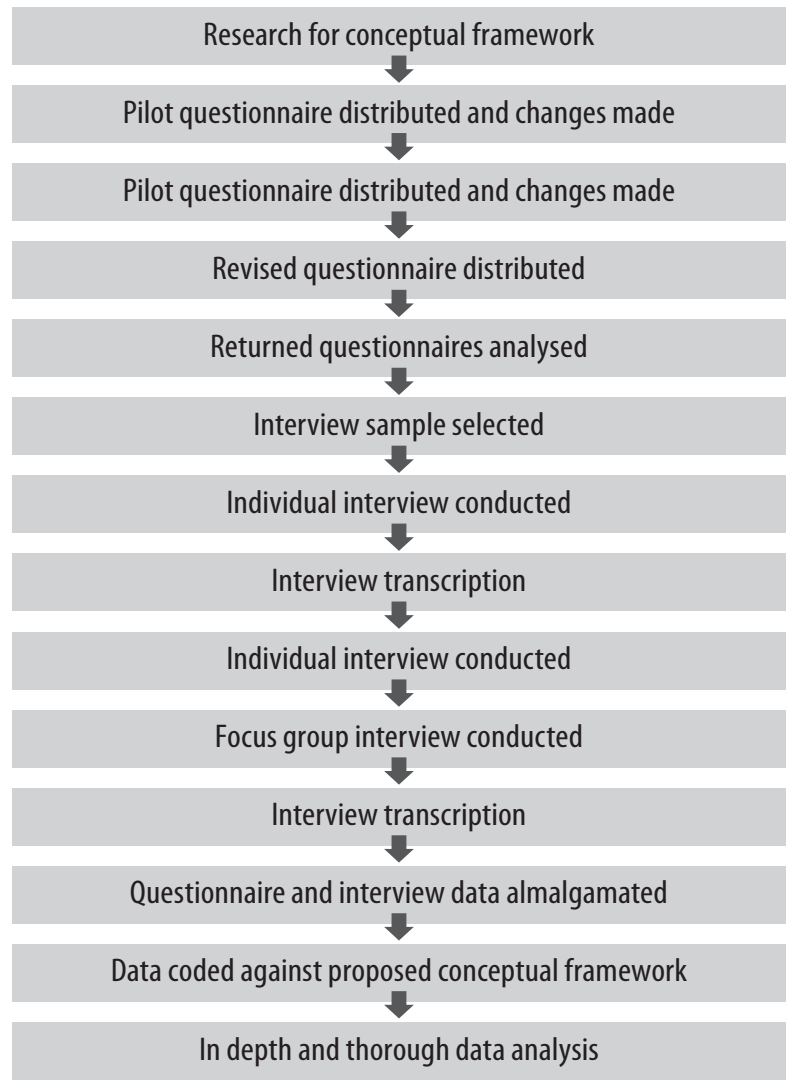

Figure 1. Representation of the research process

\section{Reliability and validity}

To ensure that the research was valid, a paper trail was acquired throughout the entire process. The interviews were recorded using a recording app called 'Recorder'. Permission was obtained to record the interviews prior to them commencing and it was explained that it would be used for transcription and analysis throughout the study. The interviews were transcribed on the day of the recordings and the participants were offered the opportunity to read through the transcription to ensure that everything transcribed was valid and exactly as was said. All participants declined the offer to read through the transcript. 


\section{Findings}

The three benefits of formative assessment that were presented in the literature were facilitation, formative assessment within the moment and the process of enabling children to be in control of their own learning.In hindsight, the wording of the questionnaires gave more opportunity for the benefits of formative assessment to be discussed, than the shape of the interview did. The structure of the interviews scaffolded the conversations towards the barriers to the implementation of formative assessment because the interviewees had been selected from their responses to the questionnaires.

\section{Facilitating formative assessment}

Within the responses to the questionnaire, the emphasis on how formative assessment facilitates children's learning was clear. One participant identified that:

[Formative assessment] determines progress and gaps in learning and understanding that can help teachers to monitor pupils’ progress and give feedback that helps children to move on in their learning.

There was an optional box at the end of the questionnaire that offered participants the opportunity to add any further comments. Six of the eleven participants chose to add a comment and within these six responses, three referred to the benefit of formative assessment in children's learning. This emphasises the findings from the literature, whereby formative assessment moves children's learning forward (Black and Wiliam, 1998; Antoniou and James, 2013).

\section{Formative assessment 'in the moment'}

The findings from the data correlate with the literature found regarding how formative assessment is used 'in the moment' to inform learning (Black and Wiliam, 1998; Sornson, 2012; Antoniou and James, 2013). Within the questionnaires, there was an abundance of relevant responses encompassing this theme. In fact, of the benefits discussed, this was the most common theme that appearedin the data.

Whilst analysing the data, two sub-themes emerged.While both fitted within the theme of formative assessment 'in the moment', they had significantly different emphasis. The two sub-themes suggested are as follows: firstly, the time element of formative assessment and how frequently it takes place; secondly, the process of changing teaching based upon formative assessment strategies. 
The time element of formative assessment was presented in response to Question 1 (What is formative assessment?) as: "Formative assessment is the daily (minute by minute even) assessment of a child's ability and attainment." Furthermore, how frequently formative assessment should take place was identified too: "A range of assessment methods that take place during EVERY lesson in order to inform the teaching and learning." This response to the questionnaire is one piece of information that was found to be interchangeable between both sub-themes, because it mentions the frequency that formative assessment needs to be happening within each lesson, while also placing a prevalence of consequently changing teaching based upon the strategies that have taken place.

The second sub-theme that appeared in the responses to the questionnaire was the adaptation process that needed to happen based on the formative assessment strategies that had taken place. Of the two sub-themes, this was more recurrent. Anexample of the responses to Question 1 (What is formative assessment?) is: "Making decisions throughout a lesson or a series of lessons regarding children's understanding in order to shape the direction of the lesson." This response was poignant because it correlates closely with the literature found, particularly with the influential work by Black and Wiliam (1998) that emphasises that for formative assessment to be effective, it must happen during the lesson,andit also really clarifies the purpose of formative assessment because without the modification to the lesson, the learning that takes place may be limited.

The benefit of using formative assessment within the lesson to transform children's learning is clear within the literature and the findings from the questionnaire responses. A key quote from the questionnaires that coagulates this idea is: "Formative assessment should be continuous and on-going in every classroom, all the time, for it to be effective."

\section{Enabling children to be in control of their own learning}

Creating learning autonomy appeared to form a crucial part of formative assessment as defined within the literature, with Pedder and James (2012) suggesting that to promote learning autonomy, teachers needed to widen the scope for students to be able to have greater autonomy over their learning objectives and in assessment of their own learning. However, within the responses to the questionnaire, the reference to this theme was extremely limited.

When responding to Question 3 [Which formative assessment strategies do you feel are of most value to children?], three participants mentioned 
self-assessment, which correlates with the literature presented by Clarke (2014), who advocates self-assessment as an important opportunity to be able to involve children in their learning as much as possible. Additionally, one of the participants mentioned child-generated success criteria and "having the child as the teacher - explain the concept in their own words". These are strategies of formative assessment that would encourage children to be more in control of their learning. However, this same participant later adds that using self-assessment and the two other strategies mentioned could be a barrier because "children don't fully understand what they are being asked to do and often have numerous guesses until they appear to have got it correct."

It is therefore important to remember the work of Wiliam (2011),which explains that whether or not students can assess themselves accurately is irrelevant, because it is actually whether they can develop sufficient insights into their own learning and improve on it. Therefore, self-assessment should enable children to be more in control of their learning because the autonomy is placed within the child's reach and it is their responsibility to strive further for their own self-sufficiency.

\section{Pragmatic barriers}

Pragmatic barriers arethe barriers that teachers face most regularly, such as being required to keep up with the demanding pace of lessons (Box et al., 2015). Of the three barriers presented in the conceptual framework, pragmatic barriers were by far the most prevalent within the findings from the questionnaires. To demonstrate quite how frequent, in response to Question 4 [What are the barriers to formative assessment?], eight out of the eleven participants referred to one or more pragmatic barriers within implementing formative assessment.

The many responses that included time as a barrier were very frequent within the responses from the teachers. The predominant barrier referred to within the literature was the demanding pace of the classroom; however, within the findings it was the time allocated to implementing assessment. This could suggest that there is a discrepancy between the well-intentioned theory and the reality within classroom practice (Chen et al., 2014). Further pragmatic barriers that were mentioned were "mixed ability groupings", "accessing all children", "too much time spent lesson planning". Another pragmatic barrier that carried more weight than these was the size of the classes. The findings from the questionnaires present two significant barriers and some smaller, less frequently mentioned pragmatic barriers. 
It is comparable within the findings from the interviews that pragmatic barriers were the most frequently coded. It is discernible that the ultimate and central barrier that teachers faced, whether represented through the literature, questionnaires or interviews is time. The focus group participants identified that: "time is definitely one of the biggest barriers, in my experience". This was corroborated and continued: "because it's hard to get around everyone in the time that you've got, especially if you find someone that's not getting it and requires a lot more attention." Another poignant quotation from the individual interview was:

The biggest barrier is time. Time constraints in every aspect, to plan and to teach effectively. Because if you're not planning effectively, then you won't be able to assess effectively within the lesson because you've not had enough time to properly plan the lesson, or you know, make time to plan assessment opportunities within the lesson.

The above quotation explains that time affects every stage of the teaching and learning process, which furthers a suggestion made by Box et al. (2015) whereby teachers are so under pressure to fulfil the demanding role of the classroom teacher that it is problematic in how much can they physically manage to do within each lesson.

Another pragmatic barrier explored within the interviews is the use of adult support. When asked to identify the barriers of formative assessment, one participant in the focus group said:

Definitely adult support, because you know you haven't always got someone and I'm sure that further up the school, you have even less support from additional adults and that makes it difficult to spread your time well.

This is extremely significant as a barrier, because it can vary so much between classrooms and could therefore be seen as either a barrier or an excellent tool.

\section{Self-efficacy barriers}

Within the conceptual framework, there appeared to be no literature that directly analysed teacher self-efficacy within implementing formative assessment. Due to the nature of a questionnaire, identifying self-efficacy is subjective and therefore a Likert scale was used to assist understanding of how confident the participants were in implementing formative assessment. Within the responses to the questions, there were a few responses that were coded to be closely linked with self-efficacy. The following response 
suggested that this participant had low self-efficacy in being able to implement formative assessment to the highest standard. When answering what the barriers to formative assessment were, they responded:

I haven't had enough subject knowledge or training so I'm not very good at doing formative assessment all the time.

This statement could overlap with the barrier about ideological disposition, due to the reference to the lack of training that could be seen to be out of the control of the particular teacher. However, this suggests that they feel that they are not as good as they can be at implementing formative assessment, regardless of the reason behind this. Additionally, the perception of why this participant feels that they are not good at implementing formative assessment is irrelevant. The feeling of not being able to implement formative assessment effectively represents their low self-efficacy in being able to complete the task of formative assessment and to produce given attainments.

Within the Likert-scale questions, when asked How confident are you in implementing formative assessment?, five participants selected 'some confidence', four participants selected 'relatively confident' and one participant selected 'extremely confident'. There was one participant that left this question unanswered. It is difficult to analyse this qualitatively because it is simply a box that has been ticked and has the capacity to be analysed quantitatively. However, when looking at this with intentional objectivity, it shows that fewer participants ticked 'extremely confident', with most favouring 'some confidence'. It could be for many reasons that they have not selected 'extremely confident', such as not wanting to appear overly confident. One reason may be that they have low self-belief in their ability to implement formative assessment.

Formative assessment is used to facilitate children's learning and teacher self-efficacy is based on whether teachers have been able to produce the given attainment (Bandura, 1997), such as moving a child's learning on within individual lessons and building up to a larger picture of assessment and data. The findings from both interviews identified some evidence of teacher self-efficacy towards specific tasks. This is important to remember that self-efficacy is not general, but task-specific. Within the focus group interview, there were a few statements made that could be suggested to demonstrate low self-efficacy in regard to certain strategies of formative assessment. One participant said: "I probably think my questions are a bit high", while another said, "I'm not good at visualiser 
stops, ${ }^{1}$ I definitely don't do that as much as we're expected to". These statements suggest that within these areas, the participants do not feel as confident within their ability, but this does not necessarily influence their self-efficacy towards all aspects of formative assessment. Therefore, while they may have low self-efficacy in implementing questions, they may have high self-efficacy in, for example, talk partners. ${ }^{2}$

One participant openly spoke about areas of formative assessment that they felt they were both good and bad at:

My questioning could be more open. I'm very good at closed questions and grabbing understanding and I'm also quite good at giving verbal feedback by showing them what they can improve or what they have done well and then taking that to visualiser stops.

This truly embodies the intricacy of self-efficacy and how within one small aspect of formative assessment, there are layers which someone may feel that they are good or bad at. All these feelings towards strategies will affect how they are implemented. Furthermore, there are many dependencies that can change self-efficacy within tasks, such as that referred to in a responsefrom the individual interview when discussing barriers: "I'm not as good as I could be because I just don't have the time.” This suggests that in an ideal world, without the demanding pace and constricted time aspect of teaching, this teacher would be far better at formative assessment, again linking to the literature that there are discrepancies between well-intentioned theory and actual practice (Chen et al., 2014).

\section{Ideological disposition}

Within the literature, ideological disposition was identified as an entirely separate strand to pragmatic barriers. However, within the findings from the questionnaires and interviews, ideological disposition is closely correlated and perhaps actually is a pragmatic barrier. The dispositions presented are similar to those in the literature, such as lack of sufficient training and lack of subject knowledge (Vlachou, 2015; Poole, 2016). Due to the responses from the questionnaire, it is felt that pragmatic barriers and ideological disposition are so closely related that they can both now be presented under the single theme of pragmatic barriers. The interviews were still critically

A visualiser is a classroom resource that connects to a computer and allows documents or objects to be enlarged and shown on screen with clarity.

2 The strategy 'talk partners' encourages children to discuss a question or topic with their partner before contributing their ideas. 
analysed in order to code any findings that represented barriers to do with ideological disposition. The main discussion point that related to this theme was the amount of training that the participants had had. Despite having had extensive training, there were ideological issues presented within the focus group interview. Two points that were made were extremely interesting:

- I would say that we all know what it is, and we all know what we should be doing, but in your training the barriers are not considered.

- With the training, you often look at formative assessment in its own little bubble, without the time constraints, without the pressure of summative assessment and then those [formative assessment strategies] get pushed to the side perhaps.

Itwas significant that, while the training was thorough and wide-ranging, it removed formative assessment from the reality of the classroom and did not truly prepare teachers for the highly demanding classroom. This section has looked at ideological disposition as a barrier of implementing formative assessment. The main barrier correlating with this theme is surprisingly how unprepared teachers are for the realities of the classroom. This, once again, interconnects ideological disposition with the pragmatic barriers that have been previously presented.

\section{Discussion}

The research questions were as follows:

1) What do primary school teachers perceive as the value of formative assessment?

2) What are the barriers to formative assessment?

Both the interviews and the questionnaires allowed a clear and thorough exploration into both questions; however, the second question was explored in more depth, due to the structure of the interviews and the ways in which they developed. The value of formative assessment was not overtly explored within the interviews. Primarily, the conversations in both interviews related closely tothe barriers found in formative assessment. This does not mean to say that the question was not answered in full because, through the passion that the participants transmitted, it was clear as a researcher that they were all enthused with the impact that formative assessment can have 
- but that they were frustrated with the barriers presented,whichcan have a negative impact upon their implementation of formative strategies. Their passion created the opportunity for a particularly interesting discussion.

The second research question was explored thoroughly in connection to the conceptual framework. Pragmatic barriers formed the largest part of the discussion within the interviews, with time prevailing as the most significant factor. Time was considered to act as a barrier throughout the whole formative assessment process, from planning to executing and evaluating lessons. Time appeared to be the overarching barrier that affected formative assessment generally, but it was also considered as having an impact on the other barriers mentioned within the interviews. For example, when the demanding role of the classroom teacher was mentioned, this again linked closely with time because part of the reason for the hugely arduous role is that teachers feel theydo not have the time to essentially " $g e t$ everything done". Other important barriers mentioned were the use of adult support, and a teacher's low self-efficacy and training that did not prepare them for the reality of a bustling and vibrant classroom.

\section{Conclusions}

The first research question looked at the value of formative assessment. This question was answered less explicitly and was presented predominantly through inferring the responses given to the interview and questionnaires. The benefits of formative assessment were paramount throughout each stage of the research process. The data collected from the questionnaires and interviews reiterated the importance of formative assessment in facilitating children's learning as found within the literature.

The second research question was more dominant throughout the study and formed a larger part of the discussion in both the questionnaires and interviews. The pragmatic barriers that were identified as a theme within the conceptual framework were touched upon in the findings, but additionally new barriers were presented that supported the theme, such as the use of adult support and the time aspect throughout the whole implementation procedure of formative assessment. The interviews created a platform to discuss the teacher training that prepared teachers for implementing formative assessment. It was identified that the training itself was not a barrier and was thorough and inclusive, but that the training did not readily prepare teachers for how demanding the primary classroom can be. This 
therefore creates a barrier that resonates with the suggestion by Chen et al. (2014) that one of the key barriers to implementing formative assessment is the discrepancy between well-intentioned theory and realities within the classroom.

The other barrier that formed part of the conceptual framework was self-efficacy. Through the literature, questionnaires and the interviews, the intricacy of self-efficacy has been evident. Equal to this was the dependency on external factors that can heavily impact on how teachers feel towards particular tasks. A significant determiner is the time that teachers have to implement formative assessment. The time barrier inevitably affects every stage of formative assessment, including a teacher's self-efficacy, but teacher self-efficacy is not a controlled variable. Self-efficacy can vary throughout lessons and throughout strategies of formative assessment, and will change. However, one thing that was identified throughout the literature was that self-efficacy will inevitably affect how a teacher performs a task.

\section{Implications for further research}

While it has been clearly stated that the results are not generalizable beyond the school, it has been a unique case that has provided some suggestions for further research. These suggestions would beresearch into the troubling impact that the time barrier has on teachers and looking at suitable modifications that could help to overcome this, research into teacher self-efficacy and how this can affect teachers in a variety of ways, and research into the intricacy of self-efficacy. In terms of further research suggested specifically from work with the teachers, recommendationswould be to study what supporting adults perceive as their role in implementing formative assessment, research into successes using formative assessment to create a bank of good examples for teachers to refer to,and finally, research into how well teacher training prepares teachers for the reality of a demanding classroom.

\section{References}

Andrade, H., and Cizek, G. (2010). Handbook of Formative Assessment. Oxon: Routledge.

Antoniou, P., and James, M. (2013). Exploring Formative Assessment in Primary School Classrooms: Developing a Framework of Actions and Strategies. Educational Assessment, Evaluation and Accountability, 26 (2), 153-176. 
Bandura, A. (1997). Self-Efficacy: The Exercise of Control. New York: Freeman.

Beijaard, D., Meijer, P.C., and Verloop, N. (2004). Reconsidering Research on Teachers’ Professional Identity. Teaching and Teacher Education, 20, 107-128.

Bell, J., and Waters, S. (2014). Doing your Research Project: A Guide for First-time Researchers. Sixth Edition. Berkshire: Open University Press.

Black, P. (1998). Formative Assessment: Raising Standards Inside the Classroom. School Science Review, 80 (291), 39-46.

Black, P., and Wiliam, D.(1998). Assessment and Classroom Learning. Assessment in Education: Principles, Policy \& Practice, 5 (1), 7-74.

Box, C., Skoog, G., and Dabbs, J.M. (2015). A Case Study of Teacher Personal Practice Assessment Theories and Complexities of Implementing Formative Assessment. American Educational Research Journal, 52 (5), 956-983.

British Educational Research Association (BERA). (2011). Ethical Guidelines for Educational Research. Retrieved March 8, 2017 from https://www.bera.ac.uk/ researchers-resources/publications/ethical-guidelines-for-educational-research-2011.

Chen, Q., May, L., Klenowski, V., and Kettle, M. (2014). The Enactment of Formative Assessment in English Language Classrooms in Two Chinese Universities: Teacher and Student Responses. Assessment in Education: Principles, Policy \& Practice, 21, 271-285.

Clarke, S. (2003). Enriching Feedback in the primary classroom. London: Hodder \& Stoughton Educational.

Clarke, S. (2014). Outstanding Formative Assessment: Culture and Practice. London: Hodder Education.

Crowe, S., Cresswell, K., Robertson, A., Huby, G., Avery, A., and Sheikh, A. (2011). The Case-Study Approach. BMC Medical Research Methodology, 11 (100).

Denscombe, M. (2014). The Good Research Guide: For Small-Scale Social Research Projects. Berkshire: Open University Press.

Elliot, T. (1978). What Is Action Research in Schools? Journal of Curriculum Studies, 10 (4), 355-357.

Gardner, J. (2012). Assessment and Learning. United Kingdom: Sage Publications Ltd.

GREAT BRITAIN/GB: Department for Education. (2015). Assessment After Levels. [online], Retrieved July 12, 2017 from https://www.gov.uk/government/ speeches/assessment-after-levels.

Hammersley, M. (2012). Methodological Paradigms in Educational Research, British Educational Research Association [online]. Available at: https://www.bera. ac.uk/researchers-resources/publications/methodological-paradigms-in-educational-research. Retrieved October 7, 2017.

Harrison, C. (2012). Collaborative Action Research as a Tool for Generating Formative Feedback on Teachers' Classroom Assessment Practice: the KREST Project. Teachers and Teaching: Theory and Practice, 19 (2), 202-213.

Heritage, M. (2010). Formative Assessment: Making it Happen in the Classroom. Thousand Oaks, CA: Corwin.

Laws, S., Harper, C., and Marcus, R. (2013). Research for Development: A Practical Guide. Second Edition. London: Sage. 
Leahy, S., Lyon, C., Thompson, M., and Wiliam, D. (2005). Classroom Assessment: Minute by Minute, Day by Day. Assessment to Promote Learning, 63, 19-24.

Pajares, F. (2009). Self-Efficacy Theory. Education [online]. Retrieved September 11, 2017 from www.education.com/reference/article/self-efficacy-theory.

Pedder, D., and James, M. (2012). Professional Learning as a Condition for Assessment for Learning. In: J. Gardner (Ed.), Assessment and Learning (pp. 33-48). London: Sage.

Poole, A. (2016). 'Complex Teaching Realities' and 'Deep Rooted Cultural Traditions': Barriers to the Implementation and Internalisation of Formative Assessment in China. International and Comparative Education, 3 (1), 1-14.

Reynolds, C. (1996). Cultural Scripts for Teachers: Identities and Their Relation to Workplace Landscapes. In: M. Kompf, W. R. Bond, D. Dworet, and R. T. Boak (Eds.), Changing Research and Practice: Teachers' Professionalism, Identities and Knowledge (pp. 69-77). London, Washington, DC: The Falmer Press.

Robson, C. (2011). Real World Research. Oxford: Blackwell.

Sornson, B. (2012). Fanatically Formative: Successful Learning During the Crucial K-3 Years. United Kingdom: Corwin Press.

Stake, R. (1995). The Art of Case Study Research. California: Sage Publications Ltd.

Vlachou, M. (2015). Does Assessment for Learning Work to Promote Student Learning? The England Paradigm. The Clearing House: A Journal of Educational Strategies, Issues and Ideas, 88 (3), 101-107.

Wiliam, D. (2011). Embedded Formative Assessment. Bloomington: Solution Tree Press.

Yan, Z., and Cheng, E. (2015). Primary Teachers' Attitudes, Intentions and Practices Regarding Formative Assessment. Teacher and Teacher Education, 45, 128-136.

Yin, R.K. (2009). Case Study Research: Design and Methods (fourth edition). Thousand Oaks, CA: Sage.

Yin, R.K. (2014). Case Study Research: Design and Methods (fifth edition). Thousand Oaks, CA: Sage.

Zimmerman, B., Bandura, A., and Martinez-Ponz, M. (1992). Self-Motivation for Academic Attainment: The Role of Self-Efficacy Beliefs and Personal Goal Setting. American Educational Research Journal, 29 (3), 663-676. 


\title{
Chapter 14
}

\section{The Importance of Physical Activity in the Normative Development of Mental Body Representations during Adolescence. Implications for Teacher Education}

\author{
Beata Mirucka and Monika Kisielewska \\ Faculty of Pedagogy and Psychology, University of Bialystok, Bialystok, Poland
}

\begin{abstract}
Physical activity has a positive effect on the health of adolescents. It plays a significant role in their somatic and psycho-emotional development. The impact of physical activity on mental body representations is little known. Hence, the major aim of the present study was to investigate the relationship between physical activity and the mental representations of the body. The following research question was posed: are there significant differences between adolescents presenting different levels of physical activity in terms of body image, body schema and body awareness. A group of 437 adolescent boys $(n=208 ; 47.6 \%)$ and girls ( $\mathrm{n}=229 ; 52.4 \%)$, aged from 14 to $16(M=15.02, \mathrm{SD}=0.82)$ participated in the study. They completed the following measures: 1) A demographic survey, 2) A Battery of Tests of Body Self Representations, and 3) A single item question about the intensity of physical activity during the week. The results indicate that groups reporting different intensities of physical activity significantly differ in terms of the level of body schema and body awareness. Body image does not differentiate the group of girls. Preventive recommendations for teacher education are included.
\end{abstract}

KEYWORDS: mental body representations, body image, body schema, body awareness, physical activity, adolescence

\section{Introduction}

Physical activity plays a significant role in the normative mental development of adolescents. Physical activity in adolescence has potentially 
beneficial effects on reducing depression (Biddle and Asare, 2011). Higher levels of physical activity in adolescence are associated with lower levels of depressive symptoms among adolescent boys and girls (Baldursdottir et al., 2017; McDowell, MacDonncha, and Herring, 2017). The relation between physical activity and depression is mediated by body-esteem (Chae, Kang, and Ra, 2017). Furthermore, moderate and high physical activity are inversely related with anxiety and high trait anxiety in adolescents (McDowell, MacDonncha, and Herring, 2017). It also has a positive effect on other intrapersonal characteristics by increasing self-esteem and improving cognitive performance and academic achievement (Biddle and Asare, 2011). Interestingly, positive relations between more frequent vigorous physical activity and the reporting of fewer symptoms of depression, anxiety, low self-esteem, and life dissatisfaction were noticed only in self-report measures, but not in objective measurement of physical activity (Hrafnkelsdottir et al., 2018).

Regular physical activity by adolescents, especially of a moderate-to-vigorous intensity, is positively related to various physical health outcomes (e.g. healthy body weight and low rates of chronic disease) (U.S. Department of Health and Human Services, 2008), and not only during adolescence. It can result in positive effects in later life, during adulthood (Twisk, Kemper, and van Mechelen, 2002). Despite the fact that personal and health benefits from physical activity are well grounded in the literature, it is observed that the physical activity of adolescents gradually declines. The greatest decrease of physical activity occurs between childhood and adolescence (Nader et al., 2008; Troiano et al., 2008), and is so dramatic that over half of the adolescents in upper-secondary schools do not achieve the recommended daily intensity of physical activity (Baldursdottir et al., 2017). A particularly significant decline in physical activity occurs among girls (Nader et al., 2008; Troiano et al., 2008). Girls in early adolescence have a high risk of becoming inactive and losing positive health outcomes related to physical activity (Budd et al., 2018). Girls have lower physical activity levels than boys for all ages (Nader et al., 2008; Troiano et al., 2008). Adolescent boys reported significantly higher levels of physical activity and body-esteem than girls (Chae, Kang, and Ra, 2017). During early adolescence boys are more active than girls, whether physical activity is measured via self-report (Dumith et al., 2011) or objectively (Moore et al., 2014). Although a decline in physical activity during adolescence also occurs in boys, and its course is more precipitous, adolescent boys 
still maintained higher levels of physical activity than adolescent girls (Benítez-Porres et al., 2016). The disparate decline in intensity of physical activity in boys and girls makes it necessary to identify the reasons for this phenomenon, and to find pathways to reverse this decline (Nader et al., 2008; Troiano et al., 2008).

Body self is defined as the central instance responsible for the way of experiencing one's own body (Krueger, 2002). It constitutes the first, and at the same time the most fundamental subsystem of the self (Mirucka and Sakson-Obada, 2012), and consists of multidimensional body representations (Mirucka, 2018). Somatosensory information from the inside and the outside of the body is constantly processed in the form of mental representations of the body (Gallagher, 2005; Krueger; 2002, Mirucka, 2018). The development of body representations is based on complex brain mechanisms related to perception: interoception, proprioception and exteroception (Mirucka, 2018). In the literature the classical division relates to body schema and body image (Cole and Paillard, 1995; Gallagher, 2005; Head and Holmes, 1911). According to Mirucka (2017; 2018), there are not two but three main mental body representations. Apart from body schema and body image, body awareness is also distinguished.

Body image - most often described in the literature - is based mainly on exteroception. It relates to the individual perception manner of one's body, particularly in the context of physical appearance (Gallagher, 2005). This mental body representation includes perceptions, beliefs and emotions directed towards the body. Body image is a complex and multifaceted construct (Pruzinsky and Cash, 2002), but initially the attention of researchers was focused on its negative aspects (e.g. body dissatisfaction). The latest investigations regard broader facets, especially positive body image (Tylka, 2011). Positive body image is a multi-aspectual construct distinct from negative body image. It includes various variables regarding positive experience of one's own body, such as: holding favourable opinions of the body, respecting the body, inner positivity influencing outer demeanour, rejecting prescriptive ideals of appearance, broad conceptualisation of beauty (Tylka and Wood-Barcalow, 2015), and having love, confidence, respect and appreciation for, and acceptance of, one's physical appearance and abilities (Wood-Barcalow, Tylka, and Augustus-Horvath, 2010).

Body schema is based mostly on the arrangement of proprioceptive information resulting from the acts of motion and movement in space, as well as from the acts of body ownership (Gallagher, 2005). All these 
sensations are shaped in the form of neuronal maps that show multi-modal aspects of the body state and the functioning of the organism during movement (Gallagher, 2005; Mirucka and Sakson-Obada, 2012). Body schema constitutes the system of mental representations, including body posture, body position, awareness of body form, and awareness of the body in space (Jacob and Jeannerod, 2005).

The third mental body representation, body awareness, is mostly based on interoception, but outreaches it (Craig, 2003). Body awareness relates to the individual attentional focus on and awareness of internal body sensations (Mehling et al., 2009; Mirucka, 2018), and its essence is the person's attitude towards information coming from one's own body (Mirucka, 2018). It encompasses such experiences as feeling tension/relaxation in muscles, anxiety/joy due to perceived information from the inside of the body, or a sense of effectiveness/ineffectiveness in directing attention to one's own bodily sensations.

Mental body representations are not only interesting phenomena, but also an important part of personality and identity (ibid.). They have a meaningful role in maintaining mental health and well-being (e.g. body image, Dalley and Vidal, 2013; Gillen, 2015; Tylka and Kroon van Diest, 2013), and in cognitive functioning (e.g. Gibbs, 2006).

During adolescence the mental body representations are intensely transformed (Assaiante, et al., 2014; Cash and Pruzinsky, 2002; Gallagher, 2005). Changing body proportions and developing secondary sex characteristics change a child's body into an adult female/male body. This is reflected in a significant change in body image (Cash and Pruzinsky, 2002). Body schema is also influenced by pubertal changes. Increasing body height and weight temporarily change adolescents' ability of motor control, which is reflected in changes in body schema (Choudhury et al., 2007; Viel, Vaugoyeau, and Assaiante, 2009). Adolescents' intentional activity can also change body representations. Involvement in different types of activity is related to the degree of body schema activation and its consequent level of development (Mirucka, 2016). This observation led us to the question of the relationship between voluntary physical activity and the development of mental body representations in adolescents.

To our knowledge, the impact of physical activity on different mental body representations is little known. Thus we have decided to investigate the relationship between main mental representations of the body and physical activity during adolescence, which is the major aim of the present 
study. The research question that we posed was: are there significant differences among adolescents presenting different levels of physical activity in terms of: (a) body image, (b) body schema, (c) body awareness? Taking into account previous research indicating the possibility of deliberately influencing the mental body representations (ibid.), the assumed hypothesis was: adolescents presenting different levels of physical activity differ significantly in terms of: (a) body image, (b) body schema and (c) body awareness.

\section{Methods}

\section{Participants}

The study was conducted in a group of 437 adolescent boys $(n=208 ; 47.6 \%)$ and girls $(n=229 ; 52.4 \%)$. All the participants were aged from 14 to 16 $(M=15.02, \mathrm{SD}=0.82)$ years old, who took part in the study voluntarily and did not receive any financial remuneration. They received information about the procedure and signed an agreement to participate in the study. The parent's or legal guardian's consent was also obtained. The procedure of the present research complied with APA ethical standards in the treatment of participants.

Both gender groups have similar places of residence and similar body mass index, but differ significantly in physical and mental difficulties. Girls reported more difficulties (Table 1).

Table 1. Demographic and clinical data

\begin{tabular}{|c|c|c|c|}
\hline \multirow{2}{*}{\multicolumn{2}{|c|}{ Demographic and clinical data }} & \multicolumn{2}{|c|}{ Number (and percentage) } \\
\hline & & Boys group $n=208$ & Girls group $n=229$ \\
\hline \multirow{3}{*}{ Place of residence } & $>100,000$ inhabitants & $120(57.7)$ & $165(72.1)$ \\
\hline & $<100,000$ inhabitants & $48(23.1)$ & $25(10.9)$ \\
\hline & village & 40 (19.2) & $39(17)$ \\
\hline \multirow{4}{*}{ BMI } & underweight $(<18.5)$ & $45(21.6)$ & $62(27.1)$ \\
\hline & normal (18.5-24.99) & $142(68.3)$ & $144(62.9)$ \\
\hline & overweight (25-29.99) & $10(4.8)$ & $16(7)$ \\
\hline & obese $(>30)$ & $3(1.4)$ & $3(1.3)$ \\
\hline \multirow{2}{*}{ Physical difficulties } & The number of days & $5.05(6.39)$ & $7.63(7.29)$ \\
\hline & in a month $M(S D)$ & \multicolumn{2}{|c|}{$\mathrm{F}(1,433)=15.26, p<.001$} \\
\hline \multirow{2}{*}{ Mental difficulties } & \multirow{2}{*}{$\begin{array}{l}\text { The number of days } \\
\text { in a month } \mathrm{M}(\mathrm{SD})\end{array}$} & $5.57(7.45)$ & $10.39(8.69)$ \\
\hline & & \multicolumn{2}{|c|}{$\mathrm{F}(1,433)=38.22, p<.001$} \\
\hline
\end{tabular}




\section{Measures}

The Demographic Data Questionnaire was used for the measurement of different demographic and psychological variables. It included queries regarding place of residence, height and body weight, felt physical discomfort (How many days in the past month have you felt bad due to physical discomfort (e.g. pain, allergy)?), mental discomfort (How many days in the past month have you felt bad due to psychological difficulties, e.g. stress, sadness, fear?), and questions referring to the occurrence of physical illness. Individuals whose health condition could have substantially affected research results were excluded from the research group.

The Battery of Tests of the Body Self Representations (BT-BSR) (Mirucka, 2017; 2018) was used to assess the multi-aspectual representations of the body self. It consists of a test set: The Body Schema Test (BST), The Body Image Test (BIT), The Bodily Sensation Test (BSnT), The Body-related Emotion Test (BET), and The Physical Needs Test (PNT). Each scale is one-dimensional, with separate versions for males and females, and it has its own a priori key. Statements are rated on a 7-point Likert scale (ranging from I totally disagree to I totally agree). A Battery of Tests was constructed during a multi-stage process and completed according to the rules for creating psychological research tools based on advanced statistical procedures. The Body Schema Test (BST) consists of six test items regarding the sense of controlling the body and the sense of coordination of the body's movement. High scores in the BST indicate a strong feeling of one's own body control and the efficient coordination of one's own movements and actions. Low scores mean a weak body schema, insufficient movement coordination, and a weakened feeling of body ownership. An example of a BST item: "I think that my movements are not coordinated". The Body Image Test (BIT) consists of six items and refers to the way in which a person experiences exteroceptive signals, coming from perceiving the appearance of one's own body. High scores in this test mean the acceptance of one's own body, and a generally positive body image. Low scores prove dissatisfaction with one's own physical appearance and experiencing the body as an obstacle in relations with others. An example of a BIT item: "I would like to have a different body build". The Bodily Sensation Test (BSnT) consists of five test items. It enables the estimation of the level of awareness of the stimuli coming from different parts of body. High scores in this test mean greater ability to perceive and interpret interoceptive and proprioceptive signals, 
whereas low scores indicate a reduction of awareness of bodily sensations. An example of a BSnT item: "I feel tense most of the time". The Body-related Emotion Test (BET) contains seven statements regarding emotional experiences anchored in bodily sensations. High scores in the BET mean a well-developed skill of coping with strong emotions and experiencing positive body-related emotions in relations with others. Low scores indicate experiencing one's body as a source of negative emotions (e.g. shame) and having difficulties in coping with emotional arousal. An example of a BET item: "I find it hard to control strong emotions". The Physical Needs Test (PNT) consists of five items, which indicate the level of satisfying physical needs. High scores in the PNT means a person's ability to take care and protect the body self (e.g. keeping fit, taking rest), whereas low scores suggest ignoring physical needs and neglect of body self. An example of a PNT item: "I take care of myself". In accordance with the theoretical model proposed by Mirucka (2017; 2018), in which three main body representations were separated, the tests presented above can be used in the exploration of mental body representations - body schema (BST), body image (BIT), and body awareness (the sum of BSnT, BET, PNT).

A single item question was used to measure the intensity of physical activity during the week (apart from Physical Education classes - PE). Participants were asked the following question: "Do you do any sport activities apart from PE classes, regularly participate in other physical activities (e.g. dance, gym, martial arts, horse riding), or regularly exercise on your own? If so, please write down what you are training or practicing, and specify how many times and how long per week (e.g. I swim once a week for 45 minutes)”.

\section{Results}

To verify the hypothesis related to the question of whether adolescents presenting different levels of physical activity differ significantly in terms of: (a) body image, (b) body schema, and (c) body awareness, a three-step analysis was conducted. The first step was meant to verify whether significant differences exist in the structure of mental body representations in the group of boys and the group of girls. In order to do this, one-way ANOVA for unrelated groups was performed. Data analysis shows that the average results for body image, body schema and body awareness vary significantly among the group of boys and the group of girls: body 
image $\mathrm{F}(1,435)=57.44 ; p<.001 ; \eta^{2}=0.13$; body schema $\mathrm{F}(1,435)=16.24$; $p<.001 ; \eta^{2}=0.04$; body awareness $\mathrm{F}(1,435)=22.44 ; p<.001 ; \eta^{2}=0.05$, which makes it necessary to conduct further analysis separately in both groups. The boys' group is characterised by the highest results in all mental body representations. The structure of body representations in this group is harmonious, and the obtained results are very similar to each other. These results may suggest a high degree of integration within the whole structure of body representations. In the group of girls the differences between body image, body schema and body awareness are bigger, which in turn points to a lower degree of coherence of the structure of body representations. All mental body representations are lower in the group of girls compared to the group of boys, but body image is the lowest of all. The whole structure of body representations is less harmonious (Table 2).

Table 2. A comparison of scores obtained in the BT-BSR by the groups of boys and girls

\begin{tabular}{lcccccccc}
\hline \multirow{2}{*}{ Body representations } & \multicolumn{3}{c}{ Boys group $\boldsymbol{n}=\mathbf{2 0 8}$} & \multicolumn{5}{c}{ Girls group $\boldsymbol{n}=229$} \\
\cline { 2 - 10 } & M & SD & Min. & Max. & M & SD & Min. & Max. \\
\hline Body image & 24.35 & 7.56 & 4 & 36 & 18.35 & 9.11 & 1 & 36 \\
\hline Body schema & 24.77 & 6.61 & 4 & 36 & 22.21 & 6.72 & 6 & 36 \\
\hline Body awareness & 24.35 & 6.24 & 4 & 36 & 21.60 & 5.91 & 4 & 36 \\
\hline
\end{tabular}

The second step in the results' analysis was the exploration of boys' and girls' self-reported physical activity during the week. We divided the research group according to the intensity of physical activity: group A - adolescents who do not perform additional physical activity, B - adolescents who spend less than three hours per week on physical activity, and C - adolescents who spend more than three hours per week doing physical activity. One third of adolescents do not do additional physical activities. There are more girls among the non-exercisers, but the difference is not statistically significant. A similar proportion of the groups of boys and girls regularly train outside school, but boys spend significantly more time on it (Table 3). 
Table 3. Physical activity during the week in the groups of boys and girls

\begin{tabular}{|c|c|c|c|}
\hline & & Boys $n=208$ (\%) & Girls $n=229(\%)$ \\
\hline \multirow{3}{*}{ Physical activity } & no & $59(28.4)$ & $81(35.4)$ \\
\hline & yes & $149(71.6)$ & $148(64.6)$ \\
\hline & & \multicolumn{2}{|c|}{$F(1,435)=2.46 ; p=0.12$} \\
\hline \multirow{2}{*}{ Time of training $(M, S D)$} & & $257.16 \min (292.45)$ & $164.58 \mathrm{~min}(224.06)$ \\
\hline & & \multicolumn{2}{|c|}{$F(1,435)=13.94 ; p<0.001$} \\
\hline
\end{tabular}

The intensity of physical activity in the group of boys is different from the group of girls (Table 4). In the boys' group almost half of the group do additional physical activity more than three hours per week, and one quarter of the group do this activity less than three hours per week. This means that boys prefer more frequent physical activity. In the group of girls each degree of intensity of training is represented to a similar degree.

Table 4. Intensity of physical activity (apart from PE classes) in the boys' and girls' groups

\begin{tabular}{lcc}
\hline Intensity of physical activity & Boys $n=208(\%)$ & Girls $n=229(\%)$ \\
\hline group A (no physical activity) & $59(28.4)$ & $81(35.4)$ \\
group B (less than 3h per week) & $56(26.9)$ & $77(33.6)$ \\
group ( (more than 3h per week) & $93(44.7)$ & $71(31.0)$ \\
\hline
\end{tabular}

The last step of the analysis was the verification of the hypothesis that adolescents presenting different levels of physical activity differ significantly in terms of: (a) body image, (b) body schema, and (c) body awareness. The results displayed in Table 5 show that this hypothesis has been positively verified. In the group of boys, those who practise more have stronger body representations, especially body schema and body awareness. Most of the differences between A, B and C subgroups are significant in the group of boys. In the group of girls the situation is different. Significant differences occur only between subgroup A and subgroup $\mathrm{C}$ in body schema and body awareness, which means that body image does not depend on physical activity in the group of girls. More physical activity in this group is connected with stronger body representations, but significant differences are present only in representations of body schema and body awareness. 
Table 5. Comparison of the results of mental body representations for the subgroups of different intensities of physical activity in the groups of boys and girls: one-way ANOVA

\begin{tabular}{lccc}
\hline \multicolumn{1}{c}{ Mental body representations } & Body image & Body schema & Body awareness \\
\hline Boys $A(n=59)$ & $22.54(7.55)$ & $21.47(6.57)$ & $21.48(6.54)$ \\
$B(n=56)$ & $24.50(8.60)$ & $24.71(6.42)$ & $25.32(6.10)$ \\
$C(n=93)$ & $25.40(6.72)$ & $26.90(5.90)$ & $25.59(5.58)$ \\
differences between groups & $A \neq C$ & $A \neq C . A \neq B$ & $A \neq C . A \neq B$ \\
\hline Girls $A(n=81)$ & $17.97(8.90)$ & $20.81(6.01)$ & $20.27(5.93)$ \\
$B(n=77)$ & $18.53(9.58)$ & $22.53(6.43)$ & $21.88(5.56)$ \\
$C(n=71)$ & $18.59(8.92)$ & $23.45(7.54)$ & $22.83(6.04)$ \\
differences between groups & & $A \neq C$ & $A \neq C$ \\
\hline
\end{tabular}

\section{Discussion}

The purpose of this study was to assess the importance of physical activity in the normative development of mental body representations during adolescence. The preliminary data analysis revealed significantly different structures of mental body representations in teenage boys and girls, hence further analyses were conducted separately for both genders. Boys represent a more harmonious and strong structure of body image, body schema, and body awareness than girls. Teenage females are characterized by a lower mean value of body image that is much poorer than the other two body representations: body schema and body awareness. In consequence, the entire structure of their body representations is less coherent than this structure in the boys' group. Body self is an important part of the system of the self (Mirucka, 2018; Mirucka and Sakson-Obada, 2012), so the reduced level of some of the mental representations can lead to some negative consequences in the entire structure of the self. The urgent issue is the improvement of girls' positive body image to prevent this possibility.

The results regarding adolescents' level of physical activity show that boys reported significantly higher levels of physical activity than girls, which is consistent with previous studies (e.g. Chae, Kang, and Ra, 2017). In particular, it is worth paying attention to the group of teenagers who do not perform additional physical activity (one third of the study group). Lack of physical activity in adolescence can have an influence on later mental health outcomes (Suetani et al., 2017). The present study also indicates that non-exercisers can achieve a poorer structure of mental body 
representations, which can translate into the functioning of the system of the self. This teenage group should be particularly targeted with preventive activities.

The main results show that adolescent boys who spend more time during the week doing physical activity gain significantly higher levels of all mental body representations - body image, body schema, and body awareness than their non-exercising peers. In the groups of active and non-active girls significant differences were noticed only in body schema and body awareness. This means that adolescents' body schema and body awareness are especially susceptible to changes caused by physical activity.

The results indicating that physical activity does not affect body image in the group of girls is very intriguing. The causes of this phenomenon may be complex. Girls more often experience greater dissatisfaction with their appearance or body weight (Kostanski, Fisher, and Gullone, 2004; Kostanski and Gullone, 2007), so perhaps doing physical activity exposes them to greater monitoring of their own bodies, which can exacerbate body dissatisfaction. Some group forms of physical activity, like fitness or aerobics, may cause them to compare themselves with other exercisers. Even individual exercise at home can trigger intrusive comparisons with instructors from the Internet. It has been shown that girls habitually monitor themselves (e.g. Fredrickson and Roberts, 1997). The second reason can be related to the drive for thinness, which is very intensified in the group of girls (Ricciardelli and McCabe, 2004; Smolak and Stein, 2006). Physical activity can lead to increased muscle mass and, as a result, to increased weight and/or change of the figure into a more muscular one. These possible changes may intensify anxiety about not fulfilling the cultural ideals of beauty.

\section{Implications for teacher education}

The presented study emphasis the role of physical activity in the development of mental body representations in adolescents, and is a part of the research trend indicating the important role of physical activity in the general development of young people (e.g. Biddle and Asare, 2011). Therefore, it is crucial to provide future teachers with knowledge about this relevant role. Teachers are among the adults who provide information about the meaning of physical activity to children and adolescents. They are often the authorities whose opinions and attitudes affect the pupils and students very much. 
The most important issue is to increase preventive actions aimed at promoting physical activity. Teachers can popularize it through: a) appropriate selection of teaching content, b) presenting a positive attitude toward one's own body, and c) creating a supportive school environment. Including knowledge about potential benefits from increased physical activity (McDowell, MacDonncha and Herring, 2017) in teaching is crucial. Students should receive some detailed information about the relation between intensity of training and potential health and mental benefits to enable them to choose and plan the intensity of their own practise consciously. It was proved that when teachers provided girls with a variety of non-competitive physical activity options and allowed them to choose what they would like to do, they spontaneously increased their own physical activity (Camacho-Mińano, LaVoi, and Barr-Anderson, 2011). Furthermore, a relevant issue is encouraging young people to spend free time on common physical activity with friends. Previous research indicates that social support from friends is related to intensity of physical activity (Budd et al., 2018). The second important issue is teachers' presentation of a positive attitude toward one's own body. The teacher is observed as an authority, and his/her own attitudes (even unconscious) can have an impact on his/her students. Thus, teachers' personal development is very important, including awareness of one's own attitude towards the body and improving the positive experience of the body. Another relevant facet is creating a positive way of referring to pupils'students' bodies. This can be expressed by a positive, full of acceptance way of talking about the body, sexuality and puberty. The third area of possible preventive actions is creating a school environment which will support physical activity. This can be implemented in various ways. Some forms of non-competitive physical activity can be included in daily school activity (e.g. taking breaks in lessons to stretch) and special events (e.g. organizing dance lessons). Previous research shows that part of a supportive school environment for girls includes supportive behaviour from boys (Burns, Fu, and Podlog, 2017). Teachers should initiate and reinforce this type of behaviour. Any kind of intervention to increase physical activity can enable effective prevention of future mental health problems (Suetani et al., 2017), so it can be very important and influential during adolescence. Efforts to promote physical activity ought to start early in an individual's life (Hallal et al., 2006), hence teachers' involvement in popularizing knowledge about the role of physical activity can be a response to this postulate. 
The risk of developing poorer body representations in the group of non-exercising adolescents should be teachers' special concern. Inspiring the students to do physical activity is as important as identifying individual reasons for limited activity. Another important area of preventive action, especially in girls, can be improving enjoyment in physical activity. This important variable has an impact on physical activity (Cairney et al., 2012; Jago et al., 2011; Sallis, Prochaska, and Taylor, 2000). It is defined in multiple ways: 1) as a positive feeling toward physical activity (Cairney et al., 2012), 2) as believing that this kind of activity is fun (Cairney et al., 2012), or 3) as a type of intrinsic motivation to perform physical activity (Labbrozzi et al., 2013). Physical activity enjoyment - no matter how it is defined - is an important determinant of girls' physical activity. The more the girl enjoys physical activity, the more likely it is that she will practice regularly and continue it over time, greatly reducing the risk of poor health outcomes (Cairney et al., 2012; Labbrozzi et al., 2013).

\section{References}

Assaiante, C., Barlaam, F., Cignetti, F., and Vaugoyeau, M. (2014). Body Schema Building During Childhood and Adolescence: A Neurosensory Approach. Clinical Neurophysiology, 44 (1), 3-12.

Baldursdottir, B., Valdimarsdottir, H.B., Krettek, A., Gylfason, H.F., and Sigfusdottir, I. D. (2017). Age-Related Differences in Physical Activity and Depressive Symptoms Among 10-19-year-old Adolescents: A Population Based Study. Psychology of Sport and Exercise, 28, 9-99.

Benítez-Porres, J., Alvero-Cruz, J.R., Carrillo de Albornoz, M., Correas-Gómez, L., Barrera-Expósito, J., Dorado-Guzmán M., Moore, J.B., and Carneroet, E.A. (2016). The Influence of 2-Year Changes in Physical Activity, Maturation, and Nutrition on Adiposity in Adolescent Youth. PLoS ONE, 11 (9), e0162395.

Biddle, S.J.H., and Asare, M. (2011). Physical Activity and Mental Health in Children and Adolescents: a Review of Reviews. British Journal of Sports Medicine, 45, 886-895.

Budd, E.L., McQueen, A. Eyler, A.A., Haire-Joshu, D., Auslander, W.F., and Brownson, R.C. (2018). The Role of Physical Activity Enjoyment in the Pathways from the Social and Physical Environments to Physical Activity of Early Adolescent Girls. Preventive Medicine, 111, 6-13.

Burns, R.D., Fu, Y., and Podlog, L.W. (2017). School-Based Physical Activity Interventions and Physical Activity Enjoyment: A Meta-Analysis. Preventive Medicine, 103, 84-90.

Cairney, J., Kwan, M.Y., Velduizen, S., Hay, J., Bray, S.R., and Faught, B.E. (2012). Gender, Perceived Competence and the Enjoyment of Physical Education in Children: a Longitudinal Examination. International Journal of Behavioral Nutrition and Physical Activity, 9 (1), 26. 
Camacho-Mińano, M.J., LaVoi, N.M., and Barr-Anderson, D.J. (2011). Interventions to Promote Physical Activity among Young and Adolescent Girls: A Systematic Review. Health Education Research, 26 (6), 1025-1049.

Cash, T.F., and Pruzinsky, T. (2002). Body Image. A Handbook of Theory, Research, and Clinical Practice ( $1^{\text {st }}$ ed.). New York, London: Guilford Press.

Chae, S.M., Kang, H.S., and Ra, J.S. (2017). Body Esteem is a Mediator of the Association Between Physical Activity and Depression in Korean Adolescents. Applied Nursing Research, 33, 42-48.

Choudhury, S., Charman, T., Bird, V., and Blakemore, S.J. (2007). Adolescent Development of Motor Imagery in a Visually Guided Pointing Task. Consciousness and Cognition, 16, 886-896.

Cole, J., and Paillard, J. (1995). Living without Touch and Peripheral Information about Body Position and Movement. Studies with Deafferented Subjects. In: J.L. Bermudez, A.J. Marcel, and N. Eilan (Eds.), The Body and the Self (pp. 245-266). Cambridge: Bradford Books.

Craig, A.D. (2003). Interoception: The Sense of the Physiological Condition of the Body. Current Opinion in Neurobiology, 13 (4), 500-505.

Dalley, S.E., and Vidal, J. (2013). Optimism and Positive Body Image in Women: The Mediating Role of the Feared Fat Self. Personality and Individual Differences, 55, 465-468.

Dumith, S.C., Gigante, D.P., Domingues, M.R., and Kohl, H.W. $3^{\text {rd }}$. (2011). Physical Activity Change During Adolescence: A Systematic Review and a Pooled Analysis. International Journal of Epidemiology, 40 (3), 685-698.

Fredrickson, B.L., Roberts, T.A. (1997). Objectification Theory: Toward Understanding Women's Lived Experiences and Mental Health Risks. Psychology of Women Quarterly, 21 (2), 173-206.

Gallagher, S. (2005). How the Body Shapes the Mind. Oxford: Oxford University Press.

Gibbs, R.W. (2006). Embodiment and Cognitive Science. Cambridge: Cambridge University Press.

Gillen, M.M. (2015). Associations Between Positive Body Image and Indicators of Men's and Women's Mental and Physical Health. Body Image, 13, 67-74.

Hallal, P.C., Victora, C.G., Azevedo, M.R., and Wells, J.C.K. (2006). Adolescent Physical Activity and Health - A Systematic Review. Sports Medicine, 36 (12), 1019-1030.

Head, H., and Holmes, G. (1911). Sensory Disturbances from Cerebral Lesions. Brain, 34 (2-3), 102-254.

Hrafnkelsdottir, S.M., Brychta, R.J., Rognvaldsdottir, V., Gestsdottir, S., Chen, K.Y., Johannsson, E., Guđmundsdottir, S.L., and Arngrimssonet, S.A. (2018). Less Screen Time and More Frequent Vigorous Physical Activity is Associated with Lower Risk of Reporting Negative Mental Health Symptoms Among Icelandic Adolescents. PLoS ONE, 13 (4), e0196286.

Jacob, P., and Jeannerod, M. (2005). The Motor Theory on Social Cognition: A Critique. Trends in Cognitive Sciences, 9 (1), 21-25.

Jago, R., Davis, L., Mcneill, J., Sebire, S.J., Haase, A., Powell, J., and Cooper, A.R. (2011). Adolescent Girls’ and Parents’ Views on Recruiting and Retaining Girls 
into an after-School Dance Intervention: Implications for Extra-Curricular Physical Activity Provision. International Journal of Behavioral Nutrition and Physical Activity, 8 (91), 1-10.

Kostanski, M., and Gullone, E. (2007). The Impact of Teasing on Children's Body Image. Journal of Child and Family Study, 16 (3), 307-319.

Kostanski, M., Fisher, A., and Gullone E. (2004). Current Conceptualisation of Body Image Dissatisfaction: Have We Got It Wrong? Journal of Child Psychology and Psychiatry, 45 (7), 1317-1325.

Krueger, D.W. (2002). Integrating Body Self and Psychological Self (1 $1^{\text {st }}$ ed.). New York - London: Brunner-Routledge.

Labbrozzi, D., Robazza, C., Bertollo, M., Bucci, I., and Bortoli, L. (2013). Pubertal Development, Physical Self-Perception, and Motivation Toward Physical Activity in Girls. Journal of Adolescence, 36 (4), 759-765.

McDowell, C.P., MacDonncha, C., and Herring, M.P. (2017). Brief Report: Associations of Physical Activity with Anxiety and Depression Symptoms and Status Among Adolescents. Journal of Adolescence, 55, 1-4.

Mehling, W.E., Gopisetty, V., Daubenmier, J., Price, C.J., Hecht, F.M., and Stewart, A. (2009). Body Awareness: Construct and Self-Report Measures. PLoS ONE, 4 (5), e5614.

Mirucka, B. (2016). The Meaning of the body Schema in Reaching Maturity During Late Adolescence. Polish Psychological Bulletin, 47 (1), 149-158.

Mirucka B. (2017). A Battery of Tests of the Body Self Representations. The Review of Psychology, 60 (20), 243-263.

Mirucka, B. (2018). Podmiot ucieleśniony. Psychologiczna analiza reprezentacji ciała i tożsamości cielesnej (1 $1^{\text {st }}$ ed.). Warszawa: Scholar.

Mirucka, B., and Sakson-Obada, O. (2012). Ja cielesne - od normy do zaburzeń. Sopot: GWP.

Moore, J.B., Beets, M.W., Morris, S.F., and Kolbe, M.B. (2014). Comparison of Objectively Measured Physical Activity Levels of Rural, Suburban, and Urban Youth. American Journal of Preventive Medicine, 46 (3), 289-292.

Nader, P.R., Bradley, R.H., Houts, R.M., McRitchie, S.L., and O’Brien, M. (2008). Moderate-to-Vigorous Physical Activity from Ages 9 to 15 Years. JAMA, 300 (3), 295-305.

Pruzinsky, T., and Cash, T.F. (2002). Understanding Body Images: Historical and Contemporary Perspectives. In: T.F. Cash and T. Pruzinsky (Eds.), Body Image: A Handbook of Theory, Research, and Clinical Practice (pp. 3-12). New York, NY: The Guilford Press.

Ricciardelli, L.A., and McCabe, M.P. (2004). A Biopsychosocial Model of Disordered Eating and the Pursuit of Muscularity in Adolescent Boys. Psychological Bulletin, 130, 179- 205.

Sallis, J.F., Prochaska, J., and Taylor, W. (2000). A Review of Correlates of Physical Activity of Children and Adolescents. Medicine \& Science in Sports \& Exercise, 32, 963-975.

Smolak, L., and Stein, J.A. (2006). The Relationship of Drive for Muscularity to Sociocultural Factors, Self-Esteem, Physical Attributes, Gender Roles, and Social Comparison in Middle School Boys. Body Image, 3, 121-129. 
Suetani, S., Mamun, A. Williams, G.M., Najman, J.M., McGrath, J.J., and Scott, J.G. (2017). Longitudinal Association between Physical Activity Engagement During Adolescence and Mental Health Outcomes in Young Adults: A 21-year Birth Cohort Study. Journal of Psychiatric Research, 94, 116-123.

Troiano, R.P., Berrigan, D., Dodd, K.W., Mâsse, L.C, Tilert, T., and McDowell, M. (2008). Physical Activity in The United States Measured by Accelerometer. Medicine \& Science in Sports \& Exercise, 40 (1), 181-188.

Twisk, J.W.R., Kemper, H.C.G., and van Mechelen, W. (2002). Prediction of Cardiovascular Disease Risk Factors Later in Life by Physical Activity and Physical Fitness in Youth: General Comments and Conclusions. International Journal of Sports Medicine, 23, 44-49.

Tylka, T.L. (2011). Positive Psychology Perspectives on Body Image. In: T.F. Cash and L. Smolak (Eds.), Body Image: A Handbook of Science, Practice, and Prevention (2 pp. 56-64). New York, NY: The Guilford Press.

Tylka, T.L., and Kroon van Diest, A.M. (2013). The Intuitive Eating Scale 2: Item Refinement And Psychometric Evaluation with College Women and Men. Journal of Counseling Psychology, 60 (1), 137-153.

Tylka, T.L., and Wood-Barcalow, N.L. (2015). What is and What is not Positive Body Image? Conceptual Foundations and Construct Definition. Body Image, 14, $118-129$.

U.S. Department of Health and Human Services. (2008). Physical Activity Guidelines for Americans. Washington D.C. Retrieved July 22, 2018 http://www.health. gov/paguidelines/guidelines/.

Viel, S., Vaugoyeau, M., and Assaiante, C. (2009). Adolescence: A Transient Period of Proprioceptive Neglect in Sensory Integration of Postural Control. Motor Control, 13 (1), 25-42.

Wood-Barcalow, N.L., Tylka, T.L., and Augustus-Horvath, C.L. (2010). "But I Like My Body": Positive Body Image Characteristics and a Holistic Model for Young-Adult Women. Body Image, 7, 106-116. 


\title{
Chapter 15
}

\section{Children's Rights and Human Rights as a Key Condition for the Education of Transformative Teachers}

\author{
Anna Babicka-Wirkus \\ Pomeranian University in Słupsk, Słupsk, Poland
}

\begin{abstract}
This paper addresses the issue of the importance and needs of teacher education in the aspect of respect for children's rights and human rights. This is a particularly important direction of change which reflection and pedagogical practice should follow, especially in the context of contemporary attempts by citizens to appropriate freedoms for all citizens and widespread examples of assault and lack of understanding for other people. Currently, the education of future teachers about the rights of the child is very cursory, and in many cases it does not take place at all. This chapter argues that a modern transformative teacher should have expert knowledge of children's rights and be able to implement it into his or her daily practice, as well as having the competencies to engage other members of the school community in the implementation of the provisions of the Convention on the Rights of the Child. This thesis is further developed by referring to Jacques Rancière's concept of the 'ignorant schoolmaster'. KEYWORDs: transformative teacher, children's rights, teacher training, education
\end{abstract}

\section{Introduction}

Today's world is in the process of constant change, which is also reflected in education. Teachers and students are faced with new and more complex requirements as a response to market demands and the requirements of neoliberal culture. In this context, it is still true that education has not kept pace 
with the changes and that they are not of its own making, but rather primary to it. What was a useful skill yesterday may prove to be an obstruction tomorrow. That is why there are questions about educating future teachers, e.g.: What should they be trained for? What practical knowledge should they have? What social competences should they have? Answers to these questions can form a somewhat clichéd model of a transformative teacher. Thus new questions emerge: What does it mean to be a transformative teacher nowadays? Is it enough to be fluent with technological tools, hold a prestigious university diploma, and know how to put theory into practice? After all, this is what school principals, parents and society expect (Cutler, 2016; Gautreaux and Delgado, 2016).

In the context of contemporary changes as well as increasing and more complex social issues, the above-mentioned skills are insufficient. Thus, the need arises to prepare future teaching staff for spreading and implementing the idea of children's and human rights, especially through education. It is demanded by the creators of the Promoting Rights in School program (ActionAid, 2011), which is addressed to public schools and aims at increasing the quality of education in these institutions. One of the recommendations of the program is as follows: "schools should have a sufficient number of trained teachers of whom a good proportion are female; [and] teachers should receive good quality pre-service and in-service training with built-in components on gender sensitivity, non- discrimination, and human rights” (ActionAid, 2011, p. 4). Another recommendation relates to the necessity of educating children about, in and through children's rights: "Right to know your rights: schools should teach human rights education and children's rights in particular. Learning should include age-appropriate and accurate information on sexual and reproductive rights” (ibid.).

Therefore, the education of teachers should not focus exclusively on providing them with knowledge on children's and human rights but, most of all, it should create the conditions for the implementation of rights into daily educational activities (Howe and Cowell, 2010; Śliwerski, 2018; Tomasevski, 2001; Verhellen, 1993, 1994). This requirement is particularly observable now, when many countries are struggling with the crisis of democratic values, a return to populism and increasing nationalistic tendencies (Arditi, 2005; Balibar, 1992; Galston, 2017). Education, especially education focused on respecting children's and human rights, is the only tool which can stop these processes. 
This article argues that a modern transformative teacher should, above all, have thorough knowledge of human rights and children's rights, be able to put it into everyday practice and have social competences for engaging their pupils and other members of the school community in this process. These are key competences which should be acquired during the higher education process. Their significance in the context of modern problems related to terrorism, nationalism, and hate speech as well as an increasing social divide and intolerance of otherness is invaluable.

\section{Who is a real transformative teacher?}

In pedagogical and sociological literature, there are many models describing who a so-called 'good teacher' should be. According to Carl Rogers (1992) it is a facilitator, whereas for Henry A. Giroux (1985) it is a transformative intellectual; for Peter McLaren (1999) it is a 'luminal servant', and for Jacques Rancière (1991) it is a master ignorant. According to teachers and adepts of this profession participating in the Educational Doctorate in Teacher Education program, a transformative teacher "should adapt and be open to diverse classroom practices and embrace multiculturalism; catch up with the latest technological skills; invite learners to be critical thinkers; and prepare learners to be active change agents in an interdependent and connected world” (Paneru et al., 2017, pp. 25-26). These characteristics show a view that it is the teacher who should prepare the students for entering the world and critically analyzing it, as well as show them the elements of social structure that enslave them, thus unveiling the hidden reality.

This definition, created on the basis of the opinions of teachers from various countries, places itself in the modern perception of a transformative teacher as a facilitator and a transformative intellectual who, despite his/ her openness and positive attitude towards students, remains in a hierarchal relation with them. Therefore, as Rancière (1991) claims, we cannot talk about equality with regard to these two subjects of the educational interaction. Such equality is possible only if both the student's and the teacher's intelligence are recognized and accepted as equal. "To emancipate an ignorant person, one must be, and one need only be, emancipated oneself, that is to say, conscious of the true power of the human mind. The ignorant person will learn by himself what the master doesn't know if the master believes he can and obliges him to realize his capacity” (Rancière 1991, p. 15). This is possible under the condition of respecting human rights and children's 
rights in the educational process. This issue is crucial since it changes the traditionally fixed relationships in the classroom where the teacher is considered to be the one who knows better and is more experienced; thus, their privileged position is obvious. The student, however, passively submits to these interactions (Jones and Welch, 2010).

When education is based on the idea of children's and human rights, the teacher and the student are considered equal subjects of the interaction who develop throughout its duration. Both parties are perceived, in the first place, as independent human beings who are 'equally intelligent' (Rancière 1991, xix), which means they are equal as cognitive entities. Therefore, it is essential for reflections upon the concept of a modern transformative teacher to emphasize this aspect of education which, among other significant skills and competences, is key to the whole process of education and development of students, teachers and a democratic civil society.

\section{Human rights and children's rights in educating teachers}

Currently, the education of future teachers about the rights of the child is very cursory, and in many cases it does not take place at all, as evidenced by numerous studies both Polish and international (Babicka-Wirkus, 2018a; Covell, 2013; Jerome et al., 2015). Detailed knowledge, understanding and acceptance of human and children's rights by future teachers is crucial for further education in this matter at lower levels of the educational system. Therefore, I emphasize that the training of transformative teachers, as Gert Biesta (2011) argues, requires reliable knowledge and understanding of the essence of children's rights and human rights. This is the main purpose of teachers' preparation, because knowledge and acceptance of these rights will make it possible to change the relationship of domination and subordination prevailing in schools, and also enable an egalitarian dialogue between the student and the teacher. Respect for another person, and for their dignity is the foundation of a democratic society and should be realistically present in educational relations. This is significant for three reasons. First, teachers who know their rights as human beings are aware of the possibility of expressing their own opinions and manifesting civil disobedience to morally reprehensible actions by authorities. Secondly, these teachers respect the right of every human being to express themselves and allow students to speak and listen with attention. This situation is conducive to the practice of hearing children's voices in matters that are important to 
them, which makes it possible to overcome the 'silent treatment' present in schools. Thirdly, respect for children's rights in educational situations puts teachers in the position of needing to constructively dealing with students' resistance, which is the biggest challenge for the teacher. However, it is a developmental situation for both sides, because it introduces reflection on the accepted way of reading reality and teaches how to manifest civil disobedience, which is so important in the present world.

According to Malewska and Najmowicz (1990), the period of studenthood is crucial for shaping young people's views and values. In study institutions, they learn how to work and how to treat others, especially those who are in an inferior position to them. The kind of experience they get from this will affect their future work. Therefore, it is important to raise the issue of human rights at universities - it may increase the awareness of higher education teachers and students in this matter. Fritzsche and Tibbitts (2006) stress the notion of human rights education at universities for young people's development, especially for their professional development. Human rights education links theoretical reflection and action, so it is different from the banking concept of education ${ }^{1}$ (Freire, 2000).

Despite the obligations imposed on States Parties by the Universal Declaration of Human Rights (Article 13 and Article 26), and the Convention on the Rights of the Child (Article 28, Article 29 and Article 42), issues related to human rights and children's rights are often marginalized in the education of teachers, especially subject teachers. This is indicated by the results of studies on the implementation of human rights and children's rights in the education process conducted in twenty-six countries (Table 1). From the point of view of the present work, the fourth column from the left is especially significant as it contains the answer to the question: Are all teachers trained in children's rights and the CRC as part of their initial training? This kind of training fully takes place only in Scotland. In two of the countries, Iceland and Sweden, teachers are trained in this respect to some extent. However, as many as twenty countries admitted that educating teachers about children's rights is not part of their compulsory education. In Poland, Slovenia and Italy, various subjects taking part in the study gave opposing answers.

According to Polish studies (Babicka-Wirkus and Groenwald, 2018; Kozak, 2013), pedagogical students are not prepared for their future work

1 The banking concept of education is the concept developed by Paulo Freire. In this approach a student is perceived as a container which should be filled in by the knowledge. The knowledge is transmitted by teachers who try to educate conformist and obedient citizens. 
in terms of respecting children's rights and creating a school environment that would foster their implementation into everyday practice. Research conducted in secondary schools (Babicka-Wirkus, 2018a) shows that teachers have scarce and colloquial knowledge of children's rights, which results from lack of adequate higher education in this aspect. As a consequence of this deficiency, children's rights are perceived in terms of the obligations children have to fulfill in order to apply for having their rights respected (Osler and Starkey, 2005). As emphasized by Howe and Covell (2010), children's rights and human rights are linked to obligations, especially the obligation of respecting the rights of other people and enabling them in the implementation of these rights. Howe and Covell claim (2010, p. 94):

[...] although responsibilities are secondary, they nevertheless are very important. If someone has a right, other persons or their government must have a responsibility to provide that right or allow the rights-holder to exercise the right. If rights are truly of fundamental importance, they must have implications for action. And if they have implications for action, there must be persons or governments responsible for taking action in support of rights. Thus, responsibilities are derived from rights.

However, respecting them is not dependent on fulfilling student duties subjectively established by the teacher, such as behaving well during lessons.

The fifth column of the Table 1 shows the response to the question about the existence of regulations relating to children's rights that determine if someone is qualified to be a teacher. The situation seems to be even worse than the previous aspect, since such regulations only exist in Scotland. The other twenty-five countries do not regulate such issues.

The above data clearly indicates that education of future teachers in human rights and children's rights is rather marginal, and is not well-established among the competences of a transformative teacher as commonly interpreted. It is only marked (simulated) on the level of formal regulations and education programs because it is required by the signed international legal instruments that defend human rights.

Human rights and children's rights are often only a catchy slogan which are incorporated into formal education programs on every level of education. They are usually not reflected in everyday practices (Jones and Welch, 2010), as can be seen from the culture of silence that has developed in many educational institutions, as well as the phenomenon of dropping out from the process of education, the violence towards students from different cultural backgrounds that exists in schools, etc. 
Table 1. Child Rights Education in 26 countries

\begin{tabular}{|c|c|c|c|c|c|}
\hline & $\begin{array}{l}\text { Is there a } \\
\text { requirement } \\
\text { in the } \\
\text { curriculum for } \\
\text { all children to } \\
\text { learn about } \\
\text { child rights? }\end{array}$ & $\begin{array}{l}\text { Does the } \\
\text { goverment, } \\
\text { or a public } \\
\text { agency, mon- } \\
\text { itor/inspect } \\
\text { the quality of } \\
\text { CRE? }\end{array}$ & $\begin{array}{l}\text { Are the } \\
\text { teachers } \\
\text { trained in } \\
\text { children's } \\
\text { rights and the } \\
\text { CRC as part } \\
\text { of their initial } \\
\text { training? }\end{array}$ & $\begin{array}{l}\text { Do the } \\
\text { regulations } \\
\text { concerning } \\
\text { who is } \\
\text { qualified to } \\
\text { teach refer to } \\
\text { child rights? }\end{array}$ & $\begin{array}{l}\text { To what } \\
\text { extent are } \\
\text { schools } \\
\text { required to } \\
\text { run student } \\
\text { councils? }\end{array}$ \\
\hline Australia & 0 & 0 & 0 & 0 & 0 \\
\hline Austria & - & 0 & 0 & 0 & - \\
\hline Belgium & - & - & 0 & 0 & $\bullet$ \\
\hline Canada & - & 0 & 0 & 0 & $\bullet$ \\
\hline Denmark & 0 & 0 & 0 & 0 & - \\
\hline Finland & - & 0 & 0 & 0 & $\bullet$ \\
\hline France & 0 & - & 0 & 0 & - \\
\hline Germany & v & - & 0 & 0 & v \\
\hline Hong Kong & 0 & 0 & 0 & 0 & 0 \\
\hline Hungary & ○ & 0 & 0 & 0 & 0 \\
\hline Iceland & - & 0 & - & - & - \\
\hline Ireland & 0 & 0 & 0 & 0 & - \\
\hline Israel & - & 0 & 0 & 0 & - \\
\hline Italy & - & - & & - & 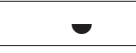 \\
\hline New Zeland & 0 & 0 & 0 & 0 & 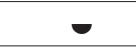 \\
\hline Norway & $\bullet$ & 0 & 0 & 0 & $\bullet$ \\
\hline Poland & $\bullet$ & & - & 0 & $\bullet$ \\
\hline Republic of Korea & 0 & 0 & 0 & - & $\bullet$ \\
\hline Scotland & 0 & 0 & 0 & 0 & $\bullet$ \\
\hline Slovakia & 0 & 0 & 0 & - & v \\
\hline Slovenia & 0 & - & - & - & - \\
\hline Spain & 0 & 0 & 0 & 0 & - \\
\hline Sweden & 0 & 0 & v & 0 & - \\
\hline Switzerland & - & 0 & 0 & 0 & - \\
\hline The Netherlands & 0 & 0 & 0 & 0 & 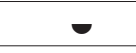 \\
\hline \multicolumn{6}{|c|}{ For the USA questions were amended to refer to international human rights } \\
\hline USA & $\bullet$ & 0 & 0 & O & $\boldsymbol{\bullet}$ \\
\hline
\end{tabular}

Key: - Yes, - Yes, in some places/to some extent, O No,- Disagreement among respondents Source: Jerome et al. (2015, p. 23) 
Respecting human rights and children's rights involves risk while, in the common view, education should be safe. Risk is understood here as a potential of certain dangers, such as undermining a teacher's authority as well as pupils and students calling for their rights and the opportunity to express their opinions. Biesta (2013, p. 3) claims that safe education leads to infantilization. Implementing human rights is associated with risk, and therefore implementing human rights at school carries such a risk.

\section{Why should a transformative teacher be ignorant?}

In the light of Rancière's (1991) education theory, which provides a framework for this paper, it can be assumed that there is a culture at schools based on the order imposed by the police, which he understands as a force which creates the prevailing social discourse. However, it is not about the uniformed services but about the order imposed by the dominating logic of inequality. It is based on the discourse created by subjects with social identity, meaning those who have a place and a function in the system. This part of society determines who does not exist socially and who produces 'incomprehensible sounds, ${ }^{2}$ thus not being able to participate in creating the existing discourse. The only thing they have to do is to surrender to it. The representatives of the privileged group are teachers, educational authorities and politicians. Students are the ones who produce a 'semantic noise' (Franczak, 2017, p. 122).

A traditionally-shaped relation between teachers and students is visible in the names used for describing the subjects in the educational relationship. The teacher is the one who knows and understands more. He/she has access to some secret knowledge and can allow the student to acquire it if he/she chooses to do so, by leaving the proverbial door ajar. The student, on the other hand, is someone who has a deficiency and has to learn something. "The learner is the one who is missing something. The learner is the one who is not complete" (Biesta, 2011, p. 32). The student does not have the skills to self-learn. In this context, the student's emancipation process can only occur as a result of exposing his or her limited aspects to the teacher (the higher intelligence). However, this does not then equalize the relation of inequality between the teacher and the emancipated student (Biesta, 2013).

2 Rancière uses the term 'noise' which refers to this part of society which figuratively has no voice. In other words, in society we have people who speak and those who only make noise. The noise is not part of social discourse because it is meaningless, and nobody can and want to understand it (Rancière, 1999, p. 30). 
This traditional concept is opposed by Rancière (1991) who claims that the teacher's intelligence and the student's intelligence are equal in the process of education. The teacher's role is crucial but it is not only about 'leaving the door ajar'. On the contrary, it is about keeping it closed. The point is to provoke the student to make an effort, and to draw attention to various aspects of a particular reality. The student's role is to pursue knowledge and ask the following questions: What do I see? What do I think about it? What can I do with it? (Cornelissen, 2011, pp. 26-28). "The educator is still there, but not as an explicator, not as a superior intelligence, but as a will, as someone who demands the effort from the student and verifies that an effort has been made” (Biesta, 2011, p. 35). In this educational relationship, the teacher is 'ignorant' since he/she does not recognize the student's limitations in the form of lack of knowledge or life experience. One can say that this ignorance is based on the equality of all human beings and their ability to self-develop which is inscribed into the concept of human rights.

The ignorant teacher assumes intelligence equality and the importance of the student's voice. Speaking is the key aspect of the education process because "in the act of speaking, man doesn't transmit his knowledge, he makes poetry; he translates and invites others to do the same” (Rancière, 1991, p. 65). Speaking is a reality-transforming action because the subject conveys his or her ways of thinking and making meanings through it. Thereby, the speaker encourages discussion and the mental effort needed to face different interpretations. Thus the requirement to speak, discuss and ask questions is the most important aspect of the process of transformative education and the subject's emancipation.

A transformative teacher who, according to Rancière (1991), is an 'ignorant schoolmaster' does not pay attention to the inequality of positions assigned to the roles of student and teacher. He or she also ignores the student's lack of life experience, and instead focuses on motivating students to actively speak out because this is the most important feature of a human being, crucial in the process of emancipation. By speaking out, students perform their own construction and interpretation of meanings, thus becoming creators, not performers, as in the case of the traditional master-student relation. Students are no longer deficient entities and they become speakers (Biesta, 2011), capable of creating themselves and their knowledge. 


\section{Conclusion}

The aim of my paper was to show the importance of including the knowledge of human rights and children's rights in the education process of future teachers. Education based on the principle of equality, where both the teacher's and the child's voices are of the same importance, is possible only when teachers have full knowledge of these rights and understand their essence (Babicka-Wirkus, 2018a; Covell, 2013; Öztürk and Doğan, 2017). Though this practice, the teacher is able to go through an actual and profound transformation on the level of thinking about the world and relations with other people: younger, older, and representative of different cultures and religions.

The responsibility of enabling future teachers to become transformative practitioners rests with the universities which train professionals. Therefore, in order for the implementation of human rights and children's rights to no longer be a pretense or, at best, to be 'decoupled' from each other, it is necessary to introduce it into everyday university reality. However, it should not only be about teaching the concept of human rights and children's rights but mainly about giving the opportunity to practice those rights and protect them when they are violated. Therefore, it is about creating suitable conditions for a dialogue based on the logic of equality in the education process. Only this can lead to emancipation which, according to Rancière (1991, p. 39), "is the consciousness of the equality, of that reciprocity that alone permits intelligence to be realized by verification. What stultifies the common people is not the lack of instruction, but the belief in the inferiority of their intelligence”.

Education based on children's rights and human rights changes the traditionally established attitude in education that it is the process of a oneway movement of knowledge (from teacher to student). Concentrating on the process of a student's emancipation is difficult and requires a high level of competence and a change in the way of thinking about education. Apart from adjusting the teacher's attitude, it also requires changing the dominating school culture (Osler and Starkey, 2010; Rasmusson et al., 2016) which will become more open to manifestations of disagreement and disobedience, and thus the culture of resistance (Babicka-Wirkus, 2019). In order for such a change to happen, children's and human rights have to become a starting point of education that is reflected in the knowledge, skills and values of teachers and students (Covell, 2013). This requirement 
is important because of a student's development as an individual, as well as a responsible and active member of civil society who knows his/her rights, demands their execution and acts when those rights or the rights of other people are violated. It is important for one more reason: this kind of education is crucial for transforming the traditional school culture into a new one, where students are "equally respected and valued" (United Nations Children's Fund, 2007, p. 2) and where they have the opportunity to think critically, make decisions and be responsible for them.

Teachers play important role in the school environment and they have a big impact on the day-to-day experiences of children in school. Therefore, they are responsible for a high quality education based on children's rights in which students want to take part. According to the authors of the report A Human Rights-Based Approach to Education for All by the United Nations Children's Fund (2007, pp. 95-97), teachers need to focus on several main tasks: creating an inclusive and respectful environment accommodated to different needs; treating children as equal partners; encouraging local engagement, and balancing children's rights and responsibilities. It is a crucial issue because there is a big problem with the real implementation of children's rights into every-day practice in schools and in the family environment (Wirkus, 2018). This problem is highlighted in many reports. I refer to some of them in this chapter. Nevertheless, most of them emphasize that there is a lot of work to do in the field of respecting children's rights in daily life (Babicka-Wirkus, 2018b). As far as the school environment is concerned, teachers are the most powerful subjects who can introduce this kind of education, but they need to be prepared for this role.

In her article 'How to Become a Reflective, Innovative, and Self-Critical Educator' (2018, p. 174), Tatyana Tsyrlina-Spady concludes: “Teachers, like no other professionals, are obliged to be keen observers of their students and learn how to constantly reflect, analyse, and change day-to-day activities in accordance with these observations and reflections”. To fulfill this obligation, teachers should know, understand, accept and practice the idea of children's and human rights. Only then will they treat children like human beings and avoid making a basic mistake which is, according to Janusz Korczak (1995, p. 37), “not seeing a human in a child”. 


\section{References}

ActionAid (2011). Promoting Rights in Schools: Providing Quality Public Education. Retrieved November 13, 2018 from http://www.actionaid.org/sites/files/ actionaid/prs_-_english-final__4_may_2011_2_0.pdf

Arditi, B. (2005). Populism as an Internal Periphery of Democratic Politics. In: F. Panizza (Ed.), Populism and the Mirror of Democracy (pp. 72-98). New York: Verso.

Babicka-Wirkus, A. (2018a). Respektowanie prawa do autoekspresji a rytuały oporu gimnazjalistów [Respect for the Right to Self-Expression in Relation to Rituals of Resistance of Lower Secondary School Students]. Warszawa: Biblioteka Rzecznika Praw Dziecka.

Babicka-Wirkus, A. (2018b). Democracy and Children's Right to Self-Expression in Lower Secondary School. Voces de la Educatión, Special issue, 61-74.

Babicka-Wirkus, A. (2019). Kultury oporu w szkole. Działania - motywacje - przestrzeń [Cultures of Resistance at School. Actions-Motivations-Space], Warszawa: Wolters Kluwer.

Babicka-Wirkus, A., and Groenwald, M. (2018). Głos dziecka w przedszkolu - między swobodą wypowiedzi a milczeniem [Child's Voice in Kindergarten - between Freedom of Speech and Silence]. Problemy Wczesnej Edukacji, 1 (40), 95-104.

Balibar, E. (1992). Racism and Nationalism. In: E. Balibar, I. Wallerstein, Race, Nation, Class: Ambiguous Identities (pp. 37-67). New York: Verso.

Biesta, G.J.J. (2011). Learner, Student, Speaker: Why it Matters how We Call Those We Teach. In: M. Simons and J. Masschelein (Eds.), Rancière, Public Education and the Taming of Democracy (pp. 31-42). Oxford: Wiley-Blackwell.

Biesta, G.J.J. (2013). The Beautiful Risk of Education. London and New York: Routledge.

Cornelissen, G. (2011). The Public Role of Teaching: To Keep the Door Closed. In: M. Simons and J. Masschelein (Eds.), Rancière, Public Education and the Taming of Democracy (pp. 15-30). Oxford: Wiley-Blackwell.

Covell, K. (2013). Children's Human Rights Education as a Means to Social Justice: A Case Study from England. Revista International de Educatión Para La Justica Social, 2 (1), 35-48.

Cutler, D. (2016). How to Become and Remain a Transformational Teacher. Retrieved May 29, 2018 from https://www.edutopia.org/blog/become-and-remain-transformational-teacher-david-cutler.Błądzące słowa. Jacques Rancière i filozofia literatury [Wandering Words. Jacques Rancière and The Philosophy of Literature]. Warszawa: Instytut Badań Literackich PAN.

Freire, P. (2000). Pedagogy of the Oppressed. 30 ${ }^{\text {th }}$ Anniversary Edition. Trans. Myra Bergman Ramos. New York-London: Continuum.

Fritzsche, K.P., and Tibbitts, F. (Ed.) (2006). International Perspectives on Human Rights Education. Journal of Social Science Education. Special issue. Retrieved March 12, 2017 from http://www.jsse.org/index.php/jsse/article/view/997/900

Galston, W.A. (2017). The Populist Moment. Journal of Democracy, 28 (2), 21-33.

Gautreaux, M., and Delgado, S. (2016). Portrait of a Teacher for All (TFA) Teacher: Media Narratives of the Universal TFA Teacher in 12 Countries. Education Policy Analysis Archives, 24 (110), 1-24. 
Giroux, H.A. (1985). Teachers as Transformative Intellectuals. Social Education, 49 (5), 376-379.

Howe, R.B., and Covell, K. (2010). Miseducating Children about Their Rights. Education, Citizenship and Social Justice, 5 (2), 91-102.

Jerome, L. Emerson, L., Lundy, L., and Orr, K. (2015). Teaching and Learning about Child Rights: A Study of Implementation in 26 Countries, QUB \& UNICEF. Retrieved September 23, 2018 from https://www.researchgate.net/publication/299454868_Teaching_and_learning_about_child_rights_a_study_of_ implementation_in_26_countries.

Jones, P., and Welch, S. (2010). Rethinking Children's Rights: Attitudes in Contemporary Society. London/New York: Continuum.

Korczak, J. (1995). In: M. Chymuk, Janusz Korczak. Dziecko i wychowawca [Janusz Korczak. The Child and the Educator], Kraków: WAM.

Kozak, M. (2013). Prawo dziecka do edukacji. Założenia pedagogiczno-prawne i bariery realizacyjne [The Child's Right to Education. Pedagogical and Legal Assumptions and Implementation Bariers]. Warszawa: Biblioteka Rzecznika Praw Dziecka.

Malewska, E., and Najmowicz, W. (1990). Wybrane problemy wychowania w szkole wyższej [Selected Problems of Upbringing in a University]. Warszawa: Wydawnictwo Szkoły Głównej Gospodarstwa Wiejskiego - Akademii Rolniczej.

McLaren, P. (1999). Schooling as a Ritual Performance: Towards a Political Economy of Educational Symbols and Gestures, $3^{\text {th }}$ Edition, Lanham-Boulder-New YorkOxford: Rowman and Littlefield.

Osler, A., and Starkey, H. (2005). Rights and Responsibilities. In: A. Osler, H. Starkey (Eds.) Changing Citizenship: Democracy and Inclusion in Education (pp. 154-167) Maidenhead: Open University.

Osler, A., and Starkey, H. (2010). Teachers and Human Rights Education. London: A Trentham Book, Institute of Education Press.

Öztürk, A., and Doğan G.Ö. (2017). Effective Children's Rights Education from the Perspectives of Expert Teachers in Children's Rights Education: A Turkish Sample. Journal of Education and Learning, 6 (4), 303-314.

Paneru, D. R., Muhammad, S., Seden, K., Szelei, N., Pesti, C., Yunga D., and Bernard, W. (2017). Transformative Teacher Learning: An Analysis of Transformative Dimensions and Relevance. In: L. Rasiński, T. Tóth, J. Wagner (Eds.), European Perspectives in Transformative Education (pp. 15-33). Wrocław: Wydawnictwo Naukowe Dolnośląskiej Szkoły Wyższej.

Rancière, J. (1991). The Ignorant Schoolmaster: Five Lessons in Intellectual Emancipation. Trans. K. Ross, California: Stanford University Press.

Rancière, J. (1999). Dis-agreement. Politics and Philosophy. Trans. J. Rose, Minneapolis: University of Minnesota Press.

Rasmusson, B., Andersson, L., Flinck, A.W., Leo, U., and Wickenberg, P. (Eds.). (2016). Realising Child Rights in Education. Experiences and Reflections from the International Training Programme on Child Rights, Classroom and School Management. Lund: Lund University.

Rogers, C. (1992). Freedom to Learn for the 80s. New York: Merill. 
Śliwerski, B. (2018). Children's Rights to their Own Rights. In: M. Michalak (Ed.), The Rights of the Child Yesterday, Today and Tomorrow - the Korczak Perspective. Part I, (pp. 92-141). Warszawa: Rzecznik Praw Dziecka.

Tomasevski, K. (2001). Human Rights Obligations: Making Education Available, Accessible, Acceptable and Adaptable. Lund: Raoul Wallenburg Institute.

Tsyrlina-Spady, T. (2018). How to Become a Reflective, Innovative, and Self-Critical Educator. In: M. Michalak (Ed.) The Rights of the Child Yesterday, Today and Tomorrow - the Korczak Perspective, Part III (pp.164-178). Warszawa: Rzecznik Praw Dziecka.

United Nations Children's Fund. (2007). A Human Rights-Based Approach to Education for All, United Nations Educational, Scientific and Cultural Organization. Retrieved May 29, 2018 from https://www.unicef.org/publications/files/A_ Human_Rights_Based_Approach_to_Education_for_All.pdf

Verhellen, E. (1993). Children's Rights and Education. Social Psychology International, 14 (3), 199-208.

Verhellen, E. (1994). Convention on the Rights of the Child. Kessel-Lo, Belgium: Garant Publishers.

Wirkus, Ł. (2018). The Role of the Family Court in Poland in the Prevention of Demoralization and Juvenile Delinquency on the Example of Prophylactic and Rehabilitation Activity of Probation Officers. The Polish Journal of Criminology, 1, 70-89. 


\title{
Chapter 16
}

\section{Are Innovations a Contribution to the Professional Development of Teachers?}

\author{
Elżbieta Jaszczyszyn and Iwona Lewkowicz \\ Faculty of Pedagogy and Psychology, University of Bialystok, Bialystok, Poland
}

\begin{abstract}
It is quite common to develop innovative programmes in Polish educational institutions. They enable teachers-authors to combine their interests or curiosities (use of desirable competencies) with professional development (developing their own necessary competencies). We determined whether pedagogical innovations are treated as investments in the process of teacher education and professional development, and whether innovative programs are perceived by the authors of the innovations themselves as a contribution to the process of lifelong learning and professional development. The research covered documentation of two innovations implemented in kindergartens (2015-2016, 2017-2018) and one implemented in the first year of primary school (2017-2020), and the publications devoted to them, as well as photographic documentation and chronicles. To supplement the information obtained, the interview method was used with one of the authors of the innovations. Pedagogical innovations give their authors a sense of self-efficacy, create opportunities to use both necessary and desirable competencies in children's learning, promote a holistic approach to educational situations, and act as an 'assistant teacher' in the process of supporting children in their own activities. It is not a bad thing for teachers to find their own well-being. Planning and implementing innovations motivates the teaching staff to introduce new innovations. The potential of the local environment is used.
\end{abstract}

KEYWORDS: innovation, children education, professional development, teacher's competences

CONTACT Elżbieta Jaszczyszyn, EMAIL: e.jaszczyszyn@uwb.edu.pl 


\section{Introduction}

Innovative activities in Polish educational institutions (including in kindergartens and schools) are treated as an integral element of a teacher's work with children. The initiative to implement innovations has been left to the kindergarten/school principals and teachers, as well as the choice of the type and form of their documentation (Stawinoga, 2018, pp. 160-161). The Act of 14 December 2016 - Educational Law (Article 1.8) guarantees, for example, the formation of attitudes of entrepreneurship and creativity in pupils (also in preschool children) conducive to active participation in business life, including through the application in the education process of innovative software, organizational and methodological solutions. The legal regulation includes, for example,

opportunities to support teachers, as part of pedagogical supervision, in the implementation of tasks aimed at improving existing or implementing new solutions in the education process, using innovative programs, methodological and organizational activities aimed at developing students' and teachers' competences - (Art. 55 section 1.4 Act of 14.02.2016. - Educational law Dz.U. of 2017, item 59 as amended - authors‘ translation).

The term 'innovation' itself is one of those concepts for which it is impossible to define precise boundaries. Activation of participants, their empowerment in thinking and real educational results are considered to be the pedagogical value of innovation (all these effects are considered immeasurable) (Jasińska, Jasiński, and Lerka, 2011; Majewska, 2017; Polak, 2016). Combining knowledge from various fields, often seemingly distant, creates the foundations of creative thinking and arouses the desire to discover non-standard combinations of information and create practical solutions on this basis (Piwowar-Sulej, pp. 23-25). In general, the literature in the field assumes that "the perception of innovation, including its novelty and differences, can be crucial for its success" (Kirkland and Sutch, 2009, p. 18). The mechanism for increasing the probability of successful implementation of innovation is, among other things, an understanding by persons functioning in the inventor's environment and the innovator him/herself of the distance which divides innovation from current practices. The basic competences of the author of innovation seem to be important here. They house the "efficient operation of at least some senses, the necessary level of intellectual and moral development and the required level of social development. Therefore, when introducing innovations, the competencies that 
allow one to communicate with co-workers and participants of the planned activities are important” (Dylak, 1995, p. 37).

From an individual perspective, innovations enable their authors to combine their own interests or curiosity (use of possessed desirable competencies) with professional development (developing their own necessary competencies). Desired competencies may be in the professional profile of the teacher, but they do not have to be. Their possession can be very helpful in fulfilling the role of a teacher in professional activities (eg playing the violin, playing sports, interest in art, social involvement, but also having specific political or religious views that may be required in a given school) (ibid.). Competences are necessary because "without [them] a teacher would not be able to work constructively, i.e. fulfil the educational tasks attributed to a given school" (ibid.). Among them are: (a) interpretative, (b) auto-creational and (c) implementation competences. They are acquired in the course of vocational training. Dylak (ibid.) makes the observation that "necessary competencies, ideologically inert, may be shaped without referring to ideology, although they are ideologically functional, when the teacher, interpreting the world or evaluating himself, engages the system of values he recognizes”. General conclusions

stemming from their detailed characteristics result from the assumptions made about the teacher, as the animator of the learning process and the intellectual making independent choices, the creator of personal pedagogical knowledge and his own professional profile and the performer of desired learning outcomes (ibid., p. 38).

If innovations are to initiate changes, they should, according to Kirkland and Such (2009), be characterized by: a) longevity, b) accessibility, and c) the ability to replicate the idea.

We have made the process of designing and implementing innovations in preschool and early childhood education the subject of our research, and we learn to what extent the idea of implementing the professional development of teachers has become a reality due to the interests and skills of innovation teachers-authors and innovation-realizers. We assumed that the innovative activities that are the subject of our research are initiatives that identify and describe the conditions conducive to creation (including the legal framework), identify possible barriers in their implementation, and then take action to implement the planned innovations.

The chapter prepared by us provides inspiring information that complements the current state of knowledge on the promotion and implementation 
of innovative proceedings. Our research has three main objectives: (1) to satisfy the curiosity of researchers and their willingness to better understand the subject of research, (2) to identify the possibility of undertaking broader research and (3) to develop a research procedure that can be used in other research of this type (Babbie, 2001). Research questions are questions about whether and why innovation is seen as an investment in teachers' professional development and whether innovation programmes are seen by the innovators' teachers themselves as a contribution to their own process of lifelong learning and professional development.

We have adopted specific objectives that relate to the exploration, description and explanation of the issues under investigation (Pilch and Bauman, 2010, pp. 22-23). Cognitive goals allowed us to direct our research activities and create an image of the studied reality, learn about the content of documentation, learn about the motives of nursery and school employees, plan and implement innovations, learn about the competences of persons conducting classes in the field of innovation (pedagogue and speech therapist, psychologist, physiotherapist, forest educator) in the studied institutions, determine the level of equipment in kindergartens and schools with objects and teaching aids useful in the implementation of innovation, determine natural conditions and the state of adaptation of buildings to the needs of innovation, learn about the economic situation in kindergartens and schools in terms of financial needs for innovation implementation possibilities. Descriptive objectives include situational contexts and documentation, which give the possibility to obtain detailed characteristics. We have taken into account descriptions of the organisation and cooperation between teachers, as well as authors of innovations and employees of the analysed institutions, parents of children participating in the implementation of innovations and cooperating persons and institutions. The explanatory goal set the criteria on the basis of which opinions on the motives of becoming an author and implementer of innovations and defining one's own place in them were analysed.

We have assumed that pedagogical innovations give the teachers-authors of innovations a sense of self-efficacy. They create the possibility of: using the necessary and desired competences in situations of occasional and formal learning, promoting a holistic approach to educational situations, and realizing oneself as a teacher supporting children in their actions. Planning innovations and their implementation probably dares and motivates innovation teachers to introduce their own innovations aimed at children and parents. 
The main objective of the presented research was to learn about how the planning and implementation of the idea of innovation in the model of preschool and school work takes place, and the importance of such innovations for the professional development of innovation teachers-authors and innovation implementers.

\section{Materials and methods}

The research was carried out on a group of teachers who were the authors of pedagogical innovations or teachers-implementers of innovations. A non-probability sampling technique based on purposive sampling was applied. A selected group of innovators and implementers was examined, recognizing that sometimes it is right to choose a sample based on one's own knowledge about the studied population and the chosen research goal (Babbie, 2001; Flick, 2012). This selection was chosen because educational procedures differing from standard activities in kindergartens and schools were examined. These are cases that do not correspond to generally accepted patterns of behaviour, but help to better understand commonly accepted patterns of work with children (on a contrasting basis) (Babbie, 2001). The sample was selected in such a way as to include persons with specific features of professional conduct (teacher-author of innovation/ teacher-implementer of innovation).

The study group consists of eight people. All of them are women with higher education. There are among them two authors of innovations. The first one is employed as a psychologist in a kindergarten (appointed teacher). The second person is employed as a kindergarten teacher, who is also the creator of innovation (contract teacher). The remaining six persons form a group of independent implementers: a physical education teacher employed in the kindergarten (teacher trainee), a teacher employed in the kindergarten, a speech therapist (teacher trainee), a class teacher in the primary school (appointed teacher) and a person employed in the primary school class as an auxiliary teacher/physiotherapist (contract teacher). The external institution was represented by a forest educator (participating in the implementation of innovation No. 3). In the research work we have adopted a pragmatic paradigm that develops on the basis of actions, situations and their consequences, and places emphasis on practical effectiveness and problem solving. We treat pragmatism as a philosophical foundation of the strategy of mixed research with its variant of the transformative mixed research procedure as the overarching 
perspective for a project involving quantitative and qualitative data. This allowed for a parallel method of data collection (Creswell, 2008). Using mixed methods, we have utilised the quantitative and qualitative databases together, thanks to which it was possible to freely choose the methods, techniques and research procedures best suited to their needs and objectives. Mixed research takes into account the post-modern perspective, which is the theoretical focus on a reflection on social justice and political goals. Pragmatism in these studies has opened the way to multiple views and diverse assumptions as well as various ways of collecting and analyzing data (Creswell, 2008). The selected methodological approaches were assigned appropriate methods: the semi-structured interview method and the participant observation method (open, hidden) and the method of collecting documents. The methods of data interpretation were content analysis and document analysis.

The interview served to gather information from innovation authors, teachers implementing innovations (including the person employed as a teacher supporting a child with autism - innovation No. 3) and a forest educator. Questions were elaborated, on which answers were sought through interview techniques.

Authors of innovation were asked questions about the reasons for taking up the pedagogical innovation, evaluation of the accession procedure and launching innovations, difficulties with the formal side of implementing innovation and the accomplishment of innovation implementation, benefits for the implementing institution, innovation authors and cooperating institutions. They were also asked about the motives of possible planning of further innovations and the fact of sharing their own experiences in the field of conducted innovations. Respondents were given the possibility to talk about ways to share their ideas with other people working in and outside the education system. Teachers carrying out innovations were asked in an interview about the participation of teachers in the role of an educator in pedagogical innovation, difficulties in implementing innovation from the teacher's point of view, the benefits they see for the implementing institution, for themselves and cooperating institutions. They were also asked about the motives of potential participation in further innovations and sharing their own experiences with others. The forest educator presented the responsibilities that are assigned to this function in the State Forests.

Participating observations took place during field activities. One of the authors of this chapter performed research from the position of a member of 
the teaching community acting as a hidden observer (innovation No. 1, 2, 3). The second acted as an open observer in innovation No. 3.

The analysis of documents covered the documentation of a) two innovations implemented in kindergartens (Innovation No. 1: 2013-2014, Innovation No. 2: 2015-2016) and one being currently implemented, which started in 2017 in the first year of primary school (Innovation No. 3: years 2017-2020), b) publications on innovation, c) photographic documentation related to innovation, and d) preschool chronicles and school chronicles).

\section{Results}

The interviewed authors gave a number of reasons for undertaking the design and implementation of pedagogic innovations in educational practice. Innovators emphasized above all personal development, and in it: the use of existing knowledge and skills, gaining new experiences (including tackling the challenges posed by introducing new solutions to existing situations), and the desire to create something new. They also saw the possibility of pursuing personal interests in such activities. There were answers indicating professional motives - implementing professional promotion requirements and improving the functioning of the facility (increasing the quality of didactic activities, enriching the offer with new ways of working with children, establishing cooperation with the Forest District).

In the opinion of the interviewed innovators, the currently applicable provisions contained in the Act - Educational Law are clearly structured. They do not contain complex legal solutions. The formal path they had undergone was not complicated, in their assessment. The regulations guarantee innovators the shortest possible formal path, starting from planning and ending with the approval of the kindergarten/school Teaching Staff for ideas for innovation. The procedure was documented by the written consent of the authors of the innovation for its implementation, the consent of persons who will implement the innovation, the opinion of the Teaching Staff and, finally, the resolution of the Teaching Staff to proceed with implementation. All innovators indicated a feeling of acceptance for the proposed novelties. It was carried out by the principals of the institutions as well as teachers and parents of children who were to take part in innovations. The only difficulty indicated by the innovators were financial issues (the cost of travelling by coach to the Forest District, the purchase of cross-country skis and Nordic Walking poles, teaching aids - such as a trolley for 
transporting didactic aids and loupes). The money was allocated by the principal of the educational institution (innovation No. 1, 2, 3), Parents Councils (Innovation No. 1, 2, 3), Forestry (Innovation No. 2), sponsors and parents (preparations against ticks and mosquitoes, clothing and shoes adapted to the conditions and the type of activity practiced by children) and private entrepreneurs (paper, markers and crayons, plasticine, photo frames and prizes for children at the end of innovation No. 2).

The authors of innovations pointed to the benefits, which they believe benefit the educational institutions that implement the innovations. They emphasized the development of the kindergarten/school. They clarified that by this they mean the good reputation of the institution and its promotion among potential beneficiaries, closer cooperation with parents and cooperation with institutions operating in the local environment of the institution.

In the opinion of the authors of innovations, the cooperating institutions also obtained benefits thanks to cooperation. They pointed to non-material profits - promotion of such an institution in a wider environment than the local community, stimulating the willingness of its employees to undertake innovative activities in relation to standard duties and developing new forms of cooperation, reaching children's families as a group of potential visitors visiting previously unknown areas of an educational and recreational site as part of tourism and sightseeing. The authors of innovations cited the motives that led to the planning of further innovations. The reference to success in the first innovation, the satisfaction of the achieved effects (including the satisfaction of children and their parents participating in innovation) and the award (oral, financial) from the principal of the educational institution performing classes were signs for them that encouraged further activity. They willingly took actions involving sharing their own innovation experiences with other teachers. They used forms of propagating the work method adopted in innovations, such as: meetings based on personal contact (Teaching Staff, private meetings), publishing information in the local press and on the Internet, documenting the taking place of activities for the promotion of ideas (reports, preschool/school newsletters, publications of a scientific nature, exhibitions of children's works and photographs documenting the innovation).

Statements from the implementers show that they were obligatorily delegated by the principals of the institutions to conduct classes of an innovative nature. They agreed to this, guided by the desire to face new challenge 
and the need for self-development, acquiring new experiences and learning from teachers with longer seniority than theirs. They emphasized the emergence of the possibility of meeting the formal requirement of documenting the progress of their professional development. Recognizing that they were the performer, they declared that they counted on the opportunity to share their ideas with the innovations' authors and enriching the activities they carried out, which turned out to be feasible in their assessment. They did not encounter difficulties during the implementation of innovations. They noticed the benefits that brought the innovation to the implementing institution and to themselves. They pointed to the promotion of the kindergartens/ schools in the local environment and the raising of institutions' prestige. They noticed the opportunity for professional development of teaching staff and the possibility of participating in pedagogical conferences, including international ones.

Their professional development consisted of learning about non-standard methods and forms of working with children, some specialist content, and the officially sanctioned possibility of activities outside the institution's building. The acceptance of the professional environment was accompanied by the satisfaction of parents and lasting cooperation with external institutions (sports school, Forest District). In assessing the benefits of participation in innovation, teachers are unanimous with the authors of innovations. The motives for possible participation in subsequent innovations by the implementers have made it necessary for them to join the professional promotion procedure and given them the opportunity to obtain an incentive payment. Professional development, thanks to participation in the next innovations, would involve searching for new methodological solutions. The final effects were recognized as one of the reasons for possible participation in further innovations.

Answers related to the question of how to share personal experiences with other people working in and outside of the education system coincide with the answers of the innovation authors. While implementing innovations they shared their experiences with other people through reports, photo documentation, websites and texts in the school newsletter. They talked to other teachers interested in this form of work, explaining the goals of innovation.

A forest educator participating in the implementation of innovation No. 3 provided information on the legal grounds and the scope of his duties in connection with the implemented innovation. The document regulating forest education in Poland is the - Regulation No. 57 of the Director General of 
State Forests of 2003 (Guidelines for creating the forestry education program applied in the forest district). The aim of universal forest education is:

dissemination throughout society of knowledge about the forest environment and multifunctional and sustainable forest management; raising public awareness of the rational and responsible use of all forest functions; building social trust in foresters' professional activity (http://blogedukatora.erys.pl, 2018).

The topics of the classes on offer are related to the age of participants and the educational needs of a given study group (curriculum, interests of participants combined with the potential existing in the natural environment of the Forest District).

Open and hidden participant observations have shown that the authors of innovations have noticed and accepted the issue described in the pedagogical literature regarding the fact that kindergartens/schools are only one of many places to acquire knowledge and skills. They admitted that teachers form one of many groups of people co-creating the social and educational environment of children. They emphasized that it is most convenient to be an author and at the same time an implementer, with the support of specialists invited to the implementation. In discussions, they addressed the issue of innovation topics as issues that are of interest to them. An important topic for them was the degree of career advancement for which they applied and the progress of this procedure.

One of the topics of conversation among innovation implementers was the content of the innovation scenarios. They made comments regarding the possibility of their implementation in conditions different from school ones. They tried to conduct classes exactly according to the scenarios. With each subsequent activity, their 'freedom' from the rules of the class was observed. The process of implementing the innovations outdoors allowed them to gradually, but only partially resign from classrooms rules (eg ceasing to observe total silence, clearly individualizing work with children, partial withdrawal from pursuing educational goals over children's interests, no longer deferring answering questions outside of the subject matter, ensuring and accepting children's physical activity during the learning process, reducing formalism in dealing with children, using desirable competences (playing the instrument, singing) during the activities.

The analysis of documents allowed the identification of certain characteristics of innovation. In innovation 1: 'Waking up the child's awareness of 
promoting physical activity' (Table 1), the potential of the local environment was used, ie: terrain (favourable terrain conditions for sports, sports school in the city), the sporting tradition of the city, and sports achievements of the co-authors of the innovation (cross-country skiing). The innovation consisted of familiarizing children with cross-country skiing as a sport discipline and organizing situations in which children practiced cross-country skiing (and participation in ski competitions). The kindergarten bought sets of cross-country skis along with footwear from the preschool budget (10 sets). Frequency of classes: 1 h per week x 3 groups of children.

Table 1. The division of responsibilities in the implementation of innovation No. 1 'Waking up the child's awareness of promoting physical activity' (kindergarten, 5-year-old children)

\begin{tabular}{|c|c|c|c|}
\hline Role & Number of persons & Dates & Task \\
\hline Author of innovation [1] & 1 & \multirow{9}{*}{ 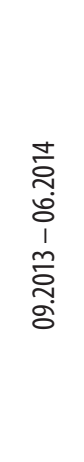 } & Group integration \\
\hline Implementer & & & Running sports competitions \\
\hline Hidden observer & & & $\begin{array}{l}\text { Observation of a group of children } \\
\text { and implementers }\end{array}$ \\
\hline Implementer & 1 & & Conducting general development \\
\hline Physiotherapist & & & exercises and breathing exercises \\
\hline Author of innovation [2] & 1 & & Conducting exercises preparing for \\
\hline Implementer & & & cross-country skiing \\
\hline PE teacher & & & Conducting skiing techniques and \\
\hline Total: & 3 & & walking techniques in Nordic Walking \\
\hline
\end{tabular}

The documentation demonstrates that the results were the building of a positive self-assessment of the child, strengthening the sense of value, the emergence of a fascination with sport, the acquisition of habits related to a healthy lifestyle by the children, and with it the proper pro-health attitude. Positive organizational changes in the kindergarten appeared - additional physical activities were treated as an attractive form of staying outdoors. Parent support was obtained, which favoured the preservation of attitudes to health outside the kindergarten. Children were given top positions in competitions and skiing competitions organized by the municipality of Supraśl. The pupils are a very large group and achieve high results. It was assessed that this is a very good basis for continuing sporting activities at further levels of education. 
In Innovation 2: 'Forest Folk' (Table 2), the potential of the local environment, ie the richness of the natural environment due to the proximity of the Arboretum in Kopna Góra and the Knyszyńska Forest, was again used. The innovation consisted of a year-round observation of nature by children (eg the cycle of reproduction of frogs, recognition of animals by footprints and sounds, the life of bees, changes occurring in nature throughout the year) and participation in some works of the forest district (eg planting trees, feeding animals). In addition, children learned about the concept of recycling, waste segregation, and nature protection. Frequency of classes: 1 trip a month (5h).

Table 2. The division of responsibilities in the implementation of innovation No. 2 'Forest Folk' (kindergarten, 5-year-old children)

\begin{tabular}{|c|c|c|c|}
\hline Role & Number of persons & Dates & Task \\
\hline Author of innovation [1] & 1 & \multirow{6}{*}{ 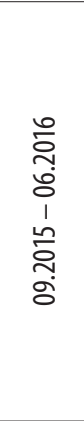 } & $\begin{array}{l}\text { Preparation of scenarios together } \\
\text { with a forest educator working } \\
\text { at the Arboretum in Kopna Góra } \\
\text { (Supraśl commune) }\end{array}$ \\
\hline Implementer & & & Implementing innovation \\
\hline Hidden observer & & & $\begin{array}{l}\text { Observation of a group of children } \\
\text { and implementers }\end{array}$ \\
\hline Implementer & 1 & & \multirow{4}{*}{$\begin{array}{l}\text { Implementing the program of } \\
\text { innovation }\end{array}$} \\
\hline Speech therapist & & & \\
\hline Kindergarten teacher & & & \\
\hline Total: & 2 & & \\
\hline
\end{tabular}

On the basis of the available documents, we have stated that the activities undertaken within the framework of innovation No. 2 allowed for the development of children's attitudes towards the laws of nature and for arousing in them a passion for nature. Since the interests of preschoolers go beyond the content of the curricula, one of the objectives stressed in the documents was to broaden the content of the curriculum with a range of ecology and environmental issues. Photographic documentation has recorded the activities which created conditions for discovering the natural world through games (especially research, creative and field). The subject matter of the classes was adapted to the seasons. During the classes, methods for activating the participants were used. It was also important to discover what the children were learning and what toys they played with (sticks, pebbles, 
leaves, cones and chestnuts became interesting). The toys used by children were primarily objects they found in their surroundings. 'Forest Folk' built towers of sticks, roads made of leaves, made dominoes of stones, practiced slalom between stumps, learned to tie knots to create a ladder of cords, counted cones bitten by squirrels or mole mounds. Learning to distinguish the names of trees, leaves or fruits; they did not need any illustrations or tables - they learned from natural material. In the course of implementation, as shown in the pictures, they did not carry backpacks or bags. Instead, they used a wooden cart on wheels that served to transport a second breakfast and found treasures. When it was getting colder, the children could warm up by the campfire, which was kindled by the adults. Meals were also eaten in the open air. Tree stumps or blankets and mats spread on the ground served instead of table and chairs. If it was raining or snowing, it was possible to use a wooden shed or a room in a forester's lodge. The analyzed documents clearly showed the idea that children spend as much time in the open air as possible - and this is not about the playground, but about the natural environment, which is the forest/forest glade.

Innovation No. 3: 'Forest World' (Table 3) is a proposal for children of a younger school age. Its implementation is planned to take place over three years. It uses the possibilities inherent in the local environment, ie: the richness of the natural environment (the proximity to the Knyszyńska Forest). Innovation consists in providing children with contact with objects and natural phenomena.

In the three-year education cycle (classes I-III), children and teachers will implement the content provided for in the curriculum, in accordance with the idea of 'Outdoor education'. Children's and implementers' exploration of the forest life began in September 2017. The headquarters of the Żednia Forest District became the permanent educational base along with its social facilities. A cooperation plan was prepared together with topics that were to be implemented during trips in the first year of innovation. Frequency of classes: 1 trip a month (5h). Further issues to be implemented as part of the innovation will be planned after analyzing the progress of the first year of its implementation, in consultation with the forest educator. 
Table 3. The division of responsibilities in the implementation of innovation No. 3 'Forest World' (school, children 7 years)

\begin{tabular}{|c|c|c|c|}
\hline Role & Number of persons & Dates & Task \\
\hline Author of innovation [1] & 1 & \multirow{10}{*}{ 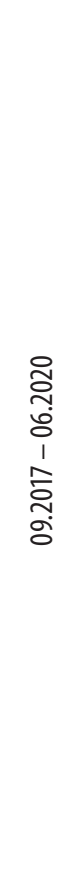 } & $\begin{array}{l}\text { Preparation of scenarios } \\
\text { together with a forest educator } \\
\text { working in the Żednia Forest } \\
\text { District (Zabłudów commune) }\end{array}$ \\
\hline Hidden observer & & & $\begin{array}{l}\text { Observation of a group of } \\
\text { children and implementers of } \\
\text { innovation }\end{array}$ \\
\hline Author of innovation [2] & 1 & & $\begin{array}{l}\text { Implementation of the } \\
\text { innovation program }\end{array}$ \\
\hline Preschool education teacher & & & \\
\hline First class teacher & 1 & & $\begin{array}{l}\text { Implementation of the } \\
\text { innovation program }\end{array}$ \\
\hline Supporting teacher & 1 & & $\begin{array}{l}\text { Work with a student on the } \\
\text { autism spectrum }\end{array}$ \\
\hline Forest educator & 1 & & $\begin{array}{l}\text { Implementation of the } \\
\text { innovation program in the scope } \\
\text { specified for the employee of the } \\
\text { Żednia Forest District }\end{array}$ \\
\hline Co-author of the paper & 1 & & $\begin{array}{l}\text { Observation of implementers of } \\
\text { innovation }\end{array}$ \\
\hline \multicolumn{2}{|l|}{ Open observer } & & \\
\hline Total: & 6 & & \\
\hline
\end{tabular}

The analysis of the available documentation shows that the purpose of innovation No. 3 is to provide children with the possibility of communing with nature throughout the school year. The photographic documentation and records contained in the reports describe specific objectives which were determined as: teaching how to show respect for all aspects of life in nature, creating conditions for children to discover mutual relationships between the world of plants and animals, and getting children accustomed to protecting nature by the means available to them.

These activities have been linked to goals which will result in the participants learning a wider content than that provided for in the curriculum, such as acquiring habits of economical management of resources and natural materials, and transferring this knowledge and some behaviours to their families. 


\section{Conclusions}

Our research examined the procedures for planning and implementing pedagogical innovations in the preschool and school work model, as well as the reasons for authors and implementers to undertake this type of professional activity. Similarly to other studies, our research has shown that the interviewed teachers have become active participants in many educational activities created by an internal developmental need and/or compulsion to participate in the process of education and professional development (Chmielińska and Modrzejewska-Świgulska, 2018; Kirkland and Sutch, 2009; Stawinoga 2018). They solve this issue by engaging in the design and implementation of pedagogical innovations. They treat such activity as investment in the process of vocational education and training, and sometimes personal training. Undertaking "activities seeking new trends and educational [gaps] filled with creative competences” (Jasińska, Jasiński, and Lerka, 2011, p. 219) is part of the expectations of the beneficiaries of the education system (children, parents, principals, local government activists, politicians). The combination of this type of activity with the paths of career advancement is, in the intention of decision-makers, in order to guide teachers on the path of innovation. Although our project does not include a formal assessment of how innovative programs are perceived by the authors themselves as a contribution to their lifelong learning and professional development process, we have seen evidence for it. Authors of innovations think about their actions as something important for them, as well as educational institutions and institutions from outside the educational field. With the passage of time devoted to the implementation of innovation, the authors were encouraged by the observed effects (the joy and high level of activity of children; parents ${ }^{*}$ satisfaction; acceptance by the school principals) and are planning their next inventions. They boldly approached institutions that could be involved in the implementation of a given innovation.

Noticeable professional activity by innovators was sustained by their personal interests. However, our interviews show that the interviewed implementers confessed that the most important effect of participation in innovation was the fact that this kind of professional activity counted towards their promotion proceedings. They were not going to develop their own innovations. The results of our research can provide insights into the process in which teachers develop innovations for professional and personal purposes. The area of activity envisaged in innovations, as noted by the interviewed teachers, is 
limited by the following conditions of implementation: 1) the safety of participants, 2) costs of implementation and the possibility of obtaining funds for innovation, 3) approval of the principal and parents or lack thereof, and 4) atmosphere around the implementation process based on the judgments of colleagues at work. The described innovations have the potential to initiate lasting changes. They are distinguished by features which could be defined as prognostic: longevity (innovation may be maintained for a long time in these projects), accessibility (innovation can be used by any experienced teacher) and the ability to replicate the idea (they can be transferred to other kindergartens/schools) (Kirkland and Sutch, 2009, p. 18).

\section{References}

Babbie, E. (2001). The Practice of Social Research. Belmont, CA: Wadsworth Thomson Learning.

Blog edukatora. (2018). Serwis Internetowy Lasów Państwowych. Retrieved August 12, 2018, from http://blogedukatora.erys.pl.

Chmielińska, A., and Modrzejewska-Świgulska, M. (2018). Bariery w pracy nauczycieli oraz innowatorów edukacyjnych w perspektywie badań pedagogicznych. Edukacja Elementarna w Teorii i Praktyce, 13, 13-26.

Creswell, J.E. (2008). Research Design: Qualitative, Quantitative, and Mixed Methods Approaches. Thousand Oaks: SAGE Publications, Inc.

Dylak, S. (1995). Wizualizacja w kształceniu nauczycieli. Poznań: Wydawnictwo Naukowe Uniwersytetu im. Adama Mickiewicza w Poznaniu.

Jasińska, E., Jasiński, M., and Lerka, A. (2011). Ewaluacja innowacji pedagogicznych i projektów edukacyjnych na przykładzie „Monolitu geometryczno-zadaniowego”. In: B. Niemierko and M.K. Szmigel (Eds.). Ewaluacja w edukacji: koncepcje, metody, perspektywy: XVII Konferencja Diagnostyki Edukacyjnej (pp. 218-223). Kraków: Polskie Towarzystwo Diagnostyki Edukacyjnej.

Kirkland, K., and Sutch, D. (2009). Overcoming the Barriers to Educational Innovation. A Literature Review. Futurelab. Retrieved August 24, 2018 from https:// www.nfer.ac.uk/publications/FUTL61/FUTL61.pdf.

Majewska, M. (2017). Innowacyjność w pedagogice. Co to znaczy? Edunews.pl. Retrieved July 12, 2018, from https://www.edunews.pl/nowoczesna-edukacja/ innowacje-w-edukacji/3772-innowacyjnosc-w-pedagogice-co-to-znaczy.

Pilch, T., and Bauman, T. (2010). Zasady badanì pedagogicznych. Strategie ilościowe i jakościowe. Warszawa, Wydawnictwo Akademickie „Żak“.

Piwowar-Sulej, K. (2017). Teacher's Creative Potential as a Determinant of Schools Innovativeness. Education of Economists \& Managers, 46 (4), 23-35.

Polak, M. (2016). O innowacji pedagogicznej. Edunews.pl. Retrieved August 12, 2018 from https://www.edunews.pl/badania-i-debaty/opinie/3577-o-innowacji-pedagogicznej.

Stawinoga, R. (2018). Innowacja pedagogiczna - realizacja pasji czy formalności? Prima Educatione, 1, 155-171. 


\title{
Chapter 17
}

\section{Teachers' Team Learning in the Context of Creating Learning Schools: Implications for Teacher Education}

\author{
Bożena Tołwińska \\ University of Bialystok, Bialystok, Poland
}

\begin{abstract}
The aim of this text is to analyze the phenomenon of teachers' learning as part of a team from the perspective of the development of a school as a learning organization. In this paper, I will present the characteristics of team learning in light of source literature and example results of a study concerning this aspect. In school life there are many situations that make it possible for teachers to learn from each other, but the conditions in school and out of school might be serious barriers. I will stress subjective factors (attitudes of teachers and school principals) that determine mutual learning. I disregard the role of the context in which schools' function, such as cultural, social and political factors, because I have discussed this aspect in my previous publications. I treat the characteristics of the model of a learning school as a source of inspiration in teacher education, as teachers are going to be the main promoters of the development of schools in this direction. There is a clear need to prepare teachers to understand the process of learning, not only individually but as a collective activity understood as a reflection on practice experienced in diverse forms of collaboration.
\end{abstract}

KEYWORDs: school as a learning organisation, teachers' team learning, teacher education, teacher-principal relations, relations between teachers

CONTACT Bożena Tołwińska, EMAIL: b.tolwinska@uwb.edu.pl 


\section{Introduction}

According to Kwiatkowska (2000, p. 27):

There is no doubt the way a modern human learns has to be different and quicker than it was in the past. Thanks to the proper way of learning, we can cope with the growing complexity of the world and dynamics of its changes. Currently, learning is the basic tool we can use to adapt to the changing conditions we live in. Moreover, it is the fundamental fact of human existence.

Contemporary learners no longer need to obtain a certain set of knowledge at school. They need to acquire learning skills instead, necessary to live in a world of constant changes. However, as OECD experts point out, “...many schools look much the same today as they did a generation ago, and too many teachers are not developing the pedagogies and practices required to meet the diverse needs of $21^{\text {st }}$-century learners" (OECD, 2016). There are more and more opinions that schools "should be reconceptualised as 'learning organisations' that can react more quickly to changing external environments, embrace innovations in internal organisation, and ultimately improve student outcomes" (ibid.).

The aim of this chapter is to analyze the phenomenon of teachers' learning as part of a team from the perspective of the development of a school as a learning organization. In this paper, I will present the characteristics of team learning in light of source literature and example results of a study concerning this aspect. In school life there are many situations that make it possible for teachers to learn from each other, which is necessary in order to create learning schools, but the conditions in and out of school might be serious barriers. In my chapter I will stress subjective factors (attitudes of teachers and school principals) that determine mutual learning, and I will ignore the role of the context in which schools function, such as cultural, social and political factors, because I have discussed this aspect in my previous publications (Tołwińska, 2016, 2017). I will also present a fragment of data from my own study as an example of interpersonal relations that ensure good conditions for teachers' mutual learning, in which the features of a learning organization are visible. I treat these characteristics as a source of inspiration in education for teachers, as they are going to be the main promoters of the development of schools in this direction. There is a clear need to prepare teachers to understand the process of learning, not only individually but as a collective activity understood as a reflection on practice manifested in diverse forms of collaboration. 


\section{Theoretical background}

The concept of a learning organization was developed by Peter Senge (1990). It is a metaphor for a modern organizational model, which has been recognized by many circles as the organization of the future. According to Senge, learning organizations are ones that are capable of self-discovery, understanding their own problems and self-improvement, able to learn from their own mistakes and successes (2006). An organization's learning, i.e., its development as a result of introducing changes which improve its functioning, is possible thanks to learning by individuals, who then share their knowledge with others and learn from others (Argyris and Schön, 1996; Lave and Wenger, 1991; Senge, 2006). Schools find it challenging to become organizations like this. In the model of a school as a learning organization, learning is perceived as a process leading to a change in the way of perceiving oneself, others, and the world (Senge, 2006). OECD experts define a learning organization as ,a place where the beliefs, values and norms of employees are brought to bear in support of sustained learning; where a 'learning atmosphere', 'learning culture' or 'learning climate' is nurtured; and where "learning to learn" is essential for everyone involved” (OECD, 2016, p. 2). However, although the knowledge and skills developed by individual teachers are very important, they are not enough to enhance the quality of work in the school as a whole. Only externalization and sharing them with everybody else makes it possible to learn from others and initiate the process of improvement (Fullan, 2011). However, as Kędzierska and Maciejewska (2014) emphasize, the belief that the key factor in improving the quality of school work is the development of the teacher has been unreflectively repeated for many years. As a result, both researchers and practitioners still concentrate on activities to improve the effectiveness of teachers' work, identifying key competencies for the job, analyzing the process of teacher education and professional development and evaluating teachers' work. According to the authors, one of the most persistent and popular pedagogical axioms is equalizing the quality of school work with the quality of teachers' work. Although high professional qualifications for a teacher do contribute to the quality of school work, they are not the decisive factor (Kędzierska and Maciejewska, 2014). Although in many organizations individuals engage very much in performing their tasks, their energy is dispersed. The lack of orientation towards a common goal means that this great effort does not translate into effects, and the energy put 
into it by individuals does not enhance the possibility of development of the whole team or organization (Senge, 2006). "Individuals in an organization learn all the time; yet, it is not tantamount to organizational learning. Micro worlds that stimulate organizational learning can only be formed when whole teams learn" (ibid., p. 267). If information is generated in an organization and then transformed into action, the organization is a learning one.

If we look at schools from this perspective, we will see that the situation is the same. Teachers learn individually, raise their qualifications and develop competencies, but one more step is necessary for the quality of work of the school as a whole to improve: the transition from individual learning to team learning, creating an open learning environment in which the potential of each person plays a role. This aspect is very important in Fullan's views on change in schools. He considers teachers' team work to be the key factor in improving a school's quality. Good quality educational systems, focused on building potential, involve investment in the practice of collaboration and supporting professional development rather than external tests, lesson observations and reports (Fullan, 2011).

In the concept of the learning organization developed by Senge (2006), team learning is one of the five pillars, along with: systems thinking, personal mastery, mental models, and shared vision. It is an activity that may occur in different situations. Different forms of collaboration serve as the "training ground” (Senge, 2006, p. 289) for mutual learning. Performing typical tasks together, solving problems that are encountered, creating innovations or focusing on a certain aspect of work provide good conditions for team learning (Roberts, 2002). Such situations are necessary for teams to learn. Individual reflection is not enough (Isaacs, 2002). As Senge points out, developing team learning skills is much more difficult than individual learning, so teams need their "training grounds" to practise the skills of mutual learning. The lack of such opportunities for "training together" prevents the beginning of the process of learning from others (Senge, 2006, p. 289).

As for teachers' work at school, every day they face situations that provide opportunities for mutual learning. And yet, as Elsner observes, “working and learning together mostly occurs during the performance of tasks that require of teachers something more than a subject-based approach" (Elsner and Tarkota, 2013, p. 112). It may occur when teachers voluntarily engage in activities to improve their places of work and do something they consider as significant. Elsner and Tarkota give the following examples of activities at school: 
- developing the concept of school work: formulation of the mission, vision and priorities by the whole staff;

- $\quad$ performing internal evaluation and analyzing its results with the participation of teachers beyond the evaluation team;

- lesson planning by all teachers who teach a class;

- $\quad$ student assessment by all teachers who teach a class;

- $\quad$ mutual lesson observation and providing feedback;

- $\quad$ providing support to beginners, newly employed teachers and underperformers;

- $\quad$ introducing critical friendship in school: each teacher has their own critical friend, including the principal;

- $\quad$ implementing innovations together (ibid.).

However, not all work performed by a team is the same as a learning activity. Actually, it may even be the opposite - the process of learning may be blocked. For learning to occur, proper intra-organizational conditions and special interpersonal relations are necessary, depending both on teachers and on the principal. Team members should communicate openly, be allowed to express their opinions in every situation without fearing consequences, and be able to discuss sensitive issues and taboos, which - when ignored - become obstacles to learning. Two forms of communication are especially recommended: dialogue and discussion. In accordance with Senge's concept, team learning involves the use of dialogue as an everyday communication practice to solve problems. Senge (2006) refers to views by David Bohm and describes dialogue as a way of communicating with another person that allows individuals to pay attention to their own thinking as it is expressed, and to notice any inconsistency. However, as Isaacs (2002, p. 437) argued, "Dialogue cannot be forced, but it can be nurtured. It is possible to create conditions that are conducive to dialogue". These conditions refer to the characteristics of the interpersonal climate. Dialogue should be supplemented with discussion, whose purpose is to take all necessary decisions together. Dialogue is needed to understand the problem thoroughly and to see diverse points of view, whereas the goal of discussion is to choose the path of activity in a certain situation. The objective of these practices is to improve the quality of interpersonal interactions. Teams that do so will notice an improvement in their functioning. The effect of collective learning is new ways of understanding certain situations and new behaviours. In organizations with a hierarchical structure, stressing the 
superior-subordinate relation, dialogue and mutual learning cannot occur. Hence, the attitude of managerial staff plays a significant role. Treating each other as partners is fundamental for the creation of proper learning conditions. It is connected with the willingness to give up one's privileges, the authoritarian attitude, power and dominance (Senge, 2006).

In this context, a very important issue is to investigate intra-school conditions for teachers' team learning. Therefore, the attitude of the school principal is essential. One expression of the principal's readiness to learn from others, and at the same time the model for the principal's behaviour, is the perception of oneself as the "leading student" (Fullan, 2006, p. 30), not an omniscient holder of secret knowledge (Senge, 2006, p. 282), convinced that he or she knows the answers to most questions and understands the sources of problems without analyzing them. Teachers' mutual learning takes place when interpersonal relations are full of trust and a sense of security. This kind of climate is favourable for revealing one's thoughts and opinions, admitting mistakes, asking for help etc. (OECD, 2016).

Selected studies concerning the problem of teachers' team work and team learning show that there are schools in which teachers do create mature teams (e.g., Erculj, 2013; Jones, 2013; Stoll et al., 2006; Zamorska, 2008). Yet, in many schools this area is still a weak point that needs to be improved (Kędzierska and Maciejewska, 2014; Kołodziejczyk and Kołodziejczyk, 2015; Zamorska, 2008). Very often, a team’s maturity to learn as a result of mutual reflection on practice still needs considerable enhancement (Tołwińska, 2016, 2018).

An attempt to explain this situation leads to two different conclusions, involving extra-school and intra-school causes. What blocks collaboration are the increasingly popular standards of individualism and treating others as rivals. ${ }^{1}$ Another cause for this is the legal standard centrally imposed on teachers, concerning the obligation to collaborate and assist each other, whose effects must be documented in reports and is externally evaluated (MEN, 2017). This solution includes the assumption that human behaviour can be centrally controlled, and professional tasks must be imposed on teachers as an arduous obligation. This is in opposition to the idea of the learning organization expressed by Senge, who is of the opinion that people want to feel that they are part of an organization, belong to a team, and do something that is valuable for them and considered to be important 
for the common good (Senge, 2006). An enforced standard only results in a superficial form of collaboration, which in many teachers' teams is not regarded as valuable (Kędzierska, 2015; Sajdera, 2015).

According to Filipiak:

The model of reflective teaching and the ability to create knowledge on the basis of one's own practice still evokes teachers' resistance and misapprehension. It may result from the behaviouristic strategy of education, where reflection and interpretation are absent, which is still deeply rooted despite declarations of preferring constructivism in education (Filipiak, 2012, pp. 179-180).

Teachers feel tired, discouraged and overloaded with the need to document their activities. They lose the desire to take part in change, as they feel no support from the school principal or the parents (ibid., p. 180). Such conclusions also point to intra-school, subjective factors, such as the attitudes of teachers and principals. Researchers studying this issue emphasize that the creation of learning communities requires activities other than attempts to control teachers' and principals' behaviours top-down, which is doomed to failure. What is needed is support in building interpersonal relations based on trust, a sense of security and communication openness (Bezzina and Farrugia, 2018; Calleja, Mizzi, and Riolo, 2018). The multiple benefits of being a member of a constructive team which makes mutual learning possible (Borukało and Kiciński, 2012; Erculj, 2013; Jones, 2013; Zamorska, 2008), may serve as an inspiration for developing teachers' self-awareness in this regard and for looking for different ways of improving teachers' functioning in teams.

\section{Methodology}

One barrier in everyday functioning mentioned by teachers is the lack of support from the school principal (Filipiak, 2012). So as to present at least fragmentarily a different image of school relationships, I will show below a small sample of the data from my own study carried out in 2017 as part of the research project devoted to the specificity of functioning of schools which have been awarded the certificate 'Leader of a Learning Organization’. The multiple case study (Yin, 2015) was used as the research method. The study involved five schools of different types (one primary school, one general secondary school, and three secondary school complexes with different professional profiles) located in a provincial capital city in central Poland. The participants were the principals, teachers and students of those 
schools. The participation in the study was voluntary; anonymity and confidentiality were also ensured.

In this chapter I present a small fragment of data from qualitative, semi-structured, in-depth interviews with school principals (four females and one male). The interviews were recorded and then transcribed. The data from the interview transcriptions was subject to qualitative analysis. Yin (2015) points to four analytical strategies which can be used in a case study: 1. reference to theoretical assumptions, 2. developing data from scratch, 3. creating a case description as part of a certain structure, and 4. investigating other probable explanations. In conformity to Yin's approach, the strategy of data analysis I used was the reference to theoretical assumptions, which motivated me to carry out this study (ibid. p. 168). In light of the theoretical assumptions concerning team learning as one of the elements of the learning organization concept developed by Senge, for the purposes of this paper I approached the school situation described by each of the principals from the point of view of subjective factors, i.e., the specificity of the interpersonal relations they create.

\section{Results}

Here I present the perspective of principals as people who create the conditions for mutual learning in schools as organizations. Senge (2006) believes that the best way to understand the role of the leader in the context of building a learning organization is to analyze the ways people who do this describe their own actions (p. 386).

Principal of School no. $1^{2}$ :

I asked them to write in this analysis form their ideas on how to solve various school situations, e.g. how to improve information flow. Some possible responses were provided in the form, and then they were to provide their own ideas. It seems to me that the fact that I discussed all that during the staff meeting and took their ideas into consideration was really important. We discussed it together, I asked them about their opinions and the opinions of others. After the discussion, we summed it up and we are now implementing what we collected by means of these forms. It worked and now the teachers are very happy about it. 
At School no. 1, the values produced by team learning are being consciously applied. As a result of internal evaluation, significant areas that need improvement are identified and ideas are worked out on how to solve the identified problems. Each person was allowed to express their opinion, point out the perceived problems, and suggest a solution. In this situation, arranged by the principal, all team members were allowed to present varied points of view and then choose the best solution together. The school's ability of self-discovery and understanding problems leads to implementing changes so as to improve its functioning.

Principal of School no. 2:

You need to have good relationships, to have the courage to tell each other what is wrong, what is not going well and how we failed. You cannot treat the principal as a guru. It's not good, 'cause then everyone is afraid to approach you and tell you that something is wrong.

For the principal of School no. 2, good relationships are open relationships, which make it possible to reveal failures and mistakes. The principal is aware that creating a big distance makes people too afraid to tell the truth, and hiding or distorting the truth prevents self-discovery and the attempt to improve what needs to be improved.

Principal of School no. 3:

I think a very important thing for them is the atmosphere that we've managed to create, the proper evaluation and appreciation of their work ... and that they can say anything, they are not afraid to tell the principal about something. They appreciate it a lot that they can tell me everything. I accept every comment from a teacher, not as a reprimand or a reward but as their own feeling, and their feeling is, for example, that I didn't notice something that happened at school.

A similar issue is here highlighted by the principal. This person highly values open communication. In his perception, the teaching staff also highly appreciate communication relations in which they can talk about any topic without fear.

Principal of School no. 4:

If I make a decision but a teacher comes and says this is not going to work because this and that... I may say 'You're right, I didn't think about it'.

In this response we can see that the principal is not attached to the privilege of making decisions; she easily gives up on the dominant position and is 
able to admit someone else is right. What matters is whether the decision is right, not who makes it. This attitude, without the facade of conviction, allows the team to achieve its maturity phase. In the immature phase, team members always agree with the opinion of the superior and decisions are unquestionable, which is an obstacle to learning (Tołwińska, 2018).

Principal of School no. 5:

This is also the reason why I have stayed at this school. There is no isolating from colleagues, no claiming that ' $\mathrm{I}$ did it so it is mine'. People here have this need, and rightly so, that if they have done something and others use it, it's good to mention who's the author, and it is quite natural, but apart from this, I can't see any competition. I have one case that only confirms the rule, there is only one case, and I still think I have a very nice staff, people don't avoid each other, if a teacher needs it, he or she can talk about something and nobody will tell them: 'you deserved it'.

Interpersonal relations at School no. 5 were one of the most important reasons why the principal decided to stay there. In his perception, apart from one person, teachers do not compete with each other, and do not have individualistic attitudes but share the effects of their work. They can also talk to each other about the problems they experience in an atmosphere of safety.

The interpersonal relationships described by the principals above ensure good conditions for mutual learning. They also reflect the characteristics of a learning organization, and strengthening the belief that we can create the world we live in by: 1 . allowing all teachers to express their views, 2 . arranging situations favourable for identifying inefficiencies in school functioning, and ideas for solutions, 3. discussing together the choice of which solutions to implement, 4. eliminating the distance between the superior and the subordinate, 5. eliminating the fear of revealing one's mistakes and failures, 6 . the principal revealing their own way of thinking, which gives teachers the opportunity to express their justified doubts about the principal's decisions, 7. preferring the proper decision rather than the decision-making person, and 8. talking about difficulties in the atmosphere of safety.

\section{Conclusions}

Transforming schools into learning organizations requires the recognition of all barriers that prevent individuals from learning, as well as teachers' 
mutual learning, and sharing of knowledge and skills in pursuit of new solutions to problems and in performing daily tasks. As a result of team learning, the teacher's way of thinking and acting changes, which is reflected in the development of the school as a whole (Erculj, 2013; Jones, 2013). The quality of the environment offered to students by the school depends both on the professionalism of each teacher and on how teachers function together as a team. It is impossible to create a good school individually. The problem of organizing a modern learning environment was tackled in the OECD report on preparing teachers for the $21^{\text {st }}$ century:

Teachers need to be able to work in highly collaborative ways, working with other teachers, professionals and para-professionals within the same organization, or with individuals in other organizations, networks of professional communities and different partnership arrangements, which may include mentoring teachers (Schleicher, 2012, p. 52).

By means of this analysis, I would like to highlight the importance of the process of teacher education. As Filipiak (2012) argued - referring to theses by Bruner (2006) and quoting conclusions from a study by Zamorska (2008) and Gołębniak (2007) - teaching styles are affected much more by teachers' previous experiences than by their preparation during their pre-service university course or various forms of professional development. Therefore, it is good to investigate these experiences and find out what beliefs teachers have formed on that basis.

Future teachers (and principals) will not gain experiences that can help them become members of a learning school if they only acquire theoretical knowledge, and the theoretical elements of team learning are not really applied by university teachers in building relationships with students. During classes, these elements may take the form of choosing the style of managing group work, methods of work and styles of communication, but most especially emphasizing that the teacher is the 'leading student', ready to learn from others. The teacher avoids the mask of omniscience and absolute certainty and shows others that expressing doubts or anxiety is not an expression of weakness. He or she uses dialogue to learn the opinions and views of all the participants, and invites discussion to choose solutions. He or she does not force others to accept his or her point of view. He or she attempts to learn about the educational experiences of future educators and their beliefs concerning school, teachers and students so as to challenge those beliefs which block development. As a result of these activities, even at university young people can gradually acquire the conviction that the 
rules of interpersonal relations at a school in which the teacher is a member of a collaborating team and not an individual trying to solve problems alone, or competing with others, are really valuable. A great illustration of this kind of school culture is the metaphor of an orchestra, used by Kędzierska and Maciejewska (2014, p. 2): “An orchestra is an example of team work in which all the musicians - playing their parts perfectly well - need to listen to the others and to their own playing attentively, follow the central, basic rhythm, change opinions, acquire new skills, inspire each other, and share their enthusiasm”.

\section{References}

Argyris, C. and Schön, D. A. (1996). Organizational Learning II: Theory, Method and Practice. Boston: Addison-Wesley.

Bezzina, C. and Farrugia, M.A. (2018). A Professional Learning Community Model for a Maltese Catholic Church Primary School: A Case Study. In: M. AttardTonna and J. Madalińska-Michalak (Eds.), Teacher Education Policy and Practice - International Perspectives and Inspiration, Key Concepts Series vol. 1 (pp. 314-341). Warsaw: Foundation for the Development of the Education System.

Borukało, A. and Kiciński, A. (2012). Jaką społecznością uczącą się są nauczyciele? Forum Oświatowe, 1, 302-316.

Calleja, J., Mizzi, D., and I. Riolo, (2018). Teachers in Communities of Practice: Perspectives and Experiences from Three Doctoral Research Students. In: M. Attard-Tonna and J. Madalińska-Michalak (Eds.), Teacher Education Policy and Practice - International Perspectives and Inspiration, Key Concepts Series vol. 1. (pp. 344-370). Warsaw: Foundation for the Development of the Education System.

Elsner, D. and Tarkota, J. (2013). Tworzenie organizacyjnych warunków do współpracy i zespołowego uczenia się. In: D. Elsner (Ed.), Sieci współpracy i samokształcenia. Teoria i praktyka (pp. 110-121). Warszawa: Wolters Kluwer Polska SA.

Erculj, J. (2013). Sieć Uczących się Szkół. In: D. Elsner (Ed.), Sieci współpracy i samokształcenia. Teoria i praktyka (pp. 194-214). Warszawa: Wolters Kluwer Polska SA.

Filipiak, E. (2012). 'Produkty’ kultury uczenia się uczniów szkoły podstawowej i gimnazjum. Forum Oświatowe, 1 (46), 159-183.

Fullan, M. (2006). Odpowiedzialne i skuteczne kierowanie szkołq. Translated by Krzysztof Kruszewski, Warszawa: Wydawnictwo Naukowe PWN.

Fullan, M. (2011). Choosing the Wrong Drivers for Whole System Reform, Centre for Strategic Education Seminar Series Paper No. 204. Retrieved August 3, 2018 from http://michaelfullan.ca/wp-content/uploads/2016/06/13396088160.pdf

Isaacs, W. (2002). Dialog. In: P.M. Senge, A. Kleiner, C. Roberts, R.B. Ross and B.J. Smith, Piqta dyscyplina. Materiały dla praktyka. Jak budować organizacje uczqca się. Translated by Grzegorz Łuczkiewicz, Kraków: Oficyna Ekonomiczna. 
Jones, J. (2013). Tworzenie uczącej się społeczności w szkole i w sieci. Doświadczenia brytyjskie. In: D. Elsner (Ed.), Sieci współpracy i samokształcenia. Teoria i praktyka (pp. 122-135). Warszawa: Wolters Kluwer Polska SA.

Kędzierska, H. (2015). (Współ)brzmienie nauczycielskiej orkiestry - o komunikacji w społecznym świecie nauczycieli. In: H. Kwiatkowska (Ed.), Uczłowieczyć komunikację. Nauczyciel wobec ucznia w przestrzeni szkolnej. Kraków: Oficyna Wydawnicza Impuls.

Kędzierska, H. and Maciejewska, M. (2014). Odpowiedzialny nauczyciel - (nie) odpowiedzialna wspólnota - co pomaga, a co przeszkadza w budowaniu nauczycielskich wspólnot praktyków. In: G. Mazurkiewicz (Ed.) Edukacja jako odpowiedź. Odpowiedzialni nauczyciele w zmieniajq̨cym się świecie (pp. 83-95). Warszawa - Kraków: Wydawnictwo Uniwersytetu Jagiellońskiego.

Kołodziejczyk, J. and Kołodziejczyk, J. (2015). Ewaluacja własnej pracy nauczycieli - obszary, rozumienie, współpraca. Forum Oświatowe, 27 (2), 115-130.

Kwiatkowska, H. (2000). Kształcenie nauczycieli a nowe sposoby uczenia się człowieka. In: H. Kwiatkowska, T. Lewowicki, and S. Dylak (Eds), Współczesność a kształcenie nauczycieli (pp. 27-42). Warszawa: WSP ZNP.

Lave, J. and Wenger, E. (1991). Situated Learning: Legitimate peripheral participation. Cambridge: Cambridge University Press.

MEN. (2017). Rozporządzenie Ministra Edukacji Narodowej z dnia 25 sierpnia 2017 r. w sprawie nadzoru pedagogicznego (Regulation of the Minister of National Education on pedagogical supervision. 2017), Dz. U. z dnia 31 sierpnia 2017 r. Poz. 1658.

OECD. (2016). What makes a school a learning organisation? A Guide for Policy Makers, School Leaders and Teachers, Retrieved June 22, 2018 from http://www. oecd.org/education/school/school-learning-organisation.pdf

Roberts, C. (2002). Czego można oczekiwać, praktykując dyscyplinę zespołowego uczenia się. In: P.M. Senge, A. Kleiner, C. Roberts, R.B. Ross, and B.J. Smith, Piqta dyscyplina. Materiały dla praktyka. Jak budować organizację uczqcq się. Translated by Grzegorz Łuczkiewicz, Kraków: Oficyna Ekonomiczna.

Sajdera, J. (2015). Działania zespołowe nauczycieli w perspektywie zarządzania edukacją. Biblioteka Współczesnej Myśli Pedagogicznej, 4, 61-70.

Schleicher, A. (Ed.). (2012). Preparing Teachers and Developing School Leaders for the $21^{\text {st }}$ Century: Lessons from around the World, OECD Publishing.

Senge, P.M. (1990). The Fifth Discipline: The Art and Practice of the Learning Organization. 1990. New York: Doubleday.

Senge, P.M. (2006). Piq̨a dyscyplina: Teoria i praktyka organizacji uczqcych się. Translated by Helena Korolewska-Mróz. Wydanie V. Kraków: Oficyna Ekonomiczna.

Stoll, L., Bolam, R., McMahon, A., Wallace, M. and Thomas, S. (2006). Professional Learning Communities: a Review of the Literature. Journal of Educational Change, 7, 221-258.

Tołwińska, B. (2016). Overcoming Organisational Silence: Looking for Opportunities to Change School Culture. In: L. Daniela, L. Rutka (Eds.), Selected Papers of the Association for Teacher Education in Europe. Spring Conference 2015 (pp. 209-221). Cambridge: Cambridge Scholars Publishing. 
Tołwińska, B. (2017). Do Pedagogy Students Perceive Collaboration as Valuable? Rocznik Teologii Katolickiej, XVI/2, 191-207.

Tołwińska, B. (2018). Teacher Team’s Maturity as the Basis for a Learning School. In: M. Attard-Tonna and J. Madalińska-Michalak (Eds.), Teacher Education Policy and Practice - International Perspectives and Inspiration, Key Concepts Series vol. 1. (pp. 194-213). Warsaw: Foundation for the Development of the Education System.

Yin, R.K. (2015). Studium przypadku w badaniach naukowych. Projektowanie i metody. Translated by Joanna Gilewicz. Kraków: Wydawnictwo Uniwersytetu Jagiellońskiego.

Zamorska, B. (2008). Nauczyciele. (Re)konstrukcje bycia-w-świecie edukacji. Wrocław: Wydawnictwo Naukowe Dolnośląskiej Szkoły Wyższej. 


\title{
Chapter 18
}

\section{Components, Models and Operational Mechanisms of Teacher Collaboration}

\author{
Katalin Tóth-Pjeczka, Nóra Rapos, and Judit Szivák \\ Institute of Education, ELTE Eötvös Loránd University, Budapest, Hungary
}

\begin{abstract}
Teacher collaboration could play a key role in the development of education systems, as this approach helps to improve student performance through teachers' professional learning (Hargreaves and Fullan, 2012; OECD, 2005). TALIS-research (OECD, 2009) highlighted that an 'exchange and cooperation' type of collaboration is dominating more significantly in Hungary than in Europe in general, while 'professional collaboration' rarely appears. During the recent trend of developing teacher collaboration, a significant body of research has pointed out the importance of school leaders in forming a school culture based on teacher collaboration (Ashley, 2017; Hord and Sommers, 2008). This research aims to examine the elements and components of the two aforementioned types of teacher collaboration, with an in-depth investigation of the operation of two schools, identifying the characteristics of school leaders impacting the different cultures of collaboration. In this comparative case study the system that Vangrieken et al. used in their literature review (Vangrieken et al., 2015) serves as a base for our analysis of impact factors of teacher collaboration. The results enumerate the factors, which are directly connected to school leaders and their views, and that reveal the mechanisms that effect teacher collaboration. These results serve as a foundation for a future teacher collaboration development program aiming to train principals.
\end{abstract}

KEYWORDS: teachers collaboration, teachers collaborative learning, professional development, view of school leaders 


\section{Introduction}

\section{The importance of teacher collaboration}

The Teaching and Learning International Survey (TALIS, 2009) distinguished two types of teacher collaboration: 'exchange and cooperation' and 'professional collaboration'. The first oneis the functional level of collaboration amongst teachers on a local level while the second one isaimed at professional development and higher student achievement. This professional collaboration has been in the focus of educational scientific discourse during the last decades. The significance of developing teacher collaboration lies within the phenomenon that could be described as the power of change. The change, which most of the educational systems need to increase its effectiveness (Fullan, 2011). There is plenty of research evidence to show that deep professional collaboration has a positive impact on teaching quality and student performance (Berry et al., 2005; Bolam et al., 2005; Caena, 2011; Clement and Vandenberghe, 2000; Rosenholtz, 1985).

Although 'Teacher collaboration' seems like an informal expression, it is not a clear and obvious concept for most of the actors in the educational system. There are several notions interrelated to this term such as learning organisation, organisational learning, community learning, collective learning, horizontal learning, community of practice and professional learning community (PLC). Some of these terms function as synonyms with only some slight contextual difference (e.g. collective learning, horizontal learning, community learning), while the others overlap in meaning (e.g. community of practice and PLC). However, these are expressions describing different angles of the phenomenon that connect teachers on a deeper level, as they target a common goal throughout common activities: professional learning for the sake of professional development and improvement of student achievement.

These notions originate from one root: collaboration. The act of professional development is achieved by collective learning actions. Professional development can not be replaced by adding up the professional learning experiences of individuals. Its significance and its power comes from the interrelation of several learning actions. Knowledge lies within relationships, learning takes place through specific connections. The speciality of this phenomenon comes from collaboration - the learning action of teaching.

As our interest is in the mechanisms that operate within the phenomenon described in the international literature of educational science, we have 
chosen to focus on teacher collaboration. We wanted to understand the deepest coherence between professional development and the power of collaboration. We wanted to know how and why collaborative learning works effectively.

The social constructivist approach to learning states that knowledge formation is strongly dependent on our environment and the partners around us. Our thinking patterns are constructed through interactions with people or in other words: knowledge is created in a social space (Vygotsky, 1962). This theory corresponds to the practice of professional learning communities that are spreading and growing in number in some education systems around the globe. This is one of the theoretical bases of our study.

The other foundation is organisational theory. A holistic perspective of schools has evolved under the influence of organisational studies. From this perspective we consider the school organisation as an entity. This entity is embedded into a large context and functions under the influence of external and internal powers. A school as an organisation has an impact on its members, even on the style of collaboration and the professional learning of the teachers within it.

\section{The role of leadership in teacher collaboration}

Besides the conceptual variegation and the tied-ness to practice, there is a factor that has been brought into focus in almost every study related to teacher collaboration and collaborative learning. This is the role of school leadership.

When we look at the broad circle of organisational research, the significance of leadership is represented by its partially insulated appearance. Educational science in different parts of the world has also emphasised the importance of principals in facilitating teacher collaboration. Some PLC developer-researcher groups have analysed and categorized the role of school leadership.

Bolam and his team in the UK (2005) described the operation processes of professional learning communitiesand identified leadership and management as primary factors.

The other three processes are also dependent on this first one. Although these processes could be isolated from the aspect of operation, they are all connected to the leader from the perspective of the starting point. These four processes are: leadership and management, the optimalization of resources and structures, the support of individual and collective professional learning and the support, evaluation and maintenance of the PLC. 
Hord and Sommers (2008) even devoted a separate book to the topic of leadership in connection with teacher collaboration with the title 'Leading Professional Learning Communities'. In their work, the authors presented the '7C'-model' of PLC leadership. They stated that, to lead a professional learning community, collaboration, coaching, change of culture, conflicts, creativity, courage and communication are needed and desirable.

Hord and Sommers also identified three different styles of leaders: the responder, the proactive manager and the initiator. The expressions here imply that the main aspect of the categorisation was the activity potential for change management. Does the leader work with a strategy of reacting to problems or rather have a practice of preventing problems? Or is the school leader the person who initiates the changes? All three kinds of leadership styles could connect to communities implementing teacher collaboration, but the initiator style is more suitable for introducing and establishing a professional learning collaboration in the organisation.

An other researchgroup for the study of teacher collaboration is Sleegers, Verbiest and their colleagues (2013). These Dutch experts also grant the role of leadership high importance. Verbiest (2011) himself distinguishes three categories of the leadership role: the culture-builder, the educator and the architect. With these expressions he refers to those roles which point out the important tasks with regards to a collaborative teachers' community. Every leader who intends to integrate collaborative learning into the organisational culture needs to fulfill these roles, even if not in an equal proportion.

School leadership is also a key factor in the work of Michael Fullan. He has written several books focusing on the role that leadership could play in the change of the educational system (DuFour and Fullan, 2013; Fullan, 2011, 2013, 2014). He also states - on the basis of cited pieces of research - that strengthening collaborative culture by leadership will result in organisational and systemic improvement in performance. "If principals directly influence how teachers can learn together, they will maximize their impact on student learning” (Fullan, 2014, pp. 65-66). He describes principals who are able to increase the performance of their own schools as "lead learners". It means the school leader is not only the positive example of continuous learning, but is in the process of creating improvement on a daily basis. 


\section{The state of teacher collaboration in Hungary}

The first TALIS-research (OECD, 2009) revealed that the 'exchange and cooperation' type of collaboration dominated Hungarian schools more significantly than European ones in general. At the same time 'professional collaboration' - which is more effective in terms of positive influence on students performance - is extremely rare in our country, as stated in the aforementioned OECD research.

To look behind these facts, we examined the cultural context of teacher collaboration in Hungary in a previous study to see whether the Hungarian society is able to host such an educational approach (Tóth-Pjeczka, Rapos, and Szivák, 2018).

Examining which cultural dimensions could be hindering or favourable to teachers' professional collaboration, we used Hofstede's 'six cultural dimensions model' (Hofstede, 1980; Hofstede, Hofstede, and Minkov, 2010). Our findings were that two of those dimensions were supporting: low power distance, short-term orientation; three were hindering: individualism, masculinity, uncertainty avoidance; and one was neutral or rather could have either effect: indulgence.

According to the GLOBE-study (House et al., 2004), Hungarian society could be characterised by its highly competitive features and low levels of trust. This character of our society is explicable by the history of the country and is strongly related to its lower tendency to collaborate.

Beside the international comparison of outside observers, Hungarian research within the system found resonating results as well. In a recently-ended evaluative study by a development project in the European Framework for Facilitating Collaborative Learning of Teachers (EFFECT) findings show similar overwhelmingly more hindering elements than supporting ones in the Hungarian context (Kálmán and Rapos, 2018).

Taking into consideration the results of our theoretical analysis, and the relevant literature, we can conclude that Hungarian culture, and the state of our society altogether, is not supportive of teachers' collaboration. In this cultural environment the mainstream of educators and educational practitioners are not likely to turn towards collaborative culture by themselves in an unsupported process of evolution in the education system.

However, we do have positive examples of teachers' deep professional collaboration - as we will see in the description of our research below which shows that it is not an impossible mission in the Hungarian system. 


\section{Study design}

\section{Research questions}

Since our aim was to understand the operation of teacher collaboration in its abstract depths, our research questions were:

1. How does teacher collaboration work? What kind of models could represent teachers' professional collaboration?

2. What components emerge from the series of elements of teacher collaboration?

3. What are the views of the school leaders on teacher collaboration in a school that realises professional collaboration? What are the differences in the views of the school leaders in a school based on professional collaboration and in a school that is in the process of developing its professional collaboration culture? Are there any specific collaboration mechanisms that stand out, according to the leaders?

During our review of the literature we found the answer for one of our questions. A model of teachers' professional collaboration has already been discovered and described, as we will show below.

\section{Data collection}

As our main interest was why and how teacher collaboration could work in our Hungarian context, we turned to an in-depth examination and we chose the case study as the most appropriate research format. In our qualitative approach the focus on the views of school leaders also helped us to choose the research method. We found that semi-structured interviews were effective data-gathering methods for this purpose.

Our original aim - inspired by TALIS research and its terms - was to compare the 'exchange and cooperation' type of collaboration with the 'professional collaboration', to see the differences in the views of school leaders. We started the selection of the case by choosing a school that proclaims cooperation as its main basic value. Than we chose an other school from the same district of Budapest (a rather homogenic middle class area)so the comparison would be ina similar sociocultural background, although one of the schools is an alternative school and the school we compared it to is a state-funded institute that operates under central sustainment. The first aspect for the selection of the second school was the similar sociocultural background - therefore the geographical limitation. However, we did not 
need a further selection aspect, as there was only one school (out of twelve) willing to participate in the research. This institute was actually a school that had already started development work, a kind of transformation towards a more collaborative organisational culture. Therefore what we finally achieved is a comparative study of a formative and a transformative organisational culture of teacher collaboration on a local level.

There were a total of ten interviews conducted in the two schools after having a trial interview - with a school leader independent from the examined institutions - to validate our research tool. Beside the two principals, we interviewed the leaders of the different teams of teachers, the vice-principals amongst them. We decided to choose five leaders from both schools because before the data collection, during the preparation of the research, the principal of the formative school had informed us about the special structure of decision- making in this school. Comparing this with the documents of the school we realised that in an organisation with such a reduced hierarchical structure we needed to ask more than one person to get a realistic picture of the leadership of this school. Therefore we interviewed not only the principal in the comparison school, but in mapping the structure of leadership in the transformative school, we chose those who could have similar roles, or influence in the leadership of that organisation.

In the formative school this meant three women and two men, and in the transformative school one man and four women; all of the interviewed leaders were aged between 40-55 years, each with at least three years of teaching and leading experience.

\section{Data analysis}

Vangrieken and her colleagues embarked upon creating an overview of the literature of teacher collaboration after 2000 (Vangrieken et al., 2015). They encountered the facilitating factors of teacher collaboration and separated those factors under the terms team, PLC and collaboration. The factors have also been categorised into the following groups: personal, structural, team, process organisation or directional. Having examined the table of these factors, we filtered them according to their direct connection to the leader. We used this list of factors at the end of the semi-structured interviews, asking about the importance of those factors in a 1-5 scale. We arranged the data into a table, computed the average point of each factors and compared the results of the two organisations. 
We also used document analysis to compare the data gathered from interviews with the official and observable structure and norms of the organisations. We explored the following documents of the schools: Pedagogical Program, the Operating Rules, the Annual Plan of Work and the Alternative Framework Curricula (in the case of the formative school).

\section{Limitations}

As it is always with case studies, the limitation of the research is in its generalization. The sample size of only two schools limits the generailzability of the findings.

Since this research is looking primarily at teacher collaboration, the demographics of the schools' students are not primary variables and should not create significant limitations.

\section{Results}

We present the findings of our research arranged around three main themes: components, models and operational mechanisms of teacher collaboration. We start with the models as this is the part of our research that has been fully discovered by our literature review, and the empirical research itself did not modify the picture gained through reading the literature. The conceptual model of PLC mirrors the operation of the examined school which has a school-culture based on teacher collaboration.

\section{Operational modelsand attributes of teacher collaboration}

How does teacher collaboration work? What kind of models could represent teachers' professional collaboration?

There is no surprise in the fact that thedevelopment work of PLC is forged with close observation of the forming and working process of PLC and is followed by the modelling of the phenomenon.Those developer/researcher experts who are deeply in the process of building a structure are concerned with the functioning mechanism and the essential elements of the given subject. Therefore the literature of deep professional collaboration is already rich in description of the operation of PLC. Descriptions evolved from the lists of attributes through a conceptual model to a synchronic model.

Bolam and his colleagues (2005), after conducting a development project for teachers' collaborative learning, defined the attributes of PLC: 
'An effective professional learning community (EPLC) fully exhibits eight key characteristics: shared values and vision; collective responsibility for pupils' learning; collaboration focused on learning; individual and collective professional learning; reflective professional enquiry; openness, networks and partnerships; inclusive membership; mutual trust, respect and support.' (Bolam et al., 2005).

Four operational processes have been identified in addition to these attributes: - leadership and management; optimalization of resources and structures; support of individual and collective professional learning and support, evaluation and maintenance of PLC.

Hord and Sommers (2008) defined the attributes of PLC as follows: shared beliefs, values and visions, shared and supportive leadership, collective learning and its application, supportive conditions, and shared personal practice. Besides these attributes, Hord detailed the role of leadership, which she described as the '7C's-model', stating that to lead a professional learning community the leader needs to deal with collaboration, coaching, change of culture, conflicts, creativity, courage and communication.

Verbiest (2011) summarised his model of PLC operation with three key factors. The main dimensions are: personal, interpersonal and organisational capacities. Verbiest pursued his action-research together with Peter Sleeger, Perry de Brok, Nienke M. Moolenaar and Alan J. Daly (2013). As result of their development work they connected a three-capacities conceptual model with seven factors:

1. (re) constructing knowledge actively, reflectively and critically;

2. currency (under personal capacity);

3. shared values and a common vision of learning and of the teacher's role;

4. collective learning and shared practices (belong to interpersonal capacity),

5. supportive conditions: resources, structures and systems;

6. supportive conditions: culture,

7. supportive, stimulating and shared leadership (parts of organisational capacity).

Professional learning community development started in Hungary as well, in an action-research project carried out in the Southern Great Plain Region - supported by the European Union. This action-research used the term horizontal learning as a synonym of collaborative learning. The project developed 


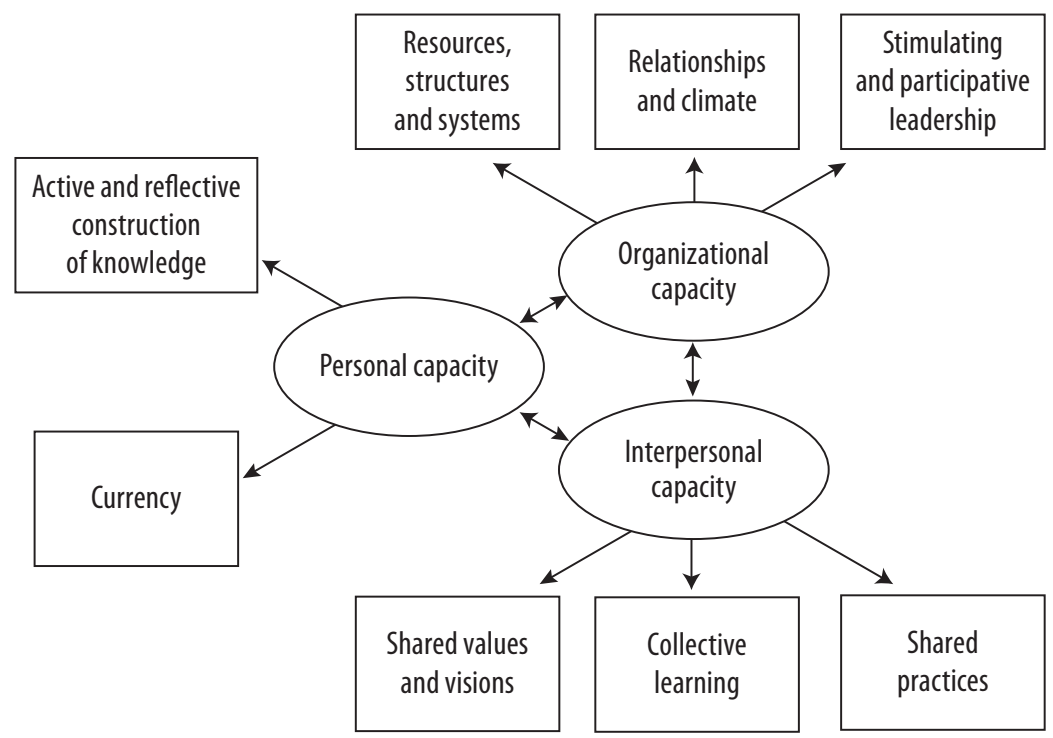

Figure 1. The Conceptual - model developed by Verbiest and his colleagues (2013)

an organisational diagnostic tool, which is an actual enhancement of a Dutch model. A new capacity has been added to the personal, interpersonal and organisational capacities. This fourth capacity is the networking capacity (Horváth, Simon, and Kovács, 2015). What is more, the four capacities are divided into further sub-dimensions (See Figure 2 below).

1. Personal capacity: self- and further education; proactivity;

2. Interpersonal capacity: trust and openness; reflectivity;

3. Organisational capacity: knowledge management; supportive and empowering leadership; learning- and learnercentred vision;

4. Network capacity: systems-thinking approach; building and sustaining networks.

The static aspect of this model has been supplemented with a dynamic aspect: the capacities work in a flow of evolution, i.e., knowing, understanding, believing, and acting. This aspect highligths the countinuous developmental dimension of PLC, the professional lifelong learning of teachers.

In our empirical research we found that the formative school mirrored the model of PLC and the model of horizontal learning described above. 


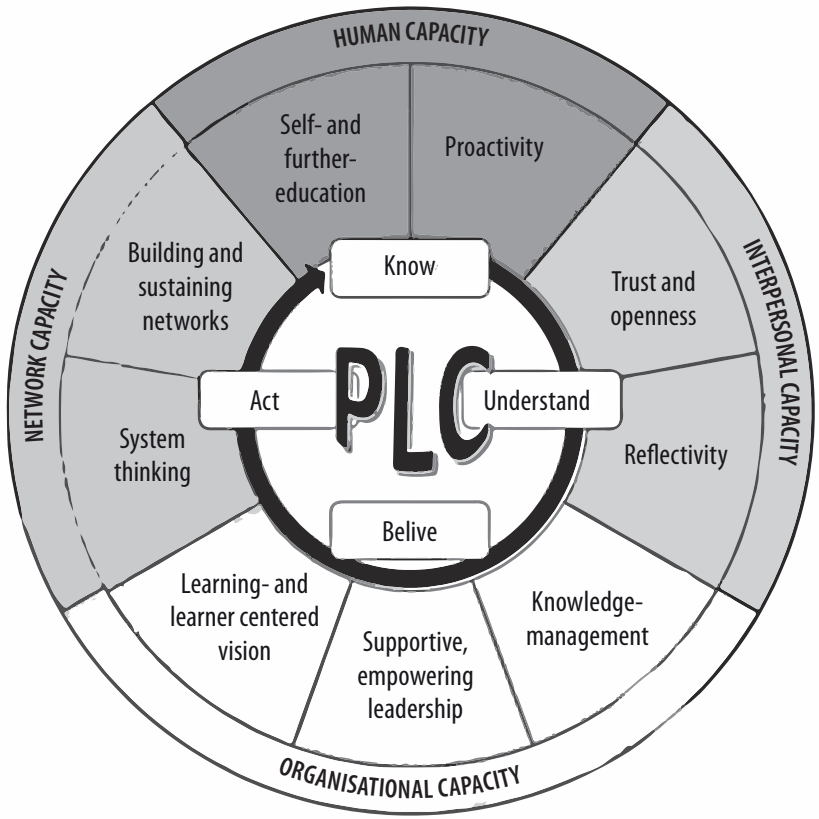

Figure 2. The model of horizontal learning

\section{Components of teacher collaboration}

What components emerge from the series of elements of teacher collaboration?

In the models and attributes we could see a list of elements that built teacher collaboration into a learning community. This knowledge, combined with the understanding of the views of leaders who support teacher collaboration, might bring us closer to seeing what can be done to form the perspective of school principals in Hungary.

We wanted to know if any of the factors of teacher collaboration identified by Vangrieken et al. (2015) in their systematic literature review could be lifted to the level of components: necessary and indispensable. Therefore we asked the interviewed leaders to indicate what factors were essential to teacher collaboration. It turned out that willingness to work in a team was unquestionably a component. A positive attitude towards teaming, understanding the benefits of teaming, giving time to collaboration, commitment to the team and creating an atmosphere of mutual trustare those factors that leaders could agree on as necessary andessentialto teacher collaboration. 
In the case of the transformative school, we could see characteristic differences in the attitude of the leaders. The initiators of the transformation (one of them is the principal) refer to supporting collaboration as an essential part of collaboration, while the majority of their fellow leaders show less interest and willingness to support collaboration. They do not deem it to be their responsibility. This division within leadership is an important difference between the two examined schools. Those who build their school on the values of cooperation are united in supporting collaboration and their views on collaboration are much closer to each other than in the other school, which has also built a system to support this unity. They mention the selection of new colleagues as an important issue. This selection is supported by a long process involving several steps followed by a guided initiative period. Meanwhile, the selection of teachers was not mentioned separately by any of the leaders of the transformative school.

Table 1. Comparison of the view of leaders on the importance of factors

\begin{tabular}{|c|c|c|c|c|c|c|c|c|c|c|c|c|c|}
\hline \multirow{3}{*}{\multicolumn{2}{|c|}{$\begin{array}{l}\text { Factors contributing to teacher } \\
\text { collaboration based on the } \\
\text { Vangrieken at al.' literature review }\end{array}$}} & \multicolumn{7}{|c|}{$1^{\text {st }}$ school } & \multicolumn{5}{|c|}{$2^{\text {nd }}$ school } \\
\hline & & \multicolumn{5}{|c|}{ interviews } & \multicolumn{7}{|c|}{ interviews } \\
\hline & & 1 & 2 & 3 & 4 & 5 & Avg. & 1 & 2 & 3 & 4 & 5 & Avg. \\
\hline 1. & willing to teaming & 1 & 1 & 1 & 1 & 1 & 1 & 1 & 1 & 1 & 1 & 1 & 1 \\
\hline 2. & positive attitude towards teaming & 2 & 1 & 1 & 1 & 1 & 1.2 & 1 & 1 & 1 & 1 & 1 & 1 \\
\hline & $\begin{array}{l}\text { understands the benefits of } \\
\text { teaming }\end{array}$ & 3 & 1 & 1 & 1 & 1 & 1.4 & 1 & 2 & 1 & 1 & 1 & 1.2 \\
\hline 4. & has good communication skills & 2 & 2 & 1 & 2 & 2 & 1.8 & 1 & 3 & 1 & 2 & 2 & 1.4 \\
\hline 5. & has experience in teamwork & 1 & 2 & 2 & 2 & 3 & 2 & 2 & 2 & 2 & 2 & 1 & 1.8 \\
\hline 6. & has knowledge of team processes & 1 & 2 & 2 & 1 & 4 & 2 & 2 & 1 & 2 & 2 & 1 & 1.6 \\
\hline 7. & has self- and team-evaluation skills & 2 & 2 & 1 & 2 & 2 & 1.8 & 1 & 1 & 2 & 1 & 1 & 1.2 \\
\hline 8. & gives time to collaboration & 1 & 1 & 1 & 1 & 1 & 1 & 1 & 2 & 1 & 1 & 2 & 1.4 \\
\hline & $\begin{array}{l}\text { focuses on student-centered } \\
\text { planning and accountability }\end{array}$ & $1 / 2 !$ & $1 / 4 ! 2$ & & 3 & 3 & $2 / 3.2$ & 1 & 1 & 2 & 1 & 1 & 1.2 \\
\hline 10. & distributes leadership & 2 & 3 & 1 & 2 & 1 & 2.2 & 2 & 2 & 1 & 1 & 1 & 1.4 \\
\hline 11. & $\begin{array}{l}\text { builds whole school-philosophy } \\
\text { that support teaming (rituals and } \\
\text { customs, espoused values, shared } \\
\text { meaning, group norms) }\end{array}$ & 1 & 2 & $3 x$ & 2 & 3 & 2.2 & 2 & 2 & 2 & 1 & 1 & 1.6 \\
\hline
\end{tabular}




\begin{tabular}{|c|c|c|c|c|c|c|c|c|c|c|c|c|c|}
\hline \multirow{3}{*}{\multicolumn{2}{|c|}{$\begin{array}{l}\text { Factors contributing to teacher } \\
\text { collaboration based on the } \\
\text { Vangrieken at al.' literature review }\end{array}$}} & \multicolumn{7}{|c|}{$1^{\text {st }}$ school } & \multicolumn{5}{|c|}{$2^{\text {nd }}$ school } \\
\hline & & \multicolumn{5}{|c|}{ interviews } & \multicolumn{7}{|c|}{ interviews } \\
\hline & & 1 & 2 & 3 & 4 & 5 & Avg. & 1 & 2 & 3 & 4 & 5 & Avg. \\
\hline 12. & $\begin{array}{l}\text { has commitment to the reform: } \\
\text { administrative support, leadership, } \\
\text { stability of teams, ongoing training }\end{array}$ & 1 & 2 & 1 & 2 & 3 & 1.8 & 2 & 2 & 1 & 1 & 2 & 1.6 \\
\hline 13. & has commitment to the team & 1 & 1 & 1 & 1 & 2 & 1.2 & 1 & 2 & 1 & 1 & 1 & 1.2 \\
\hline 14. & - provides administrative support & 3 & 3 & 3 & 3 & 4 & 3.2 & 3 & 2 & 2 & 1 & 3 & 2.2 \\
\hline 15. & . consciously builds school culture & 2 & 2 & 2 & 1 & 2 & 1.8 & 2 & 2 & 1 & 1 & 1 & 1.4 \\
\hline 16. & $\begin{array}{l}\text { consciously forms school governance } \\
\text { structures }\end{array}$ & 2 & 2 & 1 & 2 & 2 & 1.8 & 2 & 1 & 1 & 1 & 1 & 1.2 \\
\hline 17. & seeks transformation & 1 & 4 & $1 / 2 x$ & 1 & $x$ & & 2 & 1 & 1 & 3 & 2 & 1.8 \\
\hline 18. & . supports collaboration & 1 & 1 & 1 & 1 & 1 & 1 & 1 & 2 & 1 & 2 & 2 & 1.6 \\
\hline 19. & $\begin{array}{l}\text { plays an important part in balancing } \\
\text { the individual needs and the } \\
\text { organisational needs and facilitating } \\
\text { professional community }\end{array}$ & 1 & 1 & 3 & 2 & 1 & 1.6 & 1 & 1 & 1 & 2 & 2 & 1.4 \\
\hline 20. & $\begin{array}{l}\text { gives support in different areas: time } \\
\text { for collaboration offering flexibility, } \\
\text { encouraging feedback, giving } \\
\text { guidance }\end{array}$ & 3 & 2 & 1 & 2 & 1 & 2.2 & 2 & 2 & 1 & 1 & 2 & 1.6 \\
\hline 21. & $\begin{array}{l}\text { monitors the collaboration to make } \\
\text { sure it does not lead to contrived } \\
\text { collegiality }\end{array}$ & 3 & 2 & 1 & 2 & 2 & 2 & 2 & 3 & 2 & 4 & 3 & 2.8 \\
\hline 22. & $\begin{array}{l}\text { creates atmosphere of mutual } \\
\text { trust }\end{array}$ & 1 & 2 & 2 & 1 & 1 & 1.4 & 1 & 1 & 2 & 1 & 2 & 1.4 \\
\hline 23. & - gives feedback & 2 & 2 & 2 & 1 & 1 & 1.6 & 1 & 1 & 2 & 1 & 1 & 1.2 \\
\hline 24. & $\begin{array}{l}\text { extends team support over a longer } \\
\text { period of time }\end{array}$ & 2 & 2 & 1 & 2 & 2 & 1.8 & 1 & 2 & 1 & 1 & 2 & 1.4 \\
\hline 25. & $\begin{array}{l}\text { other: } \\
\text { additional important factors } \\
\text { mentioned by interviewed leaders }\end{array}$ & & & $\begin{array}{l}\text { trol, s } \\
\text { edom } \\
\text { bility } \\
\text { g who } \\
\text { ice of } \\
\text { wing }\end{array}$ & & & $\begin{array}{l}\text { on } \\
\text { onal } \\
\text { with } \\
\text { ush / }\end{array}$ & $\begin{array}{l}\text { part } \\
\text { non- } \\
\text { com } \\
\text { firm } \\
\text { stea } \\
\text { goal } \\
\text { shar } \\
\text { tean }\end{array}$ & & & & $\begin{array}{l}\text { his - } \\
\text { ness), } \\
\text { rith th }\end{array}$ & \\
\hline
\end{tabular}

Key: ! - Separated, $\mathrm{x}$ - Depending on the case, 3x - Together 
One of the factors the literature mentions as causing disruption, which was reflected in the interviews with formative leaders, was the focus on student-centered planning and accountability. The majority of formative leaders wanted to separate this factor into two parts. They considered student-centered learning important and accountability less important, with some even reckoning it as a hindering factor regarding its administrative aspect. Yet, accountability does exist in the formative system as well, although it appears as a side-effect or consequence of the collaborative culture, not an aim of the operation or component of teacher collaboration.

While there was an even asessment of the importance of each factor by formative leaders, during the interviews hidden differences became possible to observe. On the part of the change-initiator leaders there was determination and commitment, but there were also leaders with signs of burnout and slight disinterest in changing school culture. Lack of time as a hindering factor of professional collaboration appeared in many interviews. This is undoubtedly connected to the fact that in the Hungarian educational system teachers' working hours increased significantly in addition to a growing administrative burden. This creates a rather big obstacle for teacher collaboration.

\section{Operational mechanisms}

Comparing the formative culture of teacher collaboration with the transformative one, we could see that while the first one was rather united in terms of views and values, the transformative school showed important differences in the views of its leaders. Formative leaders emphasised the involvement of all teachers in the collaboration and even in the decisional part of the leadership of the school.

Teachers who work here are leaders at the same time, because they are obliged to make decisions. (Interview 4)

Here everyone equally counts... everyone's opinion is factored in the decision. (Interview 3)

Two year ago we had an official inspectoral visit ... After checking the documents there was a final conversation where I was asked: How much extra reward do I give to the teachers to have them work so much? I said: 'Believe me, there is no difference, everyone receives the same amount of salary according to the national pay scale and extra benefits are equally distributed.' They did not want to believe it. Why do they work so much, then? - they asked me. My answer was: because they are and they feel they are important. They are involved. Their words count, we build on what 
they say, because they have the knowledge. Not what we leaders say but what they say, they know, they are there, they do the work, so they know. So involvement is very important. (Interview 1)

According to the interviews, in the school where professional teacher collaboration thrives leaders do not make decisions alone; they build on the reflective feedback of the professional community. They consider this involvement as the foundation of the inner motivation of teachers to work harder than the average - according to external assessment - and operate a deep level of collaboration despite its time-consuming nature.

According to the findings of our research, we could state that professional growth realised through teachers' professional collaboration takes place through a process that originates from involvement through inner motivation.

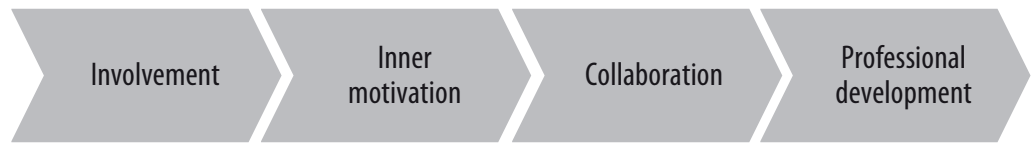

Figure 3. Mechanism of involvement in teacher collaboration.

Could we consider teachers' professional collaboration a system that is run by inner motivation and is fuelled by involvement in decision making? Is it a process that could strengthen decisional capital and professional capital? (Hargreaves and Fullan, 2012).

An other important stepappeared in the interviews of transformative school leaders. They highlighted the effect of creating opportunities for building informal relations amongst colleagues. Informal events for teachers organised outside of schools strengthened the link and opened their connection to facilitate sharing views and improving communication amongst colleagues. This is a process of opening up to each other that resulted in sharing experiences, problems, ideas, questions, and good examples and supporting each other by listening and understanding.

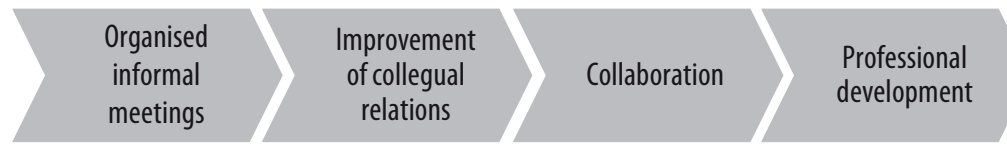

Figure 4. Mechanism of informal community-building in teacher collaboration. 


\section{Conclusions}

We can see that although professional development through teacher collaboration is an effective way of strengthening professionalization, the context in Hungary is not in favour of this kind of professional growth. Even so, there is a positive example of teacher collaboration as an alternative of the mainstream educational practice, and we can also see the need for transformation towards collaborative culture.

Although one possibility of changing this educational culture is through school leaders, their options for action are limited by the transition toa more centralized educational system in the last few years. What we observed here is the importance of involvement and the effect of strenghtening informal connections amongst teachers, which provide positive examples.

A future development program that targets broadening the knowledge and forming the attitude of school leaders regarding collaborative culture, needs tobuilt on the components of teacher collaboration, and must find a way to improve the following: willingness and positive attitude towards teaming, understanding the benefits of teaming, giving time to collaboration, commitment to the team, creating an atmosphere of mutual trust and supportive leadership.

\section{References}

Berry, B., Johnson, D., and Montgomery, D. (2005). The Power of Teacher Leadership. Educational Leadership, 62 (5), 56-60.

Bolam, R., McMoahon, A., Stoll, L., Thomas, S., and Wallace, M. (2005). Creating and Sustaining Professional Learning Communities. University of Bristol, Retrieved October 10, 2017 from http://dera.ioe.ac.uk/5622/1/RR637.pdf.

Caena, F. (2011). Literature Review Quality in Teachers' Continuing Professional Development. European Commission, Brussel, Retrieved October 21, 2017 from http://ec.europa.eu/dgs/education_culture/repository/education/policy/strategic-framework/doc/teacher-development_en.pdf.

Clement, M., and Venberghe, R. (2000). Teachers Professional Development: A Solitary or Collegial (Ad)venture? Teaching and Teacher Education, 16 (3), 81-101.

DuFour, R., and Fullan, M. (2013). Cultures Built to Last. Systemic PLCs at Work. Bloomington: Solution Tree Press.

Fullan, M. (2011). Change Leader. Learning to do What Matters Most. San Francisco: Jossey-Bass.

Fullan, M. (2013). Motion Leadership in Action. Thousand Oaks: Corwin SAGE Publication. 
Fullan, M. (2014). The Principal. Three Keys to Maximizing Impact. San Francisco: Jossey-Bass.

Hargreaves, A., and Fullan, M. (2012). Professional Capital: Transforming Teaching in Every School. New York: Teachers College Press.

Hofstede G., (1980). Cultures Consequences. International Differences in Work-Related Values. Beverly Hills, CA: Sage Publication

Hofstede, G., Hofstede, G.J., Minkov, M. (2010). Cultures and Organisations: Software of the Mind. New York: MGraw-Hill Co.

Hord, S.M., and Sommers, W.A. (2008). Leading Professional Learning Communities. Corwin Press: Thousand Oaks.

Horváth, L., Simon, T., and Kovács, A. (2015). Development and Embedding of the Horizontal Learning System into the Hungarian Institutional System of Pedagogical Service. Paper presented at the ATEE Annual Conference 2015 August 24-26 Glasgow.

House, R.J., Hanges, P.J., Javidan, M., Dorfman, P.W., and Gupta, V. (Eds.). (2004). Culture, Leadership, and Organisations: The GLOBE Study of 62 Societies, (Vol. 1), Sage Publications Inc.

Kálmán, O., and Rapos, N. (2018). A pedagógusok együttmúködő tanulásának tapasztalatai a három hazai pilotban. EFFECT Projekt értékelés. Under publishing manuscript from the authors.

OECD (2009). Creating Effective Teaching and Learning Environments. First results from TALIS, 2009 Retrieved October 22, 2017 from http://www.oecd.org/education/school/43023606.pdf.

OECD (2005). Teachers Matter. Attracting, Developing and Retaining Effective Teachers. Retrieved October 21, 2017 from http://www.oecd.org/education/ school/34990905.pdf

Rosenholtz, S.J. (1985). Effective Schools. Interpreting the Evidence. American Journal of Education, 93 (3).

Sleegers, P., Den Brok, P., Verbiest, E., Moolenaar, M.N., and Daly, A.J. (2013). Toward Conceptual Clarity: A Multidimensional, Multilevel Model of Professional Learning Communities in Dutch Elementary Schools, 2013 Retrieved May 23, 2017 from https://ris.utwente.nl/ws/portalfiles/portal/6581457.

Tóth-Pjeczka, K., Rapos, N., and Szivák, J. (2018). The Factors of Teacher Collaboration Impacting on Local Level. In From Borsszem Jankó to Bologne. ELTE PPK - L’Harmattan Kiadó, Budapest, 2018.

Vangrieken, K., Dochy, F., Raes, E., and Kyndt, E. (2015). Teacher Collaboration. A Literature Review. 2015 Retrieved October 3, 2017 from https://www.sciencedirect.com/science/article/pii/S1747938X1500024X.

Verbiest, E. (2011). Developing Professional Learning Communities. AERA Conference, 2011 Retrieved November 6, 2017 from http://samen-wijs.nl/docs/Verbiest\%20-\%20Developing\%20Professional\%20Learning\%20Communities.pdf.

Vygotsky, L.S. (1962). Thought and Language. Cambridge: MIT Press. 


\title{
Chapter 19
}

\section{Didactic Cooperation between Teachers and Students in Higher Education: Utopia or Real Opportunity?}

\author{
Anna Krajewska \\ University of Bialystok, Faculty of Pedagogy and Psychology, Bialystok, Poland
}

\begin{abstract}
This paper deals with the didactic cooperation between teachers and students in higher education. The research described in this study aims at investigating the opinions of teachers and students on the level of didactic cooperation in the educational process (the quality of educational effects). Data were collected by using three scales designed to examine the level of didactic cooperation between teachers and students in each phase of the educational process. The results indicate that teachers and students often view the level of didactic cooperation as medium or low. This study concludes that it is necessary to improve the level of cooperation and mutual assistance of teachers and students, enabling and facilitating actions and activities in each phase of the educational process, because the achieved effects are interdependent, and they mutually determine the quality of education.

KEYWORDs: didactic cooperation, teachers and students, teaching in higher education
\end{abstract}

\section{Introduction}

Human cooperation always has very positive effects, whether it comes in its direct, face-to-face form, e.g., at school, or the indirect one, in virtual reality. It is highly valued in educational theory and practice, and also in other areas, such as computer programming or social and economic problem solving, for example. Cooperative learning is a very important determinant of human development with a strong theoretical background that helps to describe, understand and predict the processes and problems occurring

ConTACT Anna Krajewska, EMAIL: ankraj3@wp.pl 
in this type of education, which is extremely important for educational research and practice. Studies concerning this issue have been carried out in Europe and all over the world for many years and published in literature on social psychology, developmental psychology, socio-cultural and sociological research (e.g., Johnson and Johnson, 2009; Sharan and Sharan, 1992; Slavin, 1996). This issue has also been discussed widely in Polish literature (Czarniawski, 2002; Karolczak-Biernacka, 1987; Krajewska, 2016).

The aim of the study presented in this paper is to explore the opinions of teachers and students on the level of didactic cooperation in the educational process (the quality of educational effects). Therefore, I present the theoretical background of didactic cooperation, the outline of research methodology, and selected findings of my research. The paper ends with some conclusions for teaching approaches in higher education.

\section{Theoretical background}

The theoretical background of research on didactic cooperation between teachers and students lies in constructivist theories of teaching and learning, cognitive and socio-cultural constructivism (the concept of cognitive development by J. Piaget and L. Vygotsky), in theories of student-centered education, and social theories of interpersonal communication, social interdependence, and praxeological concepts of cooperation.

The basic assumptions of cognitive development adopted by Piaget are still valid. Piaget (1971) identified the stages of human cognitive development. He argued that people differ in the pace of transition from one stage to another, and progress in each stage depends on various determinants: maturation, experience, and social environmental factors. Piaget (1992) emphasized the importance of cognitive conflict for individuals' learning and individual activity in studying, initiating actions, solving problems, reflecting on and thinking about reality, which he contrasted with direct instruction and reinforcing the desired (required) responses. According to this author a considerable part of an individuals' knowledge is built as a result of interaction, mutual relations with the social and material environment, and social experiences which are important for cognitive development and ongoing changes (ibid.). He thought that cooperation between peers may encourage one to really discuss issues and share opinions, and cooperation between children is as significant as in the case of adults: it plays a major role in cognitive development (Falchikov, 2001). 
L.S. Vygotsky contributed a theory of development and the study of higher psychological functions. From his perspective, one’s psyche develops as a result of cooperation with the people around, thanks to social bonds, the person's social activity and interests. Social environment allows the person to learn and develop (Vygotsky, 1978), because knowledge is built and internalized as a result of social interactions. The theory is based on the assumption that comprehensive development at any age requires social interaction, influencing one another. Vygotsky stressed that individuals' cooperation in the effort to learn, understand and solve problems is of primary importance in building knowledge and transforming agreed views into internal mental structures, which results in cognitive and intellectual development. The author argued that the scope of skills developed under the guidance of adults or in cooperation with peers surpassed the skills accomplished individually and independently.

It is significant how didactic cooperation between teachers and students in the educational process is related to Piaget's and Vygotsky's theories. Both of them present the opinion that cooperation with teachers and more talented peers is of key importance for cognitive development, particularly the development of critical thinking and reflection. Both theories emphasize the importance of proactivity and engagement on the part of both teacher and students, but also the need to limit the teacher's influences and encourage cooperation between students instead.

The theoretical background of research on didactic cooperation between teachers and students also includes theories of student-centered education, referring to the concepts of humanistic psychology. An outstanding representative of this approach is Carl R. Rogers, a supporter of an optimistic view of the potential lying in any human being, in non-inhibiting their development, and in their pursuit of personal development and mental health (Rogers, 1983). In his educational concept he pointed to the need to focus on the student, highlighted in the expression he coined - "student-centeredness" (Blackie, Case, and Jawitz, 2010). He observed that previously, typical teaching, i.e., the transfer of knowledge and skills, did not properly prepare students to function in a dynamically changing reality. He developed the concept of 'significant learning', whose key elements are: the individual's own initiative, cognitive and emotional activity, and connection with the person's real needs (Kościelniak, 2004). According to Rogers, the core tasks of education are to facilitate significant learning - to support, facilitate and assist. The teacher's attitudes 
to the students, expressed in personal relations between them, are very important in this case.

Brandes and Ginnis (1986) identify the following principles of implementing the student-centeredness concept: a student's complete responsibility for his or her learning, the need to engage in learning, ensuring balanced relationships between the teacher and students, the teacher becoming a facilitator who assists/supports students and facilitates their learning, as well as students' affective and cognitive development. At the same time, the concept of teacher-centered education faced increasing criticism. To address the need of making education more up to date, Barr and Tagg (1995) suggested changing its paradigm from the paradigm of education to the paradigm of learning, which - as they stressed - was to end the privileged position of the teacher. Kember (1997) identified two general directions of teaching: the teacher-centered concept, with the teacher providing the student with material for learning, and the student-centered one, highlighting the student's active role in understanding the material.

The theoretical background of didactic cooperation between teachers and students is significantly related to theories of student-centered education, which emphasize learners' activity and teacher's support and assistance, deep study and comprehension, learners' responsibility and sense of duty, as well as interdependence and respect between the teacher and the students.

Especially important from the point of view of effective communication in didactic cooperation between teachers and students are theories of interpersonal communication: symbolic interactionism and the theory of communicative action. Symbolic interactionism involves the three main principles of interpersonal communication, referring to meaning, language, and thought (Griffin, 2003). The basic role in this theory is played by the concept of meaning in the social context of mutual influence and the concept of interaction. Negotiating meanings in the process of symbolic interaction and imagining oneself in someone else's position allow better evaluation of the results of one's own actions and improve the chances of cooperation with others, including in education. In the theory of communicative action, Habermas (1999, p. 474) mentions four demands that are important in any communication: to speak in an understandable way; to get others to understand something; to make one's thoughts understandable; to communicate with each other.

The recommendations arising from the theory of interpersonal communication are very important for the relations of cooperation between teachers and students. Communication based on mutual understanding 
allows cooperation in the satisfying of needs as well as individual and social development. The goal of interpersonal communication is not only to transfer content and information, but also to build relationships, and the ability to communicate with others is important for the results of activities undertaken.

A theoretical background for cooperation between teachers and students can be found in cooperative learning theories whose source is the theory of social interdependence, originally developed by Deutsch (1949). In the 1980s and later, Johnson and Johnson (1989, 2005, 2009) developed those concepts and presented an extended and generalized form of the theory of social interdependence. They assumed that social interdependence occurs whenever the accomplishments of individuals are affected by other people's actions. The goals of people who are in a certain situation determine the way its participants influence each other. There are two types of social interdependence: positive (cooperation), when the actions of individuals promote the achievement of joint or shared goals, and negative (competition), when the actions of individuals obstruct the achievement of each other's goals. The authors of the concept assumed that cooperation is motivated by benefit to the individual, and extended to group benefits if other people's actions replace the individual's actions and strengthen their motivation to achieve goals that are beneficial both for others and for the individual.

After many years of extensive research on the application of the theory of social interdependence in different areas, including education, Johnson and Johnson (1998) developed the theoretical background of cooperative learning. They identified five factors determining effective, authentic cooperative learning: positive interdependence, individual and group responsibility, facilitating mutual influences, developing social skills, and the ability to transform group functioning.

Didactic cooperation between teachers and students is significantly connected with the theory of cooperative learning. The source of activities undertaken by teachers and students together is internal motivation directed at the achievement of joint or shared goals. The teacher's tasks are to allow and facilitate actions taken by individuals, and organize cooperative learning by applying appropriate methods and organizational forms of education, while students' responsibility and activity is necessary in actions taken together with the teacher and the group.

With regard to the essence, structure and possibility of assessing the level of didactic cooperation between teachers and students, praxeological theories are especially useful. In these theories, cooperation is understood 
as the positive activity of many subjects oriented at the achievement of joint or shared goals (Kotarbiński, 1975; Pszczołowski 1978). This activity is complex, made up of at least three mutually dependent phases: preparation, performance, and control/evaluation. Each phase has some interdependent components: goal, subject, object, methods, means, conditions and results. Other important assumptions are that one subject assists another in an effort to allow or at least help the other to achieve the goal; the activities of cooperating individuals are mutually determined (Kotarbiński, 1975). Besides, it is assumed that cooperation (just like action) can be evaluated using practical and mixed assessments of its goals, the characteristics of the method and the results of cooperation, and the cooperating individuals. Practical assessments refer to the usefulness or uselessness of a way of acting or a component of action (e.g., efficacy, rationality, economy and cost-effectiveness). The group of practical assessments referring to the actors includes i.a., diligence, proactivity, conscientiousness, industriousness and autonomy. There are also mixed assessments (praxeological and emotional), e.g., bravery or responsibility.

Praxeological theories lead to significant recommendations for didactic cooperation between teachers and students, such as the need to provide mutual assistance in activities undertaken in different phases of the educational process and their elements; the need for constant care by the teacher and the students of the efficacy, profitability, economy and rationality of actions taken together; the teacher's and students' responsibility for their actions or failure to take action; and the students' proactivity, autonomy and sense of subjectivity in the educational process.

The theories of student-centered education, cognitive constructivism, socio-cultural constructivism, interpersonal communication and social interdependence presented above highlight the importance of cooperative relations between the teacher and students as displayed in their activity, and the desired characteristics of their actions. Praxeological theories emphasize the significance of cooperation in human activities, specify the structure of cooperation and the manner of its evaluation on the basis of practical and mixed assessments, thus allowing the determination of the quality of its effects.

\section{Methodology}

The research described in this study refers to didactic cooperation between teachers and students in the educational process. 
The term 'didactic cooperation' was defined on the basis of findings concerning different elements and phases of activity and didactic activity, as well as the understanding of cooperation from the praxeological perspective. Hence, I assumed that didactic cooperation is a system of complex actions taken by many subjects in the educational process, including conscious actions of university teachers and students oriented at joint or shared goals, such as changing the personalities of students (learners) with the view to the adopted values and goals, in which they help each other by their activities to enable or facilitate the course of interdependent phases of preparation, performance and control/evaluation. In addition, each phase of the system of didactic cooperation has interrelated and mutually determined elements: goals, subjects, modes (object, contents, methods, means, organizational forms and conditions) and results. Therefore, didactic cooperation between teachers and students means mutual assistance, enabling or facilitating consciously taken actions and activities in their interdependent phases and in their interrelated elements (Krajewska, 2016).

The system of cooperation in the preparation phase of the educational process determines the system of cooperation in its performance phase, and these two influence the system of cooperation in the phase of control/evaluation, which in turn affects the next preparation, performance etc. Teachers' and students' actions and activities as part of the system of cooperation are cyclical and recurrent in time, and the effects achieved in its interdependent phases determine the quality of education.

For research purposes, I assumed that the level of didactic cooperation between teachers and students can be shown by practical and mixed assessments concerning the quality of effects in:

- $\quad$ the goals of cooperation - the level of their effectiveness and usefulness;

- cooperation between individuals - the level of teachers' and students' responsibility, and the level of students' proactivity, autonomy and sense of subjectivity;

- the mode of cooperation (the object, contents, methods, means, organizational forms and conditions) - the level of its efficacy, profitability, economy and rationality;

- $\quad$ the results of cooperation - the level of effectiveness and usefulness in the preparation, performance and control/evaluation phases of the educational process. 
In this paper I present the results related to the level of didactic cooperation from the perspective of teachers and students, and the quality of its effects are presented. In order to assess the quality of effects of didactic cooperation in different phases of the educational process, I have developed three evaluation scales - Didactic Cooperation Between Teachers and Students [Współdziałanie Dydaktyczne Nauczycieli i Studentów] (DCTS) in the Preparation Phase, DCTS in the Performance Phase, and DCTS in the Control/Evaluation Phase. The scales are the same for teachers and students and include 25 items each. Each scale involved the assessment of goals of cooperation (1-2), cooperating subjects (individuals) (3-7), the mode of cooperation (8-23), and the results of cooperation (24-25). The respondents assessed the items on a 1-5 scale (5 - very high, 4 - high, 3 - medium, 2 - low, 1 - very low).

After the pilot study and adjustment of the research tools, I performed the standardization of the three scales. I estimated the discriminatory power of the scale items in the three phases of the educational process for teachers and students separately (Brzeziński, 2002). Moreover, the results of assessment of didactic cooperation in each phase of the educational process were normalized through transformation into standard ten scales, for teachers and students separately.

The values of discriminatory power coefficients for each scale item in different phases of the educational process proved to be satisfactory and met the required criteria, both in the group of teachers and of students. The main study, carried out in the years 2011-2012, involved 1,166 students of pedagogy and 55 teachers from the University of Szczecin and University of Bialystok.

\section{Findings}

Didactic cooperation between teachers and students in the educational process is a system characterized by interrelated and interdependent phases and their elements. Therefore, the quality of didactic cooperation affects its level in the related phases of preparation, performance and control/evaluation (and their elements). So as to evaluate the quality of didactic cooperation between teachers and students in the educational process, I used an original research tool: SDCTS in the Preparation Phase, SDCTS in the Performance Phase and SDCTS in the Control/Evaluation Phase. The scales I have developed include 25 items corresponding to the indices of the quality of effects of didactic cooperation in each phase of the educational process and their 
elements, identical for teachers and for students. The respondent evaluates each of them in a 1-5 point scale. The score in each scale can be between 25 and 125 points. The indices of quality of the effects of didactic cooperation between teachers and students were designed so that a high total score would mean a high level of cooperation between teachers and students. The total assessment of the quality of didactic cooperation between teachers and students in each phase of the educational process includes the summative assessment of the goals of cooperation, the cooperating individuals, the modes, and the results of cooperation. Table 1 presents the numerical characteristics of the distribution of raw scores obtained in the scales by the respondents (teachers and students).

Table 1. Numerical characteristics of the distribution of raw scores in SDCTS in the: Preparation Phase, Performance Phase, and Control/Evaluation Phase obtained by students $(\mathrm{N}=1,166)$ and teachers $(\mathrm{N}=55)$

\begin{tabular}{ccccccccc}
\hline \multirow{2}{*}{ Scale } & $\begin{array}{c}\text { Respond- } \\
\text { ents }\end{array}$ & \multicolumn{6}{c}{\begin{tabular}{c} 
Numerical characteristics \\
\cline { 2 - 9 }
\end{tabular}} & of the distribution of raw scores \\
\hline $\begin{array}{c}\text { SDCTS } \\
\text { in the } \\
\text { Preparation Phase }\end{array}$ & Students & 78.9 & 85.0 & 79.0 & 33 & 122 & 14.0 & -0.43 \\
\cline { 2 - 9 } & Teachers & 84.1 & 89.0 & 85.0 & 58 & 111 & 12.8 & -0.38 \\
\hline $\begin{array}{c}\text { SDCTS } \\
\text { in the }\end{array}$ & Students & 85.3 & 85.5 & 85.0 & 39 & 124 & 14.3 & -0.01 \\
\cline { 2 - 9 } $\begin{array}{c}\text { Performance Phase } \\
\text { SDCTS }\end{array}$ & Teachers & 95.6 & 100.0 & 99.0 & 62 & 120 & 13.4 & -0.32 \\
\hline $\begin{array}{c}\text { SDCTn } \\
\text { in the Control/ } \\
\text { Evaluation Phase }\end{array}$ & Students & 82.4 & 88.5 & 83.0 & 37 & 123 & 14.4 & -0.42 \\
\cline { 2 - 9 } & Teachers & 92.2 & 101.5 & 94.0 & 60 & 112 & 13.6 & -0.68 \\
\hline
\end{tabular}

The analysis of the results of SDCTS in the Preparation Phase shows that the mean score obtained by students $(M=78.9)$ was lower than the score obtained by teachers $(M=84.1)$. Moreover, students' scores are slightly more diverse $(\mathrm{SD}=14.0)$ than teachers' scores $(\mathrm{SD}=12.8)$, from relatively very low to very high, and their range of variation is between 33 and 122 points (whereas teachers' scores vary from 58 to 111 points), which shows that in this group there are neither extremely low nor high assessments of didactic cooperation between teachers and students in the phase of preparation of the educational process. The dominant score is higher in the group of teachers $(D=89)$ than 
students $(\mathrm{D}=85)$. In both groups of respondents, the dominants are in the upper part of the series, near the medium values, and the distributions of raw scores are close to normal, with little left-side asymmetry, which proves that both among students and teachers slightly more respondents assessed didactic cooperation in the preparation phase higher than arithmetic means. Besides, the analyses show that the differences between arithmetic means of the assessments of the level of didactic cooperation expressed by students and teachers are statistically significant $\left(\mathrm{Z}_{\text {emp. }}=2.93, \mathrm{p}<0.01\right)$.

I observed an interesting distribution of raw scores in the SDCTS in the Performance Phase. In both groups arithmetic means of the assessments of the level of didactic cooperation between teachers and students are higher in this phase than in the phase of preparation of the educational process, and teachers assessed this phase significantly higher $(M=95.6)$ than students $(M=85.3)$. The variation of assessments by students $(\mathrm{SD}=14.3)$ and by teachers $(S D=13.4)$ is slightly higher than in the case of the preparation phase, but the range of variation is somewhat shifted upwards (towards higher assessments): from 39 to 124 points for students and from 62 to 120 points for teachers. The score of 85.8 is dominant among students' assessments of didactic cooperation in the performance phase; it is much lower than the score dominant among teachers (100.0). Just like in the preparation phase, both dominants are in the upper part of the series, close to the medium values. The distribution of scores in the group of students is very close to normal $\left(A_{s}=-0.01\right)$. The distribution of raw scores in the group of teachers is similar to normal, with slight left-side asymmetry $\left(A_{s}=-0.32\right)$, just like in the preparation phase, which means that slightly more teachers assessed didactic cooperation between teachers and students in the performance phase of the educational process higher than the arithmetic mean ( $M=95.6)$. The differences between arithmetic means of the assessments by teachers and by students are also statistically significant $\left(Z_{\text {emp. }}=5.55, \mathrm{p}<0.01\right)$.

Numerical characteristics of the raw scores obtained in the SDCTS in the Control/Evaluation Phase show that arithmetic means, both among students and among teachers, are lower than in the performance phase, but also higher than in the preparation phase of the educational process. The arithmetic mean of the assessments of the level of didactic cooperation between teachers and students in this phase is 82.4 for students, and just like in the previous phases, it is lower than the mean score of teachers $(M=92.2)$. In both studied groups the dispersion of scores from the arithmetic mean, i.e., the variation of assessments of the level of didactic cooperation between 
teachers and students, is relatively highest in the control/evaluation phase (as compared to the previous phases) and amounts to 14.4 for students and 13.6 for teachers. The range of variation of students' assessments is similar to the previous phases: from 37 to 123 , and in the case of teachers, from 60 to 112, like in the preparation phase. In addition, the analysis of the raw scores of assessments of didactic cooperation between teachers and students in the control/evaluation phase shows that in both studied groups the dominant values are the highest in comparison to the previous phases of the educational process. The dominant score among students is 88.5, which is lower than the dominant score among teachers, 101.5 Just like in the preparation and performance phases, both dominants are in the upper part of the series, farther from the medium values and towards high scores. Distributions of raw scores in both samples are close to normal, with slight left-side asymmetry $\left(A_{s}=-0.42\right)$ in the group of students and considerable left-side asymmetry $\left(A_{s}=-0.68\right)$ in the group of teachers. The values of asymmetry coefficient show that in both study samples, especially in the teachers' group, more respondents assessed didactic cooperation between teachers and students in the control/evaluation phase higher than the arithmetic means. The differences between teachers' and students' mean scores were also statistically significant $\left(\mathrm{Z}_{\text {emp. }}=5.20, p<0.01\right)$.

The analysis of numerical characteristics of the raw scores obtained by teachers and students in SDCTS in the Preparation Phase, SDCTS in the Performance Phase and SDCTS in the Control/Evaluation Phase leads to the following conclusions:

- $\quad$ the means of assessments of the level of didactic cooperation between teachers and students are lower in the group of students than in the group of teachers in all the phases of the educational process, and the differences between the means are very significant statistically;

- $\quad$ the highest arithmetic means of assessments of the level of didactic cooperation by teachers and students were in the phase of performance of the educational process, and the lowest in the preparation phase;

- $\quad$ the relatively highest variation of the assessments of the level of didactic cooperation (dispersion from the arithmetic mean) in both studied samples occurs in the phase of performance of the educational process, and relatively lowest in the preparation phase;

- distributions of raw scores of the assessments of didactic cooperation between teachers and students in each phase of the educational process 
are close to normal, with relatively highest left-side asymmetry of the assessments in preparation and control/evaluation phases (more assessments higher than the arithmetic mean) and lowest in the performance phase.

The results of assessment of the level of didactic cooperation between teachers and students expressed by the respondents in different phases of the educational process were normalized through transformation of the raw scores into a standard ten scale, where the scores of 1-4 are regarded as low, 5-6 as medium, and 7-10 as high. Raw scores obtained by students and teachers in each scale were transformed separately. In effect, the results obtained by teachers and students in SDCTS in the Preparation Phase, SDCTS in the Performance Phase and SDCTS in the Control/Evaluation Phase were interpreted at three levels: low, medium and high.

The analysis shows that the obtained distributions of assessments are close to normal and slightly flattened. There are minor differences between the assessments done by students and teachers. The general level of didactic cooperation in each phase of the educational process is assessed as medium by approximately $40 \%$ students and teachers, but about $30 \%$ of respondents from both groups express extreme assessments, high or low. The respondents assessed relatively lowest (as low or medium) the level of didactic cooperation in the preparation phase, and slightly higher in the other ones.

Determining three levels of assessment of didactic cooperation between teachers and students allowed me to identify groups of students and teachers who assess its level in different phases of the educational process as low (-DCTS), medium (DCTS) or high (+DCTS). Moreover, the findings prove that the level of cooperation between teachers and students in different phases of the educational process is characterized by the indices of quality of effects of didactic cooperation concerning its goals, cooperation between subjects (individuals), the modes and the results of cooperation. Therefore, analyzing partial assessments for statements concerning the above-mentioned specific variables of didactic cooperation between teachers and students will give us insight into the assessments by students and teachers who assessed the level of didactic cooperation as low, medium or high, and will also help recognize their components (Table 2). 
Table 2. Arithmetic means (M) of assessments of specific variables obtained by students (S) and teachers (T) assessing the level of didactic cooperation in each phase of the educational process as low (-DCTS), medium (DCTS) and high (+DCTS)*

\begin{tabular}{|c|c|c|c|c|c|c|c|}
\hline \multirow{3}{*}{$\begin{array}{l}\text { Phase of the } \\
\text { educational process }\end{array}$} & \multirow{3}{*}{$\begin{array}{l}\text { Elements } \\
\text { of didactic } \\
\text { cooperation }\end{array}$} & \multicolumn{6}{|c|}{ Arithmetic mean of assessments } \\
\hline & & \multicolumn{2}{|c|}{ - DCTS } & \multicolumn{2}{|c|}{ DCTS } & \multicolumn{2}{|c|}{$+D C T S$} \\
\hline & & $S$ & $\mathrm{~T}$ & $S$ & $\mathrm{~T}$ & $S$ & $\mathrm{~T}$ \\
\hline \multirow{4}{*}{ Preparation } & Goals of cooperation & 3.12 & 3.30 & 3.59 & 3.65 & 4.00 & 4.47 \\
\hline & $\begin{array}{l}\text { Cooperation between } \\
\text { subjects (individuals) }\end{array}$ & 2.92 & 2.78 & 3.44 & 3.13 & 3.93 & 4.07 \\
\hline & Modes of cooperation & 2.23 & 2.54 & 2.92 & 3.27 & 3.65 & 3.75 \\
\hline & Results of cooperation & 2.99 & 3.63 & 3.62 & 4.13 & 4.12 & 4.64 \\
\hline \multirow{4}{*}{ Performance } & Goals of cooperation & 2.80 & 3.21 & 3.37 & 3.60 & 3.91 & 4.22 \\
\hline & $\begin{array}{l}\text { Cooperation between } \\
\text { subjects (individuals) }\end{array}$ & 2.90 & 2.85 & 3.43 & 3.53 & 4.04 & 4.18 \\
\hline & Way of cooperation & 2.70 & 3.21 & 3.39 & 3.92 & 4.01 & 4.53 \\
\hline & Results of cooperation & 2.65 & 3.17 & 3.38 & 3.75 & 4.04 & 4.39 \\
\hline \multirow{4}{*}{ Control/Evaluation } & Goals of cooperation & 2.86 & 3.37 & 3.48 & 4.09 & 3.99 & 4.47 \\
\hline & $\begin{array}{l}\text { Cooperation between } \\
\text { subjects (individuals) }\end{array}$ & 2.66 & 2.82 & 3.30 & 3.41 & 3.94 & 3.95 \\
\hline & Way of cooperation & 2.56 & 3.04 & 3.25 & 3.79 & 3.95 & 4.38 \\
\hline & Results of cooperation & 2.51 & 2.78 & 3.22 & 3.65 & 3.93 & 4.05 \\
\hline
\end{tabular}

*the assessment was made on a 1-5 scale

The analysis of partial assessments within each level of assessment of didactic cooperation leads to the conclusion that students assessed the level of cooperation lower than teachers in nearly all its elements in each phase of the educational process. In the preparation phase of the educational process, regardless of the general assessment of the level of didactic cooperation (low, medium or high), both students and teachers assessed lowest the set of statements concerning the modes of didactic cooperation: in the case of students, the mean scores were 2.23, 2.92 and 3.65, respectively, and in the case of teachers $-2.54,3.27$ and 3.75. Teachers also assessed cooperation between subjects as very low (2.78, 3.13 and 4.07$)$.

In both groups, relatively highest assessments (especially assessing the general level of cooperation as medium or high) referred to statements concerning the results of cooperation: students' mean assessments were 3.62 and 4.12, and teachers' -4.13 and 4.67. 
Teachers' and students' assessments of the performance phase of the educational process differed. The group of students with the low general assessment of the level of didactic cooperation assessed lowest in this phase the set of statements referring to the results (2.65) and modes of cooperation (2.70), and the other groups, statements concerning the goals (3.37 and 3.91), but also the way of cooperation (3.39 and 4.01). Teachers, in turn, regardless of the general assessment of the level of didactic cooperation, in this phase assessed as relatively lowest the statements concerning cooperation between subjects (individuals): means 2.85, 3.53 and 4.18. However, in this phase all the students assessed relatively highest the statements concerning cooperation between subjects (individuals) - means: 2.90, 3.43 and 4.04, and teachers - the set of statements concerning the modes of cooperation 3.21, 3.92 and 4.53 .

In the phase of control/evaluation of the educational process, regardless of the general assessment of the level of cooperation, students assessed lowest the statements concerning the results (2.51, 3.22 and 3.93), but also the modes of cooperation (2.56, 3.25 and 3.95), and teachers assessed the set of statements concerning cooperation between subjects (individuals) as 2.82, 3.41 and 3.95. Both groups assessed relatively highest the statements concerning the goals of cooperation. The following conclusions can be drawn on the basis of the analyses:

- $\quad$ students assessed the level of didactic cooperation lower than teachers regarding nearly all its elements in each phase of the educational process;

- $\quad$ among the respondents, regardless of their general assessment of the level of cooperation in different phases of the educational process low, medium or high - there is relatively high consistency among students and among teachers in assessing relatively lowest and relatively highest the same elements of didactic cooperation between teachers and students (although it differs between the groups);

- $\quad$ in each phase of the educational process students assessed lowest the sets of statements concerning the modes, and often also the results, of cooperation, and teachers those statements referring to cooperation between subjects (individuals);

- students assessed relatively highest the statements concerning the goals of cooperation in the preparation phase and the control/evaluation phase, as well as cooperation between subjects (individuals), 
especially in the performance of the educational process, whereas for teachers it was those statements concerning the results of cooperation in the preparation phase, the modes and results of cooperation in the performance of the educational process, and goals of cooperation in the phase of control/evaluation of the educational process.

\section{Final remarks}

The findings of the research showed that it is necessary to improve the level of didactic cooperation and mutual assistance between the participants of the educational process, enabling and facilitating actions and activities in all its phases, because the achieved effects are interdependent, and they mutually determine the resultant quality of education. The level of didactic cooperation between teachers and students in the preparation of the educational process influences the quality of its effects in the phases of performance and control/evaluation; additionally, its level in the performance phase also influences the effects achieved in the control/evaluation phase. And due to the cyclical character of the phases of didactic cooperation system, if nothing changes, the quality of effects of control/evaluation determines the next preparation, performance etc.

The level of didactic cooperation in the educational process also depends on interrelated and mutually determined elements of the system, characterizing its phases. Relatively low or medium assessments of many elements of the system of didactic cooperation in each phase (especially in the group of students) lead to rather pessimistic conclusions. It is worth emphasizing that the level of didactic cooperation in each element of a phase is very important for the resultant quality of education, because the effects determine and influence one another.

Thus, the opportunities for improving the quality of education connected with didactic cooperation are not fully used yet; it is necessary to introduce some changes and make better use of the values of that non-economic factor. However, although didactic cooperation between teachers and students is important, it is just one of many determinants of the quality of education. Other factors, unrelated to academic circles, are also significant in this regard: financing higher education, the professional situation of university teachers, problems faced by graduates on the labor market, and many others. 


\section{References}

Barr, R.B., and Tagg, J. (1995). From Teaching to Learning: A New Paradigm for Undergraduate Education. Change, 27 (6), 13-25.

Blackie, M.A.L., Case, J.M., and Jawitz, J. (2010). Student-Centredness: The Link Between Transforming Students and Transforming Ourselves. Teaching in Higher Education, 15 (6), 637-646.

Brandes, D., and Ginnis, P. (1986). A Guide to Student Centred Learning. Oxford: Blackwell.

Brzeziński, J. (2002). Metodologia badań psychologicznych. Warszawa: Wydawnictwo Naukowe PWN.

Czarniawski, H. (2002). Współdziałanie potrzebq czasu. Lublin: „Norbertinum”.

Deutsch, M. (1949). A Theory of Cooperation and Competition. Human Relations, 2, $129-152$.

Falchikov, N. (2001). Learning Together: Peer Tutoring in Higher Education. London and New York: Routledge Falmer.

Griffin, E. (2003). Podstawy komunikacji społecznej. Translated by W. Kubiński, M. Kacmajor, Gdańsk: Gdańskie Wydawnictwo Psychologiczne.

Habermas, J. (1999). Teoria działania komunikacyjnego. Tom I. Racjonalność działania a racjonalność społeczna. Translated by A.M. Kaniowski, Warszawa: Wydawnictwo Naukowe PWN.

Johnson D.W., and Johnson, R.T. (1989). Cooperation and Competition: Theory and Research. Edina, MN: Interaction Book Company.

Johnson D.W., and Johnson, R.T. (2005). New Developments in Social Interdependence Theory. Genetic, Social, and General Psychology Monographs, 131 (4), 285-358.

Johnson D.W., and Johnson, R.T. (2009). An Educational Psychology Success Story: Social Interdependence Theory and Cooperative Learning. Educational Researcher, 38 (5), 365-379.

Johnson D.W., Johnson R.T., and Smith, K.A. (1998). Cooperative Learning Returns to College: What Evidence is there that it Works? Change, 30 (4), 26-35.

Karolczak-Biernacka, B. (1987). Współzawodnictwo i współpraca w szkole. Warszawa: WSiP.

Kember, D. (1997). A Reconceptualisation of the Research into University Academics' Conceptions of Teaching. Learning and Instruction, 7 (3), 255-275.

Kościelniak, M. (2004). Zrozumieć Rogersa. Studium koncepcji pedagogicznych Carla R. Rogersa. Kraków: Oficyna Wydawnicza „Impuls”.

Kotarbiński, T. (1975). Traktat o dobrej robocie. Wrocław: Ossolineum.

Krajewska, A. (2016). Współdziałanie dydaktyczne nauczycieli akademickich i studentów a jakość kształcenia na przykładzie studiów pedagogicznych. Białystok: Trans Humana.

Piaget, J. (1971). The Science of Education and the Psychology of the Child. Trans. D. Coltman, London: Longman.

Piaget, J. (1992). Mowa i myślenie dziecka. Warszawa: Wydawnictwo Naukowe PWN.

Pszczołowski, T. (1978). Mała encyklopedia prakseologii i teorii organizacji. Wrocław: Ossolineum. 
Retter, H. (2005). Komunikacja codzienna w pedagogice. Trans. M. Wojdak-Piątkowska, Gdańsk: Gdańskie Wydawnictwo Psychologiczne.

Rogers, C.R. (1983). Freedom to Learn for the 80s. Columbus, Ohio: Charles E. Merrill.

Sharan Y., and Sharan, S. (1992). Expanding Cooperative Learning Through Group Investigation. New York: Teacher's College Press.

Slavin, R.E. (1996). Research on Cooperative Learning and Achievement: What We Know, What We Need to Know. Contemporary Educational Psychology, 21 (1), 43-69.

Vygotsky, L.S. (1978). Mind in Society: The Development of Higher Psychological Processes. Cambridge, MA: Harvard University Press. 
PART III

Practices and Strategies 



\title{
Chapter 20
}

\section{A COOL Lab for Teacher Education}

\author{
Barbara Sabitzer*, Heike Demarle-Meusel ${ }^{* *}$, \\ and Christoph Painer* \\ * Johannes Kepler Universität Linz, Linz, Austria \\ ** Alpen-Adria-Universität Klagenfurt, Klagenfurt, Austria
}

\begin{abstract}
The COOL Lab is a meeting point for teaching, learning, research and practice, which mainly aims at fostering digital literacy and computational thinking as fundamental skills for everyone and enhancing teaching at all levels. In contrast to other learning or teaching labs the COOL Lab interlaces initial teacher education, in-service training, research and teaching practice with school practice in primary and secondary education. Every visitor can slip into the role of teachers, learners, developers or researchers and discover, apply or develop instructional technology, computer science techniques and concepts as well as cross-curricular teaching materials. The COOL Lab is partly developed from the Informatics Lab and the Teaching-Learning Lab implemented at the former university of one author, but goes further and brings together different labs and activities concerning teaching, learning, research or technologies. Following the neurodidactical teaching approach 'COOL Informatics', mainly the principle of cooperation including methods like peer teaching or talents exchange, is crucial for the success of the COOL Lab. This work-in-progress paper describes the development and implementation of the COOL Lab, its potentials and some use cases for different target groups.

KEYWORDs: $21^{\text {st }}$ century skills, computational thinking, digital literacy, innovative pedagogy
\end{abstract}

\section{Introduction}

At the beginning of the COOL Lab there was the claim for the integration of digital education and computational thinking in teacher education and

CONTACT Barbara Sabitzer, EMAIL: barbara.sabitzer@jku.at 
the demand for qualified staff in the field of computer science. COOL is an acronym for Cooperative Open Learning, Computer-(Science)-supported Open Learning as well as 'cool' in the sense of interesting, motivating, playful etc. (Sabitzer, 2014).

The COOL Lab is a meeting point for teaching, learning, research and practice, which mainly aims at fostering digital literacy and computational thinking as fundamental skills for everyone and enhancing teaching at all levels. In contrast to other learning or teaching labs the COOL Lab interlaces initial teacher education, in-service training, research and teaching practice in primary and secondary education. Everyone can slip into the role of teachers, learners, developers or researchers and discover, apply or develop instructional technology, computer science techniques and concepts (computational thinking) as well as innovative teaching methods and (cross-curricular) materials. The COOL Lab is partly developed from the Informatics Lab and the Teaching-Learning Lab implemented at the former university of one author, but goes further and brings together different labs and activities concerning teaching, learning, educational research and/or technologies. The didactical background of the lab is the neurodidactical teaching approach 'COOL Informatics', with four main principles (discovery, cooperation, individuality and activity), which are considered in lesson and task design. The COOL Lab prepares (future) teachers for the $21^{\text {st }}$ century and offers them additional possibilities for teaching practice (with or without technologies) and projects with partner schools. It supports teacher-students concerning innovative teaching methods and educational research as well as instructional technology and computational thinking. Mainly the principle of 'cooperation' including methods like peer teaching or talents exchange is crucial for the success of the COOL Lab.

This work-in-progress paper describes the development and implementation of the COOL Lab, its potentials as well as some use cases for teachers, teacher-students and pupils. Regarding the new Austrian curriculum 'Basic Digital Education' (including digital literacy and computational thinking), which became obligatory for lower secondary schools in autumn 2018, and the challenges of its implementation, our current research focuses on the question of how digital literacy and computational thinking can be integrated immediately and sustainably in teacher education and in-service training. 


\section{Theoretical background and related work}

The idea of using labs in teacher education in order to offer students opportunities for practice and to enhance their professional (didactical) competencies is not new. It can be traced back to John Dewey, who established the first laboratory school at the University of Chicago in 1896. He viewed his school as a laboratory for testing and verifying new educational theories and principles. In the laboratory school, teacher-students had the possibility to put theory into practice in an experimental setting and to modify theory by what is learned (Tanner, 1997). Since that time, many laboratories with different purposes have been implemented worldwide at universities. In the German speaking world the University of Kassel can be seen as a pioneer because of the set-up of the Grundschullabor, the first laboratory for primary teacher education, established in the 1970s. Actually, they offer fifteen laboratories with different purposes and for different subjects (Coelen and Müller-Naendrup, 2013; Schude, Bosse, and Klusmeyer, 2016). Since the 1980s several universities in German speaking countries have initiated laboratories for teacher education in different fields and with different concepts. They all have in common an open setting that allows self-organized, explorative and/or discovery learning, be it for children and adolescents, their respective school classes, or for teacher-students.

The role of the laboratories affiliated to universities is not uniform. Sometimes the focus lies on teaching practice for teacher-students as well as on their didactical and/or subject specific competences. Hence, these labs have names connected to subjects or school level such as the Grundschulwerkstatt (primary school lab) or the Lernwerkstatt Physik (learning lab physics) of the University of Kassel. Sometimes they are rather research labs or connected to extracurricular learning labs for children and/or adolescents that usually aim at increasing interest for the subjects in focus. This is the case e.g. in the Lehr-Lern-Labor Physik (Teaching-Learning-Lab Physics) at the Freie Universität Berlin (Dohrmann and Nordmeier, 2015) or the MIND Center (center for STEM-education) at the University of Würzburg (Völker and Trefzger, 2010).

Our COOL Lab, too, started from a lab for children, the Informatics-Lab at the Alpen-Adria University Klagenfurt, which initially only aimed at attracting pupils to computer science as well as at increasing subject-specific knowledge (Pasterk et al., 2016). In consequence, we extended it progressively to a Teaching-Learning-Lab, where teacher-students from 
all subjects can acquire additional teaching practice as well as digital competences (Demarle-Meusel, Sabitzer, and Sylle, 2017). With the change of one of the authors to the Johannes Kepler University Linz, both labs were adapted to regional needs and developed further concerning the topics on offer as well as didactical concepts and issues.

\section{The COOL Lab}

\section{About the COOL Lab}

The COOL Lab is an interdisciplinary teaching-learning-lab and research space that mainly aims at enhancing pedagogical, didactical and digital competences among (prospective) teachers. We offer the three key areas of teaching-learning labs mentioned by Coelen and Müller-Naendrup (2013). These include: teacher training, research and school practice - as well as a focus on digital literacy among students and teachers. Due to the origin, the Informatics Lab, we further focus on computational thinking as a fundamental skill for everyone, as demanded by Wing (2006), to prepare teachers of all subjects for the digital age with respect to, the $21^{\text {st }}$ century (Demarle-Meusel et al., 2017). We use computational thinking concepts and techniques in order to support teaching and learning in all subjects. And this is one of the features that make our COOL Lab unique and distinguish it from other labs for teacher education. The other important unique selling point is the combination and interlacing of teacher initial education and in-service training with school practice and regular lessons.

The COOL Lab is directed to different target groups - teachers, students and pupils of all subjects as well as other interested individual visitors of all ages - and therefore offers a broad range of varied activities, workshops, events etc. The main aims are as follows:

- $\quad$ integrating digital competences and computational thinking into initial teacher education in practice as well as in the curricula and

- $\quad$ enhancing didactical competencies of (prospective) teachers by offering them a framework for learning and trying innovative and effective teaching methods.

\section{Development of the COOL Lab}

The idea for a COOL Lab was born during the habilitation project of one of the authors who developed the didactical framework 'COOL Informatics', 
a neurodidactical teaching approach with the four main principles being discovery, cooperation, individuality and activity (Sabitzer, 2014). The COOL Lab in its current version (see Implementation) has been and is still being developed and implemented in several steps. The first two parts - the Informatics Lab for children and the Teaching-Learning-Lab for teacher-students - were already realized at the author's former university. Both labs started with the central aims of attracting children and adolescents for informatics and enhancing computational thinking and digital literacy among children and teachers of all subjects (Demarle-Meusel et al., 2017; Pasterk et al., 2016). Furthermore, students of teacher education programs get additional teaching practice in the Teaching-Learning-Lab and can enhance their didactical and pedagogical competences. The new COOL Lab at the Johannes Kepler University Linz, too, aims at enhancing computational thinking and digital literacy as well as pedagogical competences of future teachers, but it goes some steps further, which are related to local, national and international needs and demands. On the one hand, the COOL Lab wants to attract pupils and students not only for informatics but for all STEM subjects, which is a crucial demand of industry and enterprises in the region of Upper Austria due to the increasing skills shortage. To encounter the national lack of qualified staff mainly in the fields of sciences, technology and engineering, the COOL Lab offers different activities and events for children, adolescents, students and teachers with different backgrounds and for different purposes.

Besides this actual regional need the COOL Lab is engaged in activities helping to integrate digital literacy and computational thinking at school and in teacher education. This is the main focus of the school year 2018/2019 due to the current situation in Austria with the new compulsory curriculum Digitale Grundbildung (basic digital education) for all lower secondary schools (grades 5-8). The majority of the schools do not have enough qualified teachers or budget for the implementation of specific subjects, and therefore the contents of the curriculum will be integrated into several subjects and taught by teachers without an informatics background. And most of these teachers will need help and support at least in the first year. This is where the COOL Lab comes into play. We want to counter these problems with a combination of regular lessons, teacher education and in-service training. 


\section{Implementation}

\section{Framework}

The COOL Lab started in November 2017 and is integrated in the Department of STEM-Education at the School of Education, which is responsible for teacher education at the Johannes Kepler University Linz, Austria. All offers - workshops, events, in-service training, projects etc. - are free of charge for school classes. Not only the permanent staff of the department is involved in COOL Lab activities, but also student assistants, bachelor and master students as well as students of secondary schools, who accomplish projects or complete an internship during the summer holidays. The workshops and events for children are mainly conducted by student assistants who are financed by the university itself and in part through different thirdparty funds. They are supported by university students who get in contact with the COOL Lab in different master courses of teacher education as well as within the framework of the JKU Honors Program, a special program for gifted students of our university. These students are an important part of the COOL Lab staff, because they 'work' as co-teachers in our workshops in order to learn by doing and/or by teaching. In this way they get trained in computational thinking and enhance their pedagogical competences. On the other hand, these students bring their special skills into what the COOL Lab offers, so that participants can benefit from them.

In order to reach our goals and a broad audience we work together with regional and national stakeholders in the field of education as well as with national and international universities. For the success of the COOL Lab it is definitely necessary to build up a broad network of partners in different fields and levels, be it educational authorities, schools and teachers or universities and researchers. In Austria, in-service training of teachers is usually organized by university colleges of teacher education. That is why we closely cooperate with the two relevant institutions in Upper Austria as well as with eEducation Austria, an initiative of the Federal Ministry of Education, also responsible for teacher training concerning digital literacy. Furthermore we cooperate with the association Talente OÖ (Talents Upper Austria) in order to organize workshops and camps for gifted children and adolescents.

The four main principles of our neurodidactical approach to teaching and learning 'COOL Informatics' are not only implemented in what the COOL Lab offers, but also in the organizational level of the Lab. This is 
why cooperation on different levels and between different partners and target groups is of high priority.

Status Quo: Areas and activities of the COOL Lab

The COOL Lab consists of several areas that cannot be strictly separated because they are often interwoven. These areas include:

1. Digital Education \& Informatics

2. Teaching \& Learning

3. Sciences \& Technology (STEM )

4. Language(s) \& Communication

5. Research \& Practice

As mentioned above the main aims are bringing computational thinking and digital literacy to everyone as well as enhancing pedagogical and didactical competences of (prospective) teachers. Teacher-students of all subjects can gain additional (digital) teaching experiences in all offered workshops, clubs and events or develop innovative teaching materials in cooperation with staff and/or visitors of the COOL Lab. Hence, the two first areas cover a big part of the COOL Lab. They are interwoven with all others and therefore can have great importance for teacher education and in-service training.

\section{(1) Digital Education \& Informatics}

Under this focus, which has been developed from the original Informatics Lab, we offer several activities for different target groups (individual visitors and groups) and different purposes. The Informatics Lab, the Talents Club and the Mini Club for individual visitors aim at arousing and increasing interest in Informatics and other STEM subjects in order to counter the problem of skill shortage in these fields. Individual visitors can benefit from the following offers:

In the Informatics Lab (weekly during the school year) we work with children between 4 and 15 years in order to increase interest in computer science and to train computational thinking as early as possible. This may also help to increase the ability of problem-solving in general. This is an open lab where children can visit us once or twice a year or even every week depending on their interest and time. The Informatics Lab focuses on computer science (thinking) concepts and not so much on the use of computers with respect to digital literacy. Certainly, the children use computers 
and other devices in order to support learning and to create different learning products like web sites or blogs summarizing certain computer science topics or learning apps and quizzes.

The COOL Talents Club (age: 10-15 years) and the COOL Mini Club (age 7-10) focus on all STEM subjects and are open for gifted children, who work on cross-curricular and interdisciplinary projects and use technologies and computational thinking concepts in order to solve problems and create innovative products. The children build teams and visit us every two weeks during the school year for a total of eight meetings each. At the final event they present their projects and products to their parents and friends.

In the Summer Lab high school students older than 15 years can complete an internship of four weeks and learn more about technologies, develop sample solutions and/or hold workshops for younger children, who visit us during two weeks of the summer holidays.

For school classes we offer special workshops at the university or in the classroom in order to implement the new compulsory curriculum 'Basic Digital Education', and train or support at the same time (prospective) teachers with or without an informatics background to apply computational thinking. Most of the workshops are cross-curricular or interdisciplinary. We start from different topics, tasks or competences not related to informatics (e.g. designing and sewing a shirt, vocabulary learning in foreign languages or giving an overview of the French revolution) and connect them with steps and processes of computational thinking. This path from a general topic or from other subjects towards computational thinking is a very important issue in our work, because most of the non-informatics teachers firstly have to be convinced to integrate these contents into their lessons. And the best way of doing that is to show them the possible benefits for their own subjects. When they see that computational thinking methods or concepts are useful and supportive (e.g. modeling with diagrams as an effective learning strategy) for their daily work they are also willing to apply them in their lessons. In this way teachers and teacher-students (who are often involved as co-trainers) can 'kill two birds with one stone': they foster learning in their own subjects and teach computational thinking according to the curriculum at the same time.

\section{(2) Teaching \& Learning}

This area is the follow-up of the original Teaching-Learning Lab (see Development of the COOL Lab) and is mainly directed to students of teacher 
education programs on bachelor and master levels as well as to teachers of all subjects and school types in primary and secondary education. The main aims are the training and improvement of didactical, pedagogical and digital competences as well as providing additional opportunities for students to get more teaching practice and to learn by teaching. Teachers and teacher-students can discover, try and/or investigate innovative and effective teaching and learning methods and strategies as well as learn more about neurodidactics and brain-based teaching and learning. Schools in respect to their teachers can benefit from single offers e.g. booking only one workshop, or they can become a partner school of the COOL Lab with an individual package of measures and activities, which is specified in a written agreement.

Teaching and learning with regards to teacher education, in-service training and school practice are interwoven and everyone can learn from everybody. Hence, children and adolescents, too, can slip into the role of (co-)teachers or (peer-)tutors and develop teaching materials and sample solutions or support their teachers in classes of basic digital education. A best practice example for this interwoven teacher training is the Children's Congress, where cross-curricular projects are accomplished by teams consisting of one school class, one or two teachers of this class and two or three bachelor and master students of teacher education programs and/or computer science.

\section{Conclusion and outlook}

Demands from industry and economy for more specialists in the field of informatics needs innovative ways in order to fulfill them. The Austrian Ministry of Education set the legal framework with the obligate basic digital education for secondary level I. (BMBWF (Bundesministerium für Bildung, 2018) Now, schools are facing the challenge to meet the requirements. The COOL Lab is a support system for pupils, teachers, future teachers and other interested persons to foster abilities in digital education. It is designed with a flexible structure, which is an organizational challenge but offers maximum flexibility, also in its further development in the direction of a COOL Online Lab with international partners, target groups and activities. The COOL Lab is able to react fast to new requirements from the different stakeholders and hopes to get integrated permanently into initial teacher education in all subjects. This will be a lot of work for the core team 
of the Lab and certainly forms a strong foundation for our varied offers. But the key to success will be that the target groups themselves participate in an active and innovative way within the Lab.

\section{References}

BMBWF (Bundesministerium für Bildung, W. und F). (2018). DIGITALE GRUNDBILDUNG. In: Änderung der Verordnung über die Lehrpläne der Neuen Mittelschulen sowie der Verordnung über die Lehrpläne der allgemeinbildenden höheren Schulen. Retrieved May 14, 2018 from https://www. ris.bka.gv.at/Dokumente/BgblAuth/BGBLA_2018_II_71/BGBLA_2018 _II_71.pdfsig.

Coelen, H., and Müller-Naendrup, B. (2013). Studieren in Lernwerkstätten - Potentiale und Herausforderungen für die Lehrerbildung: Rücksicht-Einsicht-Aussicht. In: H. Coelen and B. Müller-Naendrup (Eds.), Studieren in Lernwerkstätten (pp. 9-17). Wiesbaden: Springer-Verlag.

Demarle-Meusel, H., Sabitzer, B., and Sylle, J. (2017). The Teaching-Learning-Lab: Digital Literacy and Computational Thinking for Everyone. In: CSEDU 2017 - Proceedings of the $9^{\text {th }}$ International Conference on Computer Supported Education (Vol. 2).

Dohrmann, R., and Nordmeier, V. (2015). Schülerlabore als Lehr-Lern-Labore (LLL): Ein Projekt zur forschungsorientierten Verknüpfung von Theorie und Praxis in der MINT-Lehrerbildung. PhyDid B-Didaktik Der Physik-Beiträge Zur DPG-Frühjahrstagung.

Pasterk, S., Sabitzer, B., Demarle-Meusel, H., and Bollin, A. (2016). Informatics-Lab: Attracting Primary School Pupils for Computer Science. In: Engineering Innovations for Global Sustainability: Proceedings of the 14th Latin American and Caribbean Conference for Engineering and Technology.

Sabitzer, B. (2014). A Neurodidactical Approach to Cooperative and Cross-curricular Open Learning: COOL Informatics. Habilitation thesis. Alpen-Adria-Universität Klagenfurt.

Sabitzer, B., and Demarle-Meusel, H. (2018). A Congress for Children and Computational Thinking for Everyone. In: WiPSCE $-13^{\text {th }}$ Workshop in Primary and Secondary Computing Education. Potsdam.

Schude, S., Bosse, D., and Klusmeyer, J. (2016). Studienwerkstätten in der Lehrerbildung: Theoriebasierte Praxislernorte an der Hochschule. Wiesbaden: Springer-Verlag. https://doi.org/10.1007/978-3-658-11697-2.

Tanner, L. (1997). Dewey's Laboratory School. Teachers College Press. Retrieved from https://books.google.at/books?id=Gro8DwAAQBAJ.

Völker, M., and Trefzger, T. (2010). Lehr-Lern-Labore zur Stärkung der universitären Lehramtsausbildung. PhyDid B-Didaktik Der Physik-Beiträge Zur DPG-Frühjahrstagung.

Wing, J.M. (2006). Computational Thinking. Communications of the ACM, 49 (3), 33-35. 


\title{
Chapter 21
}

\section{Intercultural Learning for Pupils and Teachers: A Good Practice Case Study from an Erasmus+ Project}

\author{
Elisa Briga \\ European Federation for Intercultural Learning, Brussels, Belgium
}

\begin{abstract}
This good practice case study presents how the Erasmus+ project 'Intercultural Learning for Pupils and Teachers' has addressed the need of fostering intercultural competence among school pupils, starting with developing the intercultural competence of teachers. The project was implemented in four countries (Belgium, France, Germany and Italy) and the partnership gathered experts in the field of intercultural learning from the non-formal education and pupil exchange sector, and representatives from the school sector such as teachers and school heads. Following a thorough definition of intercultural competence and the evidence that this is best developed through experiential learning methods, the project partnership has created a three-day teacher training on intercultural competence and a Toolbox of activities aimed at intercultural learning which educators can include in the school curricula. The objectives, content and impact of these outputs are described, together with suggestions for improvement and policy recommendations.
\end{abstract}

KEYWORDS: intercultural competence, experiential learning, teacher training, whole school approach

CONTACT Elisa Briga, EMAIL: elisa.briga@afs.org 


\section{Introduction}

This good practice case study presents how the Erasmus+ project 'Intercultural Learning for Pupils and Teachers ${ }^{11}$ has addressed the need of fostering intercultural learning among school pupils, starting with developing the intercultural competence of teachers. This objective is in line with several policies adopted at European level in the field of education, such as the Declaration on promoting citizenship and the common values of freedom, tolerance and non-discrimination through education released by the European Union Education Ministers in 2015. ${ }^{2}$

\section{Definition of intercultural competence}

Intercultural competence is understood as the ability to mobilise and deploy relevant attitudes, skills and knowledge in order to interact effectively and appropriately in different intercultural situations (Deardoff, 2009). Intercultural competence includes:

- $\quad$ no prescriptive solutions for 'specific cultures';

- $\quad$ recognition and appreciation of one's own and others' multiplicities and how they come into play in different situations;

- $\quad$ focusing on preparing for the unexpected, careful perception and dealing with uncertainty;

- $\quad$ readiness to deal with difference in an ethno-relative manner;

Intercultural competence is acquired through a lifelong learning process and is best developed through conscious, planned and facilitated experiential learning (Kolb, 1984). In fact, exposure to and interaction with people of different cultural affiliations does not imply, let alone guarantee, intercultural learning (Amir, 1998). So far, the non-formal education sector has the strongest experience in facilitating the educational process which results in the development of intercultural competence.

As intercultural competence is best developed through experiential learning, the project identified that training is key to equipping teachers with the skills to facilitate experiential activities aimed at fostering

1 The project was run by the European Federation for Intercultural Learning from October 2016 to November 2018 and was funded by the Erasmus+ National Agency of the French speaking community of Belgium, AEF Europe. More information at www.intercultural-learning.eu.

2 http://ec.europa.eu/dgs/education_culture/repository/education/news/2015/documents/citizenship-education-declaration_en.pdf 
intercultural learning in schools. As the Kolb cycle ${ }^{3}$ (Kolb, 1984) is understood only when experienced directly, the training was designed to make teachers go through an experiential learning cycle and therefore develop their own intercultural competence by taking part in some of the activities they would then deliver to pupils.

\section{Project design}

The project has the following objectives and each one corresponds to a specific output:

1) develop teacher trainings for the promotion and assessment of intercultural competence within upper secondary education, fostering the understanding of the benefits of teachers' and pupils' mobility for Intercultural Learning (ICL)and internationalisation of classrooms and schools;

2) develop and test a holistic approach for promotion and assessment of intercultural competence within upper secondary education, combining mobility experiences with in-class learning, and building on the expertise of non-formal education organisations;

3) encourage policy reform aimed at the inclusion of ICL in teachers' lifelong learning;

4) encourage policy reforms aimed at the inclusion of ICL in school curricula, also through the recognition of the pupil's study period abroad in long-term intercultural exchange programmes.

In order to reach these objectives, the European Federation for Intercultural Learning-(EFIL) ${ }^{4}$ has put together a project partnership which provides expertise, geographical coverage and involvement of different stakeholders. The focus is on four countries, namely France, Belgium, Italy and Germany, thanks to the involvement of organisations related to AFS Intercultural Programs (InterCultur Germany, Fondazione Intercultura, Italy, AFS Programmes Interculturels, Belgium, AFS Vivre Sans Frontičre, France). The

3 The Kolb cycle is the Experiential Learning cycle, which is considered an on-going process grounded in reflection that is continuously modified by new experiences. The cycle begins when an individual engages in an activity, reflects on his or her experience, then derives meaning from the reflection, and finally, puts into action the newly gained insight through a change in behavior or attitude.

4 The European Federation for Intercultural Learning is the federation of AFS Intercultural Programs organisations in Europe and the Mediterranean, www.afs.efil.org. 
stakeholders involved a range of non formal education providers such as AFS and the French-German Youth Office, schools and teachers (Lycée Faure in Tournon sur Rhône, Ecole Internationale Le Verseau, Bierges), and school principals represented by the European School Heads Association. Since European networks are also involved, the outreach goes far beyond the four countries in its focus. In order to ensure impact and outreach, the project cooperated closely with the worldwide network of AFS Intercultural Programs, and builds links with other similar Erasmus+ projects.

Within the first year of the project, the focus was on the first two objectives. The programme of a three-day teacher training on intercultural competence was developed, together with a Toolbox of activities aimed at intercultural learning which educators can include in the school curricula.

The key principles at the foundation of the teacher training and the Toolbox include:

- $\quad$ a sound definition of intercultural competence;

- a whole-school approach, namely involving all stakeholders - teachers, students, parents, NGOs, the community - in the activities organised (NESET II, 2016, p. 28);

- $\quad$ the promotion of active citizenship and volunteering, and cooperation with local NGOs;

- $\quad$ the assumption that intercultural competence can only be promoted through a comprehensive pedagogical project based on experiential learning methods , not a one-off activity;

- $\quad$ a feedback culture between students and teachers (eg. visual evaluations);

- reference to national school curricula, in order to see how intercultural competence fits in the existing framework provided by Ministries of Education.

The Toolbox is divided into four sections, namely: 'Whole-school Approach', 'Cross Curricular', 'Subject Related', and 'International Mobility', which are labels for the different situations within the school programme where the activity can be implemented.

Each section has approximately ten activities, and within the section there are three activities which are highlighted at the top. Each activity has learning objectives defined and matches one or more aspects of intercultural competence defined in a grid based on the framework of Competences 
for Democratic Culture by the Council of Europe (Barrett et al., 2016). ${ }^{5}$ All activities are available in English, French, German and Italian.

The three-day teacher training has the following set of learning outcomes:

1. be aware and able to present their own intercultural experiences and enhance their intercultural competence;

2. be able to link intercultural education theories to observed behaviours;

3. be aware about mobility opportunities for themselves and for the students and how to valorize them;

4. be able to assess the intercultural competence of pupils;

5. be empowered to implement the whole-school approach linked to ICL in a systemic approach;

6. be able to navigate existing resources;

7. be able to create modules on ICL linked to specific curricula and across curricula.

\section{Project implementation}

In August 2017, sixteen trainers (multipliers) from eleven countries (Germany, Italy, France, Belgium, Spain, Poland, Turkey, Brazil, the Netherlands, Czech Republic and Slovenia) attended the teacher training designed within the project, with the aim of getting prepared to offer it to teachers in their local context. The training was complemented with modules which provided tools to pass on the acquired intercultural competence to teachers using experiential learning methods, and adapt the training concept to the national school-system and to the needs of the teachers attending.

Even though the training foresees a three day agenda, it can easily be adapted to fit into two days by covering some modules with online learning, before and after. As a preparatory task beforehand, teachers need to fill in a Questionnaire on the intercultural dimension of the school, ${ }^{6}$ together with the school principal, and reflect on a critical incident related to meeting a different culture. The compulsory parts of the training are the following sessions:

- $\quad$ My Intercultural self;

- Intercultural education and schools;

- Intercultural education: goals, process, tools, assessment;

https://www.coe.int/en/web/education/competences-for-democratic-culture http://intercultural-learning.eu/Portfolio-Item/self-assessment-questionnaire/ 
- Planning intercultural activities on the basis of the needs of the school identified in the questionnaire, and with the support of existing resources, eg. the Toolbox developed by the project.

After the training, trainers supported teachers in creating a plan to include intercultural learning in their lessons and the overall activities of the school, and feedback their lessons plans. In fact the teachers, after having attended the training, need to:

- $\quad$ Implement at least three activities from the Toolbox;

- $\quad$ Reach at least twenty students with the activities;

- $\quad$ Try to implement one activity that supports the whole-school approach and involve at least two other stakeholders (teachers, school administrative staff, non-formal education providers, parents, local associations, etc.).

In order to monitor quality and receive feedback, standard evaluation questionnaires were filled in by the multipliers and by the teachers attending the local trainings. Moreover, after having attended the training, teachers implemented some of the activities as mentioned above, and submitted a report providing comments on the Toolbox and on their piloting experience, including the impressions gathered from the students through the visual evaluations done after each of the activities.

\section{Project evaluation}

Until August 2018, fifteen trainings took place in four countries, namely Germany (3), France (2), Belgium - Wallonia (1) and Italy (9). In total, 212 teachers participated.

Out of 212 teachers, 144 filled out the online survey evaluating the teacher training they had attended. The online survey was provided in three different languages: French, Italian and German (participants always had the possibility to answer in English as well). The evaluation questionnaire included fifteen items related to what they learned from the training modules, the duration of the training, the methods used by the trainers (communication style, clearness of content), and the applicability of the knowledge and tools to their work as teachers. The participants were asked to evaluate each item by using a 5-point Likert scale. In addition, the participants were also asked to provide any other comments/suggestions for follow-up. 
The results showed very clearly that the teacher training developed by the project mostly fulfilled expectations of the participating teachers $(M=4.30)$, was very well designed methodologically and structurally $(M=4.70)$, that teachers gained new knowledge and experienced something new and helpful during the training $(M=4.20)$, and that their understanding of the topic of intercultural learning was enhanced $(M=4.20)$. The applicability of the seminar contents to teachers' working environments was rated with an average of $59.7 \%$, and the applicability of the material of the Toolbox to their everyday work was rated with an average of $64.7 \%$.

Below are presented some of the participants' comments on the strengths of the training, the aspects to improve and the concrete learning they took away from this experience:

- $\quad$ The training was interesting and useful, I find that some activities, for instance, "Who are I" can be used at the beginning of every new school year to widen students self-awareness and to help them to improve relations among students in the class;

- I have learnt that I can plan activities for next year with a different perspective;

- $\quad$ I'll take with me a new awareness: I can apply what I have learnt in my everyday work;

- $\quad$ Provocative activities can produce better understanding among people;

- I have learned new and practical methods to create a good learning environment in my class (non-formal education);

- I I have learned about my own communication/learning/teaching styles;

- $\quad$ I left the seminar enriched and changed.

The theoretical models presented in the training in their simplicity yet comprehensibility (iceberg model, onion model of culture, cultural triangle) were perceived as very helpful and illuminative. But the main positive feedback referred to the power of the different activities in the Toolbox to foster a change of attitude and intercultural learning within the students. Having the possibility to experience many different activities by themselves and to understand the positive effect of experiential learning approaches was highly appreciated by the teachers.

From the survey results it is clear that the training contents (theoretical elements as well as practical elements) were perceived as helpful, wisely combined and clear to follow. Methods and activities facilitated by the multipliers were inspiring to teachers and the self-reflection moments seemed to 
have had the awareness-effect the project team wished for. Teachers asked that the user-friendliness be improved by allowing a search by competence in the online Toolbox, which is now provided. Moreover they suggested there should be more time to try out the Toolbox activities. However, at the same time teachers asked that the training not to be too long, preferably one day, as they cannot take time off from school. In order for the training to be effective, time needs to be dedicated to experiential learning, which requires a group of people to spend time together, in-person. Some sessions of the training which focus on knowledge could be provided through online learning. For project partners it has been difficult to recruit teachers due to the length of the training. A key factor for ensuring that teachers attend the training is to have it officially recognised by institutions so teachers can receive permission and credits for attending, and also encourage schools leadership to promote trainings that are longer than one day.

The trainers experienced that providing the training to a group of teachers from the same school is the most effective approach. In fact, it provides the opportunity for creating a community of practice and for planning organisational change together, and truly implementing the whole-school approach to intercultural learning. Another factor for success from the perspective of the trainers was their own ability to use experiential learning methods: only if trainers are confident in using these, can the learning objective be achieved and for the teachers it becomes clear how to use this new method.

The questionnaire about the implementation of the Toolbox was filled in by 131 teachers out of 212. Those 131 teachers reached 3633 pupils by delivering in their class activities from the Toolbox.

The Toolbox mostly fulfilled the expectations of the teachers $(M=4.30)$, although one critical point was the user-friendliness of the online Toolbox (see survey results above). Teachers rated the Toolbox as a valuable support to improve intercultural learning $(M=4.40)$ and that they nearly all reached their teaching goals with the activities they conducted in class. The Toolbox material seems not as easy to adapt for their individual needs, however $(M=3.95)$. This was underlined by the questions regarding the applicability of the Toolbox to teachers' classes, which was rated with an average of $56.3 \%$, and the applicability of the intercultural approach in school-life, rated with an average of $61 \%$. One reason might be that intercultural learning is not an integral part of most school curricula and ICL topics need to be adjusted to fit lesson plans. It was conspicuous that the item "I could 
convince colleagues to work with the Toolbox" was in each country the lowest rating in all surveys $(M=3.40)$. This strengthens our argument that intercultural learning should be integrated into school curricula to ensure its transfer in all school activities and by all teachers (whole-school approach).

Some teachers also gave the feedback that they feel insecure in facilitating experiential learning methods even though instructions, debriefing questions and tips are provided in the Toolbox. In fact, teachers were often surprised about the motivation and enthusiasm these methods triggered in the students and needed guidance on how to deal with this new energy. If teachers could learn and implement the methodology and didactics of intercultural learning during their initial teacher training they would be more self-confident in managing these types of activities.

In discussion rounds and oral feedback sessions with the teachers a common critical remark was that their schedules and lesson plans are too full and that they have practically no time for activities that are not explicitly part of the curriculum. In fact, intercultural learning may be found as a transversal competence or implicitly in other competences, but is not a specific or explicit learning goal named comprehensively in school curricula. Since most of the Toolbox activities and intercultural theories are time consuming, it seems to be difficult to include them in curricular classroom activities.

Given the fact that the teachers who participated in the trainings gave very good feedback on the training, its methods and approaches, the main obstacles to using the Toolbox (apart from technical issues) might be as follows:

1) the subject teachers teach (it is probably easier for a social sciences teacher to use the material than for a nature science teacher),

2) the teaching hours a teacher has in one class,

3) the lack of support from other teachers or school heads,

4) a high number of pupils nowadays in classrooms that might not speak the language of communication properly: since most of the Toolbox activities require a good understanding of the spoken language this might be a factor for the adaptability of activities as well.

The survey results showed that the Toolbox provides activities which are useful for teachers to promote intercultural learning in schools. A key aspect for success and outreach of the Toolbox is that it needs to be available in the language of instruction used by teachers, therefore further translation efforts would be needed in order to reach teachers in other countries. 


\section{Conclusions and further steps}

In conclusion, besides teachers' and school heads' willingness to foster intercultural learning, a change on policy level needs to take place: intercultural learning and the practice of experiential learning methods should be integrated in teachers' initial training and should be promoted and supported officially in teachers' continuous professional development. Also, mobility experience for teachers would contribute to strengthening the intercultural competence of teachers and therefore their ability to plan intercultural learning activities. At the same time, intercultural learning should be mentioned more clearly as an objective in school curricula, in order to give the indication that this is a fundamental competence to be developed, across the subjects and through a whole-school approach. The Toolbox and the training can be helpful tools to support this policy process.

The next step for the project is ensuring sustainability by implementing the teacher trainings regularly through the efforts of project partners, and inform policy by providing an overview and related recommendations on teacher and student training on intercultural competence around Europe, within different education systems, and including the possibilities of international mobility.

\section{Acknowledgements}

The Erasmus+ project consortium: Kristien Adriaenssen (Ecole Internationale Le Verseau ELCE, Bierges), Flaminia Bizzarri (Fondazione Intercultura), Marie-Catherine Châtelier (Lycée Gabriel Faure, Tournon sur Rhône), Marie Dossogne (AFS Programmes Intercultures), Dominique Granoux (French-German Youth Office), Wiebke Hoffmann (InterCultur), Noémie Pagan (AFS Vivre Sans Frontiére), Fred Verboon (European School Heads Association).

\section{References}

Amir, Y. (1998). Contact Hypothesis in Ethnic Relations. In: E. Weiner (Ed.), The Handbook of Interethnic Coexistence (pp. 162-181). New York: Continuum Publishing.

Barrett, M. et al. (2016). Competences for Democratic Culture: Living Together as Equals in Culturally Diverse Democratic Societies. Council of Europe Publishing. Retrieved August 31, 2018 from https://rm.coe.int/16806ccc07.

Deardorff, D.K. (2009). The SAGE Book of Intercultural Competence. Los AngelesLondon-New Delhi-Singapore-Washington DC: Sage. 
Kolb, D.A. (1984). Experiential Learning: Experience as the Source of Learning and Development. Englewood Cliffs: Prentice Hall.

NESET II. (2016). Education Policies to Foster Tolerance in Children and Young People in the EU. Luxembourg: Publications Office of the European Union. Retrieved August 31, 2018 from http://ec.europa.eu/dgs/education_culture/ repository/education/library/study/2016/neset-education-tolerance-2016_en.pdf. 


\title{
Chapter 22
}

\section{A Restorative Approach to Address Cyber Bullying}

\author{
Roelof Petrus Reyneke
}

Department of Social Work, University of the Free State, South-Africa

\begin{abstract}
Bullying leads to trauma experiences. In many instances, bullies are victims of bullying and/or other traumatic experiences. Neuroscience has shown that this negatively influences the brain and leads to discipline problems. The fight, flight or freeze response associated with trauma, influences the behaviour of the victims as well as the bully. Most adults use a punitive approach to try and change this negative behaviour. Unfortunately, this usually exacerbates the problem. In this paper the restorative practices approach is explained as an alternative to address bullying and cyber bullying. The difference between a punitive and a restorative approach to wrongdoing is explained. In a restorative approach, the focus is on fixing the harm caused by the transgressor and teaching socially acceptable behaviour in a non-punitive manner. The restorative practices model that consist of different levels of intervention is explained within the context of cyber bullying. The model provides guidelines for a whole school approach to preventing deviant behaviour such as cyber bullying. KEYWORDS: cyber bullying, restorative justice, restorative practices, resilience, emotional intelligence
\end{abstract}

\section{Introduction}

Interpersonal trauma in children can lead to depression, post-traumatic stress, anxiety, anger, dissociation and aggression. Adding to this some of the negative effects of bullying include problems with psychosocial adjustment, a higher risk of criminal behaviour, dropping out of school, sexual harassment, health problems, delinquency, drug use and academic problems 
(Penning, Bhagwanjee, and Govender, 2010, pp. 132-133). Research has also indicated that a victim of bullying could become a bully when still in school (O'Brien and Moules, 2013, p. 58) but also in later life in his/ her work and family environment. Bullying and victimisation can result because of trauma or post-traumatic stress disorder (Penning, Bhagwanjee, and Govender, 2010, p. 134). Trauma experiences in the community could therefore result in bully behaviour and bully behaviour could also lead to trauma.

The aim of this article is to explain how the restorative practices approach could be used as an alternative way to address bullying and cyber bullying. A short overview will be provided on how neuroscience provides some insight on what happens when a person experiences the traumatic effects of bullying. This will be followed by the introduction of the concept of restorative practices after which the restorative discipline model will be used to explain how bullying and cyber bullying could be managed in a school environment. The article ends with a few recommendations for schools on how the restorative approach could contribute to help prevent cyber bullying and discipline problems in general.

\section{Bullying and neuroscience}

Bullying is a form of aggressive behaviour with the aim of hurting another person. There is also a power imbalance between the bully and the victim. The victim is not in a position to protect him/herself and the behaviour is repetitive (Smith, 2016, p. 519). Repetitive stressful events such as being bullied are related to symptom-clusters of ongoing trauma. Traditionally bullying is experienced as physical, face to face violence towards a person, however since the development of technology, bullying has evolved. Social media has become a preferred method of social interaction between people and consequently also the method of choice for many bullies to get to their victims. Although the method has changed, the results are still the same.

Victims experience serious emotional and psychological problems due to the constant aggression and humiliation experienced. What makes it even worse is that in many instances the bullies are anonymous and the victims do not know who is targeting them (O’Brien and Moules, 2013, pp. 54-55). Feeling unsafe even when you are not in the direct vicinity of the bully can constantly create a stress response. The constant experience of being targeted could then lead to toxic stress that could change the architecture of 
the brain in early childhood development. This could lead to the stress-response system to become overly sensitive to stressors or perceived stressors. The result can be conduct problems, impulsivity, lack of attention in class, hyperactivity and antisocial behaviour (Blitz and Lee, 2015, p. 23).

There is a strong relationship between bullying and trauma, and so is the correlation between victims and depression. A study by Penning, Bhagwanjee, and Govender (2010, p. 131) found that 22.4\% of their participants could be clinically and sub-clinically diagnosed with posttraumatic stress and $21 \%$ with disassociation. Victims have a higher level of stress, anxiety, illness and depression with a higher likelihood of committing suicide (Morrison, 2002, p. 1).

Intense emotions such as the emotions associated with being bullied will activate the limbic system, specifically the areas called the amygdala and the hippocampus. The function of the amygdala determines if a situation, person or stimulus is threatening and to warn the person of possible danger. The hippocampus will then link the fear response to the context in which this response of the amygdala occurred (National Scientific Council on the Developing Child, 2010, pp. 2-3). Studies have shown that when a traumatised person is presented with images, sounds and thoughts that are related to their particular traumatic experience, the amygdala is triggered. This will then activate the body's stress response, unleashing stress hormones such as cortisol and adrenalin that will increase heart rate, blood pressure and oxygen intake, preparing the person for fight, flight or freeze. Brain research has shown that when a person experiences images of past trauma, the left hemisphere of the brain is deactivated and the right side of the brain is activated. The right side of the brain accommodates the emotional, visual, intuitive, spacial and tactual functions of the brain whereas the left side houses the linguistic, sequential and analytical parts of the brain (National Scientific Council on the Developing Child, 2010; van der Kolk, 2014).

The traumatised person's capacity to think rationally is consequently decreased and the emotional, and sometimes irrational, responses increase. The victim or the bully-victim will also not be able to effectively deal with facts and statistics, and language will also be impaired. This means that when a person experiences the trauma of being bullied, s/he will not be able to fully take part in academic activities in the classroom, and since the fight, flight or freeze response is also activated, behavioural problems might be experienced. Using a punitive discipline system will also exacerbate the 
problem since it will keep on activating the limbic system (amygdala and hippocampus) which will continue to stimulate the stress response. This can add to the understanding of why bullying has a direct impact on school performance (Betts, Spenser, and Gardner, 2017, p. 472).

It is also important to consider the fact that victims of cyber bullying are under constant stress since their social life revolves around their online presence. If they stop using the internet and/or their mobile phones, they risk losing their connection with their peers. Unfortunately when going online or accessing their phones they are again vulnerable to the bully. So it is clear that the stress is unrelenting and will continue as long as the person is using technology and the bully keeps on attacking his/her victim. Although many of these attacks do not necessarily take place in the school (O'Brien and Moules, 2013, p. 55), it has to be managed to ensure the psychological and academic wellbeing of the learner. Different discipline methods could be used to do this.

\section{The difference between a punitive and a restorative approach}

Traditionally schools use a punitive response to discipline learners. This response will focus on identifying the possible perpetrator, determining which rule was broken, deciding who is to blame, and then concluding with identifying a punishment. Forms of punishment could include the removal from class, isolation from the rest of the class, detention, removal of privileges, group punishment, humiliation, yelling, shouting and sometimes even caning in some countries (Thorsborne and Blood, 2013). Psychological and/or physical pain is thus used to deter the wrongdoer and the rest of the school community from breaking the rule again.

The restorative approach uses a different strategy when it comes to dealing with discipline problems. A primary focus of the restorative justice philosophy is to build and restore relationships that have been tarnished through the misbehaviour, showing respect and seeking to repair the harm that occurred by taking responsibility for what happened and taking steps to making things as right as possible (see Table 1) (Teasley, 2014, p. 132; Thorsborne and Blood, 2013). 
Table 1. Differences between a punitive and a restorative approach when dealing with bullying

\begin{tabular}{lll}
\hline $\begin{array}{l}\text { Basic discipline } \\
\text { principle to be } \\
\text { considered }\end{array}$ & $\begin{array}{l}\text { Punishment instils a narrow } \\
\text { and selfish way of thinking } \\
\text { in a perpetrator. In his mind, } \\
\text { the focus is on himself and } \\
\text { not the victim and self-pro- } \\
\text { tection kicks in. Blame and } \\
\text { guilt is established. }\end{array}$ & $\begin{array}{l}\text { Restorative is about making amends and think- } \\
\text { ing about how the behaviour impacted other } \\
\text { people, respecting that person and ultimately } \\
\text { taking responsibility for his/her actions. The } \\
\text { perpetrator is not the focus anymore, the victim } \\
\text { becomes the focus. Focus on problem solving by } \\
\text { expressing feelings and needs. }\end{array}$ \\
\hline $\begin{array}{ll}\text { Infraction } \\
\text { Physical bullying } \\
\text { of younger } \\
\text { learners }\end{array}$ & $\begin{array}{l}\text { Detention, having privi- } \\
\text { leges removed, demerit } \\
\text { points, chores }\end{array}$ & $\begin{array}{l}\text { Reading to younger learners, supporting teachers } \\
\text { in their programs e.g. helping them with soccer } \\
\text { training. }\end{array}$ \\
\hline $\begin{array}{l}\text { Cyber bullying } \\
\text { Detention, having privi- } \\
\text { leges removed, demerit } \\
\text { points, chores, suspend } \\
\text { use of phone and access to } \\
\text { computer at school. }\end{array}$ & $\begin{array}{l}\text { Contribute to a school newsletter on how cyber } \\
\text { bullying damages relationships. Do a research } \\
\text { paper on the consequences of bullying and cyber } \\
\text { bullying. Apologise to victim and make amends. }\end{array}$ \\
\hline
\end{tabular}

Source: Ashley and Burke, 2009, p. 7

As can be seen from Table 1, the restorative philosophy differs significantly from the punitive approach. It should be emphasised that there are always natural consequences in a restorative approach; it is not a soft approach in which perpetrators receives a pass because there is no direct physical or emotional pain inflicted by a higher power. The biggest difference is that the concept of punishment is not used and there is joint participation in determining the consequences for being disrespectful towards someone else. The process of getting to these consequences are described in the mediation process that usually follows (Figure 2, below).

\section{Restorative practices as a framework to manage bullying and the trauma experienced by victims of bullying}

When working within the restorative justice philosophy it would be essential to understand the philosophy as well as having tools that support this way of thinking and doing. The restorative model provides a conceptual framework for understanding the different levels of intervention and it also offers some guidelines on specific techniques and other theories and models that support a restorative school environment. 


\section{Restorative discipline model}

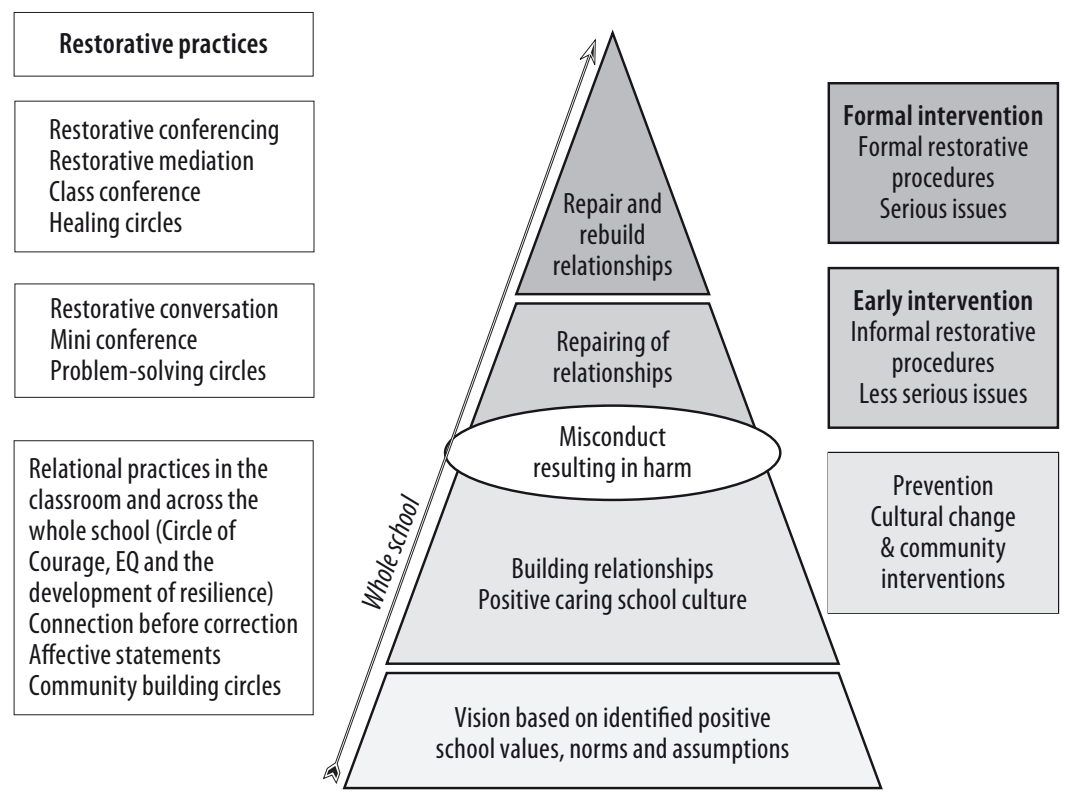

Figure 1. Restorative discipline model

Source: Reyneke and Reyneke, 2017

\section{The restorative model}

According to Thorsborne and Blood (2013, p. 19) restorative practice is:

the practice of restorative justice, a philosophical approach to crime and wrongdoing that puts harm done, accountability for that harm by the wrongdoer, and repair of that harm at the centre of the problem-solving, involving the stakeholders in the matter.

While working in schools that use a retributive approach to discipline, it has become abundantly clear that this discipline approach does not have the desired impact that is needed to have a disciplined environment where learners can excel in their academic work, especially when there is a high incidence of trauma amongst learners; it actually creates more behavioural problems. When considering the described developments in neuroscience, it becomes abundantly clear that a punitive environment creates stress and that learners who have been traumatised by their environment are not 
capable of dealing effectively with teachers that are authoritarian, sometimes disrespectful, and not caring enough to support learners in crisis.

Morrison, Blood and Thorsborne (2005) developed a basic restorative practices model. This model was adapted and further developed to provide a restorative discipline model that is currently used to conceptualise restorative practices and specifically restorative discipline in some South African schools (Reyneke and Reyneke, 2017).

This model basically consists of four levels, beginning with the foundational point of departure that in order to develop a caring school community, schools have to cultivate a positive climate that is informed by the school culture. A positive school climate will also decrease the levels of school violence (Barnes, Brynard, and De Wet, 2012, p. 69).

\section{Level 1: School values, norms and assumptions}

Changing the culture starts with the identification of positive school values and norms and by reviewing the assumptions of the school governing body (SGB), school management and teachers concerning their views of learners, especially the ones with discipline problems, as well as current discipline practices and the educational philosophy practiced at the school. This will then inform the subsequent levels of intervention (Hellriegel et al., 2004, p. 357).

\section{Level 2: Prevention}

In terms of the time spent on the implementation of the restorative practices model, most of it should be spent on programs and actions that focus on changing the culture of the school and making it a safe and caring environment. The successful implementation of this model will result in the prevention of misconduct in the classroom as well as violence such as bullying.

School bullying is a predictor for future criminal behaviour and thus prevention programs can in the long term benefit the community at large as well as the school environment (Morrison, 2002, p. 1; Ttofi, Farrington, and Lösel, 2011. p. 81). It should also be considered that schools have an obligation to prevent bully behaviour since Article 1 (1) (c) of the South African Children's act, no 38 of 2005 (Republic of South Africa, 2005) identifies one of the areas of abuse of a child as bullying by another child. It does not differentiate between cyber bullying and ordinary face-to-face bullying. One of the problems with cyber bullying is that it is not always easy to identify the perpetrator, so it is not always known who to work 
with and who should take responsibility for the harm caused (Lauren and Ratliffe, 2011, p. 103). This is why the opinion is held that the best way to deal with cyber bullying is to prevent this from happening in the first place.

Furthermore, it is known that the online bully's conduct harms others that are not in a position to protect themselves. The victims suffer emotional harm, fear and anxiety, humiliation, short-term grief and other psychological problems (Langos, 2012, p. 300). It is thus safe to say that their stress response will be activated and the fight, flight or freeze reaction will be identifiable through their behaviour. It is also notable that most cyber bullies are victims of bullying themselves (Brack and Caltabiano, 2014) and because they are victims, they will be hurting. Programs that will tend to the needs of both victims and bullies need to be adopted.

In order to prevent bullying and other discipline problems, programs that focus on healthy interpersonal relationships should be developed (Yadav and Yadav, 2018). This could include teaching socially appropriate behaviour through the promotion of value (values-level), community building activities (circles) (Costello, Wachtel, and Wachtel, 2009), specific programs such as the development of emotional intelligence (Lomas et al., 2012), management of disputes in a restorative manner (Basar and Akan, 2013, p. 29), improved communication (Green, Johnstone, and Lambert, 2013, p. 454), shame management (Morrison, 2002, p. 2) and the development of resilience (Mampane and Bouwer, 2011). For the purpose of this article resilience, emotional intelligence and shame management will be highlighted.

In order to understand how to develop resilience, the Circle of Courage model may be useful. This model covers four basic human needs, namely belonging, mastery, independence and generosity (Brendtro et al., 2005, p. 102). Belonging refers to a strong need to belong to something or someone. When children are connected to the school, they will be more receptive to learning and being guided by authority figures (Kline, 2016, p. 100). Mastery speaks to what should happen in the school environment in order for a learner to feel that s/he has become proficient in what they are doing in the environment. When guided by a caring adult, learners feel more competent and motivated to achieve. However, when achievement is not experienced, troubled behaviour could surface through signs of helplessness and inferiority (Brendtro, Brokenleg, and van Bockern, 2002, p. 49). Children experience independence when they have power over their own behaviour and their environment and are able to cope with challenges and make responsible decisions. They thus demonstrate an internal locus of control and intrinsic motivation 
(Brendtro, Brokenleg, and van Bockern, 2014). The last element of the circle is generosity. This refers to being generous, unselfish and empathetic. Not only could troubled youth improve their self-worth when they help others, they could also experience that they have a purpose in life (Brendtro et al., 2002, p. 45; Brendtro et al., 2005, p. 102). As part of preventative as well as early intervention strategies, restorative practitioners will develop a culture that in essence will focus on the development of resilience and more specifically the self-image of learners. Developing the self-esteem of learners is important, since learners with a high self-esteem score low on bullying behaviour (Idemudia, 2013, p. 5208).

People are social beings and children need human contact to fully develop their social skills. Our current culture is moving away from this personal contact to the use of impersonal technology (Brokenleg, 2015, p. 17). This does not contribute to the development of emotionally intelligent people since people are not learning how to recognise other people's feelings and how to communicate effectively with them. It therefore becomes more difficult to develop satisfying interpersonal relationships with others (Vengertsev, 2014). In an effort to change this culture of disconnection, restorative practices are creating learning environments where people can connect with each other on a deeper level. Circles and relationship-building is crucial in preventing conflict and poor interpersonal relationships and forms part of the restorative interventions. Diversity training should be considered as part of the development of emotional intelligence. This is particularly important since bullying shows elements of discrimination. In such a program, power imbalances and social inequalities should be attended to (Novick, 2013, pp. 22-23). Schools in South Africa are becoming more diverse, not just in relation to population and cultural groups but also with regard to other factors such as family composition, religion, socioeconomic lines etc. This training should be linked to the basic human rights of people as indicated in the Constitution (Republic of South Africa, 1996).

According to Idemudia (2013, p. 5215) bullies tend to be extroverts and are not always aware of their own feelings and behaviour; they have narcissistic, impulsive traits and also show conduct problems. As part of the prevention strategy, emotional intelligence training can help children to deal effectively with shame and the emotions that go hand in hand with the shame response. Learners have to be helped to become aware of their emotions, acknowledge them and then act on them in a socially appropriate manner (Morrison, 2002, p. 3; Vengertsev, 2014). 
Shame can be conceptualised as: "an individual's social thermostat, mediating the state of social relationships” (Morrison, 2002, p. 2). Generally people experience the feeling of shame when they behave improperly to what is commonly expected by their community of support (family, school, etc.) and that community becomes aware of this. Victims of bullying experience shame when the bully places content on social media or makes degrading comments about the victim where the community can notice this. In dealing with the perpetrator, a punitive approach is usually to try to shame the person so that the behaviour is not repeated. However, when shame is not dealt with effectively, it could be expressed in anger (ibid.). In the restorative approach the perpetrator has the opportunity to take responsibility and repair the wrongdoing (see Figure 1, above), and the shame is acknowledged and discharged. In this process the connection with the community will stay intact. This contributes to the learner's feeling of belonging to the community. When using a punitive approach to discipline, learners do not have the opportunity to make amends and discard the shame feeling. If this then leads to anger, the perpetrator will continue with socially unacceptable behaviour and bullying will not be prevented. On the other hand this could also explain why victims of bullying become bullies themselves, as their shame is not dealt with effectively and then they retaliate in anger towards others.

Teachers play an important role in the prevention of discipline problems in schools. Restorative practices propose some programs and training to empower teachers. It is suggested that teachers should be supported with knowledge and skills on how to improve class management, the consistent enforcement of discipline (teaching socially acceptable behaviour), clear guidelines for conduct (values), negotiating consequences for misconduct and improving the quality of teaching. Teachers should also be made aware of the need to be less authoritarian, not to attempt to change behaviour through intimidation and punishment and not to role-model aggressive and demeaning behaviour since this teaches learners to bully others (De Wet, 2012, p. 239).

\section{Level 3: Early intervention}

Early intervention starts when there has been misconduct. Usually this is less serious conduct that can range from failing to comply with rules, calling people names, using foul language, not doing homework, etc. One of the main aims of early intervention is to prevent less serious discipline problems from progressing to serious behaviour problems like violence, criminal behaviour and in this case, bully behaviour. 
There are different techniques that can be used on this level. Methods include restorative conversations, mini-conferences and problem-solving circles (Thorsborne and Blood, 2013). A restorative conversation usually focuses on answering the restorative questions, namely: what happened, who was affected by your behaviour, what can be done to make things right and how can we make sure that this does not happen again? A mini-conference will also answer these questions but both the victim and the perpetrator will be involved in the process. This process is explained in Figure 2 and in the discussion on formal interventions (Hansberry, 2009; Jansen and Matla, 2011).

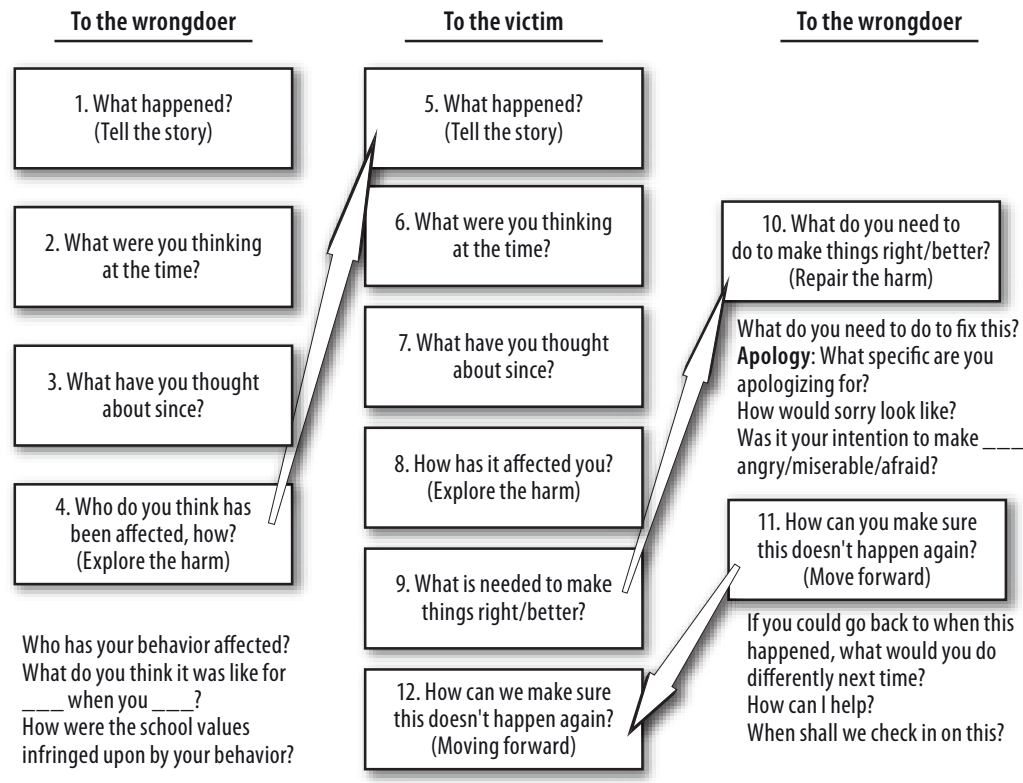

Figure 2. Restorative mediation

Source: Hansberry, 2009; Jansen and Matla, 2011

\section{Level 4: Formal intervention}

When working on the formal intervention level there is a clear indication that the learner has committed a serious offence and that the learner probably has serious psychosocial and other issues. Interventions include healing circles, class conferences, restorative mediation and restorative conferences, and the services of professionals such as social workers and psychologists (Costello et al., 2009; Costello, Wachtel, and Wachtel, 2010; Thorsborne and Blood, 2013). 
A restorative conference is a formal conference where everybody that was affected by the wrongdoing gets together to look for ways of solving the consequences of the wrongdoing. This process is usually facilitated by a trained mediator although the same process could also be used for minor infractions where it is facilitated by a teacher or a peer mediator (Ashley and Burke, 2009, p. 14). The main focus of this conference is to determine what happened, who was affected by the wrongdoing, how were these people affected, to decide what can be done to make things right and how can it be ensured that this behaviour is not repeated (Costello, Wachtel, and Wachtel, 2009). In Figure 2 (above) it is explained how this process is managed. It shows how the bully is being provided with the opportunity to tell his/ her side of the story. The facilitator then goes further to probe the thinking behind the incident and then starts the process of exploring the harm. Then the focus changes to the experiences of the victim, who is provided with the opportunity to answer the same questions. The main difference is that the victim is provided with the opportunity to explain to the bully how his/ her behaviour has affected the victim. In a full conference, people near the victim could also provide some insight on how the bullying impacted on the victim. Thereafter the focus moves to making things better. First the victim and his/her support system are provided with the opportunity to make some contributions to solving the problem, after which the perpetrator and his/her support system can provide some input. After negotiating what the consequences should be, the facilitator moves towards working on preventing the problem from happening again. This might include actions like ensuring psychosocial help for the perpetrator or ensuring that the underlying reasons for the bully behaviour receives professional attention (Hansberry, 2009; Jansen and Matla, 2011). This will also include some support for the victim.

On this level learners with psychological and social problems are also provided with professional help that includes psychological treatment and services by social workers and other professionals (Idemudia, 2013). This can also consist of programs in anger management, social skills training and mediation between the perpetrator and the victim (Dawson and McHugh, 2006, p. 269).

\section{Recommendations}

With the previous discussion in mind the following recommendations are made: 
- Schools should follow a whole school approach to discipline problems - using the restorative model. This can contribute to the prevention of cyber bullying.

- $\quad$ Prevention programs focussing on the development of resilience, emotional intelligence and conflict resolution should be part of the services provided at schools.

- Training and further development of teachers is a necessity. They should be trained in restorative practices and how to deal with learners that are bullies as well as the victims of bullying.

- $\quad$ The School governing body should consider infusing the restorative practices model and the restorative justice philosophy into the governing policies of the school.

\section{Conclusion}

Cyber bullying creates toxic stress in the bodies of victims. If this is not dealt with in a timely way, it can create irreparable harm to the brain as well as contribute to 'acting out' behaviour. Restorative practices can assist in the creation of a safe and respectful environment. This whole-school approach can also help prevent and eradicate the problems that are associated with cyber bullying. Prevention, early intervention and formal intervention strategies can save lives and ensure justice for the victims of cyber bullying.

\section{Acknowledgements}

Participation in the ATEE 2018 Spring Conference was partly funded by VLIR UOS.

\section{References}

Ashley, J., and Burke, K. (2009). Implimenting Restorative Justice: A Guide for Schools. Chicago: Illinois Criminal Justice Information Authority.

Barnes, K., Brynard, S., and De Wet, C. (2012). The Influence of School Culture and School Climate on Violence in Schools of the Eastern Cape Province. South African Journal of Education, 32, 69-82.

Basar, M., and Akan, D. (2013). Assessment of Class Teachers’ Dispute Resolution Applications in Conflict Environments on the Basis of Restorative Justice. International Journal of Academic Research, 5 (5), 26-30. 
Betts, L.R., Spenser, K.A., and Gardner, S.E. (2017). Adolescents’ Involvement in Cyber Bullying and Perceptions of School: The Importance of Perceived Peer Acceptance for Female Adolescents. Sex Roles, 77 (7-8), 471-481.

Blitz, L.V., and Lee, Y. (2015). Trauma-Informed Methods to Enhance School-Based Bullying Prevention Initiatives: An Emerging Model. Journal of Aggression, Maltreatment and Trauma, 24 (1), 20-40.

Brack, K., and Caltabiano, N. (2014). Cyberbullying and Self-Esteem in Australian Adults. Cyberpsychology: Journal of Psychosocial Research on Cyberspace, 8 (2), article 7.

Brendtro, L.K., Brokenleg, M., and van Bockern, S. (2002). Reclaiming Youth at Risk. Bloomington: Solution Tree.

Brendtro, L.K., Brokenleg, M., and van Bockern, S. (2014). Environments Where Children Thrive: the Circle of Courage Model. Reclaiming Children and Youth, 23 (3), 10-16.

Brokenleg, M. (2015). Growing Your Own Kids Today. Reclaiming Children and Youth, 23 (4), 15-19.

Costello, B., Wachtel, J., and Wachtel, T. (2009). The Restorative Practices Handbook for Teachers, Disciplinarians And Administrators (Kindle). Bethlehem: International Institute for Restorative Practices. Retrieved June 10, 2018 from www. amazon.com.

Costello, B., Wachtel, J., and Wachtel, T. (2010). Restorative Circles in Schools: Building Community and Enhancing Learning (Kindle). Bethlehem: International Institute for Restorative Practices.

Dawson, N., and McHugh, B. (2006). Commentary - A systemic Response to SchoolBased Violence from a UK Perspective. Journal of Family Therapy, 28 (3), 267-271.

De Wet, C. (2012). Risk Factors for Educator-Targeted Bullying: A Social-Ecological Perspective. Journal of Psychology in Africa, 22 (2), 239-244.

Green, S., Johnstone, G., and Lambert, C. (2013). What Harm, Whose Justice?: Excavating the Restorative Movement. Contemporary Justice Review: Issues in Criminal, Social, and Restorative Justice, 16 (4), 445-460.

Hansberry, B. (2009). Working Restoratively in Schools. Victoria: Inyahead.

Hellriegel, D., Jackson, S.E., Slocum, J., Staude, G., Amos, T., Klopper, H.B., and Oosthuizen, T. (2004). Management (Second Edition). Cape Town: Oxford University Press.

Idemudia, S. (2013). EPQ and Self-esteem Scores of Male and Female Bullies in Mafikeng Schools, South Africa. Gender and Behaviour, 11 (1), 5208-5219.

Jansen, G., and Matla, R. (2011). Restorative Practice: a Change of Heart. Wellington: Restorative Schools.

Kline, D.M.S. (2016). Can Restorative Practices Help to Reduce Disparities in School Discipline Data? A Review of the Literature. Multicultural Perspectives, 18 (2), 97-102.

Langos, C. (2012). Responding to Cyberbullying: The Case for Family Conferencing. Deakin Law Review, 28 (4), 213-220.

Lauren, M., and Ratliffe, K.T. (2011). Cyber Worlds: New Playgrounds for Bullying. Computers in the Schools, 28 (2), 92-116. 
Lomas, J., Stough, C., Hansen, K., and Downey, L. A. (2012). Brief Report: Emotional Intelligence, Victimisation and Bullying in Adolescents. Journal of Adolescence, 35 (1), 207-211.

Mampane, R., and Bouwer, C. (2011). The Influence of Township Schools on the Resilience of Their Learners. South African Journal of Education, 31, 114-126.

Morrison, B. (2002). Bullying and Victimisation in Schools: A Restorative Justice Approach (Trends and Issues in Crime and Criminal Justice). Canberra: Australian Institute of Criminology.

Morrison, B., Blood, P., and Thorsborne, M. (2005). Practicing Restorative Justice in School Communities : the Challenge of Culture Change. Public Organization Review: a Global Journal, 5, 335-357.

National Scientific Council on the Developing Child. (2010). Persistent Fear and Anxiety Can Affect Young Children's Learning and Development (No. Working paper 9). Retrieved June 10, 2018 from http://www.developingchild.net.

Novick, R. M. (2013). Compelling Reasons to Battle Bullying and Lessons From The Field. Journal of Social Distress and the Homeless, 22 (1), 22-34.

O’Brien, N., and Moules, T. (2013). Not Sticks and Stones but Tweets and Texts: Findings From a National Cyberbullying Project. Pastoral Care in Education, 31 (1), 53-65.

Penning, S.L., Bhagwanjee, A., and Govender, K. (2010). Bullying Boys: the Traumatic Effects of Bullying in Male Adolescent Learners. Journal of Child and Adolescent Mental Health, 22 (2), 131-143.

Republic of South Africa. Constitution of the Republic of South Africa, Pub. L. No. No. 108 of 1996, 230 Cape Town 1241 (1996). South Africa.

Republic of South Africa. Children's Act, No. 38 of 2005, Pub. L. No. 38 of 2005 (2005). Republic of South Africa: Government Printers.

Reyneke, R.P., and Reyneke, J.M. (2017). Implimentation of Restorative Practices. In: Restoring the Dignity of Mathematics Learners Through Quality Teaching and Learning. Port Elizabeth: AMESA.

Smith, P.K. (2016). Bullying: Definition, Types, Causes, Consequences and Intervention. Social and Personality Psychology Compass, 9, 519-532.

Teasley, M.L. (2014). Shifting from Zero Tolerance to Restorative Justice in Schools. National Association of Social Workers, 36 (3), 131-133.

Thorsborne, M., and Blood, P. (2013). Implimenting Restorative Practices in Schools: a Practical Guide to Transforming School Communities (Kindle). London: Jessica Kingsley Publishers.

Ttofi, M.M., Farrington, D.P., and Lösel, F. (2011). The Predictive Efficiency of School Bullying Versus Later Offending: A Systematic/Meta-Analytic Review of Longitudinal Studies. Criminal Behaviour and Mental Health, 21, 80-89.

van der Kolk, B. (2014). The Body Keeps the Score: Mind, Brain and Body in the Transformation of Trauma (Kindle). New York: Viking.

Vengertsev, D. (2014). Emotional Intelligence Explained (Kindle). Retrieved June 10, 2018 from www.amazon.com.

Yadav, M., and Yadav, R. (2018). Impact of Spirituality/Religiousness on Cyber Bullying and Victimization in University Students: Mediating Effect of Emotional Intelligence. Journal of Religion and Health, 57 (5), 1961-1979. 


\title{
Chapter 23
}

\section{Motivational Strategies of Local and Foreign Students: Socio-Cultural Commonalities and Differences}

\author{
Julia Kazakova \\ Elabuga Institute of Kazan Federal University, Kazan, Russia
}

\begin{abstract}
This paper examines the commonalities and differences in the formation of intrinsic motivation of local and foreign students based on their sociocultural background. Previous research indicated that motivation has an important effect on academic achievement and is an integral component of educational and instructional processes (Awan, Noureen, and Naz, 2011, pp. 72-79). The article describes the psychological process in interaction with social and cultural environments and may serve as a tool for teachers to support developmental strategies. The sample consisted of 107 students from the Kazan Federal University (56\% Russians, $44 \%$ foreign). Psychological questionnaires were used not only to rate the importance and frequency of different motivational strategies but also to understand the contrasts in internal goals for achievement in students, and to rate the importance and frequency of different motivational strategies. As teachers need to focus more attention on shaping students' goals and influencing their internal motivation, they must identify effective motivational methods which balance between foreign and local students and make this contrast in motivating factors relatively neutral. Motivated studies result in high-quality learning and conceptual understanding, as well as enhanced personal growth and adjustment.

KEYWORDS: foreign students, international education, internal motivation
\end{abstract}

\section{Introduction}

A foreign student is not only an element of the social system that created him or her, but this student also represents a most complex structured system (Benet-Martínez, Lee, and Leu, 2006; King and McInerney, 2016, p. 386).

CONTACT Julia Kazakova, EMAIL: kazakova696@gmail.com 
Every personality reflects the social institutes and systems of accepted standards and values in which she or he was formed (Inkeles, 2017; Kazakova, 2015, pp. 780-784). That is, any personality represents a fruit of this or that culture, bringing and developing the presumed stereotypes (Larsen et al., 2017; McCrae et al., 2013, p. 831). Thus, it is important to examine the sociocultural background and motivational strategies of foreign students in modern higher education institutions both in the context of the interpersonal relations and cultural norms, and in the context of educational processes (Jamaludin, Sam and Sandal, 2018; Wilson et al., 2017, p. 1475).

Foreign students acquire the values of their new sociocultural environment (Church, 2000, p. 651); they have to establish social contacts (Wright and Schartner, 2013, pp. 113-128), overcome a language barrier (Dörnyei, 2006; Shastina, Gizatullina and Sibgatullina, 2017, p. 158) and integrate into a new society (Benet-Martínez, Lee, and Leu, 2006, p.388). Their success in educational activity has to do with the social environment of the higher institution and the stimulation of their intellectual activity (Bakadorova and Raufelder, 2014, p. 348). It is very important for teachers to consider the specifics of their sociocultural adaptation and their psychological and individual features (Mahmood and Beach, 2018, p. 295).

Several models shape the educational concept of sociocultural differences in formation of motivation and foreign language motivation in particular. These basic theories include the theory of integrative motivation introduced during the social-psychological period, by Gardner and Lambert (1972); attribution theory and its implications for task persistence and goal attainment as developed by Weiner (2005), and the self-determination theory with its categories of intrinsic and extrinsic motivation developed during the cognitive-situated period, by Ryan and Deci (Ryan and Deci, 2000, p. 58). In this work, I am talking mainly about the third theory.

Teachers believe motivation is important to student learning (Ormrod, 2010; Raufelder et al., 2013; Thoonen et al., 2011, p. 170). As such, methods they employ to address student motivation may prove ineffective (Matteson, Swarthout, and Zientek, 2011, p. 290). Foreign students have higher values and educational motives at the initial stages of education (during their first two years of study) (Csikszentmihalyi, 2014). They are willing to master a profession and obtain a diploma, so they develop quite dynamically (Zhou, 2015, p. 730). In their attempt to maintain emotional balance as they start getting involved in the new sociocultural environment, they lean on what is called the "less unknown" (Jamaludin, Sam, and Sandal, 2018; Shafaei, 
Nejati, and Abd Razak, 2018, p. 45), and thus they enter the educational process willingly, to compensate for all the 'unknown' surrounding them (Gu, Schweisfurth, and Day, 2010, p. 16).

It is pertinent to point out that motivational strategies decline across the transition from junior to senior high school (Rjosk et al., 2015; Kyndt et al., 2015, p. 1171). In addition, identified, introjected and external motivation also decline over time (Otis, Grouzet, and Pelletier, 2005, p. 170). Motivation also remains as one substantial aspect that influences the different stages of foreign language acquisition (O’Reilly, Ryan, and Hickey, 2010, p. 594). Thus, language teaching should result in the students understanding the foreign culture and acquiring positive attitudes to, and acceptance of, the speakers of the foreign language and their cultures (Shastina et al., 2018, p. 158).

The idea of summing up the experience and carrying out research into the topic came after the author noticed a certain difference between the ways first-year students get motivated, either highly or not at all. Recently, there have been many changes in the general conception of Russian universities, which due to the globalization of studies naturally leads to having more international students all around the country (Minina, 2017, p. 180). The percentage of ethnic minorities among students at the Kazan Federal University has grown rapidly lately. In addition, the difference between local and foreign students seems somehow very contrastive at some points. It also gives an idea of how different their concepts of life and study are.

Although there is huge research into the topic of motivational strategies of students, we still see the necessity to describe some peculiarities and possible differences of the process in a certain region of Russia. The main aim of the research is to see what differences and commonalities local and foreign students have between their motivational strategies. My main hypothesis is that foreign students from Eastern countries like Uzbekistan, Turkmenia, Tadzhikistan, etc. tend to develop successful motivational strategies more easily than those students living in the area (or in the region).

\section{Method}

\section{Participants}

The participants of the research were first-year students at the Foreign Languages Department of the Elabuga Institute of Kazan Federal University (Russian Federation). The sample consisted of 107 students, aged between 
18 and 20 (male $=37.4 \%$; female $=62.6 \%$; standard deviation 0.9 ). The choice of age was not a random result; it was based on the existent curriculum and the most obvious difference between first-year students (freshers). The differentiation by gender is related to the specifics of the educational specialty.

There were local and foreign students respectively. Distribution of students according to nationality is presented in detail in Table 1.

Table 1. Distribution of students by nationality (\%)

\begin{tabular}{lcc}
\hline \multirow{2}{*}{ Nationality } & Number of students of Foreign Languages Department \\
\cline { 2 - 3 } & Frequency & Percentage (\%) \\
\hline Russians & 60 & 56 \\
\hline Uzbeks & 12 & 11.2 \\
\hline Turkmens & 22 & 20.6 \\
\hline Tajiks & 13 & 12.2 \\
\hline
\end{tabular}

All participants of the research understood its purpose and program. All points regarding the ethics of the study were agreed upon.

\section{Research approach and procedure}

A qualitative case study paradigm was used in order to explore the motivational strategies and socialcultural aspects related to foreign students. The qualitative approach was chosen because of its focus on meaning as it is understood in the context of participants' life experiences inside and outside of the lecture theatre (Creswell et al., 2007; Phillips and Schweisfurth, 2014, p. 239).

To clarify the motivation of the students in the classroom, the first part of the Rean technique was applied (Rean and Yakunin, 2014, p. 61). Interviews and psychological questionnaires were used to understand the contrasts in internal goals for achievement in students, and to rate importance and frequency of different motivational strategies.

Rean and Yakunin's technique has advanced the most comprehensive model of self-determination motives for human development in the fields of personality psychology and education. This also refers to intrinsic regulation, which means doing the activity for the inherent satisfaction of the activity itself. One can note that the experience of self-determination might slightly differ in various cultural settings (Chirkov et al., 2003). Thus, for example, self-determined motivation for studying a second language 
negatively predicted students' anxiety, but positively predicted their intention to continue studying (Noels et al., 2000).

The above-mentioned theorists have posited the nature of family relations as explanatory factors in personal development and educational achievement. Thus, most interviews were used to measure family relations, which reflect the degree to which family members are perceived to be involved in the educational environment. As the curriculum for first year-students comprises such topics as 'Family. Relations', 'House and Home', 'Professions and Occupations', it helps a teacher to know some information about the ethnic and socioeconomic status their students had prior to student life.

Each unit lasted for 6 weeks.

The students were interviewed during their first year of study, all through the semesters (2016-2017). They usually had three special English conversational classes a week, which comprised a half of their six scheduled English lessons weekly. Their tutors were responsible for the results of the questionnaires, both for receiving them and summing up. A certain number of events and incidents provoked research assisted by the professional psychologists of the university.

The questionnaires consisted of the following questions:

- How many are you in the family?

- How many brothers/sisters do you have?

- What do your parents do?

- Who earns in your family?

- Describe your family relationships.

- $\quad$ Describe your childhood (youth).

- How do you usually spend weekends with your family?

- How would you describe relations with your parents?

- $\quad$ Are you home-sick (for foreigners)?

- What were your favourite places in your native city?

- What do you usually do in your spare time?

- What are your favourite sports?

- $\quad$ Do you go in for any sports?

- What film would you advise your friends to see?

- What university lessons do you like best?

- What do you plan to do after graduation?

- Do your parents support your choice? 
These are just a few of the questions; students were asked with the purpose of enriching their vocabulary and lexical skills.

Most qualitative interviews were held in the lessons, when students answered questions about their family structure, and made up dialogues and situations about what their life used to be like before they went to university. The students were given from one up to four minutes to answer each question.

As a result of each study unit, the teacher delivered a final diagnostic test, during which students had an individual talk with their tutor and were supposed to revise all the studied material by answering a list of questions on the topic. Thus they gave their tutor a chance to sum up their experience and analyze it. All answer sheets turned out to be relevant. The standard error was $\pm 4 \%$. Statistical data analysis was carried out with the IBM SPSS Statistics 22 within one week.

\section{Results}

Research results showed that foreign students are well motivated by different factors which externally appear to present better conditions than those they have in their native towns. While most local students do not feel homesickness and loneliness from their families, they are more easily motivated by some intrinsic factors like developing important skills for future social roles or feeling the moral need to do so as recompense for parents' support.

$63 \%$ of foreign students claim that they are home-sick and the absence of relatives prevents them from focusing on formation of motivation, 14\% of students complain that they lack their habitual way of life and conditions, and $23 \%$ of students cannot formulate the exact reason. At the same time, $45 \%$ of local students consider that support of relatives and feeling at home allows them to feel motivated, $21 \%$ consider that an opportunity to lead their most convenient life and maintain normal conditions has direct influence on their motivation, while $36 \%$ do not even try to examine the reasons for their motivation.

Being more often motivated by the factors within themselves, local students get engaged in school activities because they also feel ethically obliged to study, as all their surroundings, parents, relatives and most people know what kind of job they have to do and build great expectations upon that. Foreign students, in comparison, feel far from home and may lose this moral link to study well and achieve the necessary results. However, the 
sociocultural context they come from forms the inner aspects of their reality and external motivation turns into internal motivation. Foreign students upon the whole tend to exhibit more educational outcomes because their motivation is built upon sociocultural sources and has enough stimulating methods from the outside to motivate them positively.

$56 \%$ of local students responded that obligations in their family and fear of disappointing their relatives serves as their best motivation to study well. 19\% of respondents connect good marks with great professional opportunities in the future. $17 \%$ of local students want to study well in order not to be expelled from the educational institution, and $8 \%$ find it difficult to respond as to what motivates them to receive high marks. The answers of foreign students differ strikingly: $48 \%$ want to get the highest marks in order to continue their education, 23\% are afraid of disappointing their relatives with slow progress, $11 \%$ connect good marks with their potential success in the future, and 18\% cannot answer this question at all.

When Uzbek students were asked questions on the topic 'My Family', ten out of twelve participants answered that they would like to change the relations they have with their families. Therefore, they are motivated to study well as they see it as the only way to modernize their reality, enter a profession to realize their life-long ambitions, and thus give their life a 'European' approach. Nevertheless, they feel quite obliged to follow the rules and norms their society taught them and consciously or subconsciously continue the usual routine. Foreign students are more disciplined and careful in their tasks, as their internal motivation tells them to perform what is demanded of them as a means to begin to achieve their desires. Local students, on the contrary, tend to feel erroneously that they could have and see twice as much if they were not studying in their native town (or region). They feel disappointed about not changing their surroundings (as an accepted students' metamorphosis) and thus they underestimate the level of education they are provided with, and it spoils their general attitude towards their studies.

While studying the topics 'My House' and 'Professions and Occupations' it becomes absolutely clear how students from Eastern republics are influenced by their peculiar customs and traditions, which oblige them to be conservative, obedient and even executive in the educational aspect. With local students, the answers during lesson interviews were less predictable, especially on the points of family life. 
The local students tend to give answers that are more negative and they seem unwilling to transform their general attitude. While differing in some attitudes, students still exhibit similar ways of developing internal motivation. For example, when asked about their life-goals and future ambitions, both local and foreign students gave similar answers based on most modern stereotypes, built upon common conceptions of wealth and success. This is one point in which all of them always become interested in getting their diploma and becoming highly qualified specialists in their fields. University teachers should try to use this developmental strategy frequently and employ more tasks during lessons involving the idea of students' future lifestyle, so that it could constantly remind them of the necessity to work harder to achieve their goals. Motivated studies result in high-quality learning and conceptual understanding, as well as enhanced personal growth and adjustment.

Due to considerable differences in climate, geography, religion, national food, culture and customs, foreign students at fist feel very stressed about this change of sociocultural environment. Habitual communication is broken, and they have to adapt to new external and internal conditions. Students from former Soviet republics (Uzbekistan, Turkmenia) experience shock and misunderstanding about what they see in Russia. We must also consider their previous low education level, weak preparation on profile disciplines and special school subjects, and differences in forms and methods of training in Russian higher education institutions from the forms and methods of training in the high schools of their native land.

In the Eastern republics students feel the authority of the teacher and adults more strongly, and they respect their elders, while in Russia communication between age groups is getting more and more like a partnership. All this, when summed up, gives a picture of how motivated they must be.

As teachers need to focus more attention on shaping students' goals and influencing their internal motivation, they must identify effective motivational methods which balance between foreign and local students and make this contrast in motivating factors relatively neutral.

\section{Discussion}

Motivation has an important effect on academic achievement (Hidi and Harackiewicz, 2000, p. 165), and is an integral component of educational and instructional processes (Awan, Noureen, and Naz, 2011, p. 77). It is 
worth pointing out here that many of the difficulties in learning experienced by students might be attributable to the passive role assigned to them during traditional lectures (Andrews et al., 2011, p. 397). With regard to this, some scholars suggest that 'flipped' approaches might improve student motivation, and help manage the cognitive load with computer technology and the Internet (Fattah, 2017; Hernández-Nanclares and Pérez-Rodríguez, 2016, p. 90; O’Flaherty and Phillips, 2015). The information-transmission component of a traditional lecture is moved out of class-time and replaced by a wide range of interactive activities designed to provoke active learning (Abeysekera and Dawson, 2015, p. 9).

While the potential of online learning for enhancing international education remains substantial (Volet and Wosnitza, 2004, p. 21), Chen, Bennett and Maton (2008, p. 319) highlight the difficulties in students' adaptation to learning in an online flexible delivery environment with the example of Chinese international students at an Australian university.

The hybridized sociocultural framework was applied in this study. Using the same approach Heng (2018) conducted a study among Chinese undergraduates in the USA in order to define the influence of the sociocultural context on learning environments. Results show that Chinese students face challenges around relearning new language skills and communication styles, thinking like a 'Westerner', understanding new classroom expectations and sociocultural contexts, and finding balance between work and play (Heng, 2018, p. 33).

The most frequently reported predictors of psychosocial adjustment of international undergraduate and graduate students in the United States included stress, social support, English language proficiency, country of origin, acculturation, social interaction with Americans, self-efficacy, gender, and personality (Yan and Berliner, 2011, p. 144; Zhang and Goodson, 2011). To sum up, the more multicultural competency international students have, the more social support and more competency in academic settings in the USA they have. Both multicultural personality and academic self-efficacy can help in better adjust to American education (Lee and Ciftci, 2014, p. 101).

International student experience in the South African context also proves that individuals demonstrate higher motivation where cultural intelligence and a higher interest in acculturation means they are more likely to self-identify as needing support. If universities can motivate international students to be involved in university activities, student performance might be much higher (Mokhothu and Callaghan, 2018, p. 11). 
One can note that many higher educational institutions in developing countries aim at intensifying globalization through increasing the number of international students (O’Neil, 2015, p. 363; Yusoff, 2012). However, many international students struggle with adjusting to a new culture and this process is not always successful.

\section{Conclusions}

This paper gives an idea of how modern first-year students, both foreign and local, get motivated for study. Research work with 107 students from the Kazan Federal University has shown that foreign students coming to study from different countries (Uzbekistan, Tadzhikistan and Turkmenia) tend to experience mental and even physical discomfort, which strengthens their general belief in achieving their goal. Local students, on the contrary, feel at home, and thus do not feel separate from their usual way of life and have to search for some inner inspiration. Though it might not be noticed at first glance, motivation is largely influenced by the society and family in which students were born and raised in. In forming their initial learning motivation both foreign and local students tend to look back on those ideas and words they were given by parents, former teachers and friends. For foreign students this might vanish with time, leaving only memories, which creates some space for a new type of motivation constructed in the mind. As for local students, they continue being supported day by day by parents and relatives and their motivation is constantly 'warmed up'. The process of adjustment might be quite long and sometimes unsuccessful for foreign students. Understanding this can help teachers identify levels of internal motivation and help students achieve their desired outcomes.

\section{References}

Abeysekera, L., and Dawson, P. (2015). Motivation and Cognitive Load in the Flipped Classroom: Definition, Rationale and a Call for Research. Higher Education Research and Development, 34 (1), 1-14.

Andrews, T.M., Leonard, M.J., Colgrove, C.A., and Kalinowski, S.T. (2011). Active Learning not Associated with Student Learning in a Random Sample of College Biology Courses. CBE-Life Sciences Education, 10 (4), 394-405.

Awad, G. (2014). Motivation, Persistence, and Crosscultural Awareness: A Study of College Students Learning Foreign Languages. Academy of Educational Leadership Journal, 18 (4), 97. 
Awan, R.U.N., Noureen, G., and Naz, A. (2011). A Study of Relationship between Achievement Motivation, Self Concept and Achievement in English and Mathematics at Secondary Level. International Education Studies, 4 (3), 72-79.

Bakadorova, O., and Raufelder, D. (2014). The Mediating Role of Socio-Motivational Support in the Association Between Individual School Self-Concept and Achievement Motivation Amongst Adolescent Students. European Journal of Psychology of Education, 29 (3), 347-366.

Benet-Martínez, V., Lee, F., and Leu, J. (2006). Biculturalism and Cognitive Complexity: Expertise in Cultural Representations. Journal of Cross-Cultural Psychology, 37 (4), 386-407.

Chen, R.T.H., Bennett, S., and Maton, K. (2008). The Adaptation of Chinese International Students to Online Flexible Learning: Two Case Studies. Distance Education, 29 (3), 307-323.

Church, A.T. (2000). Culture and Personality: Toward an Integrated Cultural Trait Psychology. Journal of Personality, 68 (4), 651-703.

Creswell, J. W., Hanson, W. E., Clark Plano, V. L., and Morales, A. (2007). Qualitative Research Designs: Selection and Implementation. The Counseling Psychologist, 35 (2), 236-264.

Csikszentmihalyi, M. (2014). Intrinsic Motivation and Effective Teaching. In: M. Csikszentmihalyi, Applications of Flow in Human Development and Education (pp. 173-187). Springer Netherlands.

Dörnyei, Z. (2006). Individual Differences in Second Language Acquisition. AILA review, 19 (1), 42-68.

Fattah, S.F.E.S.A. (2017). The Effectiveness of Adopting a Flipped Learning Approach in an Applied Linguistics Course for University Students. British Journal of English Linguistics, 5 (1), 32-43.

Gardner, R.C., and Lambert, W.E. (1972). Attitudes and Motivation in Second-Language Learning. Rowley, MA: Newbury House Publishers.

Gu, Q., Schweisfurth, M., and Day, C. (2010). Learning and Growing in a ‘Foreign’ Context: Intercultural Experiences of International Students. Compare, 40 (1), 7-23.

Heng, T.T. (2018). Different is not Deficient: Contradicting Stereotypes of Chinese International Students in US Higher Education. Studies in Higher Education, 43 (1), 22-36.

Hernández-Nanclares, N., and Pérez-Rodríguez, M. (2016). Students’ Satisfaction with a Blended Instructional Design: The Potential of 'Flipped Classroom' in Higher Education. Journal of Interactive Media in Education, 2016 (1).

Hidi, S., and Harackiewicz, J.M. (2000). Motivating the Academically Unmotivated: A Critical Issue for the $21^{\text {st }}$ Century. Review of Educational Research, 70 (2), 151-179.

Inkeles, A. (2017). National Character: A Psycho-Social Perspective. London: Routledge.

Jamaludin, N.L., Sam, D.L., and Sandal, G.M. (2018). Destination Motivation, Cultural Orientation, and Adaptation: International Students' Destination-Loyalty Intention. Journal of International Students, 8 (1), 38-65.

Kazakova, J. (2015). Crosscultural Aspects in Modern Literary Fiction: Daniel Kehlmann. The Social Sciences, 10 (6), 780-784. 
King, R.B., and McInerney, D.M. (2016). Culturalizing Motivation Research in Educational Psychology. British Journal of Educational Psychology, 86 (1), 1-7.

Kyndt, E., Coertjens, L., van Daal, T., Donche, V., Gijbels, D., and van Petegem, P. (2015). The Development of Students' Motivation in the Transition from Secondary to Higher Education: A Longitudinal Study. Learning and Individual Differences, 39, 114-123.

Larsen, R.J., Buss, D.M., Wismeijer, A., Song, J., and van den Berg, S.M. (2017). Personality Psychology: Domains of Knowledge about Human Nature. McGraw Hill Education.

Lee, J.Y., and Ciftci, A. (2014). Asian International Students’ Socio-Cultural Adaptation: Influence of Multicultural Personality, Assertiveness, Academic Self-Efficacy, and Social Support. International Journal of Intercultural Relations, 38, 97-105.

Mahmood, H., and Beach, D. (2018). Analysis of Acculturative Stress and Sociocultural Adaptation Among International Students at a Non-Metropolitan University. Journal of International Students, 8 (1), 284-307.

Matteson, S.M., Swarthout, M.B., and Zientek, L.R. (2011). Student Motivation: Perspectives from Mathematics Teachers. Action in Teacher Education, 33 (3), 283-297.

McCrae, R.R., Chan, W., Jussim, L., De Fruyt, F., Löckenhoff, C.E., De Bolle, M., and Allik, J. (2013). The Inaccuracy of National Character Stereotypes. Journal of Research in Personality, 47 (6), 831-842.

Minina, E. (2017). ‘Quality Revolution’ in Post-Soviet Education in Russia: from Control to Assurance? Journal of Education Policy, 32 (2), 176-197.

Mokhothu, T.M., and Callaghan, C.W. (2018). The Management of the International Student Experience in the South African Context: The Role of Sociocultural Adaptation and Cultural Intelligence. Acta Commercii, 18 (1), 11.

O’Flaherty, J., and Phillips, C. (2015). The Use of Flipped Classrooms in Higher Education: A Scoping Review. The Internet and Higher Education, 25, 85-95.

O’Neil, P.H. (2015). Essentials of Comparative Politics: Fifth International Student Edition. WW Norton and Company.

O’Reilly, A., Ryan, D., and Hickey, T. (2010). The Psychological Well-Being and Sociocultural Adaptation of Short-Term International Students in Ireland. Journal of College Student Development, 51 (5), 584-598.

Ormrod, J.E. (2010). How motivation affects learning and behavior. Pearson Allyn Bacon Prentice Hall: Boston.

Otis, N., Grouzet, F.M., and Pelletier, L.G. (2005). Latent Motivational Change in an Academic Setting: A 3-Year Longitudinal Study. Journal of Educational Psychology, 97 (2), 170.

Phillips, D., and Schweisfurth, M. (2014). Comparative and International Education: An Introduction to Theory, Method, and Practice. A and C Black. Bloomsbury Academic.

Raufelder, D., Drury, K., Jagenow, D., Hoferichter, F., and Bukowski, W. (2013). Development and Validation of the Relationship and Motivation (REMO) Scale to Assess Students' Perceptions of Peers and Teachers as Motivators in Adolescence. Learning and Individual Differences, 24, 182-189. 
Реан, А.А., аndЯкунин, В.А. (2014). Методика изучения мотивов учебной деятельности студентов [Электронный ресурс]. Режим доступа: Retrieved 10 June, 2018 from http://psylist. net/praktikum/00108. html.

Rjosk, C., Richter, D., Hochweber, J., Lüdtke, O., and Stanat, P. (2015). Classroom Composition and Language Minority Students' Motivation in Language Lessons. Journal of Educational Psychology, 107 (4), 1171-1185.

Ryan, R.M., and Deci, E.L. (2000). Self-Determination Theory and the Facilitation of Intrinsic Motivation, Social Development, and Well-Being. American Psychologist, 55 (1), 68.

Ryan, R.M., and Deci, E.L. (2000). Intrinsic and Extrinsic Motivations: Classic Definitions and New Directions. Contemporary Educational Psychology, 25 (1), 54-67.

Shafaei, A., Nejati, M., and Abd Razak, N. (2018). A Model of Psychological Well-Being Among International Students. Educational Psychology, 38 (1), 17-37.

Shastina, E.M., Gizatullina, A.V., and Ashrafullovna, A. (2017). Didactisation of Authentic Text When Teaching German as a Second Foreign Language with English as the First in a Higher Educational Institution. Revista Espacios, 38 (40).

Shastina, E., Shatunova O., Borodina T., Borisov A., and Maliy, Y. (2018). The Role of Reading in the Development of Giftedness in the Context of Globalization and National Identity. Journal of Social Studies Education Research, 9 (1), 158-167.

Thoonen, E.E., Sleegers, P.J., Peetsma, T.T., and Oort, F.J. (2011). Can Teachers Motivate Students to Learn? Educational Studies, 37 (3), 345-360.

Volet, S., and Wosnitza, M. (2004). Social Affordances and Students' Engagement in Cross-National Online Learning: An Exploratory Study. Journal of Research in International Education, 3 (1), 5-29.

Weiner, B. (2005). Motivation from an Attribution Perspective and the Social Psychology of Perceived Competence. In: A.J. Elliot and C.S. Dweck (Eds.), Handbook of Competence and Motivation (pp. 73-84). New York, London: The Guilford Press.

Wilson, J., Ward, C., Fetvadjiev, V.H., and Bethel, A. (2017). Measuring Cultural Competencies: The Development and Validation of a Revised Measure of Sociocultural Adaptation. Journal of Cross-Cultural Psychology, 48 (10), 1475-1506.

Wright, C., and Schartner, A. (2013). 'I Can’t ... I Won't?' International Students at the Threshold of Social Interaction. Journal of Research in International Education, 12 (2), 113-128.

Yan, K., and Berliner, D.C. (2011). Chinese International Students in the United States: Demographic Trends, Motivations, Acculturation Features and Adjustment Challenges. Asia Pacific Education Review, 12 (2), 173-184.

Yusoff, Y.M. (2012). Self-Efficacy, Perceived Social Support, and Psychological Adjustment in International Undergraduate Students in a Public Higher Education Institution in Malaysia. Journal of Studies in International Education, 16 (4), 353-371.

Zhang, J., and Goodson, P. (2011). Predictors of International Students’ Psychosocial Adjustment to Life in the United States: A Systematic Review. International Journal of Intercultural Relations, 35 (2), 139-162.

Zhou, J. (2015). International Students' Motivation to Pursue and Complete a Ph.D. in the US. Higher Education, 69 (5), 719-733. 


\title{
Chapter 24
}

\section{The Importance of Emotional Intelligence in the Creative Activity of Students}

\author{
Katarzyna Szorc and Beata Kunat \\ University of Bialystok, Faculty of Pedagogy and Psychology, Bialystok, Poland
}

\begin{abstract}
There is a lot of research indicating that positive emotions and mood hold an important role in developing human creative activity. Particularly valuable is the ability to accept experienced emotions and the skill to react accordingly, as well as absorb them into the thought process and invoke and regulate them. Those predispositions are, according to Salovey and Mayer's (1990) model, components of emotional intelligence. Therefore, emotional intelligence can encourage creative activity as it facilitates 'emotional creativity cost' management. In our paper we will present the results of research carried out among pedagogy students, i.e. future teacher candidates. It was assumed that there is a correlation between emotional intelligence and the students' creative activity. In the research the INTE Emotional Intelligence Questionnaire was used in a Polish version made by Ciechanowicz, Jaworowska and Matczak (2000) as well as the Creative Behavior Questionnaire KANH, developed by Popek (2000).

KEYWORDS: emotional intelligence, creativity, student, teacher
\end{abstract}

\section{Introduction}

There is a lot of research indicating that positive emotions and mood play an important role in human creative activity (Abele, 1992; Davis, 2009; Kramer, 2003; Tokarz, 1991). Scholars stress that positive emotions make the creative process easier (Kaufman, 2003; Kunat, 2015; Lubart and Getz, 1997; St-Louis and Vallerand, 2015; Szorc, 2015). Positive emotions open up human beings and make them more creative (Baas et al.,2013; Fredrickson, 2001; Naylor, Kim, and Pettijohn, 2013; Tokarz, 2005).

CONTACT Katarzyna Szorc, EMAIL: k.szorc@uwb.edu.pl 
Particularly important is the ability to accept experienced emotions and the skill to react accordingly, as well as absorb them into the thought process and invoke and regulate them. Those predispositions are, according to Salovey and Mayer's (1990) model, components of emotional intelligence. Therefore, emotional intelligence can encourage creative activity as it facilitates 'emotional creativity cost' management (Nęcka, 2001). In our paper we will present the results of research carried out among students of pedagogy. It was assumed that there is a correlation between emotional intelligence and the students' creative activity. In the research the INTE Emotional Intelligence Questionnaire (Schutte et al., 1998) was used in a Polish version by Ciechanowicz, Jaworowska and Matczak (2000) as well as the Creative Behavior Questionnaire KANH (Popek, 2000).

\section{Theoretical background}

Behaviorally-oriented academic psychology presents a rather controversial approach to emotional intelligence (Maruszewski and Ścigała, 1998, p. 97). The term 'intelligence' refers to the cognitive side of human activity and is associated with such skills as an ability to analyze and synthesize ideas, to assess and draw conclusions and a capacity for abstract thinking. Emotions, however, due to their 'irrational' character are associated with the affective part of human existence. Due to this 'irrationality' emotions are responsible for interfering and reducing the level of intelligent function (according to cognitive psychology). Such an approach to the emotional process is not widely accepted. It has not found recognition in the works of Howard Gardner - the proponent of an extended meaning of the term intelligence. As early as 1983 he presented a theory of multiple intelligences, according to which the intelligence is a complex phenomenon (Sternberg, 1999, p. 173).

Since the term 'emotional intelligence' is still causing numerous controversies and available theoretical data are still full of blanks or even contradictions, it is hard to determine whether to qualify it as ability, competence, skill or a set of convictions. Due to the lack of unequivocal opinion there are various perspectives and theoretical attempts which translate into an evident shortage of the systematical comparison of particular trends. No wonder, then, that emotional intelligence has not been given unequivocal and coherent definition.

The most frequent models of emotional intelligence that can be found in the literature are the ability model of Salovey and Mayer (1990) or the so 
called mixed models promoted by Goleman $(1997,1999)$ and Bar-On (1997, 2001). Despite earlier attempts to associate emotional intelligence with social intelligence, contemporary researchers have made a clear distinction between those two. Emotional intelligence is conveyed by the ability of proper perception, evaluation and expression of emotions, and the ability to access the emotions and to generate them when they can support thinking. It is, again, a skill to understand emotions, and to understand emotional knowledge and handle the emotions in such a way as to boost emotional and intellectual progress (Salovey and Sluyter, 1999, p. 34).

In the emotional intelligence structure Salovey and Mayer (1990, pp. 185-211) initially identified three and then four components: 1. perception, analysis and expressing emotions, 2. emotionally supported thinking, 3. understanding and analysis of emotions, 4. applying emotional knowledge and reflective emotion regulation in order to support emotional and intellectual development.

The modified model by Salovey and Mayer (1990) places the development aspect next to an identified group of competences constituting emotional intelligence. The components exist in a hierarchical structure where at the bottom are the basic perceptive abilities as well as the abilities to express emotions. The top level is associated with a conscious and insightful regulation of emotions that allows for personal understanding and development.

According to the authors acquiring emotional skills is a life-long process and each skill from the emotional intelligence model requires constant effort and devotion. It seems, however, that people of high emotional intelligence are able to pass stages of acquiring consecutive skills faster as well as assimilate more of them.

It should be noted that despite numerous doubts (evidenced in numerous studies) as to the coherency of the presented model (see Ciarrochi, Chan, and Caputi, 2000; Day and Carroll, 2004; Mayer et al., 2003) it is probably the only one that can be called intelligence. It is supported by the following criteria:

- $\quad$ the possibility of operationalization of particular components understood as abilities;

- $\quad$ correlative with a standardized intelligence measure;

- $\quad$ improved level of intelligence with age (Mayer, 2001; Mayer, Caruso, and Salovey, 2000). 
Creativity is the production of unique, novel and valuable products, services, processes or procedures (Amabile, 1996; Hennessey and Amabile, 2010; Peterson and Seligman, 2004; Plucker, Beghetto, and Dow, 2004; Sternberg and Lubart, 1996). Creativity can be understood as an attribute of a product in which occurs "a conjunction of two features: novelty and value” (Nęcka, 2005, p. 13). And both the attribute of novelty as well as that of value generate a number of problems in evaluating what can be creative. It happens so often that both novelty and value are relative, for instance, in a historical, cultural, social or political context (ibid., pp. 15-17). In the context of personal concepts of creativity, it is associated with creative potential (Barbot, Besançon, and Lubart, 2015; Runco, 2004, 2016; Silvia, Christensen, and Cotter, 2016).

To sum up, it can be stated that human creativity is a multidimensional construct that expresses itself in such features as curiosity, tolerance of ambiguity, uniqueness, focusing on a task, seizing an opportunity and expressing one's thoughts and feelings (Szmidt, 1997).

According to a common view in the subject literature on creative human behavior (creativity as a process) or on the results of such behavior (creativity as a product), both constitute two attributes: innovation and broadly-understood usefulness (value) (Nęcka, 2001). James Averill (2000) adds the third condition of authenticity, suggesting that creative activity and creative works arise from the self of an individual. Although it is contextual factors such as environment and culture that determine creative activity, it is mainly conditioned by individual traits; people differ as to the frequency of undertaken creative behaviors and as to the quality of their effects i.e. the degree of their innovation and usefulness.

The questionnaire employed in the research (KANH) is based on a presumption that the basis of the creative attitude consists of two areas: cognition and character (Popek, 2000). The cognitive aspect is related to the intellectual traits; it is, however, a broader approach than that encountered through IQ assessment. It includes heuristic behavior determined by such features as independent observation, logical memory, creative imagination, intellectual flexibility and ability to reflect. On the opposite end of heuristic behavior is algorithmic behavior characterized by a reproductive and copying approach. Another area - character - refers to the potential cognitive abilities of a human individual. The author of the KANH questionnaire assumes superiority of personality in regard to talents and special talents, as well as that an effective realization of cognitive predispositions is only 
possible in relation to other personal traits. Popek (2000) calls those traits conformism and non-conformism. Conformism means dependency, lack of flexibility to adapt, stereotypical approach, low self-esteem. Non-conformism is described by the opposite features: independence, self-reliance, originality, resiliency, and high self-esteem.

Quite obviously both heuristic and non-conformist behavior supports the creative approach, while a reproductive approach is characterized by algorithmic behavior and conformism (Figure 1).

\begin{tabular}{|c|c|c|c|}
\hline \multirow{4}{*}{$\begin{array}{l}\text { Reproductive } \\
\text { approach }\end{array}$} & \multicolumn{2}{|c|}{ Factors of character area } & \multirow{4}{*}{$\begin{array}{l}\text { Creative } \\
\text { approach }\end{array}$} \\
\hline & Conformism (K) & Non-conformism (N) & \\
\hline & Algorithmic behavior (A) & Heuristic behavior $(\mathrm{H})$ & \\
\hline & \multicolumn{2}{|c|}{ Factors of cognitive area } & \\
\hline
\end{tabular}

Figure 1. A model of a creative approach in learning and acting Source: Popek (2000), p. 17.

\section{The present study}

\section{Research questions}

The aim of the study was to determine the connection between emotional intelligence and the creative behavior of students. The following research questions were posed:

1. What is the level of emotional intelligence of pedagogy students?

2. What is the level of creative behaviour of pedagogy students?

3. Is there a correlation between emotional intelligence and creative behavior of pedagogy students?

\section{Participants}

The study was conducted on a group of forty-nine student teachers. There were forty-three women and six men. The group consisted of eleven bachelor students in the second year and thirty-eight bachelor students in the third year. Among the students eleven of them received average marks (3.00-3.99) and thirty-eight students declared their marks as 4.00 to 5.00 . 
Table 1. Structure of test group (according to independent variable)

\begin{tabular}{|c|c|c|c|c|c|c|c|}
\hline \multirow{3}{*}{$N$} & \multicolumn{2}{|c|}{ Sex } & \multicolumn{2}{|c|}{ Year of study } & \multicolumn{2}{|c|}{ Average marks } & \multirow{2}{*}{ Total } \\
\hline & $\mathrm{F}$ & M & II & III & $3.00-3.99$ & $4.00-5.00$ & \\
\hline & 43 & 6 & 11 & 38 & 11 & 38 & 49 \\
\hline$\%$ & 87.7 & 12.3 & 22.4 & 77.6 & 22.4 & 77.6 & 100 \\
\hline
\end{tabular}

\section{Instruments}

Emotional Intelligence Questionnaire INTE

The study involved the Emotional Intelligence Questionnaire INTE (Schutte et al., 1998) in its Polish version (Ciechanowicz, Jaworowska, and Matczak, 2000). Indicators of emotional intelligence make the sum of points available for completing the INTE Questionnaire (165 points). Thirteen of the questionnaire questions are related to perception, evaluation and expression of emotions, ten relate to regulation of emotions and ten to employing emotion in thinking and action. Salovey and Mayer's (1990) emotional intelligence model provided the theoretical basis for the instrument.

\section{Questionnaire of Creative Behavior KANH}

Students answered questions from the KANH Questionnaire of Creative Behavior (Popek, 2000). It allows measurements from 0-30 points on each scale ( $\mathrm{K}$ - Conformism, A - Algorythmic behavior, $\mathrm{N}$ - Non-conformism, $\mathrm{H}$ - Heuristic behavior). Participants give from 0 to 2 points for appropriate statements.

\section{Data analysis}

All questionnaires were statistically analyzed. In order to present a connection between the emotional intelligence of pedagogy students (student-teachers) and their creative behaviour a correlation linear factor of r-Pearson was calculated. A connection between INTE variables and particular scales of KANH were also sought. The different levels of emotional intelligence were calculated according to a T-student test. All analysis was performed using SPSS software. Hypothesis were verified on the level of relevance of 0.01 and 0.05 .

\section{The results}

The zero hypothesis is: it is assumed that there is high level of emotional intelligence and creative behavior among student-teachers. It was assumed 
that the level of emotional intelligence and creative behavior in women and men is diversified.

Table 2. Level of emotional intelligence (The INTE questionnaire)

\begin{tabular}{|c|c|c|c|c|c|c|}
\hline \multirow{3}{*}{$\begin{array}{l}\text { Level of } \\
\text { emotional } \\
\text { intelligence }\end{array}$} & \multicolumn{4}{|c|}{ Sex } & \multicolumn{2}{|c|}{ Total } \\
\hline & \multicolumn{2}{|c|}{ female } & \multicolumn{2}{|c|}{ male } & \multirow{2}{*}{$\mathrm{N}=49$} & \multirow{2}{*}{$\%$} \\
\hline & $\mathrm{N}$ & $\%$ & $N$ & $\%$ & & \\
\hline high & 3 & 6.2 & 0 & 0 & 3 & 6.2 \\
\hline average & 35 & 71.4 & 0 & 0 & 35 & 71.4 \\
\hline low & 5 & 10.1 & 6 & 12.3 & 11 & 22.4 \\
\hline
\end{tabular}

The analysis of the results indicated that women displayed a higher level of emotional intelligence (77.6 \% more than men). It follows a theory of lateralization processes in the human brain, which claims that men should be characterized by a lower level of emotional intelligence. The lateralization of the brain in males is stronger, and moreover the left hemisphere is dominant (which is responsible for verbalizing emotions), whereas emotion recognizing is done chiefly by the right hemisphere. Women, in turn, with their brain less lateralized and with no significant dominance of either hemisphere, should have better awareness of their subjective and somatic conditions (Maruszewski and Ścigała, 1998). It should be noted that the results for low level of emotional intelligence in our study is lower among men seems to confirm the aforementioned theory. None of the men even reached an average level of emotional intelligence. Only $6.2 \%$ of women reached a high level in this research.

Moreover, using the T-student test the difference in the levels of emotional intelligence was calculated. The difference turned to be quite substantial and was p.i. $=0.026(\mathrm{df}=47, \mathrm{t}=-2.305)$. In the rest of the variable analysis the differences were statistically of less importance.

The results of each scale as well as the total sum $\mathrm{C}+\mathrm{A}$ (Conformism and Algorithmic behavior) and $\mathrm{N}+\mathrm{H}$ (Non-conformism and Heuristic behavior) determined who qualifies to be placed in either the creative or the reproductive group. 
Table 3. Level of creative attitude $(\mathrm{N}+\mathrm{H})$

\begin{tabular}{lccccccc}
\hline \multirow{2}{*}{ Level of creative attitude } & \multicolumn{4}{c}{ Sex } & \multicolumn{2}{c}{ Total } \\
\cline { 2 - 6 } & \multicolumn{2}{c}{ female } & \multicolumn{2}{c}{ male } & & \multirow{N}{*}{$=49$} & $\%$ \\
\cline { 2 - 7 } & $\mathrm{N}$ & $\%$ & $\mathrm{~N}$ & $\%$ & & \\
\hline high & 1 & 2 & 0 & 0 & 1 & 2.1 \\
\hline average & 26 & 53 & 2 & 4 & 28 & 57.1 \\
\hline low & 16 & 33 & 4 & 8 & 20 & 40.8 \\
\hline
\end{tabular}

The results suggested that more than half of the participants display creative behavior at an average level (57.1\%). Only one woman displayed a high level of creative approach. Male students scored low (8\%) and average (4\%) (Table 3). It should be noted that the average score among participants was 34.2 points out of a possible 60 (on scale $\mathrm{H}-17$, on $\mathrm{N}-17,2$ ).

The results were also analyzed in the context of the involvement of the cognitive and motivational sphere of the students (Table 4).

Table 4. Concomitance of particular scales, KANH Questionnaire (maximal points on each scale -30 )

\begin{tabular}{lcc}
\hline & Reproductive approach & Creative approach \\
\hline Character dimension & $\mathrm{K}-12.8 \mathrm{p}$ & $\mathrm{N}-17.2$ \\
\hline Cognitive dimension & $\mathrm{A}-13 \mathrm{p}$ & $\mathrm{H}-17$ \\
\hline Total & 25.8 & 34.5 \\
\hline
\end{tabular}

As we mentioned, scales $\mathrm{K}$ and $\mathrm{A}$ constitute the reproductive behavior sphere, while $\mathrm{N}$ and $\mathrm{H}$ constitute the creative behavior sphere. The data showed that the students display a creative approach. The highest point values for the students were in Non-conformism, which means that they are independent, active, flexible, able to adapt, original, consequent, brave, self-organized, spontaneous, open, resilient, persistent, responsible, self-criticial and possess a high sense of 'self' value. At the same time, on the Heuristic behavior scale the students scored on average 17 points, so they are self-observant, with good logical memory. They display creative imagination, divergent thinking and cognitive activity.

It should be noted that there is no difference between activity in the character sphere (motivational) and the cognitive one. The students got 30 points in each accordingly. 
The substantial statistical correlation between creative approach and sex, year of study or average marks was not corroborated.

In the methodological part of the paper we formulated a hypothesis that there is a correlation between emotional intelligence and creative behaviors.

Table 5. Pearson's correlation between different dimensions: the level of creative behaviour and the level of emotional intelligence

\begin{tabular}{rlccccc}
\hline \multirow{3}{*}{ INTE } & INTE & KANHH & KANHA & KANHK & \multicolumn{2}{c}{ KANHN } \\
\hline & Pearson's correlation & 1 & $.431^{* *}$ & -.032 & -.108 & $.284^{*}$ \\
\cline { 2 - 7 } & Significance (bilateral) & & .002 & .826 & .461 & .048 \\
\cline { 2 - 7 } & $\mathrm{N}$ & 49 & 49 & 49 & 49 & 49 \\
\hline \multirow{3}{*}{ KANH H } & Pearson's correlation & $.431^{* *}$ & 1 & -.121 & .028 & $.492^{* *}$ \\
\cline { 2 - 7 } & Significance (bilateral) & .002 & & .408 & .849 & .000 \\
\cline { 2 - 7 } & $\mathrm{N}$ & 49 & 49 & 49 & 49 & 49 \\
\hline \multirow{3}{*}{ KANH A } & Pearson's correlation & -.032 & -.121 & 1 & $.510^{* *}$ & .216 \\
\cline { 2 - 7 } & Significance (bilateral) & .826 & .408 & & .000 & .135 \\
\cline { 2 - 7 } & $\mathrm{N}$ & 49 & 49 & 49 & 49 & 49 \\
\hline \multirow{3}{*}{ KANH K } & Pearson's correlation & -.108 & .028 & $.510^{* *}$ & 1 & .125 \\
\cline { 2 - 7 } & Significance (bilateral) & .461 & .849 & .000 & & .393 \\
\cline { 2 - 7 } & $\mathrm{N}$ & 49 & 49 & 49 & 49 & 49 \\
\hline \multirow{3}{*}{ KANH N } & Pearson's correlation & $.284^{*}$ & $.492^{* *}$ & .216 & .125 & 1 \\
\cline { 2 - 7 } & Significance (bilateral) & .048 & .000 & .135 & .393 & \\
\cline { 2 - 7 } & $\mathrm{N}$ & 49 & 49 & 49 & 49 & 49 \\
\hline
\end{tabular}

* Significant correlation at level 0.05 (bilateral); ** Significant correlation at level 0.01 (bilateral)

It turned out that emotional intelligence correlates the strongest with both the Heuristic Behavior scale $(\mathrm{r}=431, p=0.002)$ and the Non-conformism scale $(\mathrm{r}=284, p=0.048)$. These are statistically significant correlations with a high level of significance. It means that the higher the indicator of emotional intelligence, the higher the creative behaviors.

\section{Conclusions and discussion}

The conducted study confirms that women display higher emotional intelligence (77.6\% more than men). All men scored low in the research. Only $6.2 \%$ of women scored high. More than half of the participants display creative behavior at an average level (57.1\%). Only one woman displayed 
a high level of creative approach. Male students scored low (8\%) and average (4\%) in creative approach. The highest point values for the students were in Non-conformism, which means that they are independent, active, flexible, able to adapt, original, consequent, brave, self-organized, spontaneous, open, resilient, persistent, responsible, self-critical and possessed a high sense of 'self' value. At the same time, on the Heuristic behavior scale the students scored on average 17 points, so they are self-observant, with good logical memory. They display creative imagination, divergent thinking and cognitive activity. Emotional intelligence correlates the strongest with both the Heuristic Behavior scale ( $\mathrm{r}=431, p=0.002)$ and the Non-conformism scale ( $\mathrm{r}=284, p=0.048)$. Therefore, the higher the indicator of the students' emotional intelligence the higher their creative behaviors. The results of this study did not confirm all expected associations between emotional intelligence and creativity. However, they seem to suggest that emotional intelligence can favour creativity. The correlation between emotions and creativity have also been confirmed by other studies (Baas et al., 2013; Fredrickson, 2001; Naylor, Kim, and Pettijohn, 2013; St-Louis and Vallerand, 2015; Tokarz, 2005). The results may also indicate that both the creativity and the emotional intelligence of the students have the potential for improvement. They can be honed during their pedagogical studies through providing the right educational environment that favours creative learning. The emotional competence of the students should be worked upon from the first semester. Moreover, in the course of various subjects there is a need to develop creativity in the cognitive area as well as in the cognitive-motivational and performance areas. Educational simulations that call for creative thinking should be generated (fluidity, flexibility, novelty). It is essential to stimulate divergent thinking among students of pedagogy and develop their abilities to come up with a number of solutions and ideas. In the process of university training of future teachers it is of paramount importance to develop openness for new ideas and experiences, the stimulation of cognitive curiosity, willingness for experimentation and readiness for undertaking new tasks and professional challenges.

\section{Limitations and future studies}

Because the research covered a relatively small group of students of one university, they are scarcely representative for the whole student population. Therefore, it would be useful to expand the study area and, additionally, 
conduct a longitudinal study covering the first years of teaching practice. In further research it would be important to focus on conditioning for creative behaviour and emotional intelligence. It also seems interesting to search for the stimulants and inhibitors both of creative attitudes and emotional skills.

\section{References}

Abele, A. (1992). Positive and Negative Mood Influences on Creativity: Evidence for Asymmetrical Effects. Polish Psychological Bulletin, 23, 203-221.

Amabile, T.M. (1996). Creativity in Context. Boulder, CO: Westview Press.

Averill, J.R. (2000). Intelligence, Emotion, and Creativity: from Trichotomy to Trinity. In: R. Bar-On and J.D.A. Parker (Eds.), The Handbook of Emotional Intelligence (pp. 277-298). San Francisco: Jossey-Bass.

Barbot, B., Besançon, M., and Lubart, T.I. (2015). Creative Potential in Educational Settings: its Nature, Measure, and Nurture. Education, 43, 371-381.

Bar-On, R. (1997). EQ-i. BarOn Emotional Quotient Inventory: a measure of emotional intelligence. User's Manual. Toronto: Multi-Health System.

Baas, M., Roskes, M., Sligte, D., Nijstad, B.A., and De Dreu, C.K.W. (2013). Personality and Creativity: The Dual Pathway to a Creativity Model and a Research Agenda. Social and Personality Psychology Compass, 7 (10), 732-748.

Ciarrochi, J.V., Chan, A.Y.C., and Caputi, P. (2000). A Critical Evaluation of the Emotional Intelligence Construct. Personality and Individual Differences, 28, 539-561.

Davis, M.A. (2009). Understanding the Relationship Between Mood and Creativity: A Meta-Analysis. Organizational Behavior and Human Decision Processes, 108, $25-38$.

Day, A.L., and Carroll, S.A. (2004). Using an Ability-Based Measure of Emotional Intelligence to Predict Individual Performance, Group Performance and Group Citizenship Behaviours. Personality and Individual Differences, 36, 1443-1458.

Ekman P., and Davidson R. (1999). Natura Emocji. Translated by B. Wojciszke. Gdańsk: GWP.

Fredrickson, B.L. (2001). The Role of Positive Emotions in Positive Psychology: The Broaden-And-Build Theory of Positive Emotions. American Psychologist, 56 (3), 218-226.

Goleman, D. (1999). Inteligencja emocjonalna w praktyce. Poznań: Media Rodzina.

Goleman, D. (1997). Inteligencja emocjonalna. Poznań: Media Rodzina.

Hennessey, B.A., and Amabile, T.A. (2010). Creativity. Annual Review of Psychology, $61,569-598$.

Jaworowska, A., and Matczak, A. (2001). Kwestionariusz inteligencji emocjonalnej INTE. N.S. Schutte, J.M. Malouffa, L.E. Hall, D.J. Haggerty'ego, J.T. Cooper, C.J. Goldena and L. Dornheim. Warszawa: Pracownia Testów Psychologicznych Polskiego Towarzystwa Psychologicznego.

Karwowski, M. (2005). Konstelacje zdolności. Typy inteligencji a kreatywność. Kraków: Oficyna Wydawnicza „Impuls”. 
Kaufman, J.C. (2003). Critical Thinking, Creativity, and Culture: An Introduction. Inquiry: Critical Thinking Across the Disciplines, 22 (3), 5-7.

Kunat, B. (2015). Pasja jako źródło twórczości codziennej człowieka. In: J. Uszyńska--Jarmoc and B. Kunat (Eds.), Twórczość codzienna jako aktywność całożyciowa człowieka (pp. 94-103). Białystok: Trans Humana.

Kocowski, T., and Tokarz, A. (1991). Prokreatywne i antykreatywne mechanizmy motywacji twórczej. In: A. Tokarz (Ed.), Stymulatory i inhibitory aktywności twórczej (pp. 79-95). Kraków: Instytut Psychologii UJ.

Lubart, T.I., and Getz, I. (1997). Emotion, Metaphor and the Creative Process. Creativity Research Journal, 10 (4), 285-301.

Maruszewski, T., and Ścigała, E. (1998). Emocje - aleksytymia - poznanie. Poznań: Wydawnictwo Fundacji Humaniora.

Matczak, A., Jaworowska, A., and Stańczak, J. (2000). Rysunkowy Test Twórczego Myślenia K.K. Urbana i H.G. Jellena. TCT-DP. Podręcznik. Warszawa: Pracownia Testów Psychologicznych PTP.

Mayer, J.D., and Salovey, P. (1999). Czym jest inteligencja emocjonalna? In: P. Salovey and D.J. Sluyter (Eds.), Rozwój emocjonalny a inteligencja emocjonalna (pp. 23-69). Poznań: Dom Wydawniczy „Rebis”.

Mayer, J.D., Salovey, P., Caruso, D.R., and Sitarenios, G. (2003). Measuring Emotional Intelligence with the MSCEIT V 2.0. Emotion, 3, 97-105.

Naylor, P.D., Kim, J., and Pettijohn, T.F. III. (2013). The Role of Mood And Personality Type on Creativity. Psi Chi Journal of Psychological Research, 18 (4), 148-156.

Nęcka, E. (2001). Psychologia twórczości. Gdańsk: GWP.

Nęcka, Z. (2005). Psychologia twórczości. Gdańsk: GWP.

Nęcka, E. (2012). Psychologia twórczości. Sopot: GWP.

Popek, S. (2000). Kwestionariusz twórczego zachowania-KANH. Lublin: Wydawnictwo Uniwersytetu Marii Curie-Skłodowskiej.

Runco, M.A. (2004). Creativity. Annual Review of Psychology, 55, 657-687. http:// dx.doi.org/10.1146/annurev.psych.55.090902.141502

Runco, M.A. (2016). Commentary: Overview of Developmental Perspectives on Creativity and the Realization of Potential. Perspectives on Creativity Development: New Directions for Child \& Adolescent Development, Development, 151, 97-109.

Salovey, P., and Sluyter D.J. (Eds.). (1999). Rozwój emocjonalny a inteligencja emocjonalna. Trans. M. Karpiński. Poznań: Dom Wydawniczy Rebis.

Salovey, P., and Mayer, J.D. (1990). Emotional Intelligence. Imagination, Cognition, and Personality, 9, 185-212.

Schutte, N.S., Malouff, J.M., Hall, L.E., Haggerty, D.J., Cooper, J.T., Golden, C.J., and Dornheim, L. (1998). Development and Validation of a Measure of Emotional Intelligence. Personality and Individual Differences, 25 (2), 167-177.

Silvia, P.J., Christensen, A.P., and Cotter, K.N. (2016). Commentary: The Development of Creativity-Ability, Motivation, and Potential. Perspectives on creativity development. New Directions for Child \& Adolescent Development, 151, 111-119.

St-Louis, A.C., and Vallerand, R.J. (2015). A Successful Creative Process: The Role of Passion and Emotions, Creativity Research Journal, 27 (2), 175-187.

Sternberg, R.J. (1999). Wprowadzenie do psychologii. Warszawa: WSiP. 
Sternberg, R.J., and Lubart, T.I. (1996). Investing in Creativity. American Psychologist, 51, 677-688.

Szmidt, K.J. (1997). Elementarz twórczego życia. Warszawa: Wydawnictwo W.A.B.

Szorc, K. (2015). Związek emocji z twórczymi działaniami czyli 'Od emocji do działań twórczych i z powrotem’. In: J. Uszyńska-Jarmoc and B. Kunat (Eds.), Twórczość codzienna jako aktywność całożyciowa człowieka (pp. 83-93). Białystok: Trans Humana.

Peterson, C., and Seligman, M.E.P. (2004). Character Strengths and Virtues: A Handbook and Classification. New York: Oxford University Press.

Plucker, J.A., Beghetto, R.A., and Dow, G.T. (2004). Why isn’t Creativity More Important to Educational Psychologists? Potentials, Pitfalls, and Future Directions in Creativity Research. Educational Psychologist, 39, 83-96.

Tokarz, A. (1991). Emocje i ich stymulatory w przebiegu procesu twórczego. In: A. Tokarz (Ed.), Stymulatory i inhibitory aktywności twórczej (pp. 96-107). Kraków: Instytut Psychologii UJ.

Tokarz, A. (2005). Dynamika procesu twórczego. Kraków: Wydawnictwo Uniwersytetu Jagiellońskiego. 


\title{
Chapter 25
}

\section{Exploring Learning and Teaching Needs of Elderly People: A Comparative Study}

\author{
Emilia Kramkowska*, Wioleta Danilewicz, \\ Tomasz Prymak*, and Joăo Pedro Constâncio** \\ * Faculty of Pedagogy and Psychology, University of Bialystok, Bialystok, Poland \\ ** Uniăo das Freguesias de Gondomar (S. Cosme), Valbom e Jovim, \\ Public Local Authority, Gondomar, Portugal
}

\begin{abstract}
The aim of this article is to explore the sources and educational areas of interest of elderly people, as well as selected determinants of the attractiveness of the educational offers for this age group. The comparative study was carried out as part of the international project Erasmus+ Adult Education, entitled Silver Civic Education (2017-1-PL01-KA204-038695) to be implemented in the years 2017-2019. It involved seniors from three partner countries of the project: Poland, Portugal and Bulgaria, which made it possible both to determine general educational expectations of elderly people and to identify issues specific for each country. Education for seniors is a challenge, and diagnosing and meeting the expectations of this age group helps improve their quality of life, leads to a sense of satisfaction and self-actualization, and at the same time gives younger generations an opportunity to use the experiences of older people. KEYWORDS: seniors, education, educational needs, ageing, teacher
\end{abstract}

\section{Introduction}

Ageing is an increasingly evident characteristic of the current European society. In order to refer to a society as ageing or old, some conditions must be met. Demographic senescence occurs when the proportion of people aged 65 or over exceeds $7 \%$ of the general population, and the rate of $10 \%$ means advanced demographic senescence. Edward Rosset (1975), a Polish

CONTACT Emilia Kramkowska, EMAIL: emilka.kramkowska@wp.pl 
demographer, argued that demographic senescence occurs when the proportion of people aged 60 or over is at least $12 \%$ of the general population, and advanced demographic senescence, when those people account for $15 \%$ or more of the country population. European societies meet these conditions. Population ageing is a long-term trend which began several decades ago in Europe. The European Statistical Office (Eurostat) indicates that:

the population of the EU-28 on 1 January 2017 was estimated at 511.5 million. Young people (0 to 14 years old) made up 15.6\% of the EU-28's population, while persons considered to be of working age (15 to 64 years old) accounted for $64.9 \%$ of the population. Older persons (aged 65 or over) had a $19.4 \%$ share (an increase of 0.2 percentage points compared with the previous year and an increase of 2.4 percentage points compared with 10 years earlier) (Eurostat, 2018).

The growth in the relative share of older people may be explained by increased longevity, a pattern that has been apparent for several decades as life expectancy has risen. On the other hand, consistently low levels of fertility over many years have contributed to population ageing, with fewer births leading to a decline in the proportion of young people in the total population. All those factors are transforming the shape of the EU-28's age pyramid. If we analyze the statistics concerning different European countries, we find out that the share of persons aged 65 or older in the total population is the highest in Italy (22.3\%), Greece (21.5\%) and Germany (21.2\%), while Ireland has the lowest share (13.5\%). The situation in Bulgaria, Poland or Portugal, i.e., the countries this article refers to, is similar (with the exception of Poland). In 2017, the proportion of people aged 65+ in Bulgaria was 20.7\%, and in Portugal: 21.2\%. Polish statistics are below the European mean: in 2017, there were 16.5\% of people aged 65+ (Eurostat, 2018). However, Poland is a country where the process of ageing of the society is among the fastest in Europe, so we may expect the proportion of people aged 65+ to increase considerably in the nearest future. Similar trends have been diagnosed all over Europe. According to Eurostat,

in an attempt to look at future trends for population ageing, in Eurostat's latest set of population projections (EUROPOP, 2015) we can read that the EU-28's population is projected to increase to a peak of 528.6 million around 2050 and thereafter gradually decline to 518.8 million by 2080. During the period from 2017 to 2080 the share of the population of working age is expected to decline steadily through until 2050 before stabilising somewhat, while older persons will likely account for an increasing share of the 
total population: those aged 65 years or over will account for $29.1 \%$ of the EU-28's population by 2080, compared with 19.4\% in 2017 (Eurostat, 2018).

The demographic situation of contemporary communities contributes to increased interest in the group of oldest people. For example, the 'social clock' concept developed by Bernice L. Neugarten assumes that it is made up of age status, the status of social role attributed to chronological age, and the social norm, which means the behaviors assumed in a certain culture for a specific role and calendar age (Konieczna-Woźniak, 2012, p. 249). Due to the variability of the times and socio-cultural determinants, each generation in a unique way establishes social expectations regarding people of any age and regarding social roles attributed to different periods in life (Neugarten, 1965). Looking into the past, we can see, for example, that tasks whose performance was expected of elderly people living at the beginning of the $20^{\text {th }}$ century are no longer required of contemporary seniors. Social roles previously reserved for the younger generations are currently successfully performed by seniors as well. One example that confirms the validity of Neugarten's concept assumptions is the sphere of education. In the past, being a student was reserved for young people; today, people of different ages go to school or study at university. In addition, education of adults, including university students, is nowadays a quickly developing area of practical activity and scientific exploration.

However, the attributes of old age, such as intellectual potential, biographical competencies, financial resources, qualifications, knowledge and skills, are still not fully used or developed by younger generations. Therefore, in relation with demographic changes and 'qualitative' changes occurring in advanced age, contemporary societies also face the Millennial challenge in the sphere of education. This challenge is the need to notice the capital that elderly people have and support this potential by initiating active participation in different spheres of life, including education.

The new faces of old age require skills that cannot be worked out without the (re)construction of the approach to education. In this text, re-construction is understood as the need to include different groups of seniors in educational practice, even those who do not want to be called seniors yet or even treat this word as an insult. For this purpose, the direction of thinking about education for seniors must be broader that before, based on offering opportunities for development relevant for changing seniors and their needs. This kind of education should be constructive: creative, open to changes, engaged and oriented to the changing needs of seniors. Thus, the educational task involves 
the reconstruction of the previous direction of thinking about elderly people and the construction of study methods that will help activate those people or enrich the educational offers prepared for them. Another educational challenge is to prepare younger generations to cooperate with the 'new senior', who is active, willing to learn and to do research.

The aim of this article is to present and discuss findings on the educational needs of elderly people, including expectations concerning the subjects of classes organized for them, the preferred methods of learning, and selected determinants of the respondents' educational expectations based on comparative studies. In our view, this analysis will allow us to identify 'supranational' educational expectations displayed by the respondents as well as issues specific for each country. We are also convinced that because of the changes in the specificity of elderly people, knowledge about them must be updated all the time. The results of the study on the one hand will contribute to recognising what kind of (re)construction of the approach to senior education is needed. On the other hand, the results of the research will contribute to the practical application of such actions, which will improve the quality of individual as well as social life.

\section{Methodology}

The research presented in this paper was carried out as part of an international project by Erasmus+ Adult Education entitled Silver Civic Education (2017-1-PL01-KA204-038695). It is a two-year project (2017-2019) coordinated by the In Search of Poland Association, which has its seat in Bialystok. The project encompassed such countries as Bulgaria (the New Bulgarian University in Sofia) and Portugal (the Union of Parishes Council of Gondomar - S. Cosme, Valbom and Jovim). The project is focussed on seniors, and one of its aims is to explore the educational needs of elderly people in the partner countries. The study was carried out between February and May 2018 with a survey, using the survey technique and a survey questionnaire (identical for all three countries participating in the project). The questionnaire consists of sixteen questions pertaining to such issues as seniors' educational needs, educational methods that should be used during seniors' education and characteristics of the seniors' tutors.

The seniors who participated in the project were asked to assist in carrying out the study. After necessary training, a group of more than ten elderly people representing each country received the questionnaires, 
which they then distributed in their environments. A total of 622 filled in questionnaires were obtained: 200 in Bulgaria, 196 in Poland and 226 in Portugal. All the questionnaires were properly encoded and subject to comparative statistical analysis. Statistical calculations were performed using the SPSS Statistics 22 programme. The analysis included descriptive (distribution, means, percentages, standard deviations etc.) and inferential statistics (Pearson's chi square).

\section{Participants}

More than half (55.1\%) of all the respondents were women, whose proportion was the highest in the Portuguese sample (65.9\%), whereas the highest proportion of men (44.9\% of all the respondents) was observed in Poland (60.2\%). The most numerous group (58.8\%) was people aged 61-70 (Figure 1). Respondents from this group were the most numerous in each partner country: Bulgaria $-49.5 \%$; Poland $-63.3 \%$; Portugal $-63.3 \%$. One third of the respondents (27.0\%) are in the $71-80$ age group (Bulgaria: $28.5 \%$, Poland: 26.5\%, Portugal: 26.1\%). $11.4 \%$ of all the respondents were people aged 55-60, with the highest proportion among respondents from Bulgaria (18.5\%). In Poland and Portugal the youngest respondents accounted for approx. $8 \%$ of the sample. The oldest ones, aged $81+$, accounted for $2.7 \%$ of the respondents.

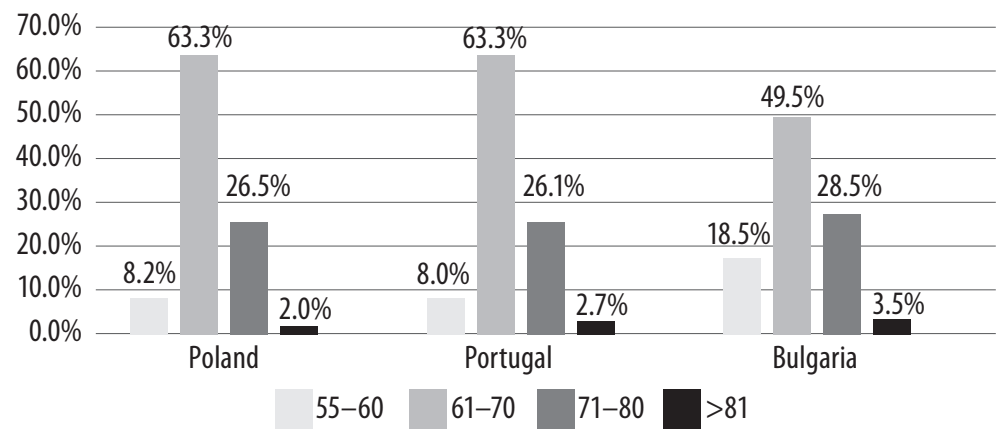

Figure 1. The respondents' age

Nearly half the respondents (48.6\%) were people with higher education, $37.8 \%$ had secondary or vocational education, and the others, elementary education (Figure 2). Regarding the specificity of the partner countries, higher education was most often declared by the respondents from Bulgaria (73\%), followed by those from Poland (50.5\%) and Portugal (25.6\%). 


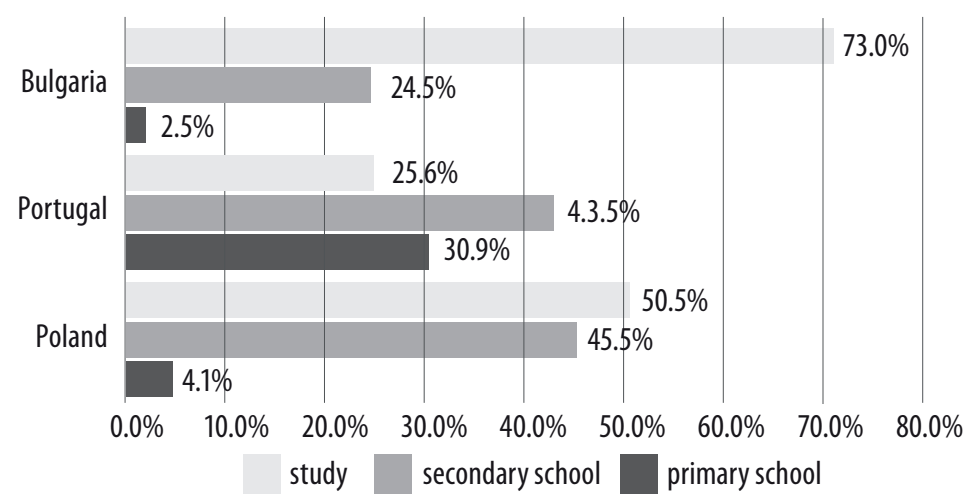

Figure 2. The respondents' level of education

\section{Results and discussion}

\section{Sources and areas of seniors' educational interests}

Firstly, the respondents were asked about seniors' present participation in activities prepared for them. We found out that more than half (55.1\%) of the respondents had participated in such activities in the past or were attending them at the moment. The analysis of data included in Figure 3 helps in grasping the specificity of each partner country (Figure 3).

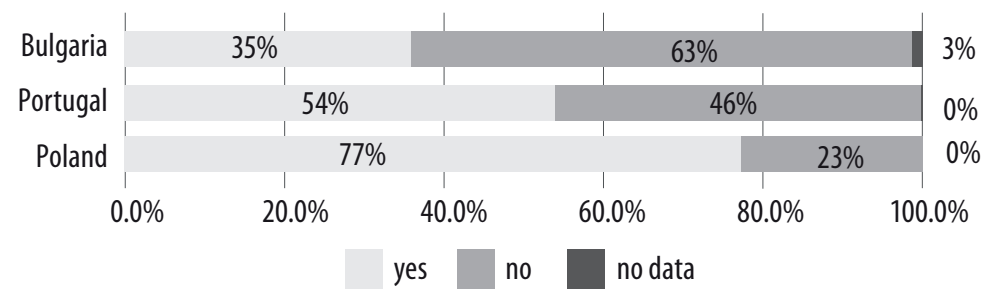

Figure 3. Taking part in educational activities for seniors

The highest level of seniors' engagement in educational activities was observed in Poland, where more than $77 \%$ respondents declared they had participated or were participating in educational activities prepared for them, and the lowest level was declared by the respondents from Bulgaria (35.0\%). In Portugal, the distribution of engagement and the lack of engagement in educational activities among seniors is similar: $54 \%$ people do and $46 \%$ do not engage in educational activities $(p<0.001)$. 
The obtained distribution of responses is interesting, especially as regards seniors from Bulgaria, 73.0\% of whom have higher education. Perhaps this low level of educational activity of Bulgarian seniors can be explained by their age: every fifth respondent from that country was in the age group 55-60. Maybe those respondents had not yet had an opportunity to use the educational offers for elderly people. Perhaps they do not even think about themselves as fitting this social category.

Another area of exploration, corresponding to the one discussed previously, was the sources of information about educational activities for elderly people (Figure 4).

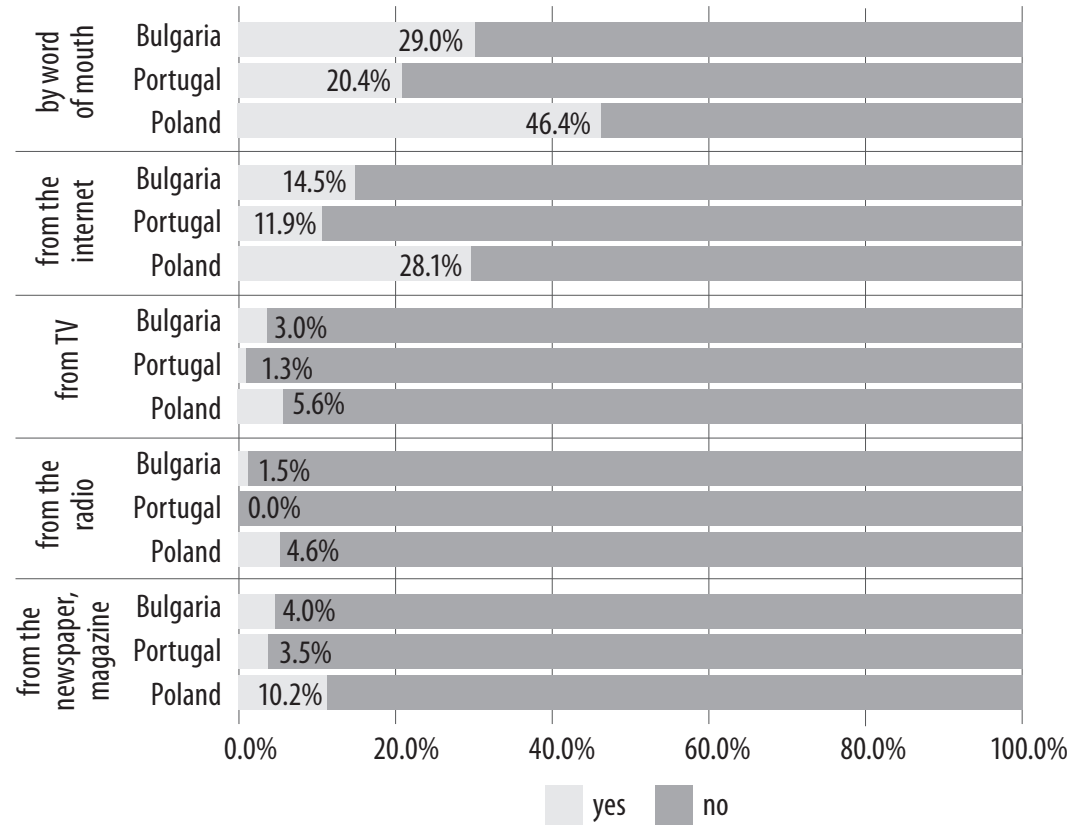

Figure 4. Sources of information about educational activities for seniors

The study showed that the most common source of information about educational activities are friends - this information spreads by word of mouth. The other information channel often mentioned by the respondents, is the Internet. The country variable did not differentiate between the results. The above-mentioned sources of knowledge were declared by similar proportions of the respondents (in each case, the correlation was statistically significant $(p<0.001)$. However, since in these three groups the rate of seniors 
who took part in educational activities was highest in Poland, responses concerning the sources of information about educational offers were most often given in Poland. It is worth adding that more than $10 \%$ of respondents from Poland learned about educational offers from the press, $5.6 \%$ from TV, and $4.6 \%$ from the radio.

Thus, the study shows that it is easiest to reach elderly people through people from their environment, who are close to them and whom they trust. But the high frequency of declarations concerning the Internet as the source of information proves that this new generation of seniors is very heterogeneous in many aspects.

As already mentioned, more than half the respondents were in the 61-70 age group. So they are people who were born after WWII: the PostWorld War II baby boomers generation. In the case of Poland and Bulgaria, this is very important. Baby boomers are surely a unique generation. They are characterized, among other things, by an increasing level of education, discussed above, which is a natural consequence of improved access to education in the countries where the political system changed after 1989.

This increase in the level of education is reflected i.e., in the changing lifestyle of the older generation, more and more often not focused exclusively on matters connected with the closest family. People of the older generation are becoming more aware of how to take care of themselves, their own health, how to maintain their capabilities or develop their own interests (Błędowski, 2012, p. 20).

It is also extremely important that "each year, the time today's seniors have lived in the new conditions initiated with the 1989 transition, based on more democratic social relations and market economy principles, is longer” (ibid., p. 19). On the one hand, functioning in the post-transition reality gives them the opportunity for universal development. On the other hand, in a way they have no choice: in order to function in the surrounding world, they have to become familiar with technological innovations, learn to use computers or the Internet. The people who took part in the Polish-Bulgarian-Portuguese study seem to be aware of the specificity of the times they live in. Probably they also function well in today's reality, if such a high proportion of the respondents have learnt about the educational offers for seniors from the Internet. Hence, digital skills have emerged as another issue as part of the study.

According to Aleksandra Marcinkiewicz-Wilk (2016, p. 18):

contemporary times are characterized by the rapid pace of change caused by the development of information technology. Therefore, ageing populations 
are facing a modern phenomenon called 'The Information Society' and education is its main pillar. The dynamic of change in the information society is causing knowledge and skills to become outdated. Therefore, continuous updating of knowledge is necessary.

Well prepared educational offers for elderly people must be relevant to their real needs. This is one of the issues/areas that need the (re)construction of the approach to senior education. Something that is interesting to learn and worth exploring for younger generations does not have to be perceived the same way by elderly people. "Educational institutions should offer a variety of activities to meet very different needs of this heterogeneous group of elderly people” (Eloniemi-Sulkava, 2013, p. 51). Therefore, it is worth finding topics for classes and other educational activities that would be attractive for seniors. This issue has already been raised during the research discussed in this text (Figure 5). This mostly referred to digital literacy.

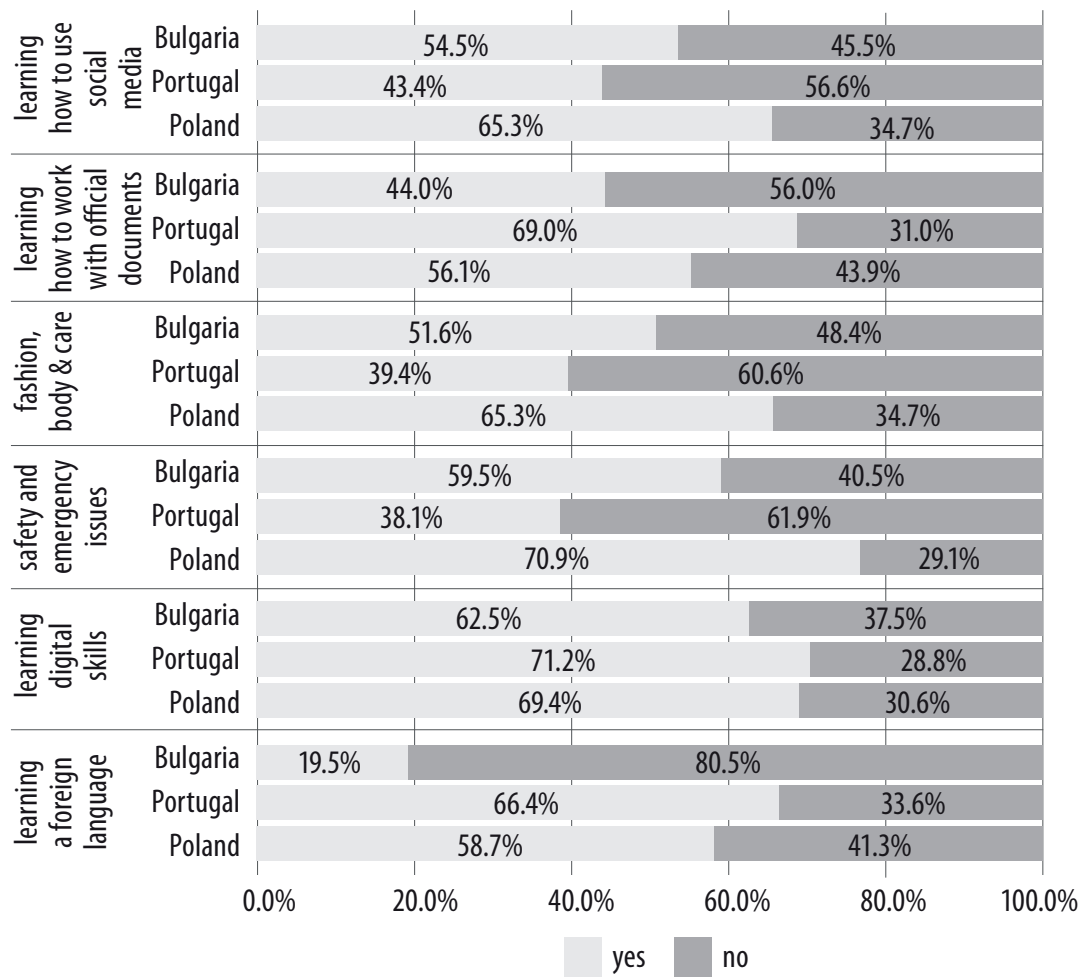

Figure 5. Interest of topics/activities undertaken during education for seniors 
We may say the seniors who took part in the study are aware of the challenges generated by functioning in the information society. The most often declared area they would like to learn about and/or develop as part of educational activities was digital skills (indicated by $67.8 \%$ of all the respondents). This response was the most frequent one in all three countries, although this issue seems to be more important for Portuguese seniors (71.2\%) than for those from Bulgaria (62.5\%) $(p<0.001)$. "Observations and specialists reports reveal that the number of seniors using information technology is still not satisfactory" (Napora, 2013, p. 62). So the positive information is that the studied seniors seem to be interested in improving their qualifications in this regard. And this need should be met by ensuring access to relevant activities or courses.

Another significant area elderly people were interested in was how to understand and fill in official documents, e.g., bank contracts, legal contracts etc. (indicted by $56.9 \%$ of all seniors). Analysing the declarations concerning this issue in the three countries, we can see that learning how to fill in official documents was more often the need of seniors from Portugal (69.0\%) and Poland (56.1\%) than from Bulgaria (44.0\%) $(p<0.001)$. The third most often mentioned area of issues interesting for seniors in the educational context was broadening their knowledge about security and ways of protection, i.e., how to avoid deception, what is domestic violence etc. More than half the respondents declared interest in this issue (55.3\%). This topic was most often indicated by seniors from Poland (70.9\%) and least often by the respondents from Portugal (38.1\%) $(p<0.001)$. Supposedly, the interest of Polish seniors in the issue of security may be the result of current public service campaigns initiated by the Ministry of Family, Labour and Social Policy or the police, which tackle the problem of domestic violence or other forms of abuse of seniors. The public discussion concerning these issues on the one hand makes people aware of their occurrence, but on the other hand may be the source of new questions and doubts (Halicka et al., 2018). Perhaps this is the reason why Polish seniors declared the need of including this subject in educational activities.

The ability to use social media and blogs (Facebook, Twitter, YouTube), indicated by a total of 53.8\% respondents, was more often mentioned by seniors from Poland (65.3\%), then from Bulgaria (54.5\%) and Portugal (43.4\%); the relationship is statistically significant $(p<0.001)$. In today's information society using social media is very important. We can read in source literature: 
as a general increasing phenomenon in our societies, most ways of contribution to active ageing are more and more mediated through cyberspace, for example by social media [...] In the same way, for those elderly persons living at home, social media can be developed as a helpful tool to keep in touch. Not as a substitute of face-to-face interaction but as devices that reinforce interaction. We know that this is still the beginning of new forms of interaction, so best uses to underpin intergenerational, neighbourhood or other relations could increase life quality for elders (Bardus and Raso, 2013, p. 78).

Out of the list of issues proposed for seniors as the subject of educational activities more than half (51.6\%) chose the subject of fashion and broadening knowledge on body \& care - more often declared by Polish (65.3\%) and Bulgarian (51.6\%) seniors ( $p<0.001)$. For seniors from Portugal (66.4\%) and somewhat less often for those from Poland (58.7\%) a very important educational area in which they would like to improve was foreign languages. Strangely, only 19.5\% seniors from Bulgaria chose this response $(p<0.001)$.

A major trend in the demographic development of Bulgaria as well as other countries is the ageing of the population. This has implications not only for the employment structure in Bulgaria but also for the education and training system.

Bulgaria has the lowest EU record for overall adult participation in formal education and training compared to the EU average. Among people aged 45 years and over, participation in educational activities declines sharply, and the 55 years and over age group has the lowest participation level (6.5 per cent). Despite the long list of institutions and NGOs active in Adult Education and Learning (ALE) in Bulgaria, training and education for seniors can [only] be obtained in rather limited institutions (ibid. p. 92).

The above-mentioned factors were maybe the reason why Bulgarian seniors so rarely chose the response concerning the learning of foreign languages. Their being rooted and raised within their specific culture and social conditions is really significant.

Historically, the demand for lifelong learning in Bulgaria has always been recognised. But for a long time there was a lack of concrete activities aimed at the improvement of general knowledge and vocational skills. Still, for a long time the system for senior education was not part of the educational system, it was informal and delivered by institutions in the form of courses, rounds and correspondence (ibid.). 


\section{Selected determinants of the effectiveness of educational offers for seniors}

In the study we asked the respondents to identify the features of teachers that in their opinion were the most valuable to the relationship between the person conducting the educational activities and their beneficiaries Then, the features were divided into two groups on the basis of the classification of teachers' competencies. One group consists of those features related to interpersonal skills, including communication competence and the ability to establish contact with others. A teacher with such traits is an adviser and guide, and their actions are oriented individually and relationally (more information in: Taraszkiewicz, 2001, p. 175). The second group are features based on didactic and methodological competencies, concerning the teachers' teaching skills and the methods and techniques they use, especially those that activate the students.

The vast majority of the respondents point out that the teacher should display general traits such as empathy, patience, sociability and creativity. In Poland and Bulgaria, more than $90 \%$ of respondents perceive this as a need. Seniors from Poland are the most consistent, unanimously confirming (95.9\%, 97.4\%, 99\% and 96.4\% for each feature, respectively) that the personality factors of the educators are important. In each case the correlation is statistically significant at the level of $p<0.001$.

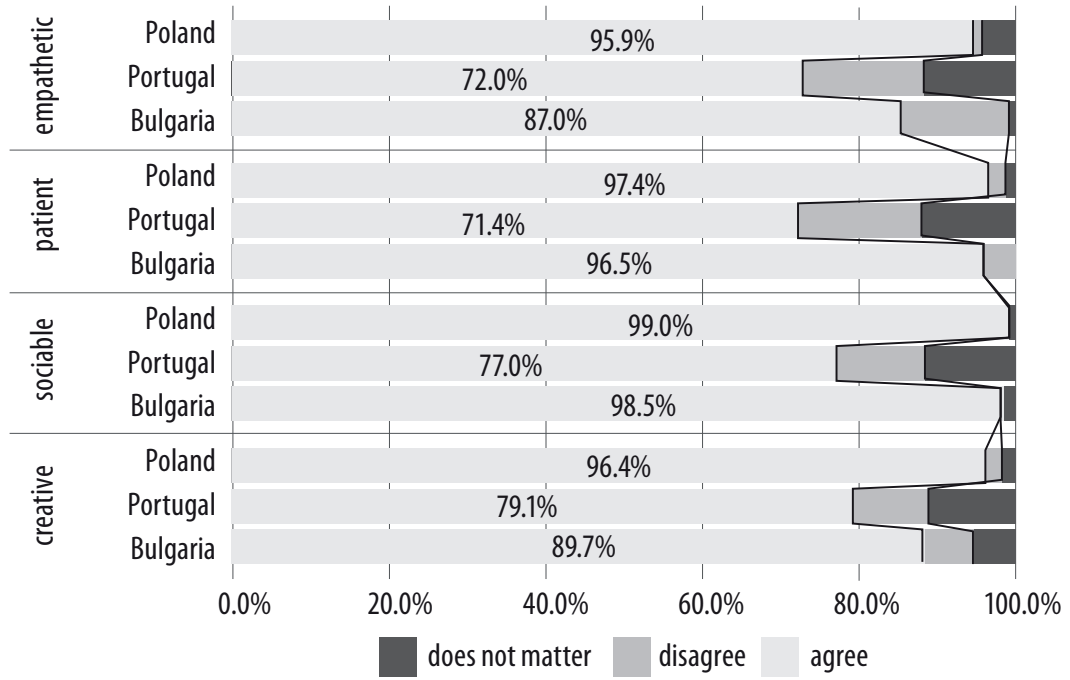

Figure 6. The importance of teachers' personal features 
For nearly $30 \%$ of respondents from Portugal, teachers' traits oriented towards relationships are unimportant for the course or the effectiveness of educational activities. We can also see that the Portuguese respondents are much more open in terms of expectations concerning teachers than are seniors from Bulgaria and Poland.

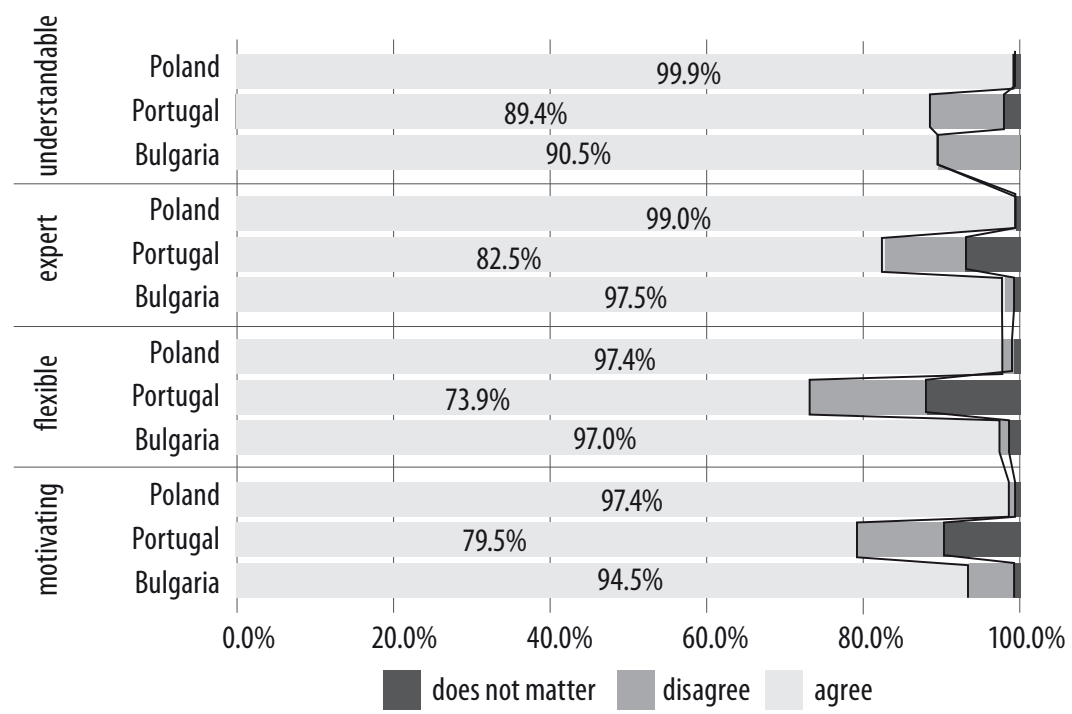

Figure 7. The importance of teachers' professional features

The analysis of data from Figure 7, showing features regarded as didactic and methodological, leads to similar conclusions. The vast majority of the respondents point out that the person conducting education activities for elderly people should display features such as communicativeness, knowledge about the subject, flexibility and the ability to motivate people to study. In the comparative context, we can again see that the largest group of Portuguese respondents $(10.6 \%, 17.5 \%, 26.1 \%$ and $20.5 \%$ for the listed features, respectively) point out that the professional features of people conducting educational activities for seniors are not significant $(p<0.001)$.

Apart from that, elderly people more often regarded educators' personal traits as more important than methodological and didactic ones. The study carried out by Ewa Jurczyk-Romanowska among seniors attending University of the Third Age classes shows that for the respondents the most important features of the educators conducting their classes were 
communicativeness and ease in imparting knowledge, being engaged, helpful, patient and understanding, possessing kindness and the ability to create a kind atmosphere, group management skills and professionalism (Jurczyk-Romanowska, 2012, pp. 91-92). That study also shows that seniors are a special group of students, as they demand specific instructions and explanations, and it is very important for them if the teacher is engaged and open to the needs and problems occurring in the course of study. This fact probably results from seniors' expectations of educational activities. They want to establish new relationships and satisfy the need for security resulting from the awareness of their own deficits. On the one hand, "the features seniors expect of a professional teacher/gerontologist clearly show that the teacher should first of all display patience. The burden of impatience, related to a negative emotional attitude to students who have some difficulty acquiring new skills, is the factor that makes their learning even more difficult” (Tomczyk, 2015, p. 215). But on the other hand, the results of a study in the group of seniors in Portugal may point to a completely different direction for educational work with seniors, based on reciprocity, cooperation, and perceiving the potential of 'new seniors'. Thus, in our view, "in education for seniors the teacher's ability to identify individual needs of their students and typologize them properly, related to the ability to select and apply their personal competencies, are extremely important" (Jaroszewska, 2010, p. 108). This is the next area that needs (re)construction in order to meet seniors' expectations connected with their education.

The data included in Figure 8 is an additional illustration of our thesis. It presents the respondents' evaluation of the effectiveness of different methods of study.

The respondents evaluate similarly the effectiveness of methods such as the use of educational games, computer-assisted education and practical classes. In these cases, almost $40 \%$ of seniors from each country (Poland, Portugal and Bulgaria) point out that these are important and useful in educational initiatives for elderly people. What is interesting is that the highest number of respondents from each country, i.e., 73\% Polish, 53.5\% Portuguese and $78 \%$ Bulgarian, declare that work in small groups is the most effective when it comes to educational activities for seniors. They reject traditional methods of work, expecting education based on personal relationships, which is much easier in small groups. 


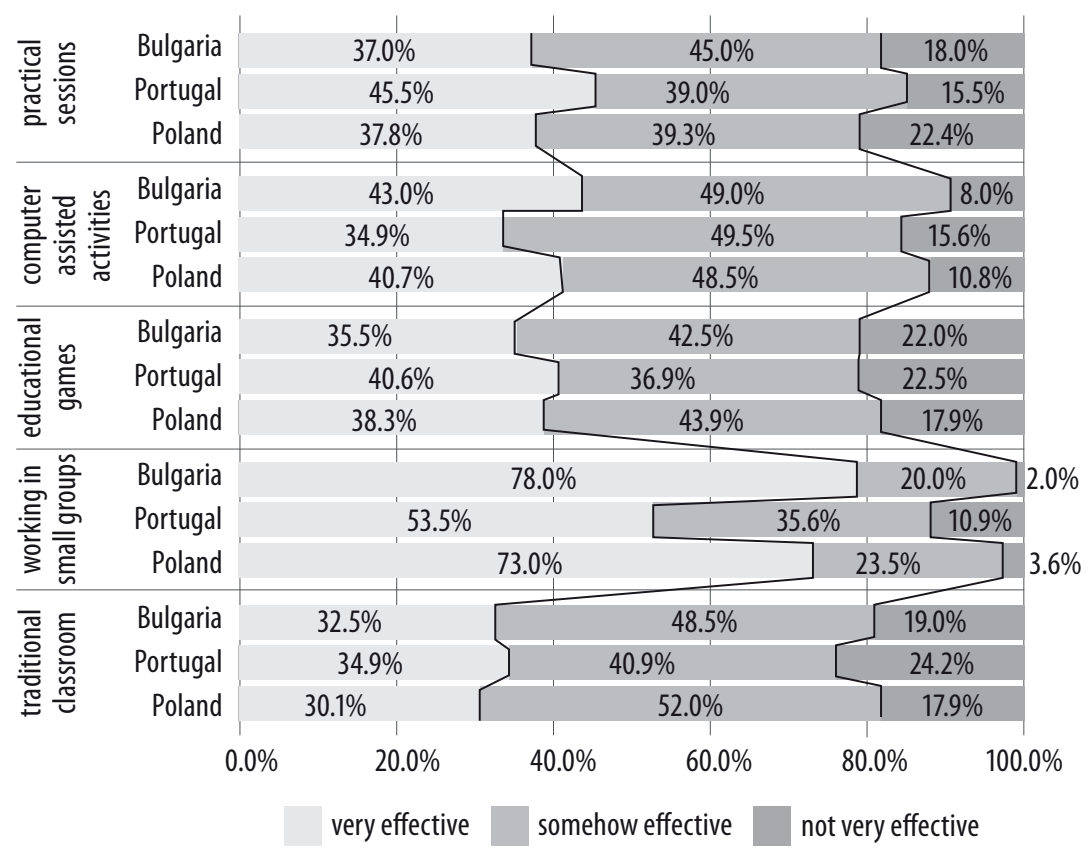

Figure 8 . The effectiveness of training methods

\section{Conclusion}

Jens Friebe and Bernhard Schmidt-Herth (2013, p. 12) point out that:

Education not only creates prerequisites for participation in different fields of social life; it is also the first step toward an active process of ageing. Therefore, we are in need of research focusing on the equality or inequality of opportunities for older people to participate in adult education that also takes into account regional and individual differences

With reference to this, we may conclude that the research presented in this text is, in a way, the response to the diagnostic need identified by Friebe and Schmidt-Herth.

On the basis of the survey carried out in Bulgaria, Poland and Portugal we can conclude that seniors' expectations of education prepared for them are twofold. Some of them expect general support in their development on the basis of personalized, almost individual contact with the educators (e.g., 
as part of group work). Others, especially the younger ones, expect support resulting from the need to actively participate in a world controlled by modern technologies, full of opportunities for physical and virtual mobility. Therefore, on the one hand, we think that:

teacher's work with adults, particularly elderly ones, is especially difficult and complex. Expectations towards a teacher working with people in the 'golden age' should include not only appropriate personality traits but also a positive attitude to their students and the knowledge of their specific qualities resulting from psychological determinants (the stage of life), the living environment and the objectives of the education (Tomczyk, 2015, p. 223).

On the other hand, it is necessary to perceive seniors' needs in categories similar to the needs of younger age groups and to adjust the educational activities prepared for them to the variety, specificity and expectations of that demographic group.

Education of the elderly is a must, as it leads to improvement in the quality of their lives, influences their self-esteem, their feeling of accomplishment and self-realization, while providing the younger generations with the opportunity to take advantage of the experiences of the seniors (Gil and Nowacka, 2013, p. 108). Therefore, teachers should be aware of all those aspects that affect an aged person's motivation and their opportunities to attend educational sessions and to participate actively in them (Eloniemi-Sulkava, 2013, p. 52). In our opinion, this is an inseparable element of reconstructed education, open to elderly people's real needs, not to the ideas the younger generation may have about them.

Educational planners and teachers should have up-to-date knowledge about normal ageing. They need to understand the aspects that support good psychological ageing as well as the facts that threaten it. They have to be aware that there are a lot of preconceptions and false assumptions regarding all dimensions of the ageing process and aged people.

\section{References}

Bardus M., and Raso, G. (2013). Social. In: P. Escuder-Mollon and S. Cabedo (Eds.), Education and Quality of Life of Senior Citizens (pp. 71-106). Castellón: Jaume I University.

Błędowski, P. (2012). Starzenie się jako problem społeczny. Perspektywy demograficznego starzenia się ludności Polski do roku 2035. In: M. Mossakowska, A. Więcek, and P. Błędowski (Eds.), Aspekty medyczne, psychologiczne, 
socjologiczne i ekonomiczne starzenia się ludzi w Polsce (pp.11-23). Poznań: Termedia Wydawnictwa Medyczne.

Eloniemi-Sulkava, E. (2013). Ageing. In: P. Escuder-Mollon and S. Cabedo (Eds.), Education and Quality of Life of Senior Citizens (pp. 51-70). Castellón: Jaume I University.

EUROSTAT Statistics Explained (2018). Population structure and Ageing. Retrieved October 10, 2018 from https://ec.europa.eu/eurostat/statisticsexplained/index. php/Population_structure_and_ageing

Friebe J., and Schmidt-Hertha, B. (2013). Activities and Barriers to Education for Elderly People. Journal of Contemporary Educational Studies, 1, 10-26.

Gil, A., and Nowacka, U. (2013). Models. In: P. Escuder-Mollon and S. Cabedo (Eds.), Education and Quality of Life of Senior Citizens (pp. 107-142). Castellón: Jaume I University.

Halicka, M., Halicki, J., Kramkowska, E., and Szafranek, A. (2018). Suggestions for Prevention Measures Based on Polish Research Concerning Older Victims of Domestic Violence. British Journal of Social Work, 48, 982-999.

Jaroszewska, A. (2010). Kompetencje kluczowe nauczyciela geragoga w kontekście nauczania języków obcych w wymiarze międzykulturowym. In: W. Hryń and J. Maciejewski (Eds.), Nauczyciel andragog we współczesnym społeczeństwie (pp. 97-109). Wrocław: Wydawnictwo Uniwersytetu Wrocławskiego.

Jurczyk-Romanowska, E. (2012). Motywacje, oczekiwania i postulaty towarzyszące seniorem w podjęctej edukacji informatycznej. In: E. Jurczyk-Romanowska (Ed.), Trzecia zmiana. Andragogiczne rozważania na temat projektu @aktywny senior (p. 79-86). Wrocław: Wyd. Naukowe Instytutu Technologii i Eksploatacji PiB.

Konieczna-Woźniak, R. (2012). “Rejuvenated” Old Age - Social and Subjective Implications. Studia Edukacyjne, 21, 249-262.

Marcinkiewicz-Wilk, A. (2016). Older People in the Information Society. Journal of Education Culture and Society, 1, 18-31.

Napora, E. (2013). Psychological Image of Seniors in Poland. In: P. Escuder-Mollon and S. Cabedo (Eds.), Education and Quality of Life of Senior Citizens (pp. 62-66). Castellón: Jaume I University.

Neugarten, B.L., Moore, J., and Lowe, J. (1965). Age Norms, Age Constraints and Adult Socialization. American Journal of Sociology, 70 (6), 710-717.

Rosset, E. (1975). Demografia Polski. Reprodukcja ludności. Warszawa: Państwowe Wydawnictwo Naukowe.

Tomczyk, Ł. (2015). Edukacja osób starszych. Seniorzy w przestrzeni nowych mediów. Warszawa: Difin. 


\section{Index}

A

academic achievement 224, 362-363

accountability 17, 162, 163, 294, 296, 345

ageing 128, 381-382, 388-389, 391, 395397

agile learning 98, 102, 107-108

Agile Manifesto 98, 100

agility 98, 99, 100, 102, 107, 108, 109

assessment 21, 30, 35-36, 98, 102-104, 107, 123, 132-133, 145-146, 157, 170, 174-175, 184, 191, 195, 203-209, 212-221, 263, 267, 273, 305-314, 333-334, 371

ATEE 9, 11, 18-19

autonomy 28, 117, 119, 122-123, 135, 169, 213-214, 305-306

\section{B}

becoming a teacher 21, 61, 79, 82, 89-90, 153 beginning teachers 132

body awareness 223, 225, 229, 230-233

body image 223, 225-233

body schema 223, 225-233

\section{C}

case study 56, 61, 63, 203, 275-276, 288, 329-330, 358

children education 253

children's rights 21, 239-246, 248-249

classroom management 168, 175-178, 180181

collaboration $20-22,31,33,51,61,71$, 100, 107, 114, 154, 269, 270-272, 275, 283-291, 293-299

collective identity of teachers 34, 38-39

common good 107-109, 275

communication 17, 33-36, 38-40, 50-52, 59, 65, 70, 73-74, 98-99, 106, 107, 113-114, 117, 145-146, 154, 277-280,
291, 294, 297, 298, 301, 303, 305, 325, 334-335, 337, 347, 362-363, 392

community 39, 44, 47, 49, 50-52, 61, 98, 100, 109, 143, 146, 184-187, 192-193, 239, 241, 259-260, 284, 286, 291, 292-293, 295-298, 330, 332, 336, 341, 343, 348-349

community of practice 100, 109, 284

comparative education 127, 129

computational thinking 22, 319-327

concurrent model 143

consecutive model 143

COOL Lab 319-322, 324-328

cooperative learning theories 304

creativity 33, 39, 51, 113, 254, 286, 291, 368-369, 371, 377

critical reflection $18,19,56$

culture 31, 38-40, 50-51, 100, 105-106, $141,146,157,191,239,244,246$, 248-249, 271, 280, 283, 286-291, 295-298, 333-336, 346-348, 356357, 362, 364, 371, 391-392

curriculum 29, 33-36, 107, 112, 136, 141, 143-144, 146, 148, 154, 157-158, 170, 174-175, 177, 179, 180-181, 185, 205-208, 245, 262, 264-266, 320, 323, 326-327, 337, 358, 359

cyber bullying 22, 340-341, 343-344, 346-347, 352

\section{D}

didactic cooperation 300-315

digital education 319-320, 323, 325-327

digital literacy 22, 146, 320-326, 389

digital natives 111-117, 120-123

dissemination 20, 147, 262

diversity 20, 33, 69, 99, 105, 129, 136, 194, 348

document analysis 34, 168, 172, 258, 290 dual identity 37 


\section{E}

early career researchers 58,60 education 38-41, 43-44, 46-50, 52-53, 56-60, 62-63, 65-66, 68, 72-75, 80, 82-83, 87, 91-92

Educational Doctorate in Teacher Education program 241

educational needs 210, 262, 384, 385

education law 12, 48, 184, 193

education policy 44, 127, 130, 192

education reform 43, 131, 162-164, 168, 171

elderly people 384-385, 381, 387-390, 393-397

emotional intelligence 340 , 347-348, 368 370, 372-374, 376-378

emotions 187, 225, 229, 342, 348, 368370, 373-374, 377

employee wellness programmes 186-187

entrepreneurial skills $46-47$

ethical value 105,163

ethics 33, 105, 192, 358

European Qualifications Framework 48 evaluation 31, 58, 106-107, 120, 146-147, 154, 163, 180-181，258, 273，277, 291, 294-295, 305-309, 311-314, 334-335, 370, 373, 394

expectancy-value theory 81,82

experiential learning 113, 118, 329-333, 335-338

extrinsic 118

\section{$\mathbf{F}$}

facilitating learning 203

feedback 50, 67-69, 114, 116-117, 119122, 164, 203, 206-207, 212, 217, 273, 295, 297, 334-335, 337-338

flipped classrooms 105

foreign students 22, 355-358, 360-362, 364

formative assessment 35, 203-210, 212

formative assessment strategies 21, 207

\section{G}

gambling-based games 116

gamification 111, 115-117

\section{H}

health $74,105,108,186-195,224,228$, 232-235，263-264，302，340-341, 388

higher education 19 , 30-31, 36-39, 44-46, 73, 84, 87, 89, 132-135, 143, 151-152, 156-157, 159-161, 172, 174-175, 241, 243-244, 257, 300-301, 314-315, 356, 362, 364, 385-386

human rights 21, 151, 189, 239, 240-244, 246-250, 348

human values 158

\section{I}

identity 20-21, 27-28, 31, 32-40, 54-61, 72-73, 158, 205, 208, 226, 246

ideological disposition 208, 216-219

inclusion 33, 34, 46, 104, 108, 164-165, $177,178,331$

induction 29, 58, 59, 61-62, 73-75, 80

Industry $4.098,99$

innovation 21, 22, 40, 43, 51, 107-108, 123, 130, 136, 253, 253-268, 270, 272-273, 371, 388

in-service teacher $20,79,151-152$

interactivity $114-115,122$

intercultural competence 22, 329-333, 338-339

international education 355, 363

isolation 31, 151, 343

\section{J}

justice 43, 108, 158, 258, 340, 343-345, 352

\section{K}

knowledge economy 51, 52, 53

\section{L}

language skills 52-53, 363

leaders 45, 102, 127-128, 155, 157, 179, 286, 288-289, 293-294, 296-298

leadership 21, 154, 176, 194, 210, 285, 286, 289, 291-292, 294-299, 336 
learning organisation 284

learning process 51, 67, 99, 103, 105-108, 111, 117-119, 145, 148, 169, 178, 215, 255, 262, 330

learning schools 269-270

learning style 105

lifelong learning $36,44,46-47,52,107$, 109, 145-147, 253, 256, 267, 292, 330-331, 391

\section{M}

master's degree 63, 129-130, 143, 152, 174 mental body representations 21, 223, 225227, 229, 230, 232-234

mentoring 51, 59, 73, 150, 175, 179, 279

methods of teaching $136,143,175-176$, 178

mobility 47, 331-333, 338-339, 396

model 16-21, 27-29, 35, 111, 129, 131133, 135, 140, 143, 177, 191, 229, 240, 241, 257, 267, 269, 271-272, 274-275, 286, 335, 290-293, 336, 340, 358, 344-347, 349, 356, 359, 369-370, 372, 345, 373, 292-293

motivated extrinsically 120

motivation 72-73, 100, 116, 119, 204, 297-298, 304, 337, 356-358, 360364, 396

motivation extrinsic $86,88-90$

motivation intrinsic $79,82,84,88-91$, 94-95, 118, 120-122, 235, 347, 355

\section{$\mathbf{N}$}

narrative inquiry $73-74$

neoliberal culture 239

neuroscience 103, 340-341, 345

\section{$\mathbf{O}$}

OECD 17, 50, 107, 128, 140, 144-146, 151, 180, 270-271, 274, 279, 283, 287

\section{$\mathbf{P}$}

partnerships 18, 132-133, 179, 291

pedagogy $103,130,180,207,307,368-$ 369, 372, 377 personal wellness 184

physical activity 21, 188, 223-226, 229235

policy $12,18,20,33,44-47,57,62,127-$ 128, 130, 134, 164, 173-174, 184, 189, 191, 193-195, 329, 331, 338, 390

pre-service teacher 58, 80-82, 131-134, 153-154

primary school $39,48,66,116,129,143$, 175, 204, 218-219, 253, 257, 259, 275, 321

primary school teachers 129, 159, 218219

profession 17-18, 27-29, 31, 34, 37-41, 45-46, 48-50, 54, 57, 73, 80-81, 85-91, 93-96, 127-128, 140, 148, 150, 152-156, 158-165, 170-173, 176-178, 192, 241, 361

professional development 15-0, 29, 30, 39-40, 50, 58, 60, 62, 72, 74-75, 80, 85, 88, 134, 146-148, 153-157, 163-164, 171, 173, 208, 243, 253, 255-257, 261, 267, 271-272, 279, 283-285, 298

professionalism 33, 37-40, 55, 70, 72, 169, 279, 394

professional profile for teachers 150, 159

progress $16,27,46,47,101,114,146,153-$ 154, 156, 176, 206, 208, 212, 261, 262, 265, 301, 319, 320, 361, 370

project-based learning 51, 106

\section{Q}

qualitative case study 56, 63, 358

quality of education 146, 150, 186, 240, 301, 306, 314, 315

\section{$\mathbf{R}$}

reasons for teaching profession 79

reflection 15, 18-19, 27, 34, 51, 66-67, 98, $100,117,146,239,243,258,269-272$, 275, 302, 331, 335-336

reflective conversation $16,18-19$

relations between teachers 269 
research 81, 82, 95-96, 103-104, 107-109, 113, 116, 123, 130, 140, 144-148, 151, 153, 159-160, 162, 170-171, 174, 179, 180, 184, 195, 204, 209, 210-212, 218-221, 227-228, 230, 233-235, 244, 253, 255-259, 264-265, 267, 283, 285-293, 297, 300-302, 304-308, 314, 319-322, 325, 341-342, 344, 355, 357-360, 364, 368-369, 371, 374, 376-378, 384, 389, 395, 396

researcher identity 58-59

resilience 69, 188, 340, 347, 348, 352

restorative approach 22, 340-341, 343344, 349

restorative justice 340, 343-345, 352

restorative practices 340-341, 344-346, 348-349, 352

\section{S}

school 11, 16-17, 20-21, 31, 33, 37, 39-41, 44-45, 48-49, 51-53, 62-63, 65-66, 68, 73, 80, 85, 88-90, 101, 104-109, 116, 122, 129, 130, 132-133, 135-136, 140-146, 151-152, 155-158, 163-164, 169-170, 173-181, 184-185, 192-193, 195, 204, 206, 209-210, 215-216, 218-221, 230-231, 234, 239-241, 243-244, 246, 248-249, 253-257, 259, 261-263, 265-267, 277-280, 283, 285-290, 292-294, 296-298, 300, 320-328, 330-338, 340-341, 343344, 346-349, 352, 362

school as a learning organisation 269

school leaders 45, 157, 283, 285, 288, 298

school values 346

self-assessment 146, 203, 214

self-awareness 52, 102, 275, 335

self-care 186, 189

self-confidence 190

self-determination theory 111, 119-120, 356

self-efficacy 57-58, 60, 81, 203, 205, 208, 215-221, 253, 256, 363, 364

social media 113, 341, 349, 390, 391

society 16, 27-28, 32-34, 43, 51-53, 68, 72, 85, 88-91, 100, 107-108, 130, 141,
145-146, 157-159, 169, 185, 188-189, 191, 240, 242, 246, 249, 262, 287, 356, 361, 364, 381, 389, 390-391

standards $20,56,61,106,150,154,157-$ 158, 163, 164-165, 173-174, 180, 190, 206, 227, 274, 356

student-centred approach 98

students with special needs $145,175-176$, 179, 181

student teachers 22-23, 36, 51, 82-84, 87, 93-94, 147, 170, 372

symbolic interactionism 303

\section{$\mathbf{T}$}

teacher education 9-10, 15-23, 27-32, 34-40, 44, 48-49, 55-60, 63, 72-73, 80-81, 95-96, 127-136, 145, 156157, 159-160, 162-164, 170, 172-173, 179, 223, 233-234, 239, 241, 253, 269, 271, 279, 319-328

teacher education policy 130

teacher education reform 131, 162, 163

teacher educator 16, 19-22, 28, 31, 36-39, 53, 54-68, 71-75

teacher-principal relations 269

teacher qualification 63, 130

teachers collaboration 283

teachers collaborative learning 283

teacher's competences 253

teachers' identities 28, 34, 39

teacher training 9, 129-134, 140-141, 143-148, 151-159, 164-165, 169, 170-175, 179-182, 208, 219-221, 239, 322, 324, 327, 329, 332-338

teacher wellness 189, 195

teaching competence framework 140

teaching license 80, 163

teaching practice $21-22,40,67,80,131$, 144, 168-173, 175, 178-181, 319323, 327-378

teaching profession $15,17,27-29,31-32$, 34, 38-41, 45-46, 49, 57, 79-80, 83, 90-96, 127-128, 140, 148, 152-154, 156-165, 170-171, 178

team learning 269, 270, 272-274, 276-277, 279-280 
Index

transfer of knowledge and skills 302

V

transformative teacher 239-242, 244, virtual classrooms 52 246-247

transition 10, 21, 45, 55, 58-60, 66, 73, vocational education 45, 47, 152, 159-160, 146, 151, 153-154, 272, 298, 301, 357,388

trauma 340-342, 344-345

$\mathbf{U}$

UNESCO 83, 107-108, 158, 170, 172, 180 267, 385

$\mathbf{W}$

Web 2.0 technology 114

well-being 108, 184-192, 194, 226, 253

WHO 186, 187

whole school approach 329, 340, 352

workplace wellness 184, 187-188, 195

work-related learning 127 


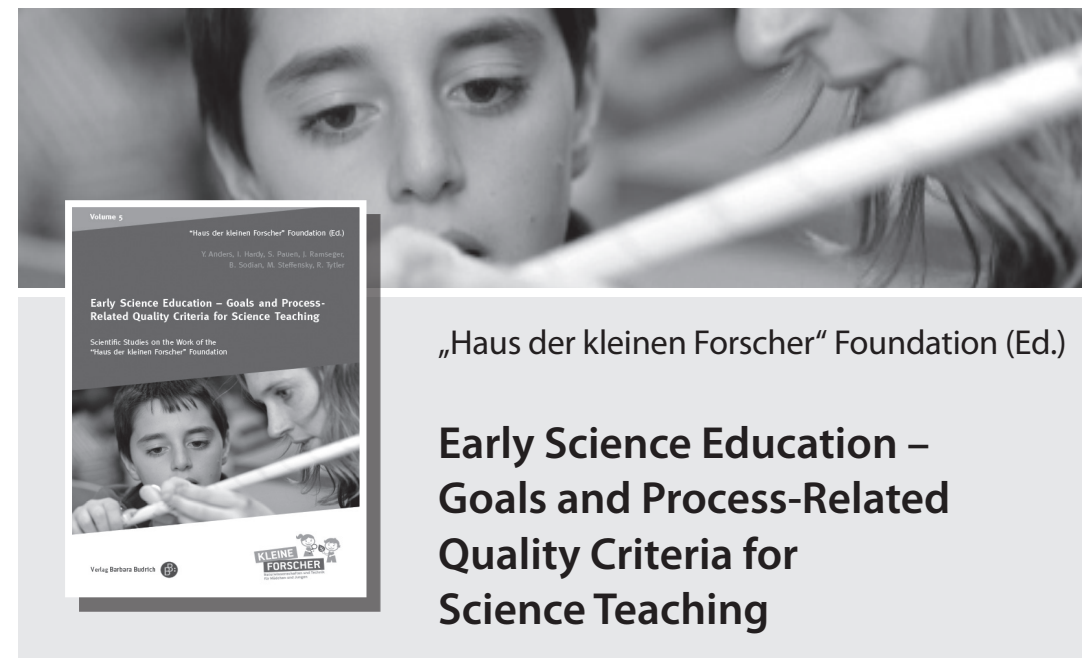

Scientific Studies on the Work of the "Haus der kleinen Forscher" Foundation, vol. 5 • 2018 • 267 pp. • Pb. • 19,90€ (D) • 20,50€ (A) • ISBN 978-3-8474-0559-7• eISBN 978-3-8474-1190-1 (eBook available in Open Access)

Scientific contributions authored by distinguished experts from the field of early education are published periodically within the framework of the series Scientific Studies on the Work of the "Haus der kleinen Forscher" Foundation. This publication series serves to foster informed dialogue between the Foundation, scientists, and practitioners with the aim of giving all early childhood education and care centres, after-school centres, and primary schools in Germany scientifically sound support in fulfilling their early education mandate.

This fifth volume in the series focuses on goals of science education at the level of the children, the early childhood professionals, and the pedagogical staff at after-school centres and primary schools, and on process-related quality criteria for science teaching at pre-primary and primary level. 


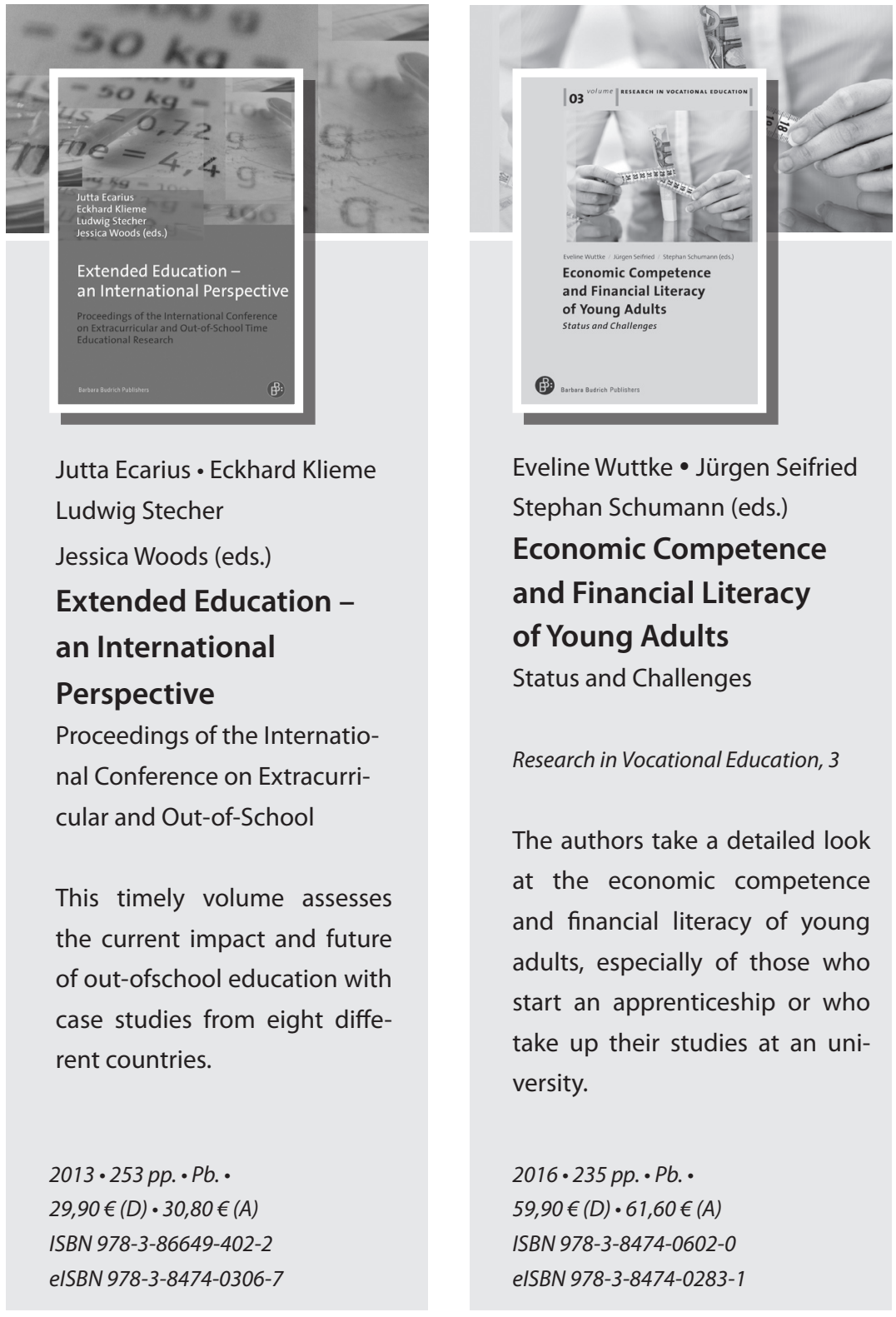

www.shop.budrich.de 


\section{Rethinking Teacher Education for the 21st Century}

The growing complexity and diversity of teaching and learning in the 21st century classroom has firmly placed the quality of teacher education as the front-rank issue of educational research and policies in Europe and beyond. This book discusses the trends, challenges and directions for teachers' preparation in the modern world. A point of departure for the ideas developed in this book was provided by the Association for Teacher Education in Europe (ATEE) 2018 Spring Conference. In line with the main theme of the conference, this edited volume deals with the strengths and limitations of different models, strategies, approaches, policies and practices of teacher education at institutional, national and international levels. These include issues of identity in teaching and teacher education, collaboration in teaching practice, the implementation of (and dealing with) technology, and the tensions and paradoxes of teacher education reforms, among others.

\section{Editors:}

Marta Kowalczuk-Walędziak, University of Bialystok, Poland Alicja Korzeniecka-Bondar, University of Bialystok, Poland Wioleta Danilewicz, University of Bialystok, Poland Gracienne Lauwers, Vrije Universiteit Brussel, Belgium

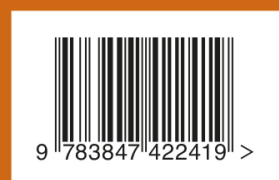

